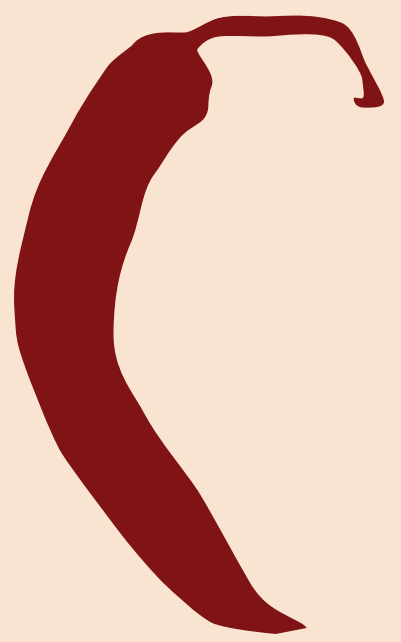

$\frac{\text { S P I C I N G U P }}{\text { Prostate CANCER Theranostics }}$ 


\section{SPICING UP PROSTATE CANCER THERANOSTICS}

L.W.M. van Kalmthout 


\section{Spicing up prostate cancer theranostics}

PhD thesis, Utrecht University, The Netherlands

(c) L.W.M. van Kalmthout, Utrecht, 2020

All rights reserved. No part of this thesis may be reproduced or transmitted in any form or by any means without prior written permission from the author. The copyright of the papers that have been published or have been accepted for publication has been transferred to the respective journals.

Dit proefschrift werd (mede) mogelijk gemaakt met financiële steun van het Koningin Wilhelmina Fonds, het St. Antonius Onderzoeksfonds, de maatschap Urologen voor $U$, de maatschap urologie Meander Medisch Centrum, Siemens Healthineers, Chipsoft B.V., en Hermes Medical Solutions.

$\begin{array}{ll}\text { Cover } & \text { Nelly van Kalmthout, edited by Roy Sanders } \\ \text { Illustrations } & \text { Nelly van Kalmthout } \\ \text { Lay-out } & \text { Roy Sanders } \\ \text { Printed by } & \text { Gildeprint, Enschede } \\ \text { ISBN } & 978-90-3937-335-4\end{array}$




\title{
SPICING UP PROSTATE CANCER THERANOSTICS
}

\author{
Nieuwe ontwikkelingen in de diagnostiek \\ en behandeling van prostaatkanker \\ (met een samenvatting in het Nederlands)
}

\author{
Proefschrift
}

ter verkrijging van de graad van doctor aan de Universiteit Utrecht op gezag van de

rector magnificus, prof.dr. H.R.B.M. Kummeling, ingevolge het besluit van het college voor promoties in het openbaar te verdedigen op

donderdag 26 november 2020 des middags te 2.30 uur

door

Ludovica Wilhelmina Maria van Kalmthout geboren op 17 oktober 1987 te Nijmegen 
Promotor:

Copromotoren:
Prof. dr. M.G.E.H. Lam

Dr. H.H.E. van Melick

Dr. J. Lavalaye 


$$
\text { (1) }
$$




\section{CONTENT}

Chapter 1 Thesis introduction and outline

\section{PART I: PROSTATE CANCER IMAGING}

Chapter 2 Prospective validation of $\left[{ }^{68} \mathrm{Ga}\right] \mathrm{Ga}-P S M A$ PET/CT in

primary staging of prostate cancer patients.

Journal of Urology, 2020

Chapter 3 Interobserver agreement in $\left[{ }^{68} \mathrm{Ga}\right] \mathrm{Ga}$-PSMA PET/CT

with structured classification.

Submitted

Chapter 4 Comparison of $\left[{ }^{68} \mathrm{Ga}\right] \mathrm{Ga}-\mathrm{PSMA}-11$ and $\left[{ }^{18} \mathrm{~F}\right] \mathrm{F}-\mathrm{DCFPyL}$

PET/CT in patients with prostate cancer and primary

or secondary biochemical recurrence after radical

prostatectomy.

Submitted

\section{PART II: PROSTATE CANCER THERAPY}

Chapter 5 Toepassing van [177Lu]Lu-PSMA bij een patiënt met gemetastaseerd castratieresistent prostaatcarcinoom. Tijdschrift voor Urologie, 2018

Chapter 6 First experience with [177Lu]Lu-PSMA-617 therapy for advanced prostate cancer in the Netherlands.

Clinical Nuclear Medicine, 2019

Chapter 7 Visual deficit possibly caused by [177Lu]Lu-PSMA treatment. 135 BMJ Case Reports, 2018

Chapter 8 Impact of external cooling on PSMA uptake in salivary glands.

EJNMMI Research, 2018 
Chapter 9 Comparison between 6.0 GBq and 7.4 GBq $\left[{ }^{177} \mathrm{Lu}\right] \mathrm{Lu}-\mathrm{PSMA}-617$ in prostate cancer.

Submitted

\section{PART III: SUMMARY AND DISCUSSION}

Chapter 10 Summary

Chapter 11 General discussion

\section{PART IV: APPENDICES}

Dutch summary (Nederlandse samenvatting)

List of publications

Acknowledgements (Dankwoord)

Biography 



\section{CHAPTER 1}

Thesis introduction and outline

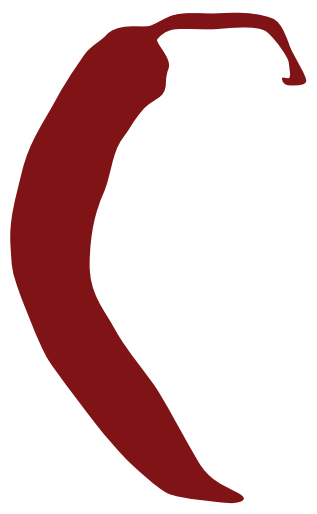




\section{PROSTATE CANCER}

\section{Epidemiology}

Prostate cancer (PCa) is the most commonly diagnosed malignancy, affecting 1 in 9 men, in the western world. ${ }^{1}$ In the Netherlands, approximately 13.557 patients were newly diagnosed in 2019.' With 2896 deaths in 2018, PCa represents the second-ranked cause of cancer mortality among men in the Netherlands. ${ }^{2}$ Due to increased prostatespecific antigen (PSA)-testing and aging of the population, this number is expected to increase even further in 2025. The majority of all prostate cancers has a relatively indolent behavior that does not lead to significant problems during a patient's life. However, high-risk PCa (according to the National Comprehensive Cancer Network: PSA level $>20 \mathrm{ng} / \mathrm{ml}$ or Gleason Score 8-10 or T-stage $\geq 3$ ), comes with a serious mortality risk. Lymph node metastases in PCa patients are considered as an adverse prognostic factor and are associated with systemic metastases. ${ }^{3}$ This supports the importance of accurate primary staging of newly diagnosed PCa patients.

\section{PROSTATE CANCER IMAGING}

Newly diagnosed PCa patients often have localized disease: a primary tumor that is restricted to the prostate gland itself in absence of lymph node, bone or visceral metastases. Initial therapy for these patients includes a local intervention with curative intent, such as radical prostatectomy (RP) or radiation therapy (RT). ${ }^{4}$ If lymph node, bone or visceral metastases are present, curative strategies are less likely to be successful. To select the most effective treatment strategy for newly diagnosed PCa patients, accurate detection of tumor sites ('staging') is essential.

To detect pelvic lymph node metastases, a bilateral extended pelvic lymph node dissection (ePLND) is currently considered the gold standard. This surgical procedure is performed if the estimated risk for positive lymph nodes exceeds a predetermined threshold (European Association of Urology guideline ${ }^{5}$ : 5\%, National Comprehensive Cancer Network guideline ${ }^{6}$ : 2\%) according to the Memorial Sloan Kettering Cancer Center (MSKCC)-nomogram.? In the Netherlands, the locally applied thresholds 
differ and range from 5-15\%. Since an ePLND is an invasive procedure with possible complications such as lymphedema, nerve injury and thrombosis, reliable imaging modalities for newly diagnosed PCa patients are desirable as an alternative for surgical lymph node staging. ${ }^{8}$ Unfortunately, X-ray computed tomography (CT) or magnetic resonance imaging (MRI) of the lower abdomen are not suitable for this purpose as a result of low sensitivity and specificity. ${ }^{9}$ These conventional modalities rely on morphologic features, such as nodal size and shape. Lymph nodes larger than 8-10 mm are considered suspicious, whereas over $80 \%$ of lymph node metastases of PCa are smaller than $8 \mathrm{~mm}^{10}$

To detect metastatic bone lesions, skeletal scintigraphy is recommended in intermediate-risk, International Society of Urological Pathology (ISUP) grade 3 (Gleason 4+3) PCa patients and high-risk PCa patients (PSA levels $>20$ ng/ mL, ISUP grade 4/5 (Gleason Score >7), >cT2C, or CN+). ${ }^{4}$ However, negative skeletal scintigraphy in patients with primary PCa does not exclude the presence of bone metastases, as bone marrow lesions that originate early in the metastatic process, are likely to be missed. ${ }^{11}$

Over the last decade, hybrid imaging with positron emission tomography/ computed tomography (PET/CT), in which morphologic (CT) and molecular (PET) information is combined, emerged as a novel diagnostic modality. Unfortunately, the commonly used radiotracer fluorine-18 ([18F]F)fluoro-2-deoxy-D-glucose (FDG), a glucose analog that visualizes increased metabolic activity in cancer cells, appeared to have low accuracy for the localization of PCa. ${ }^{12,13}$ Therefore, alternative PET radiotracers, such as $\left[{ }^{18} \mathrm{~F}\right]$ F-Choline and carbon-11 ( $\left.\left[{ }^{11} \mathrm{C}\right] \mathrm{C}\right)$-Choline, were developed to overcome these limitations. However, these tracers also appeared to have moderate sensitivity for the detection of metastases of PCa. ${ }^{14}$

\section{Prostate-Specific Membrane Antigen (PSMA)}

PSMA is a type II transmembrane glycoprotein, expressed by the apical side of benign prostate epithelium. The PSMA receptor is significantly overexpressed in 90\% of the PCa cells and its expression is increased in high-grade, de-differentiated PCa. ${ }^{15,16}$ Labelled PSMA tracers bind with a high affinity to the PSMA receptor, allowing for targeted strategies including 
tumor localization using radioactive imaging and therapeutic intervention using radioligand therapy (RLT). Although its specific role has not been clarified yet, PSMA contributes to glutamatergic neurotransmission and folate absorption. ${ }^{17}$ The protein is physiologically expressed in the salivary and lacrimal glands, proximal renal tubules, central nervous system, duodenal mucosa and colon as shown in Figure 1. ${ }^{18}$

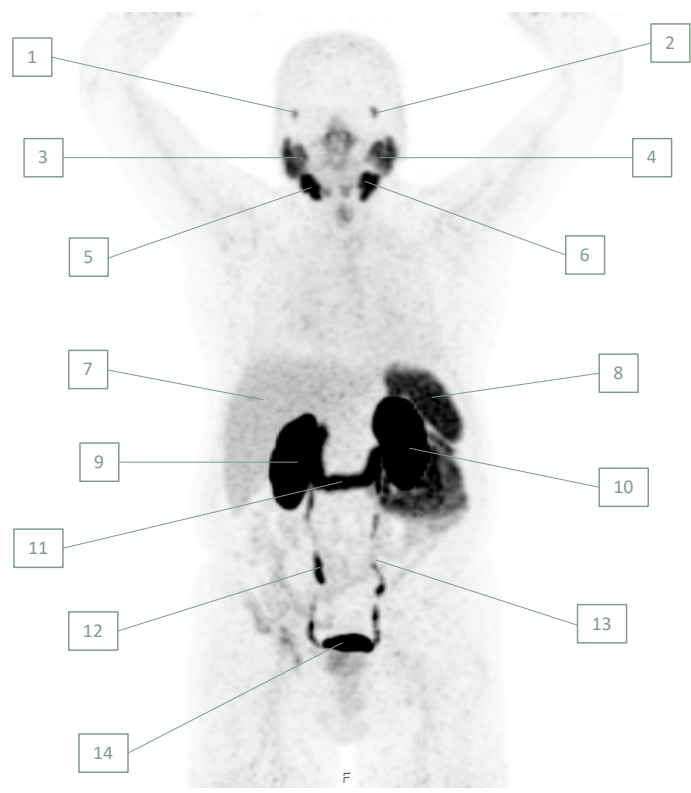

Figure 1. Frontal image of $\left[{ }^{68} \mathrm{Ga}\right] \mathrm{Ga}$-PSMA Maximal Intensity Projection (MIP) representing the uptake of PSMA in healthy tissue in a patient suspected for PCa metastases. All numbers represent healthy tissue. Non-specified areas with high activity are suspected for PCa metastases. 1. Right lacrimal gland, 2. Left lacrimal gland, 3. Right parotid gland, 4. Left parotid gland, 5. Right submandibular gland, 6. Left submandibular gland, 7. Liver, 8. Spleen, 9. Right kidney, 10. Left kidney, 11. Duodenum, 12. Right ureter, 13. Left ureter, 14. Urine bladder. 
The first studied PSMA targeting compound was termed indium-111 $\left(\left[{ }^{111} \mid n\right] \mid n\right)$-capromab pendetide (Prostascint, Cytogen Corp.). In the eighties, this antibody developed for radioimmunoscintigraphy in PCa patients targeted the intracellular part of the PSMA receptor. ${ }^{19}$ Although the general concept of capromab pendetide was promising, its implementation into clinical practice was limited as a result of its disappointing uptake and sensitivity. ${ }^{20}$ In 2012, a German research group from Heidelberg reported on PET/CT images obtained with a Gallium-68 ([ $\left.\left.{ }^{68} \mathrm{Ga}\right] \mathrm{Ga}\right)$-labelled PSMA tracer in a 67-year-old patient with biochemical recurrent PCa. ${ }^{21}$ Although the previously performed $\left[{ }^{18} \mathrm{~F}\right] \mathrm{F}$-Choline PET/ CT did not detect any lesions, $\left[{ }^{68} \mathrm{Ga}\right] \mathrm{Ga}-\mathrm{PSMA}$-HBED-CC PET/CT showed a lesion adjacent to the urinary bladder. This publication marked the start of the usage of $\left[{ }^{68} \mathrm{Ga}\right] \mathrm{Ga}$-labelled PSMA PET/CT for PCa diagnostics.

\section{Labelled PSMA tracers}

At present, two groups of PSMA tracers are used, i.e. gallium-68 ([ $\left.\left.{ }^{68} \mathrm{Ga}\right] \mathrm{Ga}\right)-$ labelled PSMA tracers (i.e. $\left.{ }^{68} \mathrm{Ga}\right] \mathrm{Ga}-\mathrm{PSMA}-\mathrm{HBED}-\mathrm{CC} /\left[{ }^{68} \mathrm{Ga}\right] \mathrm{Ga}-\mathrm{PSMA}-11$, $\left[{ }^{68} \mathrm{Ga}\right] \mathrm{Ga}-P S M A-617$ and $\left[{ }^{68} \mathrm{Ga}\right] \mathrm{Ga}-P S M A$ I\&T) and $\left[{ }^{18} \mathrm{~F}\right] \mathrm{F}-$ labelled PSMA tracers (i.e. [ $\left.{ }^{18} \mathrm{~F}\right] \mathrm{F}-\mathrm{DCFBC}$ (first generation) or $\left[{ }^{18} \mathrm{~F}\right] \mathrm{F}-\mathrm{DCFPyL}$ and $\left[{ }^{18} \mathrm{~F}\right]$ F-PSMA-1007 (second generation)) as shown in Figure $\mathbf{2}$ and $\mathbf{3}$. The second generation of $\left[{ }^{18} \mathrm{~F}\right] \mathrm{F}$-labelled PSMA tracers bind with higher affinity to the PSMA receptor, compared to $\left[{ }^{18} \mathrm{~F}\right] \mathrm{F}-\mathrm{DCFBC} .{ }^{22}$

$\left[{ }^{68} \mathrm{Ga}\right] \mathrm{Ga}$-labelled and $\left[{ }^{18} \mathrm{~F}\right] \mathrm{F}$-labelled PSMA tracers have different characteristics. Firstly, $\left[{ }^{68} \mathrm{Ga}\right] \mathrm{Ga}$ is produced by a Germanium-68 generator, whereas $\left[{ }^{18} \mathrm{~F}\right] \mathrm{F}-\mathrm{PSMA}$ is a cyclotron product. Secondly, $\left[{ }^{18} \mathrm{~F}\right] \mathrm{F}$ has a longer half-life (110 minutes) compared to $\left[{ }^{68} \mathrm{Ga}\right] \mathrm{Ga}$ (68 minutes), which allows for transportation to surrounding institutions. Thirdly, due to a smaller positron range effect, $\left[{ }^{18} \mathrm{~F}\right] \mathrm{F}$-PSMA has a better image resolution compared to $\left[{ }^{68} \mathrm{Ga}\right] \mathrm{Ga}$-PSMA. Also, $\left[{ }^{18} \mathrm{~F}\right] \mathrm{F}$-PSMA has a lower positron emission energy of $0.65 \mathrm{MeV}$ compared to $\left[{ }^{68} \mathrm{Ga}\right.$ ] Ga-PSMA (1.90 MeV), which is assumed to result in higher imaging quality. ${ }^{23-25}$ At the moment, $\left[{ }^{68} \mathrm{Ga}\right] \mathrm{Ga}$-labelled PSMA tracers are most commonly used worldwide. 
Thesis introduction and outline
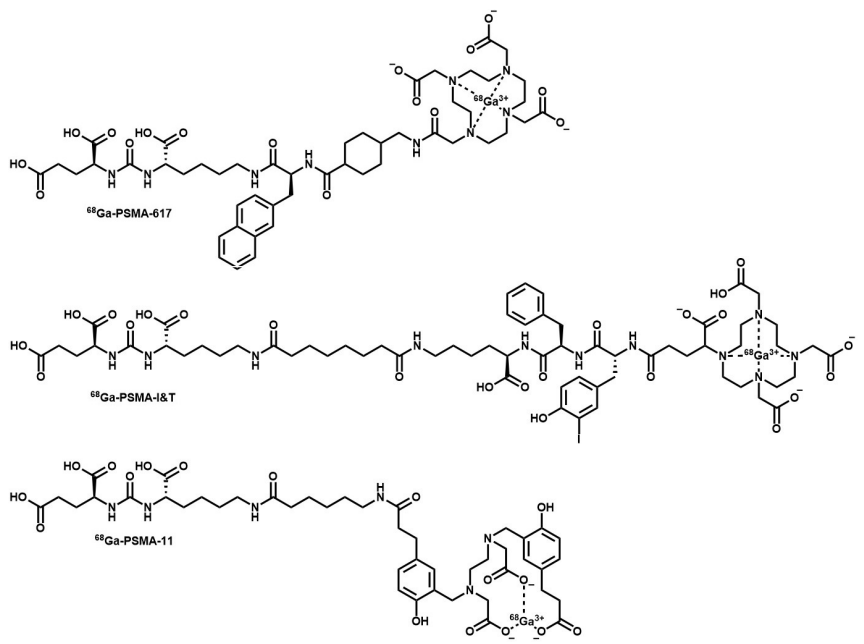

Figure 2. Different $\left[{ }^{68} \mathrm{Ga}\right] \mathrm{Ga}$-labelled PSMA tracer structures
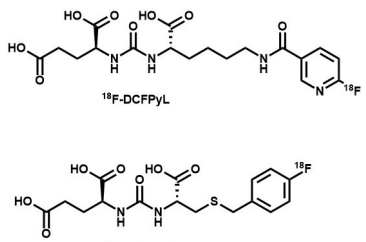

${ }^{18}$ F-DCFBC

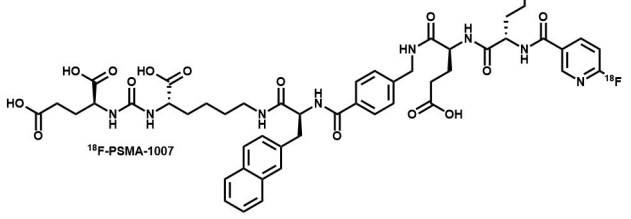

Figure 3. Different $\left[{ }^{18} \mathrm{~F}\right] \mathrm{F}$-labelled PSMA tracer structures

| 14 


\section{Other radiotracers}

In the context of radiotracers used for the detection of $\mathrm{PCa}$, anti-1amino-3-[18F]F-fluorocyclobutane-1-carboxylic acid (FACBC), or: $\left[{ }^{18} \mathrm{~F}\right]$ F-fluciclovine PET/CT (Axumin ), must also be mentioned. Unlike PSMA, $\left[{ }^{18} \mathrm{~F}\right] \mathrm{F}$-fluciclovine is a synthetic amino acid analog that shows high uptake in sites with increased protein turnover, like PCa. Interestingly, it is the only U.S. Food and Drug Administration (FDA) and European Medicines Agency (EMA)-approved, registered PET tracer for disease localization in patients with biochemically recurrent PCa. As such, $\left[{ }^{18} \mathrm{~F}\right] \mathrm{F}$-fluciclovine PET/ $\mathrm{CT}$ is incorporated in the guidelines of the Society of Nuclear Medicine and Molecular Imaging (SNMMI) and is more widely available in the USA than PSMA-targeting agents. ${ }^{26}$ Remarkably, in a recent systematic review and meta-analysis comparing $\left[{ }^{18} \mathrm{~F}\right] \mathrm{F}-$ fluciclovine PET/CT (38 studies, $\mathrm{n}=3217$ patients) to PSMA PET/CT (6 studies, $\mathrm{n}=482$ patients), detection rates of $\left[{ }^{18} \mathrm{~F}\right] \mathrm{F}$-fluciclovine $\mathrm{PET} / \mathrm{CT}$ were significantly inferior to those of PSMA PET/CT (respectively 62\% versus $80 \%$ ) in patients with PSA level ranging from 1.0 to $1.9 \mathrm{ng} / \mathrm{ml}^{27}$ For patients with PSA levels $<1.0 \mathrm{ng} /$ $\mathrm{ml}$, detection capacity of both tracers did not significantly differ, which was attributed to the limited number of patients with PSA levels below $1.0 \mathrm{ng} / \mathrm{ml}$ that were scanned with $\left[{ }^{18} \mathrm{~F}\right] \mathrm{F}$-fluciclovine. The superiority of $\left[{ }^{68} \mathrm{Ga}\right] \mathrm{Ga}-\mathrm{PSMA}$ PET/CT over $\left[{ }^{18} \mathrm{~F}\right] \mathrm{F}$-fluciclovine PET/CT at all PSA strata from $0.2-2.0 \mathrm{ng} / \mathrm{ml}$ was demonstrated by Calais et al., who prospectively randomized 50 patients with a biochemical recurrence (BCR) after radical prostatectomy between the two tracers. ${ }^{28}$ Although these results are obviously in favor of PSMA PET/CT, the TRACER-study -a large prospective study with a head-to-head comparison of [ $\left.{ }^{18} \mathrm{~F}\right] \mathrm{F}$-fluciclovine PET/CT versus $\left[{ }^{18} \mathrm{~F}\right] \mathrm{F}-\mathrm{PSMA}-1007$ - will soon provide the final evidence on diagnostic accuracy of both tracers.

\section{PSMA PET/CT and clinical practice}

A PSMA PET/CT is usually performed with low-dose CT from head to upper thigh. Image acquisition starts 50-60 minutes after injection of $1.8-2.2 \mathrm{MBq} / \mathrm{kg}\left[{ }^{68} \mathrm{Ga}\right] \mathrm{Ga}$-PSMA in accordance with the European Nuclear Medicine guidelines..$^{29}$ Radiation dose of a PSMA PET/CT scan 
is approximately 5 millisievert. Patients do not need to fast or interrupt the intake of medication, however, they need to be well hydrated (e.g. oral intake of $500 \mathrm{ml}$ of water during a 2 hour period prior to acquisition). Furosemide administration (20 mg intravenous (i.v.) shortly prior to or after i.v. administration of the radiotracer) may be used to reduce the high residual activity in the urinary system, which may lead to artefacts or even false positive findings.

\section{PSMA PET/CT in recurrent PCa ('secondary staging')}

Of all initially treated PCa patients, 28-53\% will eventually develop biochemically-recurrent $\mathrm{PCa} .{ }^{30} \mathrm{~A} B C R$ is regarded as the first sign of treatment failure. BCR is defined as PSA $\geq 0.2 \mathrm{ng} / \mathrm{ml}$ measured $>6$ weeks after radical prostatectomy, or any PSA rise of $\geq 2.0 \mathrm{ng} / \mathrm{ml}$ above nadir following radiotherapy (ASTRO-Phoenix consensus definition). ${ }^{31}$ In the setting of biochemically-recurrent PCa, accurate staging (i.e. 'secondary' staging) is important to select the most suitable subsequent therapeutic strategy. This can be challenging, especially when PSA levels are low.

Since the first paper on the superior performance of $\left[{ }^{68} \mathrm{Ga}\right] \mathrm{Ga}-\mathrm{PSMA}$ PET/ CT was published in $2012^{21}$, many publications, that were predominantly carried out in the BCR setting, followed. Promising results with regard to tumor detection in patients with BCR were demonstrated using $\left[{ }^{68} \mathrm{Ga}\right] \mathrm{Ga}$ PSMA-11 PET/CT.32 In a recent meta-analysis, analyzing 37 publications (n $=4790$ ), Perera et al. showed percentages of positive $\left[{ }^{68} \mathrm{Ga}\right] \mathrm{Ga}$-PSMA PET/ CT scans of 33\%, 45\%, 59\%, 75\%, and 95\% for the PSA categories 0-0.19, 0.2$0.49,0.5-0.99,1-1.99$ and $\geq 2 \mathrm{ng} / \mathrm{ml}$, respectively. ${ }^{33}$ Comparable detection rates of $38 \%, 57 \%, 84 \%, 86 \%$, and $97 \%$ for PSA levels of respectively $<0.5$, 0.5 to $<1.0,1.0$ to $<2.0,2.0$ to $<5.0$, and $\geq 5.0 \mathrm{ng} / \mathrm{mL}$ were reported by Fendler et al. in a large prospective multicenter trial including 635 patients with a BCR. ${ }^{34}$ Furthermore, a high patient-based positive predictive value of $84 \%$ (95\% Cl 75-90) was shown in 87 patients whose $\left[{ }^{68} \mathrm{Ga}\right] \mathrm{Ga}-\mathrm{PSMA}-11$ PET/CT results were validated by histopathology.

The radiotracer $\left[{ }^{18} \mathrm{~F}\right] \mathrm{F}$-DCFPyL was first described in the literature by Chen et al. in 2011. ${ }^{35}$ The first clinical experience in humans was obtained four 
years later, consisting of nine hormone-naïve and castration-resistant patients. ${ }^{36}$ As no severe adverse events occurred in these nine men, this study not only demonstrated the tumor uptake of [ $\left.{ }^{18} \mathrm{~F}\right] \mathrm{F}-\mathrm{DCFPyL}$, but also its safety.

To date, only limited clinical data are available regarding [ $\left.{ }^{18} \mathrm{~F}\right] \mathrm{F}-\mathrm{PSMA}$ PET/ $\mathrm{CT}$ in patients with a BCR. In a recent systematic review and meta-analysis including six publications ( $n=645$ ), overall patient-based detection rate of [ $\left.{ }^{18} \mathrm{~F}\right] \mathrm{F}-\mathrm{PSMA}$ PET/CT was $86 \%$ (95\% Cl 71-88\%). ${ }^{37}$ Pooled detection rates for PSA levels of $<0.5, \geq 0.5-1.0, \geq 1.0-2.0$ and $\geq 2.0 \mathrm{ng} / \mathrm{ml}$ were respectively 49\% (95\% Cl 23-74\%), 73\% (95\% Cl 59-85\%), 88\% (95\% Cl 73-97\%) and 92\% (95\% Cl 83-98\%). Interestingly, Dietlein et al. investigated 160 postprostatectomy patients with PSA levels ranging from $0.5-3.5 \mathrm{ng} / \mathrm{ml}$ and determined [ $\left.{ }^{18} \mathrm{~F}\right] \mathrm{F}-\mathrm{DCFPYL}$ PET/CT to have a significantly higher detection rate compared to $\left[{ }^{68} \mathrm{Ga}\right.$ ]Ga-PSMA PET/CT (88\% versus 66\%, respectively; $\mathrm{p}=0.042){ }_{.}^{23} \mathrm{In}$ patients with PSA levels $<0.5 \mathrm{ng} / \mathrm{ml}$ and $>3.5 \mathrm{ng} / \mathrm{ml}$, sensitivity of both radiotracers was found to be equal in this study $(<15 \%$ and $>85 \%$, respectively).

\section{PSMA PET/CT in newly diagnosed PCa ('primary staging')}

Although the first wave of PSMA-related publications focused on its value PCa patients with a BCR, a vast number of initial, mostly small retrospective studies followed and demonstrated promising results of $\left[{ }^{68} \mathrm{Ga}\right] \mathrm{Ga}-P S M A$ PET/CT in initial staging. ${ }^{38-41}$ Subsequently, Hope et al. performed a meta-analysis to clarify detection rate of $\left[{ }^{68} \mathrm{Ga}\right] \mathrm{Ga}$-PSMA-11 PET/CT for lymph node detection in the setting of primary staging of PCa. ${ }^{42}$ The study comprised five studies ( $n=266$ patients, mostly classified as having intermediate to high risk PCa). In all studies, PET results were compared to histopathology as a reference. A lesion-based sensitivity, specificity, positive predictive value (PPV), negative predictive value (NPV) and an accuracy of respectively $74 \%$ (95\% Cl 51-89\%), 96\% (95\% Cl 8599\%), 93\% (95\% Cl 86-99\%), 85\% (95\% Cl 75-93\%) and 86\% (95\% Cl 7292\%) was observed. 
After the publication of this meta-analysis, Luiting et al. (2020) also reviewed diagnostic performance of $\left[{ }^{68} \mathrm{Ga}\right] \mathrm{Ga}$-PSMA PET/CT for lymph node detection in primary staging in men with PCa. ${ }^{43}$ Eleven studies were included in this review: two prospective studies ( $n=63$ patients) and nine retrospective studies ( $n=696$ patients). In all studies, histopathology was referred to as gold standard. Patient-based sensitivity and specificity ranges of respectively $64-100 \%$ and $90-95 \%$ were found in the prospective studies. Lesion-based sensitivity and specificity ranges were respectively $50-58 \%$ and $96-100 \%$. In the retrospective studies, the sensitivity and specificity range was respectively $33.3-100 \%$ and $80-100 \%$. With regard to the lesion-based analysis, they found a sensitivity and specificity range of $24.4-96.1 \%$ and $98.6-100 \%$, respectively. Especially sensitivity was lower in comparison with the previously discussed meta-analysis by Hope et al. ${ }^{42}$, who included significantly less studies. This reflects that definite diagnostic value of $\left[{ }^{68} \mathrm{Ga}\right] \mathrm{Ga}$-PSMA PET/CT in primary staging of PCa still needs to be determined by future reviews and meta-analyses including well-designed prospective studies. With regard to diagnostic performance of $\left[{ }^{18} \mathrm{~F}\right] \mathrm{F}$-labelled PSMA tracers in primary staging of PCa however, only a small number of studies has been published. Gorin et al. prospectively evaluated diagnostic performance of preoperative [ $\left.{ }^{18} \mathrm{~F}\right] \mathrm{F}$-DCFPyL PET/CT in 25 men with high risk PCa being eligible for prostatectomy and ePLND. ${ }^{44}$ When compared to histopathology findings, patient-based sensitivity and specificity was respectively $71.4 \%$ (95\% Cl 29.0-96.3\%) and $88.9 \%$ (95\% Cl 65.3-98.6\%). Lesion-based sensitivity and specificity was $66.7 \%$ (95\% Cl 29.9-92.5\%) and 97.7\% (95\% Cl 80.1-98.5\%), respectively. At present, the diagnostic performance of $\left[{ }^{18} \mathrm{~F}\right] \mathrm{F}-\mathrm{DCFPyL}$ and $\left[{ }^{18} \mathrm{~F}\right]$ F-PSMA-1007 in the setting of initial staging of PCa with histopathology reference are currently under investigation in prospective trials conducted at the Amsterdam UMC, location VUmc (the SALT-study; NL6754), and the Canisius Wilhelmina Ziekenhuis in Nijmegen (the MINT-study; NL7428). 


\section{PROSTATE CANCER THERAPY}

\section{Metastatic castration resistant prostate cancer}

With 2896 deaths in 2018, PCa is an important cause of cancer mortality in the Netherlands. ${ }^{45}$ A proportion of $10-20 \%$ of the PCa patients will eventually progress to metastatic castration-resistant prostate cancer (mCRPC). ${ }^{46}$ Since PCa metastases have a preference for bone (marrow), approximately $90 \%$ of these patients develop bone metastases. Common clinical presentations include pain, fatigue, bone marrow depression or complications such as fractures and cord compression. ${ }^{47}$ Standard treatment options in advanced PCa patients include chemotherapy (docetaxel and cabazitaxel) and new hormonal agents (enzalutamide and abiraterone). However, these therapies are associated with substantial side effects. Also, for some patients, chemotherapy is not tolerated well or even contraindicated. Therefore, novel therapeutic strategies for MCRPC patients with improved outcomes and minimal side effects are profoundly needed.

\section{Radioligand therapy (RLT)}

For many years, RLT was exclusively reserved for palliation of bone metastases. Common treatments for metastatic PCa patients include samarium-153 (1535m)-labeled ethylene diamine tetramethylene phosphonate ([1535m]Sm-EDTMP; Quadramet, Lantheus) and the calcium mimetic alfa emitter radium-223 (223 Ra)-labeled dichloride (Xofigo, Bayer Healthcare), of which the latter demonstrated an improved overall survival (OS) of 3.6 months. ${ }^{48}$ The first studied PSMA targeting compound was yttrium-90 ( $\left.{ }^{90} \mathrm{Y}\right)$-capromab pendetide, the therapeutic equivalent of Prostascint. Subsequently, the potential of the $\left[{ }^{177} \mathrm{Lu}\right] \mathrm{Lu}-$ labelled PSMA monoclonal antibody J-591, was investigated. ${ }^{49}$ In a phase I and phase II study, this compound was found to have modest effect and was found to be associated with serious myelosuppression, as were all other aforementioned bone-targeting radioligand therapies. ${ }^{50-52}$ The perspective on RLT changed with the development of the novel small-molecule PSMA targeting radioligands (or 'radiotracers') [177 Lu] 
Lu-PSMA-617 and [ ${ }^{177}$ Lu]Lu-PSMA-I\&T, being composed of the PSMA receptor targeting ligand PSMA, labeled with the radioisotope and $\beta$-radiation emitter $\left[{ }^{177} \mathrm{Lu}\right] \mathrm{Lu}$ and a binding agent ('chelator'). When the radioligand $\left[{ }^{177} \mathrm{Lu}\right] \mathrm{Lu}-\mathrm{PSMA}$ binds with high affinity to the extracellular domain of the PSMA receptor, the radiotracer is transported into the cell through endocytosis, resulting in local radiation of PCa cells, intracellular DNA damage and apoptosis.

\section{PSMA ligands}

In 2015, development of [177Lu]Lu-PSMA-617 for the treatment of patients with metastatic prostate cancer was initiated by the German Cancer Research Center 'Deutsches Krebsforschungszentrum' (DKFZ) in collaboration with the University Hospital Heidelberg. ${ }^{53,54}$ Based on preclinical data demonstrating favorable characteristics (high PSMA binding affinity and compound internalization, prolonged tumor uptake, rapid kidney clearance, and high tumor-to-background ratio), [ $\left.{ }^{177} \mathrm{Lu}\right] \mathrm{Lu}-$ PSMA was clinically developed at investigative sites in Germany. Also, in an attempt to further optimize affinity of the PSMA tracer, another PSMA targeting ligand, termed PSMA-Imaging and Therapy (I\&T), was developed in München. ${ }^{55}$ Despite the fact that the molecular structures of [ $\left.{ }^{177} \mathrm{Lu}\right] \mathrm{Lu}-\mathrm{PSMA}-617$ and $\left[{ }^{177} \mathrm{Lu}\right] \mathrm{Lu}-\mathrm{PSMA}-\mathrm{I}$ T are built out of different chelator agents (respectively DOTA and DOTAGA), the two tracers were found to have comparable biodistribution. ${ }^{56}$ Several retrospective, singlearm studies were initiated and demonstrated safety, promising efficacy and limited toxicity of radioligand therapy with [177Lu]Lu-PSMA-617 and $\left[{ }^{177} \mathrm{Lu}\right] \mathrm{Lu}-\mathrm{PSMA}-\mathrm{I} \& \mathrm{~T}$ in patients with $\mathrm{MCRPC} .{ }^{57-64}$ These results induced the provision of $\left[{ }^{177} \mathrm{Lu}\right] \mathrm{Lu}-\mathrm{PSMA}-617$ on the basis of 'compassionate use' at several institutions in Europa, even while the outcomes of randomizedcontrolled trials and -presumably- subsequent approval for clinical use are still awaited. 


\section{Indications}

The decision whether or not an individual patient is eligible for treatment with [ $\left.{ }^{177} \mathrm{Lu}\right] \mathrm{Lu}-\mathrm{PSMA} \mathrm{RLT}$ is dependent on clinical assessment and evaluation of imaging and laboratory findings and is made by a multidisciplinary tumor board. In general, MCRPC patients who 1) have failed or are ineligible for alternative cytotoxic treatment options and 2) have adequate organ function and 3) show adequate radiotracer uptake on PSMA PET/CT prior to therapy are considered eligible for $\left[{ }^{177} \mathrm{Lu}\right] \mathrm{Lu}-$ PSMA RLT (Table 1). However, the definition of 'adequate uptake' is a topic for discussion. Current practice is based on previous literature on neuroendocrine theranostics, in which uptake in tumor sites must at least be higher than physiological uptake in normal organs, such as the liver.

Table 1. Current indications for [ ${ }^{177}$ Lu] Lu-PSMA-617 therapy as defined by the UMC Utrecht

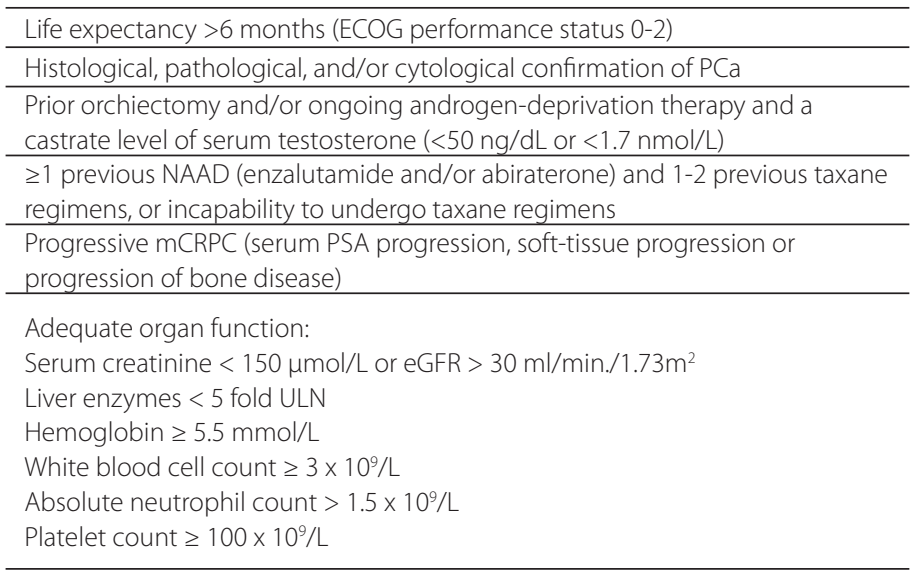

Positive PSMA PET/CT (visual assessment; radiotracer uptake in tumor sites preferably $>>$ uptake in normal liver parenchyma)

No symptomatic spinal cord compression, or clinical or radiologic findings indicative of impending cord compression

${ }^{*} \mathrm{NAAD}=$ novel androgen axis drug, eGFR = estimated glomerular filtration rate, ULN = upper limit of normal 


\section{Treatment protocol (as defined by the UMC Utrecht)}

The currently administered activity [177 Lu] Lu-PSMA RLT ranges from 6.0-7.5 GBq per cycle, in 2-6 cycles, with an interval of 6-8 weeks. To receive [ $\left.{ }^{177} \mathrm{Lu}\right]$ Lu-PSMA RLT therapy, patients are admitted to the nuclear medicine ward for treatment and released from the hospital according to Dutch regulatory radiation guidelines ( $20 \mu \mathrm{Sv} / \mathrm{h}$ measured at a distance of $1 \mathrm{~m}$ $>$ microsievert). $\left.{ }^{177} \mathrm{Lu}\right] \mathrm{Lu}-\mathrm{PSMA} \mathrm{RLT}$ is administered by slow infusion (20 $\mathrm{ml} / \mathrm{min}$ flow rate). To prevent nausea, antiemetic drugs are supplied. To monitor biochemical response and toxicity, laboratory tests (full blood count, kidney and liver function tests and PSA) are executed after every treatment cycle. Post-therapeutic scintigraphy following every therapy cycle is performed to investigate radiotracer uptake, which may serve to evaluate imaging response of PSMA positive lesions. After 2, 4 and 6 cycles, $\left[{ }^{68} \mathrm{Ga}\right] \mathrm{Ga}$-PSMA PET/CT scans are performed. Whether or not to continue therapy is discussed in a multidisciplinary tumor board meeting after every two cycles.

\section{Safety and efficacy}

Past years, four systematic reviews/meta-analyses on $\left[{ }^{177} \mathrm{Lu}\right] \mathrm{Lu}-\mathrm{PSMA}$ RLT were published, in which mainly small, predominantly German studies were included. ${ }^{65-68}$ All reviews reported on (one of the following) oncological outcomes: safety and tumor response, clinical parameters and survival effects. Significant variability between the published reviews exists, which can be explained by the different publications selected. For example, Calopedos et al. and von Eyben et al. also included publications reporting on [ $\left.{ }^{177} \mathrm{Lu}\right] \mathrm{Lu}-J 591$ therapy, known to be associated with higher toxicity rates compared to $\left[{ }^{177} \mathrm{Lu}\right] \mathrm{Lu}-\mathrm{PSMA}-617$ and $\left[{ }^{177} \mathrm{Lu}\right] \mathrm{Lu}-\mathrm{PSMA}-\mathrm{I}$ T. Moreover, heterogeneity exists with regard to outcomes and followup schemes. Therefore, I will only discuss the review of Yadav et al., that focused on small molecule treatments with [ ${ }^{177} \mathrm{Lu}$ L Lu-PSMA-617 and [177Lu]Lu-PSMA-I\&T only.

The review by Yadav et al. included 16 publications. ${ }^{68}$ Thirteen studies reported on [ $\left.{ }^{177} \mathrm{Lu}\right] \mathrm{Lu}-\mathrm{PSMA}-617$; two on $\left[{ }^{177} \mathrm{Lu}\right.$ ]Lu-PSMA-I\&T and one on 
both compounds. Overall pooled proportions of patients who had any PSA-decline and $>50 \%$ PSA decline were respectively $75 \%(95 \% \mathrm{Cl} 70$ 79\%) and 46\% (95\% Cl 40\%-53\%). Objective tumor response according to RECIST (Response Evaluation Criteria in Solid Tumors) ${ }^{69}$ was reported by eight studies ( $n=175$ patients). A proportion of $37.2 \%$ of the patients had partial remission, 38.3\% stable disease and 24.5\% progressive disease. Molecular response on PET imaging according to PERCIST (Positron Emission Tomography Response Evaluation Criteria in Solid Tumors) ${ }^{70}$ was reported by eight of the 17 studies ( $n=167$ patients). Seventy-four patients (44.3\%) had a partial molecular response, 39 patients (23.4\%) had stable disease, and 54 patients (32.3\%) had disease progression. Most side effects were mild (Common Terminology Criteria for Adverse Events (CTCAE) grade 1-2) and comprised anemia (23\%), leukopenia (14.2\%) and thrombocytopenia (15\%). Renal toxicity was reported in $9.5 \%$ of patients. Most important non-hematological toxicity was confined to the salivary glands (i.e. xerostomia; 14.5\%). These results support the safety and efficacy profile of [177Lu]Lu-PSMA therapy to treat advanced PCa.

In 2018, the first prospective study on [ ${ }^{177}$ Lu]Lu-PSMA-617 therapy was published..$^{71}$ In this phase II study, including 30 mCRPC patients, 1-4 cycles with 7.5 GBq (range: 4.4-8.7 GBq) [177Lu]Lu-PSMA-617 were administered. Main aim of the study was the analysis of PSA response rate and toxicity. In this study, $>50 \%$ PSA decline was observed in 57\% of the patients. Treatment was even ceased in two patients after two of the four planned cycles, because of an exceptional response to treatment. Most common toxicities included CTCAE grade 1 xerostomia (87\%), grade 1-2 transient nausea (50\%) and fatigue (50\%). Biochemical toxicities included grade 3-4 thrombocytopenia (13\%), grade 3 anemia (13\%) and neutropenia (7\%). After two treatment cycles, quality of life according to the European Organization for Research and Treatment of Cancer (EORTC)-questionnaire improved with 10 points in $37 \%$ of the patients. PSA progression-free survival was 7.6 months ( $95 \%$ Cl 6.3-9.0 months). Median overall survival (OS) was 13.5 months ( $95 \%$ Cl 10.4-22.7) months. Twenty-two patients (73\%) died during follow-up, most likely as a result of disease progression $(n=21)$. Therapy-related deaths were not reported. 


\section{Survival}

Little is known about the efficacy of [ ${ }^{177}$ Lu]Lu-PSMA therapy in terms of progression free survival (PFS) and/or OS. Nevertheless, Kim et al. addressed OS based on extent of PSA response (any PSA decline and $>50 \%$ PSA decline) after a single cycle of [ $\left.{ }^{177} \mathrm{Lu}\right]$ Lu-PSMA therapy and found pooled hazard ratios of 0.29 and 0.82 respectively. ${ }^{65}$ Von Eyben et al. found a median OS of 14 months in the patients treated with $\left[{ }^{177} \mathrm{Lu}\right] \mathrm{Lu}-\mathrm{PSMA} .{ }^{67}$ The median OS of 13.7 months (interquartile range (IQR): 8-14 months) reported by Yadav et al., was congruent with these findings and was found to be superior to the survival of a historical cohort, which had an OS of 11.2 months. ${ }^{68}$ Median PFS was found to be 11 months (IQR: 7.6-13.7 months). To ultimately define value of [ $\left.{ }^{177} \mathrm{Lu}\right] \mathrm{Lu}-\mathrm{PSMA}-617$ therapy, however, survival analyses based on prospectively acquired data are warranted.

\section{$\left[{ }^{177} \mathrm{Lu}\right.$ Lu-PSMA-617 therapy in the Netherlands}

Based on the initially published, promising results, [177Lu]Lu-PSMA-617 therapy was introduced into clinical practice in the University Medical Center Utrecht in the Netherlands in December 2016. Until 2019, [177Lu]Lu-PSMA-617 was administered to advanced mCRPC patients in the clinical setting on a salvage basis, after all other registered treatment strategies had failed. At present, availability of $\left[{ }^{177} \mathrm{Lu}\right] \mathrm{Lu}-\mathrm{PSMA}-617$ is confined to the context of scientific research. [ $\left.{ }^{177} \mathrm{Lu}\right] \mathrm{Lu}-\mathrm{PSMA}$-I\&T is available in the Netherlands, however, this compound is neither registered nor reimbursed.

\section{Clinical trials}

In 2018, Endocyte/Novartis started a phase 3 trial, known as the VISIONtrial (NCT03511664), to prospectively study the efficacy and toxicity profile of [ $\left.{ }^{177} \mathrm{Lu}\right] \mathrm{Lu}-\mathrm{PSMA}-617$ therapy. Four Dutch hospitals participated in this study, in which 750 metastatic PCa patients were randomly (2:1) assigned to two study-arms: either treatment with $7.4 \mathrm{GBq}\left[{ }^{177} \mathrm{Lu}\right] \mathrm{Lu}-\mathrm{PSMA}-617$ per cycle or best supportive care. The results of this study are expected in 2021. In line with the promising initial results of [177 Lu]Lu-PSMA-617 
therapy, the VISION study is expected to be positive. If indeed so, $\left[{ }^{177} \mathrm{Lu}\right] \mathrm{Lu}-\mathrm{PSMA}-617$ therapy will soon be implemented in daily clinical care in The Netherlands. According to the studied procedures in the VISION study, mCRPC patients will be eligible for treatment once every 6 weeks with a maximum of 6 cycles of $7.4 \mathrm{GBq}\left[{ }^{177} \mathrm{Lu}\right] \mathrm{Lu}-\mathrm{PSMA}-617$.

TheraP, another clinical phase 2 trial (NCT03392428) initiated by Endocyte/ Novartis, aims to determine the activity and safety of [177Lu]Lu-PSMA-617 RLT as a second line treatment and will be performed in Australia. A total number of 200 patients with metastatic PCa who have progressed despite ADT and chemotherapy, will be randomized to receive either [177Lu]Lu-PSMA-617 RLT (up to a maximum of 6 cycles of therapy) or cabazitaxel chemotherapy (up to a maximum of 10 cycles of therapy). The primary endpoint includes the effect of $\left[{ }^{177} \mathrm{Lu}\right] \mathrm{Lu}-\mathrm{PSMA}-617$ on PSA response. Secondary outcomes encompass pain response, PFS, quality of life, and frequency and severity of adverse events.

\section{THESIS OBJECTIVES AND}

Since labelled PSMA tracers bind with a high affinity to the PSMA receptor, several targeted strategies including tumor localization using radioactive imaging and therapeutic intervention using RLT have been developed. The phenomenon of radioactive labelled ligands ('radioligands' or: 'radiotracers') being suitable both for diagnostics and therapeutic purposes, is called 'theranostics'. The present thesis focusses on the role of PSMA receptor-targeting techniques to enhance PCa theranostics.

The main subjects discussed in this thesis include:

1. the diagnostic value of $\left[{ }^{68} \mathrm{Ga}\right] \mathrm{Ga}-\mathrm{PSMA} \mathrm{PET} / \mathrm{CT}$ in primary staging of PCa, and:

2. the first Dutch experience with $\left[{ }^{177} L u\right] L u-P S M A$ therapy in late phase mCRPC patients and its associated toxicities. 
Other publications incorporated in this thesis focus on the evaluation of the contemporary used protocols in PSMA targeting theranostics.

This thesis is subdivided into two parts, excluding the summary and discussion (part III) and the appendices (part IV):

\section{PART I: PROSTATE CANCER IMAGING}

In chapter 2 the results of the PEPPER-study will be presented. This prospective validation study evaluates the diagnostic accuracy of $\left[{ }^{68} \mathrm{Ga}\right] \mathrm{Ga}$-PSMA PET/CT for lymph node detection in primary staging in men with PCa with histopathology as a reference. Patient-based and template-based diagnostic performance in terms of sensitivity, specificity PPV and NPV are calculated. Moreover, change of management caused by the implementation of $\left[{ }^{68} \mathrm{Ga}\right] \mathrm{Ga}$-PSMA PET/CT into the diagnostic workup of PCa patients, is reported.

For the implementation of imaging techniques into clinical practice, robust agreement between readers is essential. In chapter 3, interobserver agreement of $\left[{ }^{68} \mathrm{Ga}\right] \mathrm{Ga}$-PSMA PET/CT reporting according to a novel, easy applicable, standardized Likert (5-point) scale is reported. Also, this method is evaluated in the light of other previously proposed classification methods.

Chapter 4 evaluates performance of $\left.{ }^{68} \mathrm{Ga}\right] \mathrm{Ga}-\mathrm{PSMA}-11$ in comparison to $\left.{ }^{18} \mathrm{~F}\right] \mathrm{F}-\mathrm{DCFPyL}$ to detect $\mathrm{PCa}$ in patients with a $\mathrm{BCR}$ after radical prostatectomy. With this study, the abovementioned results reported by Dietlein et al. (2017), suggesting that $\left[{ }^{18} \mathrm{~F}\right] \mathrm{F}$-DCFPyL outperforms $\left[{ }^{68} \mathrm{Ga}\right] \mathrm{Ga}$ PSMA in BCR patients with low PSA levels (PSA: 0.5-3.5 ng/ml) after radical prostatectomy, will be validated.

\section{PART II: PROSTATE CANCER THERAPY}

In December 2016, [177Lu]Lu-PSMA-617 treatment was introduced into clinical practice in the University Medical Center Utrecht in the Netherlands. A case-report describing the first patient who underwent 
$\left[{ }^{177} \mathrm{Lu}\right] \mathrm{Lu}-\mathrm{PSMA}-617$ treatment in the UMC Utrecht is presented in chapter 5 of this thesis.

Chapter 6 summarizes the first experience with [ $\left.{ }^{177} \mathrm{Lu}\right]$ Lu-PSMA-617 therapy in the UMC Utrecht on a larger scale. Of the first 30 patients who were treated in our institution, treatment-related efficacy (clinical, biochemical and imaging response) and (clinical and biochemical) toxicity is reported.

In general, $\left[{ }^{177} \mathrm{Lu}\right] \mathrm{Lu}-\mathrm{PSMA}$ therapy is found to be well-tolerated with low toxic effects. However, chapter 7 will report on a patient who underwent $\left[{ }^{177} \mathrm{Lu}\right]$ Lu-PSMA-617 therapy in the setting of metastatic castration resistant prostate cancer in our institution. Following administration of the second therapy cycle, the patient presented with a slowly impairing, bilateral visual loss, being either caused by dural and/or leptomeningeal metastases of advanced MCRPC or by neurological toxicity following ${ }^{177}$ Lu]Lu-PSMA therapy.

As a result of PSMA expression in the salivary glands, one of the most important anticipated side effects of [ $\left.{ }^{177} \mathrm{Lu}\right] \mathrm{Lu}$-PSMA-617 therapy includes 'xerostomia'(or: dry mouth). External cooling of with icepacks is advocated to induce local vasoconstriction, reduce blood flow and decrease PSMA uptake by the salivary glands. A study investigating the effect of cooling with icepacks on PSMA uptake in the salivary glands is presented in chapter 8 of this thesis.

[777 Lu]Lu-PSMA-617 therapy is currently administered in a fixed dose of 6.0 or $7.4 \mathrm{GBq}$ per cycle, similar to the protocols followed in peptide receptor radionuclide therapy. Since dose-escalation studies addressing this topic are sparse and comparative studies between both activities are lacking, the study presented in chapter 9 reports on toxicity rates of patients treated with 6.0 versus $7.4 \mathrm{GBq}\left[{ }^{177} \mathrm{Lu}\right] \mathrm{Lu}-\mathrm{PSMA}-617$. 


\section{REFERENCES}

1. Siegel RL, Miller KD, Jemal A. Cancer statistics, 2019. CA Cancer J Clin. 2019;69(1):7-34.

2. Integraal Kankercentrum Nederland. Incidentie, Prostaatkanker, Aantal. [Internet]. Available from: https://www.iknl.nl/nkr-cijfers. [Accessed 30 April 2020].

3. Gakis G, Boorjian SA, Briganti A, et al. The role of radical prostatectomy and lymph node dissection in lymph node-positive prostate cancer: a systematic review of the literature. Eur Urol. 2014 Aug;66(2):191-9.

4. Nederlandse Vereniging voor Urologie. Evidence based richtlijn voor de diagnostiek en behandeling van prostaatcarcinoom. [Internet]. Available from: https://richtlijnendatabase.nl/richtlijn/prostaatcarcinoom/gelokaliseerd_ prostaatcarcinoom.html [Accessed 19 May 2020].

5. European Association of Urology. EAU-EANM-ESTRO-ESUR-SIOG Guidelines on Prostate Cancer 2020. [Internet]. Available from: https://uroweb.org/ guideline/prostate-cancer/. [Accessed 30 April 2020].

6. National Comprehensive Cancer Network. Clinical Practice Guidelines in Oncology. [Internet]. Available from: https://www.nccn.org/professionals/ physician_gls/default.aspx. [Accessed 19 May 2020].

7. Memorial Sloan Kettering Cancer Center. Prostate Cancer Nomograms: PreRadical Prostatectomy. [Internet]. Available from: https://www.mskcc.org/ nomograms/prostate/pre_op. [Accessed 19 May 2020].

8. Briganti A, Chun FK, Salonia A, et al. Complications and other surgical outcomes associated with extended pelvic lymphadenectomy in men with localized prostate cancer. Eur Urol. 2006;50(5):1006-13.

9. Hövels AM, Heesakkers RA, Adang EM, et al. The diagnostic accuracy of CT and $\mathrm{MRI}$ in the staging of pelvic lymph nodes in patients with prostate cancer: a meta-analysis. Clin Radiol. 2008 Apr;63(4):387-95.

10. Heesakkers RA, Hövels AM, Jager GJ, et al. MRI with a lymph-node-specific contrast agent as an alternative to CT scan and Lymph-Node Dissection in Patients With Prostate Cancer: A Prospective Multicohort Study. Lancet Oncology. 2008;9(9):850-6.

11. Msaouel P, Pissimissis N, Halapas A, Koutsilieris M. Mechanisms of bone metastasis in prostate cancer: clinical implications. Best Pract Res Clin Endocrinol Metab 2008; 22:341-55.

12. Kitajima K, Murphy RC, Nathan MA, Sugimura K. Update on positron emission tomography for imaging of prostate cancer. Int J Urol (2014) 21: 12-23.

13. Jadvar, H. Molecular imaging of prostate cancer with ${ }^{18} \mathrm{~F}$-fluorodeoxyglucose PET. Nat Rev Urol 2009; 6: 317-323. 
14. Evangelista L, Briganti A, Fanti S, et al. New Clinical Indications for (18)F/(11) C-choline, New Tracers for Positron Emission Tomography and a Promising Hybrid Device for Prostate Cancer Staging: A Systematic Review of the Literature. Eur Urol. 2016;70(1):161-75.

15. Ross JS, Sheehan CE, Fisher H. Correlation of primary tumor prostate-specific membrane antigen expression with disease recurrence in prostate cancer. Clin Cancer Res. 2003;9:6357-62.

16. Silver DA, Pellicer I, Fair WR, Heston WD, Cordon-Cardo C. Prostate-specific membrane antigen expression in normal and malignant human tissues. Clin Cancer Res. 1997;3(1):81-5.

17. Leung K. Quenched indocyanine green-anti-prostate-specific membrane antigen antibody J591. Molecular Imaging and Contrast Agent Database (MICAD). Bethesda (MD)2004.

18. Afshar-Oromieh A, Malcher A, Eder M, Eisenhut M, Linhart HG, Hadaschik BA, et al. PET imaging with a [68Ga]gallium-labelled PSMA ligand for the diagnosis of prostate cancer: biodistribution in humans and first evaluation of tumour lesions. Eur J Nucl Med Mol Imaging. 2013;40(4):486-95.

19. Horoszewicz JS, Kawinski E, Murphy GP. Monoclonal antibodies to a new antigenic marker in epithelial prostatic cells and serum of prostatic cancer patients. Anticancer Res. 1987;7(5B):927-935.

20. Taneja SS. ProstaScint(R) Scan: Contemporary Use in Clinical Practice. Rev Urol. 2004;6 Suppl 10(Suppl 10):S19-28.

21. Afshar-Oromieh A, Haberkorn U, Eder M, Eisenhut M, Zechmann CM. [68Ga] Gallium-labelled PSMA ligand as superior PET tracer for the diagnosis of prostate cancer: comparison with 18F-FECH. Eur J Nucl Med Mol Imaging. 2012;39(6):1085-6.

22. Szabo Z, Mena E, Rowe SP, et al. Initial Evaluation of [(18)F]DCFPyL for ProstateSpecific Membrane Antigen (PSMA)-Targeted PET Imaging of Prostate Cancer. Mol Imaging Biol. 2015 Aug;17(4):565-74.

23. Dietlein F, Kobe C, Neubauer S, et al. PSA-Stratified Performance of (18)F- and (68)Ga-PSMA PET in Patients with Biochemical Recurrence of Prostate Cancer. J Nucl Med. 2017;58(6):947-52.

24. Dietlein M, Kobe C, Kuhnert G, et al. Comparison of [(18)F]DCFPyL and [ (68) Ga]Ga-PSMA-HBED-CC for PSMA-PET Imaging in Patients with Relapsed Prostate Cancer. Mol Imaging Biol. 2015;17(4):575-84.

25. Kesch C, Kratochwil C, Mier W, Kopka K, Giesel FL. (68)Ga or (18)F for Prostate Cancer Imaging? J Nucl Med. 2017;58(5):687-8. 
26. Nanni C, Zanoni L, Bach-Gansmo T, et al. [ $\left.{ }^{18} \mathrm{~F}\right]$ Fluciclovine PET/CT: joint EANM and SNMMI procedure guideline for prostate cancer imaging-version 1.0. Eur J Nucl Med Mol Imaging 47, 579-591 (2020).

27. Tan N, Oyoyo U, Bavadian N, et al. PSMA-targeted Radiotracers versus ${ }^{18} \mathrm{~F}$ Fluciclovine for the Detection of Prostate Cancer Biochemical Recurrence after Definitive Therapy: A Systematic Review and Meta-Analysis. Radiology. 2020 May 12:191689.

28. Calais J, Ceci F, Eiber $M$ et al. ${ }^{18} F-$ fluciclovine PET-CT and ${ }^{68}$ Ga-PSMA-11 PET$\mathrm{CT}$ in patients with early biochemical recurrence after prostatectomy: a prospective, single-centre, single-arm, comparative imaging trial. Lancet Oncol 2019;20(9):1286-1294.

29. Fendler WP, Eiber M, Beheshti M, Bomanji J, Ceci F, Cho S, et al. (68)Ga-PSMA PET/CT: Joint EANM and SNMMI procedure guideline for prostate cancer imaging: version 1.0. Eur J Nucl Med Mol Imaging. 2017;44(6):1014-24.

30. Cornford P, Bellmunt J, Bolla M, et al. EAU-ESTRO-SIOG Guidelines on Prostate Cancer. Part II: Treatment of Relapsing, Metastatic, and Castration-Resistant Prostate Cancer. Eur Urol. 2017;71(4):630-42.

31. Roach M 3rd, Hanks G, Thames H Jr, et al. Defining biochemical failure following radiotherapy with or without hormonal therapy in men with clinically localized prostate cancer: recommendations of the RTOG-ASTRO Phoenix Consensus Conference. Int J Radiat Oncol Biol Phys. 2006 Jul 15;65(4):965-74.

32. Afshar-Oromieh A, Avtzi $E$, Giesel FL, et al. The diagnostic value of PET/CT imaging with the (68)Ga-labelled PSMA ligand HBED-CC in the diagnosis of recurrent prostate cancer. Eur J Nucl Med Mol Imaging. 2015;42(2):197-209.

33. Perera M, Papa N, Roberts M, et al. Gallium-68 Prostate-specific Membrane Antigen Positron Emission Tomography in Advanced Prostate CancerUpdated Diagnostic Utility, Sensitivity, Specificity, and Distribution of Prostate-specific Membrane Antigen-avid Lesions: A Systematic Review and Meta-analysis. Eur Urol. 2020 Apr;77(4):403-417.

34. Fendler WP, Calais J, Eiber M, et al. Assessment of 68Ga-PSMA-11 PET accuracy in localizing recurrent prostate cancer: A Prospective Single-Arm Clinical Trial. JAMA Oncol. 2019;5:856-863.

35. Chen Y, Pullambhatla M, Foss CA, et al. 2-(3-\{1-Carboxy-5-[(6-[18F]fluoropyridine-3-carbonyl)-amino]-pentyl\}-ureido)-pentanedioic Acid, [18F] DCFPyL, a PSMA-based PET Imaging Agent for Prostate Cancer. Clin Cancer Res. 2011 Dec 15;17(24):7645-53.

36. Szabo Z, Mena E, Rowe SP, Plyku D, Nidal R, Eisenberger MA, et al. Initial Evaluation of [(18)F]DCFPyL for Prostate-Specific Membrane Antigen (PSMA)Targeted PET Imaging of Prostate Cancer. Mol Imaging Biol. 2015;17(4):565-74. 
37. reglia G, Annunziata S, Pizzuto DA, Giovanella L, Prior JO, Ceriani L. Detection Rate of (18)F-Labeled PSMA PET/CT in Biochemical Recurrent Prostate Cancer: A Systematic Review and a Meta-Analysis. Cancers (Basel). 2019;11(5).

38. Budaus L, Leyh-Bannurah SR, Salomon G, et al. Initial Experience of (68)GaPSMA PET/CT Imaging in High-risk Prostate Cancer Patients Prior to Radical Prostatectomy. Eur Urol. 2016;69(3):393-6.

39. Herlemann A, Wenter V, Kretschmer A, et al. (68)Ga-PSMA Positron Emission Tomography/Computed Tomography Provides Accurate Staging of Lymph Node Regions Prior to Lymph Node Dissection in Patients with Prostate Cancer. Eur Urol. 2016;70(4):553-7.

40. Maurer T, Gschwend JE, Rauscher I, et al. Diagnostic Efficacy of (68)GalliumPSMA Positron Emission Tomography Compared to Conventional Imaging for Lymph Node Staging of 130 Consecutive Patients with Intermediate to High Risk Prostate Cancer. J Urol. 2016;195(5):1436-43.

41. van Leeuwen PJ, Emmett L, Ho B, et al. Prospective evaluation of 68Galliumprostate-specific membrane antigen positron emission tomography/ computed tomography for preoperative lymph node staging in prostate cancer. BJU Int. 2017;119(2):209-15.

42. Hope TA, Goodman JZ, Allen IE, Calais J, Fendler WP, Carroll PR. Metaanalysis of (68)Ga-PSMA-11 PET Accuracy for the Detection of Prostate Cancer Validated by Histopathology. J Nucl Med. 2019;60(6):786-93.

43. Luiting $H B$, van Leeuwen PJ, Busstra MB, et al. Use of gallium-68 prostatespecific membrane antigen positron-emission tomography for detecting lymph node metastases in primary and recurrent prostate cancer and location of recurrence after radical prostatectomy: an overview of the current literature. BJU Int. 2020;125(2):206-14.

44. Gorin MA, Rowe SP, Patel HD, et al. Prostate Specific Membrane Antigen Targeted (18)F-DCFPyL Positron Emission Tomography/Computerized Tomography for the Preoperative Staging of High Risk Prostate Cancer: Results of a Prospective, Phase II, Single Center Study. J Urol. 2018;199(1):126-32.

45. Integraal Kankercentrum Nederland. Sterfte, Prostaatkanker, Aantal. [Internet] Available from: https://www.iknl.nl/nkr-cijfers. [Accessed on 27 March 2020]

46. Kirby M, Hirst C, Crawford ED. Characterising the castration-resistant prostate cancer population: a systematic review. Int J Clin Pract 2011 Nov;65(11):11801192

47. Hotte SJ, Saad F. Current management of castrate-resistant prostate cancer. Curr Oncol. 2010 Sep;17 Suppl 2:S72-9.

48. Parker C, Nilsson S, Heinrich D, et al.; ALSYMPCA Investigators. Alpha emitter radium-223 and survival in metastatic prostate cancer. N Engl J Med 2013; $369: 213-223$ 
49. Liu H, Moy P, Kim S, et al. Monoclonal antibodies to the extracellular domain of prostate-specific membrane antigen also react with tumor vascular endothelium. Cancer Res. 1997;57:3629-3634

50. Gallicchio R, Giacomobono S, Nardelli A, et al. Palliative treatment of bone metastases with samarium-153 EDTMP at onset of pain. J Bone Miner Metab 2014; 32:434-440

51. Bander NH, Milowsky MI, Nanus DM, Kostakoglu L, Vallabhajosula S, Goldsmith SJ. Phase I trial of 177lutetium-labeled J591, a monoclonal antibody to prostate-specific membrane antigen, in patients with androgen-independent prostate cancer. J Clin Oncol 2005; 23:4591-4601

52. Tagawa ST, Milowsky MI, Morris M, et al. Phase II study of lutetium-177labeled anti-prostatespecific membrane antigen monoclonal antibody J591 for metastatic castration-resistant prostate cancer. Clin Cancer Res 2013; 19:5182-5191

53. Kratochwil C, Giesel FL, Eder M, et al. [177Lu]Lutetium-labelled PSMA ligandinduced remission in a patient with metastatic prostate cancer. Eur J Nucl Med Mol Imaging. 2015;42(6):987-88.

54. Hillier SM, Maresca KP, Femia FJ, et al. Preclinical evaluation of novel glutamate-urea-lysine analogues that target prostate-specific membrane antigen as molecular imaging pharmaceuticals for prostate cancer. Cancer Res. 2009;69(17), 6932-40.

55. Weineisen M, Schottelius M, Simecek J, et al. 68Ga- and 177Lu-Labeled PSMA I\&T: Optimization of a PSMA-Targeted Theranostic Concept and First Proof-ofConcept Human Studies. J Nuc Med 2015 Aug;56(8):1169-76

56. Okamoto S, Thieme A, Allmann J, D'Alessandria C, Maurer T, Retz M, et al. Radiation Dosimetry for ${ }^{177}$ Lu-PSMA I\&T in Metastatic Castration-Resistant Prostate Cancer: Absorbed Dose in Normal Organs and Tumor Lesions. J Nucl Med. 2017 Mar;58(3):445-450.

57. Ahmadzadehfar H, Eppard E, Kürpig $\mathrm{S}$, et al. Therapeutic response and side effects of repeated radioligand therapy with 177Lu-PSMA-DKFZ-617 of castrate-resistant metastatic prostate cancer. Oncotarget. 2016;7:12477-88.

58. Baum RP, Kulkarni HR, Schuchardt C, et al. Lutetium-177 PSMA Radioligand Therapy of Metastatic Castration Resistant Prostate Cancer: Safety and Efficacy. J Nucl Med. 2016;57:1006-13.

59. Ahmadzadehfar H, Rahbar K, Kürpig S, et al. Early side effects and first results of radioligand therapy with (177)Lu-DKFZ-617 PSMA of castrate-resistant metastatic prostate cancer: a two-centre study. EJNMMI Res. 2015;5:114.

60. Heck MM, Retz M, D Alessandria $C$, et al. Systemic radioligand therapy with 177LU-PSMA-I\&T in patients with metastatic castration-resistant prostate cancer. J Urol. 2016;;196:382-91. 
61. Kratochwil C, Giesel FL, Stefanova M, et al. PSMA-targeted radionuclide therapy of metastatic castration resistant prostate cancer with Lu-177 labeled PSMA-617. J Nucl Med. 2016 Aug;57(8):1170-6.

62. RahbarK, Bode A, Weckesser M, et al. RadioligandTherapy With ${ }^{177}$ Lu-PSMA-617 as A Novel Therapeutic Option in Patients With Metastatic Castration Resistant Prostate Cancer. Clin Nucl Med. 2016;41:522-8.

63. Rahbar K, Ahmadzadehfar H, Kratochwil C, et al. German Multicenter Study Investigating 177Lu-PSMA-617 Radioligand Therapy in Advanced Prostate Cancer Patients. J Nucl Med. 2017;58:85-90.

64. Kulkarni HR, Singh A, Schuchardt C, et al. PSMA-Based Radioligand Therapy for Metastatic Castration-Resistant Prostate Cancer:The Bad Berka Experience Since 2013. J Nucl Med. 2016 Oct;57(Suppl 3):97S-104S.

65. Kim YJ, Kim YI. Therapeutic responses and survival effects of 177Lu-PSMA-617 radioligand therapy in metastatic castrate-resistant prostate cancer: a metaanalysis. Clin Nucl Med 2018; 43:728-734 29.

66. Calopedos RJ, Chalasani V, Asher R, Emmett L, Woo HH. Lutetium-177labelled anti-prostate-specific membrane antigen antibody and ligands for the treatment of metastatic castrate-resistant prostate cancer: a systematic review and meta-analysis. Prostate Cancer Prostatic Dis 2017; 20:352-360

67. von Eyben FE, Roviello G, Kiljunen T, et al. Third-line treatment and 177LuPSMA radioligand therapy of metastatic castration-resistant prostate cancer: a systematic review. Eur J Nucl Med Mol Imaging 2018; 45:496-508

68. Yadav MP, Ballal S, Sahoo RK, Dwivedi SN, Bal C. Radioligand Therapy With ${ }^{177}$ Lu-PSMA for Metastatic Castration-Resistant Prostate Cancer: A Systematic Review and Meta-Analysis. AJR Am J Roentgenol. 2019 Aug;213(2):275-285.

69. Eisenhauer EA, Therasse P, Bogaerts J, Schwartz LH, Sargent D, Ford R, et al. New response evaluation criteria in solid tumours: revised RECIST guideline (version 1.1). Eur J Cancer. 2009;45: 228-47.

70. Wahl RL, Jacene H, Kasamon Y, Lodge MA. From RECIST to PERCIST: evolving considerations for PET response criteria in solid tumors. J Nucl Med 2009; 50 (suppl 1): 122S-50S.

71. Hofman MS, Violet J, Hicks RJ, Ferdinandus J, Thang SP, Akhurst T, et al. [ $\left.{ }^{177} \mathrm{Lu}\right]-$ PSMA-617 radionuclide treatment in patients with metastatic castrationresistant prostate cancer (LuPSMA trial): a single-centre, single-arm, phase 2 study. Lancet Oncol. 2018 Jun;19(6):825-833. 



\section{PART I PROSTATE CANCER IMAGING}

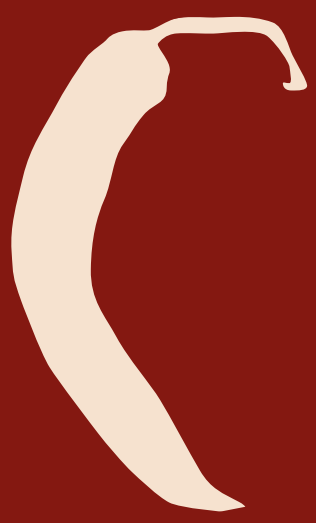





\section{CHAPTER 2}

Prospective validation of Gallium-68 PSMA-PET/CT in primary staging of prostate cancer patients

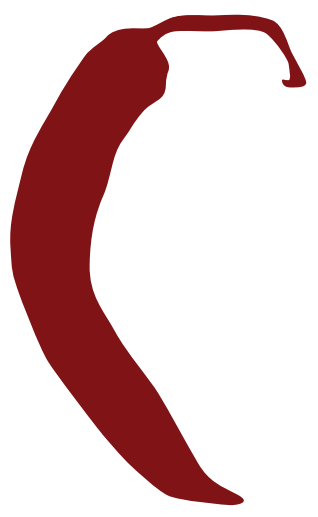

L.W.M. van Kalmthout, H.H.E. van Melick, J. Lavalaye, R.P. Meijer, A. Kooistra, J.M.H. de Klerk, A.J.A.T. Braat, H.P. Kaldeway, B. de Keizer, P.C. de Bruin, M.G.E.H. Lam Journal of Urology 2020 Mar;203(3):537-545. 


\section{ABSTRACT}

\section{Purpose}

Prospective validation of gallium-68 $\left({ }^{68} \mathrm{Ga}\right)$ prostate specific membrane antigen (PSMA)-PET/CT in initial staging of prostate cancer is lacking. This study evaluates diagnostic accuracy of ${ }^{68} \mathrm{Ga}$-PSMA-PET/CT in detection of lymph node metastases in patients with intermediate-high risk prostate cancer.

\section{Materials and Methods}

From October 2017 to October 2018, newly diagnosed prostate cancer patients with negative bone scan and $>10 \%$ MSKCC risk of lymph node metastases were prospectively included. In candidates for extended pelvic lymph node dissection, ${ }^{68} \mathrm{Ga}-\mathrm{PSMA}-\mathrm{PET} / \mathrm{CT}$ prior to planned surgery was performed. Scan results were evaluated in a second tumor board meeting to assess potential change of management. Sensitivity, specificity, positive and negative predictive value for the detection of lymph node metastases were calculated per patient and per resection template using histopathology as a reference. PET-based change of management was also reported.

\section{Results}

A total of 103 patients were eligible for analysis. Ninety-seven extended pelvic lymph node dissections were performed. Forty-one patients (42.3\%) had 85 lymph node metastases. Seventeen patients were PET-positive, resulting in a patient-based sensitivity of $41.5 \%$ (95\% Cl: $26.7 \%-57.8 \%$ ) for the detection of lymph node metastases. Patient-based specificity was $90.9 \%$ (95\% Cl: 79.3\%-96.6\%), positive predictive value was 77.3\% (95\% Cl: 54.2\%-91.3\%) and negative predictive value was 67.6\% (95\% Cl: 55.6\%-77.7\%). PET-based change of management was observed in 13 patients (12.6\%).

\section{Conclusions}

In newly diagnosed prostate cancer patients with >10\% MSKCC risk of lymph node involvement, ${ }^{68} \mathrm{Ga}$-PSMA-PET/CT detects lymph node metastases with high specificity and moderate sensitivity; this leads to change of management in $12.6 \%$ of patients. 


\section{INTRODUCTION}

Prostate cancer ( $\mathrm{PCa}$ ) is globally the most frequently diagnosed malignancy amongst men. In the United States of America in 2019, approximately 174,650 men were newly diagnosed with PCa.' Accurate staging is essential to select the most suitable treatment for these patients. Lymph node metastases (LNMs) are characterized as an adverse prognostic factor and are associated with bone or visceral metastases. ${ }^{2}$ To detect LNMs, bilateral extended pelvic lymph node dissection (ePLND) is currently considered the gold standard. ${ }^{3}$

An ePLND represents an invasive diagnostic intervention being associated with substantial complications (e.g. lymphoceles in 3-17\% and lower extremity edema in 3\%). Although the visualization of microscopic metastases with imaging methods will remain limited, more reliable imaging modalities are desirable as an alternative for lymph node (LN) staging. Conventional modalities to detect LNMs (CT, MRI) rely on morphologic features: i.e. nodal size and shape, with lymph nodes (LNs) larger than 8-10 mm considered suspicious. However, over 80\% of LNMs in PCa are smaller than $8 \mathrm{~mm}^{4}$

A novel imaging modality for PCa staging has emerged: Gallium-68 $\left({ }^{68} \mathrm{Ga}\right)$ prostate specific membrane antigen (PSMA) positron emission tomography/computed tomography (PET/CT). ${ }^{68} \mathrm{Ga}$-PSMA-PET/CT has been identified as a sensitive technique for LNMs detection of recurrent PCa. ${ }^{5}$ Diagnostic performance of ${ }^{68} \mathrm{Ga}-\mathrm{PSMA}-\mathrm{PET} / \mathrm{CT}$ in initial staging remains not definitely determined. ${ }^{6-10}$ The present study therefore aims to prospectively evaluate diagnostic accuracy of ${ }^{68} \mathrm{Ga}-\mathrm{PSMA}-\mathrm{PET} / \mathrm{CT}$ in order to guide its implementation into clinical practice.

\section{MATERIALS AND METHODS}

\section{Patient Population}

From October 2017 until September 2018, newly diagnosed patients with biopsy proven PCa and a $>10 \%$ risk of LNMs according to the Memorial 
Sloan Kettering Cancer Center (MSKCC)-criteria, considered candidates for ePLND based on multidisciplinary tumor board decision, were prospectively included at the University Medical Center (UMC) Utrecht, the St. Antonius Hospital Nieuwegein-Utrecht and the Meander Medical Center Amersfoort, the Netherlands. Patients with other malignancies or with positive skeletal scintigraphy were excluded. Written informed consent was obtained from all patients. The Institutional Review Board of the UMC Utrecht approved this study (protocol number 17-378). Principles of Helsinki Declaration were followed in lieu of formal ethics committee approval. This study was registered at the Dutch Trial Register ('Nederlands Trial Register') as NTR6830.

\section{${ }^{68} \mathrm{Ga}-\mathrm{PSMA}-11$ preparation}

${ }^{68} \mathrm{Ga}-\mathrm{PSMA}-11$ was prepared using a GMP-grade ${ }^{68} \mathrm{Ge} /{ }^{68} \mathrm{Ga}$ generator and a semi-automated synthesis module (Eckert \& Ziegler, Berlin, Germany and ITG, Munich, Germany). Each synthesis was performed following the manufacturers' instructions using PSMA-11 ligand (ABX, Radeberg, Germany).

\section{${ }^{68} \mathrm{Ga}$-PSMA-PET/CT acquisition and image reconstruction}

Images were acquired from skull vertex to the mid-thigh using a Biograph mCT40 scanner (Siemens, Erlangen, Germany) or a Gemini ToF 64 slice scanner (Philips, Best, The Netherlands). $1.5 \mathrm{MBq} / \mathrm{kg}{ }^{68} \mathrm{Ga}-\mathrm{PSMA}-11$ was administered intravenously, followed by $500 \mathrm{ml}$ of saline. PET-images were acquired 60 minutes post-injection. Low dose CT was performed directly following PET-imaging. Images were acquired according to the European Association of Nuclear Medicine-criteria. ${ }^{11}$

\section{Image analysis and interpretation}

For clinical decision-making (phase 1), all ${ }^{68} \mathrm{Ga}$-PSMA-PET/CT images were examined by experienced ( $>5$ years, $>500$ studies) nuclear medicine physicians affiliated at each participating institution. All scans were reviewed using SECTRA PACS IDS7 software version 19.1 (SECTRA, Linkoping, Sweden). In conformance with daily practice, PET-results were evaluated in a tumor board meeting for subsequent management decisions. At the 
end of the study (phase 2) all ${ }^{68} \mathrm{Ga}$-PSMA-PET/CT images were re-evaluated for primary endpoint analysis by two independent blinded reviewers, who rated suspicion of pathology in the prostate region, (non-)regional LNs, osseous- and visceral lesions according to a 5-point scale. ${ }^{12}$ Regarding sensitivity, specificity, negative and positive predictive value (PPV and NPV) calculations, categories $\geq 3$ were considered positive. Discrepancies regarding interpretation of images were solved by consensus-reading by a third independent reviewer. Consensus-based PET-evaluation after phase 2 was used to define diagnostic accuracy of ${ }^{68} \mathrm{Ga}-\mathrm{PSMA}$-PET/CT.

\section{ePLND}

All ePLNDs were performed by experienced urological surgeons affiliated at one of the participating institutions, conform to standard care as described previously. ${ }^{13}$ The anatomical extent of the ePLND was defined laterally by the genitofemoral nerve, medially by the bladder wall, cranially by the ureteral crossing of the common iliac arteries and caudally by the Cloquet-Rosenmüller node, including all fatty tissue in the obturator fossa. All collected resection templates were marked (cranial, lateral and caudal) and assigned to their initial anatomical localization (i.e. left/right and lateral/medial of the external iliac artery).

\section{Histopathological Examination}

LN specimens were examined by dedicated uropathologists, following the International Society of Urological Pathology (ISUP) the protocols. ${ }^{14}$ Presence of any metastatic deposits of PCa in the LNs was defined as disease positivity. For metastatic LNs, the largest diameter $(\mathrm{mm})$ of the metastatic deposit was reported.

\section{Follow-up}

If ePLND was cancelled because of ${ }^{68} \mathrm{Ga}$-PSMA-PET/CT findings (e.g. distant metastases), patients were followed until clinical follow-up confirmed the nature of the lesions seen on ${ }^{68} \mathrm{Ga}$-PSMA-PET/CT. Follow-up occurred as decided by the referring physician. If ePLND was performed, occurrence, nature and grade of postoperative complications ( $<90$ days post-ePLND) were reported according to the revised Clavien-Dindo classification. ${ }^{15}$ 


\section{Outcome measurements and statistical analysis}

Primary outcome was patient-based sensitivity of ${ }^{68} \mathrm{Ga}-\mathrm{PSMA}-\mathrm{PET} / \mathrm{CT}$ in detection of LNMs. With an assumed prevalence of LNMs of 30\%, an observed sensitivity of $90 \%$ and a lower boundary of the $95 \%$-confidence interval of 0.79, 100 patients were required for this study. Patient-based and template-based sensitivity, specificity, PPV and NPV for LNMs detection were calculated using histopathology as reference. Detection rate of ${ }^{68} \mathrm{Ga}$-PSMA-PET/CT as a function of size of suspected LNs was studied as well. Change of management (e.g. ePLND withdrawal or ePLND-template extension) was based on comparison of the initially planned management based on conventional imaging with the PETbased management. Statistical analyses were performed using IBM SPSS Statistics for Mac, version 24. To compare median diameter of metastatic deposit in the resected LNs, the median test was used. Statistical significance was established for $\mathrm{p}$-values $<0.05$.

\section{RESULTS}

A total of 108 patients were included in this study. Five patients were excluded due to unwillingness to undergo surgery $(n=4)$ or inability to undergo ${ }^{68} \mathrm{Ga}$-PSMA-PET/CT $(n=1)$. A total of 103 patients with $>10 \%$ MSKCC risk of LN involvement were eligible for analysis (Figure 1). Patients had intermediate $(n=11)$ to high risk ( $n=92)$ PCa according to the d'Amico classification. Median age was 70 (range: 53-82) years; median PSA-level was $21.8(1.7-298.0) \mathrm{ng} / \mathrm{ml}$ (Table 1).

Median interval between PET and ePLND was 27.0 (IQR 25.5) days. The primary tumor was suspected and showed clear radioligand uptake in all patients. In six patients ePLND was cancelled because of PETpositive distant lesions. A total of 1427 LNs in 97 patients (median: 14 per patient; range: 4-31) were removed during ePLND. Eighty-five LNMs were histopathologically identified in 41 patients. Median diameter of the metastases was $4.0 \mathrm{~mm}$ (range: 0.3-35.0 $\mathrm{mm}$ ). 


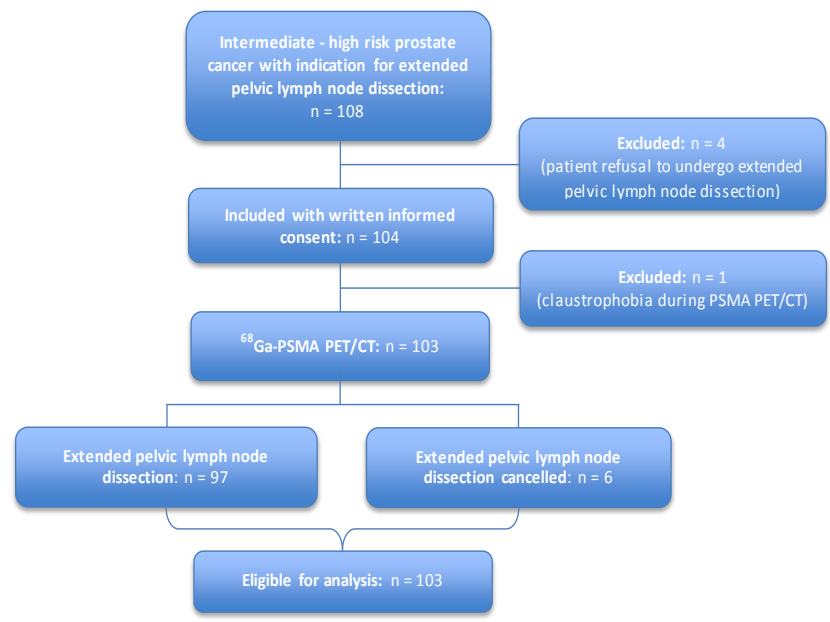

Figure 1. Flowchart

\section{Sensitivity, specificity, PPV and NPV}

Ninety-seven ePLNDs were performed: 31 including radical prostatectomy (RP); 66 patients underwent diagnostic ePLND followed by radiotherapy (Figure 1). One patient was excluded because of an inadequate ePLND. Of all 96 patients who underwent ePLND, 41 patients (42.7\%) had 85 LNMs. Twenty-two of these patients had PET-positive locoregional LNs. Patientbased sensitivity was 41.5\% (95\% Cl: 26.7\%-57.8\%) for LNMs detection. Patient-based specificity, PPV and NPV were respectively $90.9 \%$ (95\% Cl: 79.3\%-96.6\%), $77.3 \%$ (95\% Cl: 54.2\%-91.3\%) and 67.6\% (95\% Cl: 55.6\%77.7\%), (Table 2).

To perform adequate template analysis, four patients were excluded because of protocol violations regarding the templates sent for histopathological examination: one patient had adipositas and could 
Part I|Prostate cancer imaging

Table 1. Baseline characteristics

Mean age, years (range)

Median PSA, ng/ml (range)

Clinical T-stage, $\mathbf{n}$ (\%)

T1C

$\mathrm{T} 2$

T3

\section{Gleason Score biopsy, n (\%)}

$$
\begin{aligned}
& 3+3=6 \\
& 3+4=7 \\
& 4+3=7 \\
& 4+4=8 \\
& 3+5=8 \\
& 4+5=9 \\
& 5+4=9 \\
& 5+5=10
\end{aligned}
$$

$69(53-82)$

$21.8(1.7-298.0)$

$15(14.6)$

$64(62.1)$

$24(23.3)$

$$
\begin{gathered}
4(3.9) \\
16(15.5) \\
31(30.1) \\
31(30.1) \\
4(3.9) \\
14(13.6) \\
1(1.0) \\
2(1.9)
\end{gathered}
$$

Risk classification according to d'Amico, $\mathbf{n}$ (\%)
Intermediate risk
$11(10.7)$
High risk
$92(89.3)$
Pathological T-stage, n (\%)
$\mathrm{n}=31$
T2
10 (32.3)
T3a
13 (41.9)
T3b
$8(25.8)$
Gleason score RP, $\mathbf{n}$ (\%)
$\mathrm{n}=31$
$3+4=7$
10 (32.6)
$4+3=7$
$12(38.7)$
$4+4=8$
$3(9.7)$
$1(3.2)$
$3+5=8$
$5(16.1)$

Risk of LNI according to MSKCC-nomogram, n (\%) $\begin{array}{ll}\geq 10 \% & 103(100.0)\end{array}$

SD - standard deviation; LNI - lymph node involvement; RP - radical prostatectomy 
Table 2. Diagnostic value ${ }^{68} \mathrm{Ga}-\mathrm{PSMA}$ PET/CT

\begin{tabular}{lcc}
\hline & $\begin{array}{c}\text { Patient based } \\
\text { analysis }\end{array}$ & $\begin{array}{c}\text { Template-based } \\
\text { analysis }\end{array}$ \\
\hline Sensitivity & $41.5 \%$ & $35.1 \%$ \\
Specificity & $(95 \% \mathrm{Cl}: 26.7 \%-57.8 \%)$ & $(95 \% \mathrm{Cl}: 23.2 \%-48.9 \%)$ \\
Positive Predictive Value & $90.9 \%$ & $96.4 \%$ \\
& $(95 \% \mathrm{Cl}: 79.3 \%-96.6 \%)$ & $(95 \% \mathrm{Cl}: 93.5 \%-98.1 \%)$ \\
Negative Predictive Value & $77.3 \%$ & $64.5 \%$ \\
& $(95 \% \mathrm{Cl}: 54.2 \%-91.3 \%)$ & $(95 \% \mathrm{Cl}: 45.4 \%-80.2 \%)$ \\
& $67.6 \%$ & $89.0 \%$ \\
\hline
\end{tabular}

not be operated on safely, while three patients had only single templates resected (i.e. it was impossible to distinguish between medial and lateral). Another patient had a right-sided mesh because of inguinal hernia, and consequently only left-sided ePLND could be performed; only those templates were analyzed. Ultimately, template-based sensitivity, specificity, PPV and NPV of ${ }^{68} \mathrm{Ga}$-PSMA-PET/CT were $35.1 \%, 96.4 \%, 64.5 \%$ and $89.0 \%$ (Table 2). Nine presacral and 12 para-rectal LNs were detected by ${ }^{68} \mathrm{Ga}-\mathrm{PSMA}$-PET/CT. Since these LNs were located beyond the operation field and did not induce ePLND template extension, they were excluded from primary outcome analysis.

\section{Regional LNMs}

For 18 of the 85 identified LNMs, correlation between PET-detection and histology was not possible due to uncertainty regarding anatomical localization of the specimens. Ultimately, 67 LNMs were analyzed. Of these, 26 were detected by PET, resulting in a node-based sensitivity of $38.8 \%$. Median diameter of the metastatic deposit in these detected LNMs was $7.0 \mathrm{~mm}$ (range: 0.3-35.0 mm). Forty-one LNMs with a median metastatic deposit of $3.0 \mathrm{~mm}$ (range: $0.5-35.0 \mathrm{~mm}$ ) were missed by PETreading. Median metastatic deposit of the detected versus missed LNMs differed significantly (7.0 versus $3.0 \mathrm{~mm} ; \mathrm{p}=0.04$ ). 


\section{Distant metastases}

In eight patients, tissue examination of nine PET-positive distant lesions was performed ( 4 LNs, 4 bone lesions and 1 cutaneous lesion). Two of the nine lesions were PCa-positive (an inguinal LN (Figure 2) and a vertebral lesion). In two bone lesions (scapula and os ileum (Figure 3), biopsy results were PCanegative and clinical follow-up (PSA $<0.10 \mathrm{ng} / \mathrm{ml} 1-2$ months post-ePLND) ascribed a non-malignant nature to the PET-suspected lesions. Follow-up of the other five PCa-negative lesions after biopsy was as follows:

- negative rib lesion: no LNMs during ePLND. Androgen Deprivation Therapy (ADT) and radiotherapy were started. Nine months later, PSA-level was unmeasurable.

- negative mediastinal LN: two LNMs during ePLND and RP. ${ }^{68} \mathrm{Ga}$-PSMA-PET/CT was repeated because of PSA $0.9 \mathrm{ng} / \mathrm{ml}$ postoperatively, yielding two para-iliac LNs to still be in situ. Stereotactic radiotherapy was started.

- negative cutaneous lesion and mediastinal LN: two LNMs during ePLND. Six months later ADT and radiotherapy were started (Figure 4).

- negative supraclavicular LN: ePLND was cancelled and ADT was started because of multiple PET-suspected pelvic and distant LNs.

Two patients underwent additional ultrasound because of PET-positive liver lesions, but the malignant nature of these lesions remained unconfirmed.

\section{PET-reading}

Phase 1 reads concluded suspected LNs in 25 patients; 71 patients did not have PET-suspected LNs. Phase 2 reads concluded PET-suspected LNs in 22 patients; 74 patients did not have PET-suspected LNs. Agreement was moderate $(k=0.58)$. During phase 2 reads, the first reader detected PETsuspected LNs in 26 patients; 70 patients did not have PET-suspected LNs. The second reader detected PET-suspected LNs in 22 patients; 74 patients did not have PET-suspected LNs. Inter-reader agreement was substantial $(K=0.67)$. A third reviewer reached consensus in 45 discordant imaging reports. 

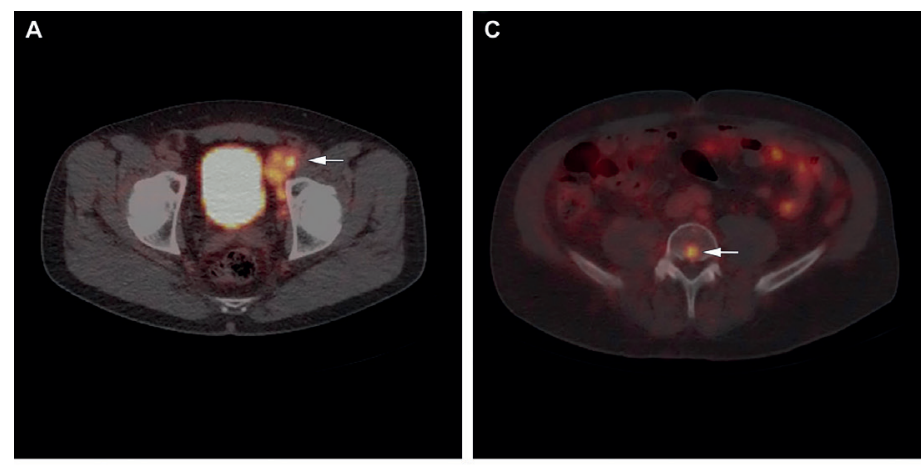

B

D
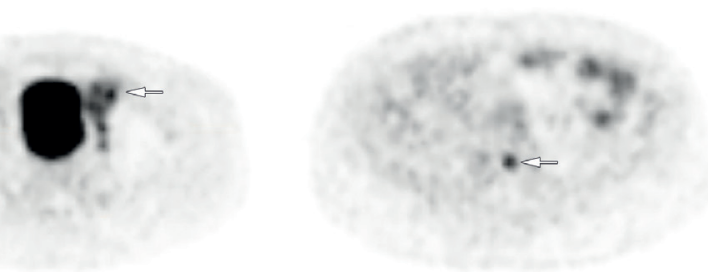

Figure 2. Transversal fused ${ }^{68} \mathrm{Ga}-\mathrm{PSMA}-\mathrm{PET} / \mathrm{CT}(\mathrm{A}, \mathrm{C})$ and PET $(\mathrm{B}, \mathrm{D})$ images of a 70-years old man with CT2C, Gleason 3+4=7 PCa (initial PSA-level of $102 \mathrm{ng} / \mathrm{ml}$ ) and considered candidate for ePLND (MSKCC-nomogram: 86\% risk of lymph node involvement). ${ }^{68} \mathrm{Ga}$-PSMA-PET/CT showed extensive bilateral lymph node involvement $(A, B)$ as well as a single suspected bone lesion in vertebra $L 4(C, D)$. Biopsy of the inguinal region confirmed the PCa nature of the metastases. During the post-PET tumor board meeting, it was decided to cancel ePLND and start ADT. Six months later, PSA-level had dropped to $0.13 \mathrm{ng} / \mathrm{ml}$. 


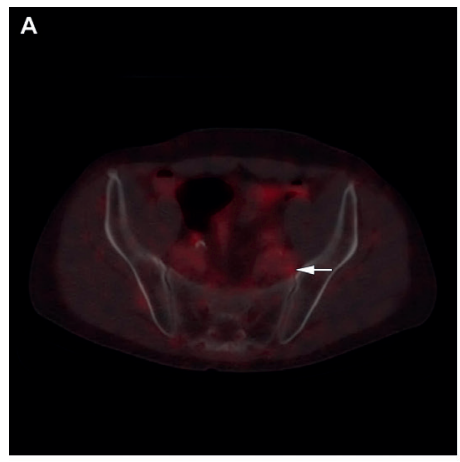

B

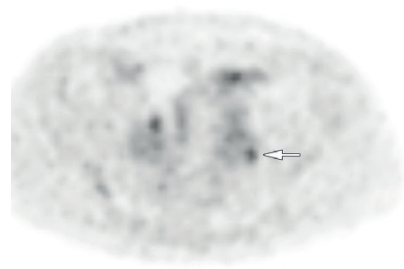

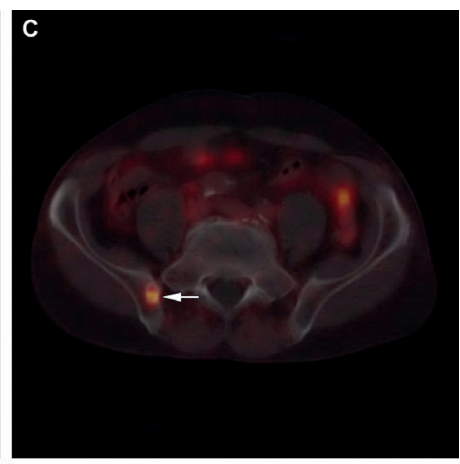

D

Figure 3. Transversal fused ${ }^{68} \mathrm{Ga}$-PSMA-PET/CT $(A, C)$ and PET $(B, D)$ images of a 74-years old man with cT2b, Gleason 4+4=8 PCa (initial PSA-level of 5,54 ng/ml). He was considered candidate for ePLND (MSKCC-nomogram: 28\% risk of lymph node involvement). ${ }^{68} \mathrm{Ga}-\mathrm{PSMA}-\mathrm{PET} / \mathrm{CT}$ showed a lymph node with mild radioligand uptake dorsal of the left external iliac artery (A, B) and a lesion in the right iliac bone $(C, D)$. Biopsy of the bone lesion confirmed a benign nature, after which it was decided to perform an ePLND with dorsal extension of the template. One of the nine lymph nodes was PCa-positive, i.e. the PET-positive lymph node $(5 \mathrm{~mm}$ tumor deposit). Postoperative PSA-level was $<0.1 \mathrm{ng} / \mathrm{ml}$, confirming the benign nature of the bone lesion. 

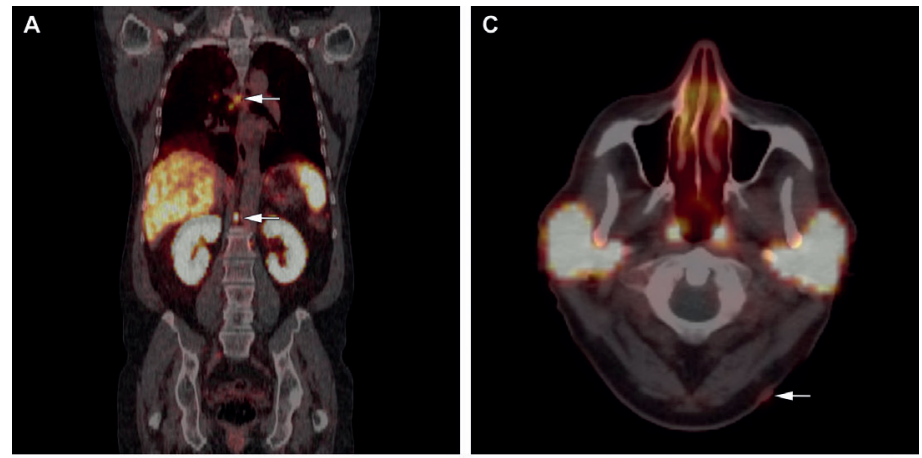

B

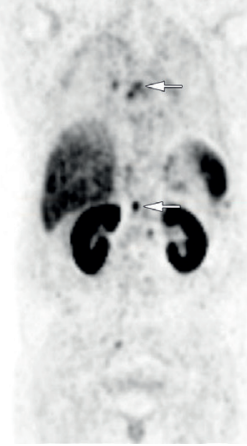

D

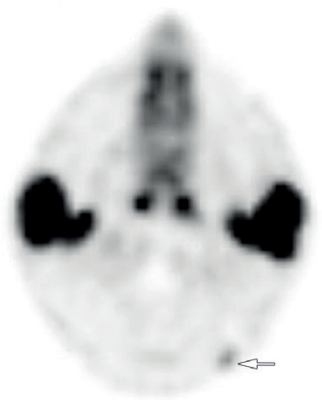

Figure 4. Fused ${ }^{68} \mathrm{Ga}$-PSMA-PET/CT $(A, C)$ and PET (B, D) images of a 66-years old man with CT2C, Gleason 4+4=8 PCa (initial PSA-level of $298 \mathrm{ng} / \mathrm{ml}$ ) and was considered candidate for ePLND (MSKCC-nomogram: $98 \%$ risk of lymph node involvement). ${ }^{68} \mathrm{Ga}$-PSMA-PET/CT showed multiple pelvic and extrapelvic lymph nodes (A, B), bone lesions and mild radioligand uptake in a cutaneous lesion (C, D). Histopathological examination of two biopsied lesions did not confirm presence of PCa (mediastinal lymph node: reactive lymph node with granuloma formation; cutaneous lesion: neurofibroma), after which an ePLND was performed. Two of the 11 resected lymph nodes were histopathologically identified as PCa-positive. It was decided to start ADT and target the pelvic area with radiotherapy, after which PSAlevel decreased to $0.13 \mathrm{ng} / \mathrm{ml}$ (six months post-ePLND). 


\section{Change of Management}

Based on PET-findings and subsequent tumor board discussion, change of management was observed in 13 patients (12.6\%): ePLND-template was extended $(n=6)$; ePLND in six patients was cancelled because of PCa-positive extrapelvic lesions following biopsy $(n=2)$, or clinical parameters in combination with suspected $\geq M 1$ a-disease on PET $(n=3)$, or additional CT-thorax confirming malignant nature of a suspected mediastinal $L N(n=1)$. In one patient with a suspected rib lesion on PET, $\mathrm{ADT}$ and radiotherapy were given to the pelvic area and suspected lesion, following ePLND (0/18 positive LNs).

\section{ePLND complications}

In 33/97 patients (34\%), peri- or post-operative complications occurred (i.e. bleeding, infection requiring antibiotic treatment, lymphedema and/ or lymphoceles). In six of the 97 cases (6.2\%), radiological intervention was required (Clavien-Dindo grade 3a); in 4/97 cases (4.1\%), surgical intervention was required (Clavien-Dindo grade $3 b$ ). No grade $\geq 4$ complications occurred.

\section{DISCUSSION}

This large prospective validation study shows a high specificity but moderate sensitivity of ${ }^{68} \mathrm{Ga}$-PSMA-PET/CT in detecting LNMs. Negative ${ }^{68} \mathrm{Ga}$-PSMA-PET/CT can therefore not rule out the presence of LNMs. In $12.6 \%$ of the patients, detection of metastases beyond the standard ePLND template on ${ }^{68} \mathrm{Ga}-\mathrm{PSMA}-\mathrm{PET} / \mathrm{CT}$ changed the management strategy. In $5.8 \%$ of the patients, because of distant metastases, an unnecessary invasive and expensive operation was avoided. These changes suggest that ${ }^{68} \mathrm{Ga}$-PSMA-PET/CT can improve individualized patient management (e.g. local, metastases-directed or systemic therapy).

Several initial studies among newly diagnosed PCa patients demonstrated high patient-based specificity (86-100\%) of ${ }^{68} \mathrm{Ga}$-PSMA-PET/CT in detecting LNMs. ${ }^{6-10}$ However, sensitivity ranged from $33-67 \%$, partly explained by the heterogeneous methods used in these predominantly small, retrospective 
studies with different patient populations included, different extent of LN dissection performed, as well as different histopathological work-up. Similarly, a recent meta-analysis evaluated five studies comparing ${ }^{68} \mathrm{Ga}-$ PSMA-PET/CT to histopathology in a total of 266 newly diagnosed PCa patients. ${ }^{16}$ A pooled sensitivity of 0.74 (95\% Cl: 0.51-0.81) and specificity of 0.96 (95\% Cl: 0.85-0.99) were found for LNMs detection. The authors concluded that ${ }^{68} \mathrm{Ga}$-PSMA-PET/CT may be of additional value in initial staging due to its high specificity. High specificity (93.5\%) and moderate sensitivity (38.2\%) of ${ }^{68} \mathrm{Ga}$-PSMA-PET/CT in LNMs detection was also reported in a large retrospective study in 206 new PCa patients. ${ }^{17}$ It was concluded that, given its moderate NPV and sensitivity, ${ }^{68} \mathrm{Ga}-\mathrm{PSMA}-$ PET/CT cannot replace ePLND in initial LN staging. These results were congruent with our findings.

To date, only one study prospectively investigated PET-based change of management in the specific setting of primary staging. ${ }^{18}$ Planned treatments changed in $1-2 \%$ of the patients. Remarkably, no change of management was observed with regard to planned ADT (40\% both pre-PET and post-PET). In our study, 'the treatment plan' changed in 13 patients (12.6\%) post-PET. More specifically, 6 patients (5.8\%) started with ADT post-PET.

In our study ePLND caused grade 1-2 complications in $34.0 \%$ and grade 3 in $10.3 \%$ of the patients. These results correspond with the 20\% reported in literature. ${ }^{19,20}$ This suggests that implementing ${ }^{68} \mathrm{Ga}$-PSMAPET/CT could be cost-effective by preventing unnecessary ePLNDs and the associated morbidity and costs. Cost-effectiveness of PSMA-PET/CT versus ePLND was recently studied using an interactive model. ${ }^{21}$ However, this study emphasized that many important parameters showed relevant uncertainty, illustrating the need for prospective studies in this area.

This study has several limitations. Firstly, six patients did not undergo ePLND; validation of scan results in these patients was impossible. Additionally, not all PET-suspected LNs beyond the operation field could be validated. Secondly, due to lack of power for the assessment of distant metastasis, in combination with false positive results and lack 
of adequate follow-up, diagnostic accuracy of ${ }^{68} \mathrm{Ga}-\mathrm{PSMA}-\mathrm{PET} / \mathrm{CT}$ could not be determined. Thirdly, PET resolution is currently limited to 3-4 mm, depending on the system, which may limit diagnostic accuracy regarding LNMs detection. Also, since by definition, sensitivity of ePLND will not reach $100 \%$, the observed specificity of ${ }^{68} \mathrm{Ga}-\mathrm{PSMA}-\mathrm{PET} / \mathrm{CT}$ in detection of LNMs may have been underestimated. Fifthly, with an assumed prevalence of positive lesions of $30 \%$ and sensitivity of $90 \%$, this study may not have been adequately powered. Sixthly, inter-reader discrepancies may have been introduced due to the two-phased PET-reading in this study. Furthermore, this multicenter study was subject to differences with regard to decision-making, imaging, surgery, and pathology. These differences were prevented, as much as possible, by consensus meetings. Lastly, a lesion-based analysis was complicated by non-adherence to template-based dissection and clipping.

The implementation of ${ }^{68} \mathrm{Ga}-\mathrm{PSMA}-\mathrm{PET} / \mathrm{CT}$ for initial staging of PCa can identify patients in whom ePLND should be omitted due to metastatic spread. Given its moderate sensitivity however, ${ }^{68} \mathrm{Ga}-\mathrm{PSMA}-\mathrm{PET} / \mathrm{CT}$ will not be able to replace ePLND.

\section{CONCLUSIONS}

In this prospective study, high specificity and moderate sensitivity was found for ${ }^{68} \mathrm{Ga}$-PSMA-PET/CT in detecting LNMs in the initial staging of PCa patients with negative bone scans and $>10 \%$ risk of LNMs. The significant impact of ${ }^{68} \mathrm{Ga}$-PSMA-PET/CT on patient management may guide future patient selection. Future clinical studies will be needed to evaluate the impact of ${ }^{68} \mathrm{Ga}$-PSMA-PET/CT implementation on oncological outcomes and overall survival, including prospective analysis of cost-effectiveness. ${ }^{22}$

\section{ACKNOWLEDGEMENTS}

This research was supported by the 'Koningin Wilhelmina Fonds' (Dutch Cancer Society; grant number 11399). We thank our colleagues Gerard Krijger, Tessa Ververs, Roeland Vis and Rakesh Madho, who provided insight and expertise that greatly assisted the research. 


\section{REFERENCES}

1. Siegel RL, Miller KD, Jemal A. Cancer statistics, 2019. CA Cancer J Clin. 2019 Jan;69(1):7-34.

2. Gakis G, Boorjian SA, Briganti A, et al. The role of radical prostatectomy and lymph node dissection in lymph node-positive prostate cancer: a systematic review of the literature. Eur Urol. 2014 Aug;66(2):191-9.

3. Cagiannos I, Karakiewicz P, Eastham JA, et al. A preoperative nomogram identifying decreased risk of positive pelvic lymph nodes in patients with prostate cancer. J Urol, 170 (2003):1798-1803

4. Heesakkers RAM, Hövels AM, Jager GJ, et al. MRI with a lymph-node-specific contrast agent as an alternative to CT scan and lymph-node dissection in patients with prostate cancer: a prospective multicohort study. Lancet Oncol. 2008 Sep;9(9):850-6.

5. Afshar-Oromieh A, Avtzi E, Giesel FL, et al. The diagnostic value of PET/CT imaging with the (68)Ga-labelled PSMA ligand HBED-CC in the diagnosis of recurrent prostate cancer. Eur J Nucl Med Mol Imaging 2015 Feb;42(2):197209.

6. Budaus L, Leyh-Bannurah SR, Salomon G, et al. Initial Experience of (68)GaPSMA PET/CT Imaging in High-risk Prostate Cancer Patients Prior to Radical Prostatectomy. Eur Urol. Switzerland; 2016 Mar;69(3):393-6.

7. Maurer T, Gschwend JE, Rauscher I, et al. Diagnostic Efficacy of (68)GalliumPSMA-PET compared to Conventional Imaging in Lymph Node Staging of of 130 consecutive Patients with Intermediate to High-Risk Prostate Cancer. J Urol 2015 Dec 9

8. Herlemann A, Wenter V, Kretschmer A, et al. (68)Ga-PSMA Positron Emission Tomography/Computed Tomography Provides Accurate Staging of Lymph Node Regions Prior to Lymph Node Dissection in Patients with Prostate Cancer. Eur Urol. 2016 Jan 19

9. van Leeuwen PJ, Emmett L, Ho B, et al. Prospective Evaluation of 68GalliumPSMA Positron Emission Tomography/Computerized Tomography for Preoperative Lymph Node Staging in Prostate Cancer. BJU Int. 2016 May 21

10. Öbek C, Doğanca T, Demirci E, et al. The accuracy of ${ }^{68} \mathrm{Ga}-\mathrm{PSMA}$ PET/CT in primary lymph node staging in high-risk prostate cancer. Eur J Nucl Med Mol Imaging. 2017 Oct;44(11):1806-1812

11. Boellaard R, Delgado-Bolton R, Oyen WJG, et al. FDG PET/CT: EANM procedure guidelines for tumour imaging: version 2.0 Eur J Nucl Med Mol Imaging (2015) 42:328-354

12. Panicek DM, Hricak H. How Sure Are You, Doctor? A Standardized Lexicon to Describe the Radiologist's Level of Certainty. AJR Am J Roentgenol. 2016 Jul;207(1):2-3. 
13. Heidenreich A, Varga Z, Von Knobloch R. Extended pelviclymphadenectomy in patients undergoing radical prostatectomy: high incidence of lymph node metastasis. J Urol 2002;167:1681-6.

14. Egevad L, Delahunt B, Srigley JR, et al. International Society of Urological Pathology (ISUP) grading of prostate cancer - An ISUP consensus on contemporary grading. APMIS. 2016 Jun;124(6):433-5.

15. Dindo D, Demartines N, Clavien PA. Classification of surgical complications: a new proposal with evaluation in a cohort of 6336 patients and results of a survey. Ann Surg 2004; 240: pp. 205-213

16. Hope TA, Goodman JZ, Allen IE, et al. Meta-analysis of ${ }^{68} \mathrm{Ga}$-PSMA-11 PET Accuracy for the Detection of Prostate Cancer Validated by Histopathology. J Nucl Med. 2018 Dec 7.

17. Yaxley JW, Raveenthiran S, Nouhaud FX, et al. Outcomes of Primary Lymph Node Staging of Intermediate and High Risk Prostate Cancer with 68Ga-PSMA Positron Emission Tomography/Computerized Tomography Compared to Histological Correlation of Pelvic Lymph Node Pathology: Can Preoperative 68Ga-PSMA Positron Emission Tomography/Computerized Tomography Replace Pelvic Lymph Node Dissection for Prostate Cancer Staging? J Urol. 2019 Jan 21.

18. Roach PJ, Francis R, Emmett $L$, et al. The Impact of ${ }^{68} \mathrm{Ga}$-PSMA PET/CT on Management Intent in Prostate Cancer: Results of an Australian Prospective Multicenter Study.J Nucl Med. 2018 Jan;59(1):82-88.

19. Keegan KA, Cookson MS. Complications of pelvic lymph node dissection for prostate cancer. Curr Urol Rep. 2011 Jun;12(3):203-8.

20. Briganti A, Chun FK, Salonia A, et al: Complications and other surgical outcomes associated with extended pelvic lymphadenectomy in men with localized prostate cancer. Eur Urol 2006; 50: pp. 1006-1013

21. Scholte M, Barentsz JO, Sedelaar JPM, et al. Modelling Study with an Interactive Model Assessing the Cost-effectiveness of ${ }^{68} \mathrm{Ga}$ Prostate-specific Membrane Antigen Positron Emission Tomography/Computed Tomography and Nano Magnetic Resonance Imaging for the Detection of Pelvic Lymph Node Metastases in Patients with Primary Prostate Cancer. Eur Urol Focus. 2019 Feb 27.

22. Hofman MS, Murphy DG, Williams SG, et al. A prospective randomized multicentre study of the impact of gallium-68 prostate-specific membrane antigen (PSMA) PET/CT imaging for staging high-risk prostate cancer prior to curative-intent surgery or radiotherapy (proPSMA study): clinical trial protocol. 2018 Nov;122(5):783-793. 




\section{CHAPTER 3}

Interobserver agreement in $\left.{ }^{68} \mathrm{Ga}\right] \mathrm{Ga}$-PSMA PET/CT with structured classification

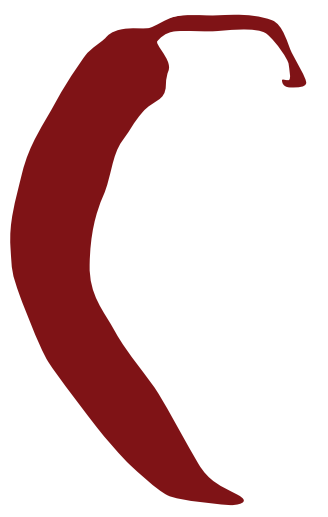

L.W.M. van Kalmthout, H.P. Kaldeway, A.J.A.T. Braat, M.G.E.H. Lam, H.H.E. van Melick, J. Lavalaye 


\section{ABSTRACT}

\section{Objective}

Over recent years, gallium-68 prostate-specific membrane antigen (PSMA) PET/CT has been incorporated into clinical practice to detect prostate cancer. To date, however, straightforward reporting classifications are not available. This study aims to determine interobserver agreement for Gallium-68 PSMA PET/CT interpretation, using a structured method.

\section{Methods}

From May 2015 to June 2018, all consecutive gallium-68 PSMAPET/CT scans for primary staging and restaging of prostate cancer were retrospectively evaluated by two experienced nuclear medicine physicians. Prostate region, regional and distant lymph node sites, bone lesions and visceral lesions were scored on a 5-point scale evaluating clinical impression for probability of malignancy. Interobserver agreement was assessed using Cohen's kappa, both on TNM-basis (including prostate region (T-stage); regional lymph nodes ( $\mathrm{N}$-stage); distant lymph nodes (M1a-stage); bone lesions (M1b-stage) and visceral lesions (M1c-stage)) and on region basis (including various anatomical lymph node sites).

\section{Results}

A number of 118 gallium-68 PSMA PET/CT scans (58 primary staging; 60 restaging) were analyzed. TNM-based evaluation showed substantial agreement for the prostate region $(\mathrm{k}=0.67)$ and regional lymph nodes $(\mathrm{k}=0.62)$; moderate agreement for distant lymph nodes $(\mathrm{k}=0.43)$; substantial agreement for bone lesions $(k=0.62)$ and fair agreement for visceral lesions ( $k=0.22$ ). Region-based analysis showed fair to substantial agreement for all sites, except for visceral lesions ( $k=0.22)$.

\section{Conclusions}

Substantial interobserver agreement was found in localizing PCa with gallium-68 PSMA PET/CT using this 5-point classification. Structured reporting according to this method may be used to optimize PSMA PET/ CT-interpretation. 


\section{Background}

Prostate specific membrane antigen (PSMA) positron emission tomography/computed tomography (PET/CT) imaging has emerged as a highly valued imaging technique for the detection of tumor sites in patients with prostate cancer (PCa). PSMA is a transmembrane glycoprotein that is 100-1000 times upregulated by PCa cells, compared to benign prostate tissue [1]. Since labeled PSMA ligands bind with high affinity to the extracellular part of the PSMA receptor of PCa cells, PSMA represents an attractive target in detection of PCa. ${ }^{68} \mathrm{Ga}-\mathrm{PSMA}$ PET/CT imaging has evolved as a widely used diagnostic imaging technique in staging and restaging of PCa due to its superiority over conventional imaging modalities, such as ${ }^{11} \mathrm{C}$ - or ${ }^{18} \mathrm{~F}$-Choline PET/CT [2]. In ${ }^{11} \mathrm{C}$ - or ${ }^{18} \mathrm{~F}$-Choline PET/CT, low tumor-to-background contrast and specificity often complicates image interpretation and subsequent decisionmaking. In contrast, interpretation of PSMA PET/CT appears much more straightforward, leading to fewer equivocal findings compared with conventional imaging and robust interobserver reproducibility [3].

Imaging is subject to the interpretation of the observer and imaging reports to the referring physician $[4,5]$. To minimize bilateral interpretation ambiguities, structured reporting of radiological imaging has been advocated [6]. In this context, a standardized Likert (5-point) scale to characterize level of suspicion for focal lesions was recommended in a variety of radiologic procedures [7-11]. In the past years, various classification methods to enhance PSMA PET/CT reporting have been published, including a standardized framework written on behalf of the European Association of Nuclear Medicine (EANM), here referred to as the EANM Consensus Criteria; the Prostate Cancer Molecular Imaging Standardization Evaluation (PROMISE)-criteria and the PSMA Reporting and Data System (RADS), version 1.0 [12-14]. The first proposal contains a framework for ${ }^{68} \mathrm{Ga}-\mathrm{PSMA}$ PET/CT interpretation to identify PCa recurrences, in which PET images are evaluated following three stages [12]: 1) Identification of anomalous findings, defined as focal radiotracer uptake higher than adjacent background; 2) Classification of these sites as pathologic, non-pathologic, or uncertain; 3) Consideration of 
the anatomical localization of the findings (up to 5 lesions). Rowe et al. suggested a 5-point scale for structured PSMA PET/CT evaluation, containing an impressive number of (sub)categories, summarized in the original publication [13]. PSMA PET/CT evaluation occurs by selecting a maximum of five target lesions, and by scoring them individually. The highest score determines the overall PSMA-RADS score of the scan. Thirdly, Eiber et al. published the Prostate Cancer Molecular Imaging Standardized Evaluation (PROMISE) framework, in which PSMA PET/CT evaluation occurs in three phases [14]: 1) Visual assessment of radiotracer uptake in suspected sites in relation to mean uptake in reference organs on a 4-point scale (miPSMA score); 2) Interpretation of the assigned miPSMA score with consideration of clinical and imaging parameters; 3) Final diagnosis (binary scale) and assessment of diagnostic certainty (5-point scale). All three aforementioned frameworks represent dedicated attempts towards standardized PSMA PET/CT reporting, especially since they elaborate on well-established, widely adopted structured reporting systems in imaging (RADS, TNM). However, as a result of these profound approaches with multiple subdivisions and evaluation phases, daily clinical applicability seems limited.

In this study, we propose a novel, easy applicable, standardized method for PSMA PET/CT reporting, evaluating SUV-value, location and pattern of spread of the tumor sites. Moreover, this study aims to analyze interobserver agreement of ${ }^{68} \mathrm{Ga}-\mathrm{PSMA}$ PET/CT reporting according to the newly proposed method, since robust agreement is essential for the implementation of this novel imaging technique into clinical practice.

\section{MATERIALS AND METHODS}

\section{Study population}

From May 2015 up to June 2018, all consecutive patients who were referred for ${ }^{68} \mathrm{Ga}$-PSMA PET/CT for staging and restaging of PCa were retrospectively included in the UMC Utrecht and the St. Antonius Hospital 
in Nieuwegein, the Netherlands. If the minimum required information on clinical parameters (e.g. PSA-level) was not available, patients were not included in this study.

\section{PET/CT acquisition and image reconstruction}

Images were acquired from skull vertex to mid-thigh using a Biograph mCT40 scanner (Siemens, Erlangen, Germany) in the UMC Utrecht and a Gemini TOF 64 slice scanner (Philips, Best, The Netherlands) in the St. Antonius hospital in Nieuwegein. After intravenous injection of 1.5-2.0 MBq/kg ${ }^{68} \mathrm{Ga}-\mathrm{PSMA}-11,500 \mathrm{ml}$ saline was intravenously administered. PET-images were acquired 60 minutes after radiotracer administration. A low dose CT was performed directly following PETimaging. Images were acquired according to the European Association of Nuclear Medicine (EANM)-criteria, a.k.a. EARL-reconstructions, with the following parameters: PET with time-of-flight and point spread function reconstruction, 4 iterations, 21 subsets, with a filter of $7.5 \mathrm{~mm}$ full width at half maximum $[15,16]$. Images acquired in the UMC Utrecht were reviewed using SECTRA PACS IDS 7 software version 19.1 (SECTRA, Linkoping, Sweden); images acquired in the St. Antonius hospital were reviewed using HERMES software 4.16 (HERMES Medical Solutions AB, Stockholm, Sweden).

\section{Image analysis}

All ${ }^{68} \mathrm{Ga}$-PSMA PET/CT scans in both institutions were evaluated by two experienced nuclear medicine physicians (>300 PSMA PET/CT studies), who were blinded for the setting of staging or re-staging and all other clinical parameters. The two readers rated suspicion of pathology in 15 anatomical regions (Table 1; Figure 1) according to the following 5-point scale including SUV-value, location and pattern of spread of the evaluated tumor sites:

1. Clinically significant cancer is highly unlikely to be present

2. Clinically significant cancer is unlikely to be present 
3. Clinically significant cancer is equivocal

4. Clinically significant cancer is likely to be present

5. Clinically significant cancer is highly likely to be present

Regarding regional and distant lymph nodes, each lesion was given a designation. If lesions were suspect (score $\geq 3$ ), image number was reported. For patients with $\geq 1 \mathrm{M} 1 \mathrm{~b}$ and/or M1c lesion(s), the lesion with the highest score was reported. Ultimately, the individual scores of both readers were counted. Both region based analysis and analysis based on the clinically relevant TNM score, 8th edition [17], were performed. Anatomical sites with differences of $\geq 3$ points between both readers were secondarily reviewed. If image number of the lesion corresponded, whereas the assigned anatomical region of a suspected lesion differed, discrepancy was considered most likely the result of anatomic misinterpretation rather than differing judgments of the two readers regarding the supposed malignancy of the lesion. The results were corrected for these discrepancies, since only agreement on the likelihood of pathology of lesions formed the focus of this study.

\section{Statistical Analysis}

Statistical analyses were performed using IBM SPSS Statistics for Mac, version 24. Assuming a Cohen's kappa of 0.8 and a confidence interval (Cl) of 0.1 , a power-analysis revealed the required number of patients to be 117 for two readers (given the five ordinal anatomic categories in which occurrence of positive lesions was estimated at 10\%,30\%, 20\%, 30\% and $10 \%$ and assuming a type I error of 0.05 ). P-values $<0.05$ were considered statistically significant. Interobserver agreement was evaluated using Cohen's kappa for the two involved observers. The involved readers were informed about this conjunction prior to PET evaluation. The following interpretation of kappa was used:

$-\mathrm{k}<0$ : poor level of agreement;

$-\mathrm{K}=0-0.20$ : slight level of agreement;

- $\mathrm{k}=0.21-0.40$ : fair level of agreement; 
Table 1. Evaluated anatomical areas

\begin{tabular}{ll}
\hline Prostate area (T-stage) & left/right lobe (1) \\
\hline Regional pelvic lymph nodes (N-stage) & $\begin{array}{l}\text { left/right external iliac (2), left/right } \\
\text { internal iliac (3), left/right obturator } \\
\text { (4), left/right perivesical (5), left/right } \\
\text { presacral (6), left/right pararectal (7) }\end{array}$ \\
$\begin{array}{ll}\text { left/right common iliac (8), suprafrenic } \\
\text { (15), paracaval (10), aortocaval (11), } \\
\text { para-aortic (12), right/left inguinal (9) }\end{array}$ \\
$\begin{array}{l}\text { Bone lesions (M1b-stage)* } \\
\text { Visceral lesions (M1c-lesions)** }\end{array}$ \\
\hline * Anatomic site represented by number 13; ** Anatomic site represented by \\
number 14
\end{tabular}

(15)

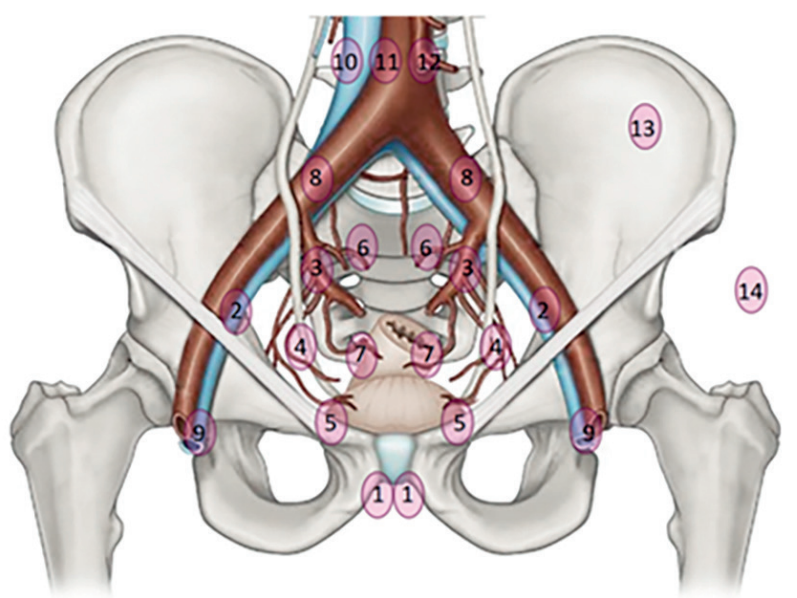

Figure 1. Evaluated anatomical areas 
- $\mathrm{K}=0.41-0.60$ : moderate level of agreement;

$-\mathrm{K}=0.61-0.80$ : substantial level of agreement;

$-\mathrm{k}>0.81$ : high level of agreement.

\section{RESULTS}

A total of 118 patients referred for ${ }^{68} \mathrm{Ga}$-PSMA PET/CT were retrospectively analyzed. Sixty patients were scanned for primary and 58 patients for restaging. Median age was 70 years. Patients had a median PSA level of 9.4 (IQR 1.7-31.1) ng/ml prior to ${ }^{68} \mathrm{Ga}-\mathrm{PSMA}$ PET/CT. Relevant baseline characteristics are summarized in Table $\mathbf{2}$.

\section{Re-analysis of anatomic sites}

Eleven out of 236 scored prostate sites (4.7\%), 80/2242 lymph node sites (3.6\%), 18/236 osseous sites (7.6\%) and 19/236 visceral sites (8.1\%) with $\geq 3$ points discrepancy were secondarily reviewed. In eight lymph node lesions (10\%), image number assigned by the two readers corresponded, whereas the assigned anatomical regions differed. Examples of PETimages with their assigned scores were shown in Figure 2. An example of an anatomic discrepancy between both readers is shown in Figure $\mathbf{3}$ and $\mathbf{4}$. These discrepancies were corrected as described in the methods-section of this article.

\section{Level of agreement on TNM-basis}

Analyzing the whole patient cohort, substantial inter-reader agreement with $k=0.67$ was found for the prostate region (T-stage). Evaluation of the regional lymph node sites ( $\mathrm{N}$-stage) showed comparable results, with $\mathrm{K}=0.62$. Inter-reader agreement of distant lymph nodes (M1a-stage) was moderate on a 5-point scale $(\mathrm{k}=0.43)$. Results are displayed in Table 3 . Results with regard to bone lesions (M1b-stage) and visceral lesions (M1c-stage) are similar to the results as displayed in Table 3: substantial agreement for bone lesions ( $k=0.62)$ and fair agreement $(k=0.22)$ for visceral lesions on a 5-point scale. 
Table 2. Baseline characteristics of the analyzed patients

Median age (y)

Mean administered activity (MBq)

Primary staging ( $\mathrm{n})$

Restaging (n)

Median PSA (ng/ml)

Gleason score (n, \%)

$3+3=6$

$3+4=7$

$4+3=7$

$3+5=8$

$4+4=8$

$5+3=8$

$4+5=9$

$5+4=9$

$5+5=10$

Hospital

UMC Utrecht (n)

St. Antonius Hospital Nieuwegein (n)
70 (IQR 66-76)

153.1 (range 76.0-273.0)

60

58

$9.4(\mathrm{IQR}$ 1.7-31.1)

114 (4 missing)

$12(10)$

$40(34)$

$16(14)$

$5(4)$

$16(14)$

$2(2)$

$15(13)$

4 (3)

$4(3)$

\section{Level of agreement on region basis}

Analysis of the whole patient cohort showed a moderate interobserver agreement with $\mathrm{k}=0.55$ and 0.60 for the right and left hemi prostate, respectively (Table 4). Evaluation of all regional lymph node regions in the whole patient group showed fair to substantial agreement, ranging from $\mathrm{k}$ $=0.32$ in the left perivesical region to $\mathrm{K}=0.75$ in the right obturator region (Table 4). With regard to the distant lymph nodes regions, interobserver agreement in the whole cohort ranged from fair $(k=0.27$ in the left inguinal region) to substantial ( $k=0.65$ in both the left common iliac and the aortocaval region) (Table 4). Interobserver agreement with regard to bone lesions in all patients was substantial. Evaluation of visceral lesions in the whole patient cohort showed fair agreement $(\mathrm{K}=0.22)$ (Table 4$)$. 

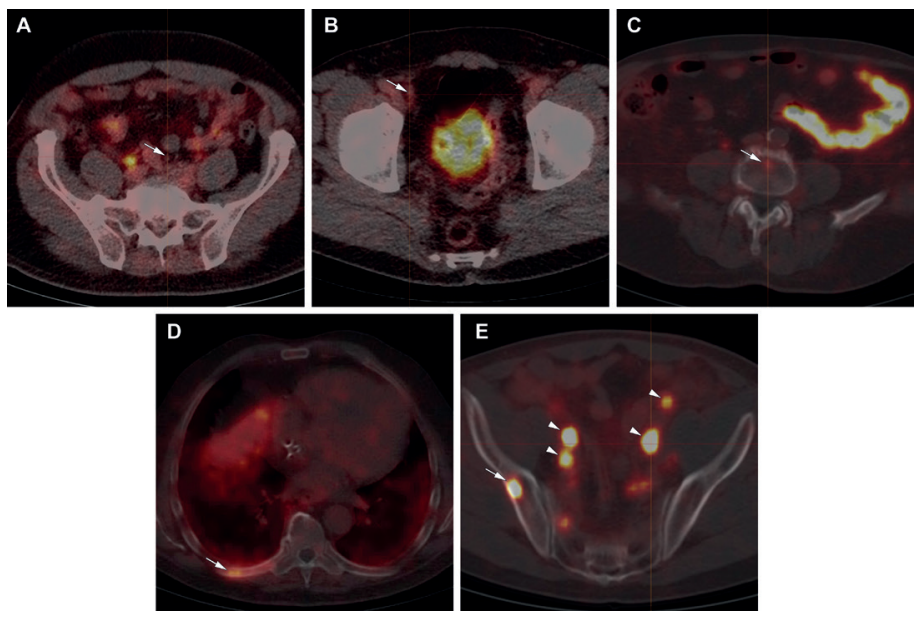

Figure 2. Five examples of ${ }^{68} \mathrm{Ga}$-PSMA PET-findings and their attributed scores A) Not-enlarged $(5 \mathrm{~mm}$ ) pelvic lymph node showing no radiotracer uptake: 1 (both readers). B) Pelvic lymph node showing mild radiotracer uptake in the right inguinal region: 2 (both readers). C) Score 3 lesion in vertebral corpus of L4, showing mild focal radiotracer uptake in absence of a sclerotic reaction on low-dose CT (both readers). D) High tracer uptake in sclerotic costa 8: score 4 (both readers). E) Multiple pelvic lymph nodes showing high radiotracer uptake (arrow heads) as well as solitary osseous 5 (both readers) lesion in the right iliac bone (arrow).

Table 3. Level of agreement on TNM-basis [17].

\begin{tabular}{lc}
\hline Whole sample $(\mathbf{n}=\mathbf{1 1 8})$ & Cohen's Kappa 5-point scale \\
\hline Prostate region (T-stage) & 0.67 \\
Regional lymph nodes (N-stage) & 0.62 \\
Distant lymph nodes (M1a-stage) & 0.43 \\
Bone lesions (M1b-stage) & 0.62 \\
Visceral lesions (M1c-stage) & 0.22 \\
\hline
\end{tabular}




\section{A}

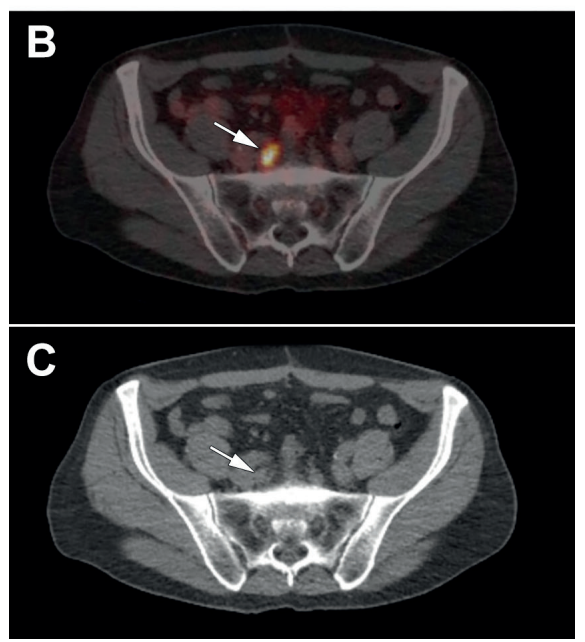

Figure 3. Example of discrepant ${ }^{68} \mathrm{Ga}-\mathrm{PSMA}$ PET/CT interpretation. ${ }^{68} \mathrm{Ga}$-PSMA PET/CT (PET-image: A; fused PET/CT-image: B; low dose (T-image: C) showing radiotracer uptake in a pelvic lymph node (arrow). The first reader scored the right internal iliac region as 5 , and the right common iliac region as 1 ; the second reader scored the right internal iliac region 1, and the right common iliac region 4 . The associated image number of the detected lesion in this patient corresponded between the two readers, indicating that both readers detected the same pelvic lymph node, but assigned the lesions to another anatomic lymph node site (respectively the right internal iliac region versus the right common iliac region). Anatomic discrepancies like these were filtered out. 

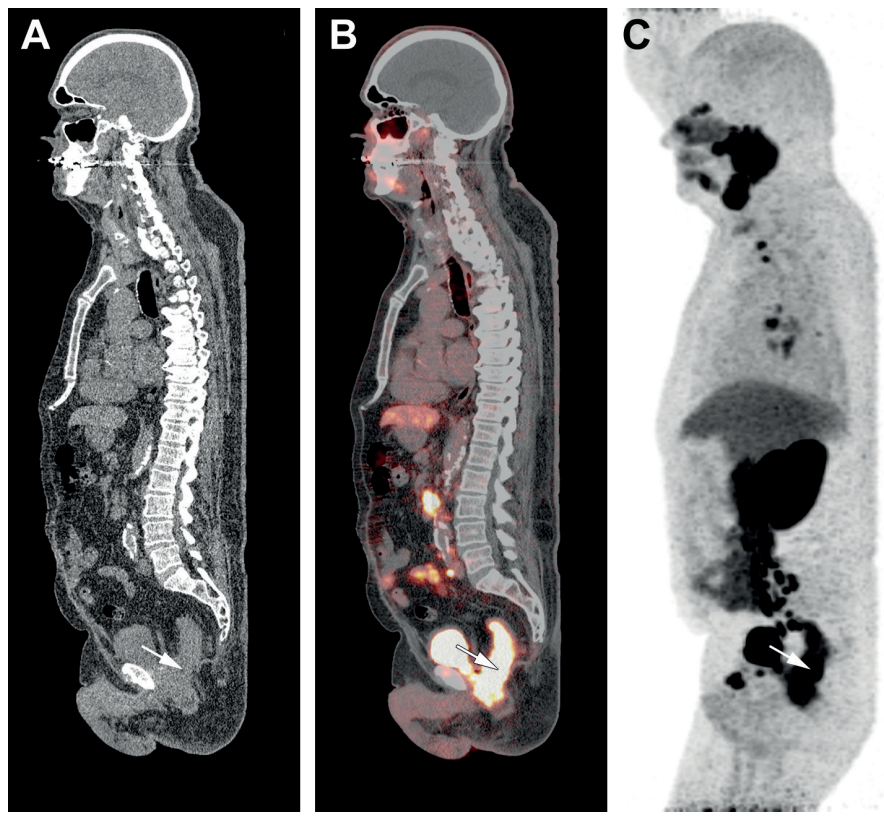

Figure 4. Example of discrepant ${ }^{68} \mathrm{Ga}$-PSMA PET/CT interpretation. ${ }^{68} \mathrm{Ga}-\mathrm{PSMA} \mathrm{PET} /$ CT (low dose CT-image: A; fused PET/CT-image: B; PET-image: C) of a patient with extensive local recurrence and multiple lymph nodes metastases (not shown). The first reader assigned 4 (clinically significant cancer is likely to be present) to the rectal region (arrow), whereas the second reader scored 1 (significant cancer is highly unlikely to be present). The rectal lesion appeared to rely on a vesicorectal fistula following initial radical prostatectomy and lymph node dissection. 
Table 4. Level of agreement on region basis

Whole sample $(n=118)$

\begin{tabular}{|c|c|c|c|}
\hline & Cohen's Kappa & & Cohen's Kappa \\
\hline \multicolumn{4}{|l|}{ Prostate region } \\
\hline Left & 0.60 & Right & 0.55 \\
\hline \multicolumn{4}{|l|}{ Regional lymph nodes } \\
\hline \multicolumn{2}{|l|}{ Left } & \multicolumn{2}{|c|}{ Right } \\
\hline External iliac & 0.50 & External iliac & 0.52 \\
\hline Internal iliac & 0.48 & Internal iliac & 0.47 \\
\hline Obturator & 0.75 & Obturator & 0.66 \\
\hline Perivesical & 0.49 & Perivesical & 0.32 \\
\hline Presacral & 0.58 & Presacral & 0.44 \\
\hline Perirectal & 0.50 & Perirectal & 0.62 \\
\hline \multicolumn{4}{|l|}{ Distant lymph nodes } \\
\hline Common iliac right & 0.50 & & \\
\hline Common iliac left & 0.65 & & \\
\hline Suprafrenic & 0.41 & & \\
\hline Paracaval & 0.52 & & \\
\hline Aortocaval & 0.65 & & \\
\hline Para-aortic & 0.46 & & \\
\hline Inguinal right & 0.45 & & \\
\hline Inguinal left & 0.27 & & \\
\hline Osseous lesions & 0.62 & & \\
\hline Visceral lesions & 0.22 & & \\
\hline
\end{tabular}

\section{Count of individual scores of both readers}

Score 1 and 5 was reported 2372 and 353 times by the first reader, compared to 2203 and 282 times by the second reader, respectively. Scores 2, 3 and 4 were reported respectively 47, 28 and 34 times by the first reader, compared to respectively 190, 50 and 106 times by the second reader. Results of these individual counts are summarized in Figure 5. 

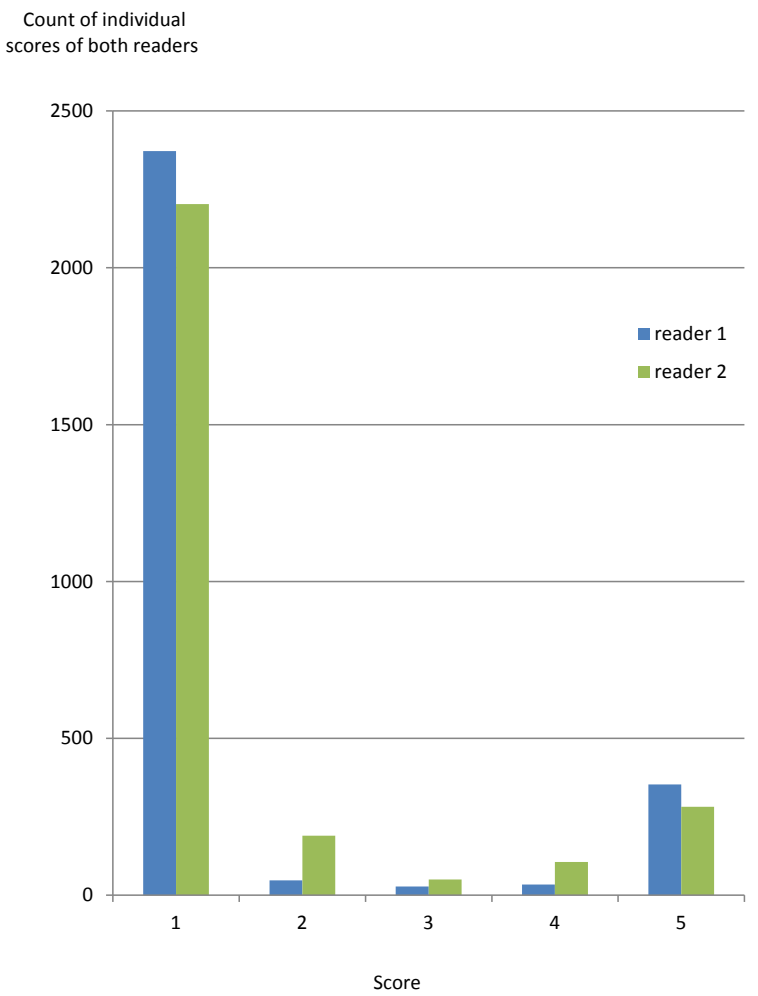

Figure 5. Distribution of individual scores of both readers

\section{DISCUSSION}

In this study, robust interobserver agreement was demonstrated for ${ }^{68} \mathrm{Ga}$ PSMA PET/CT interpretation of local, nodal and bone lesions of PCa with a structured 5 -point scale ( $K=0.67,0.62$ and 0.62 , respectively). The high concordance rate observed with this easy applicable 5-point classification method underlines the potential of ${ }^{68} \mathrm{Ga}$-PSMA PET/CT applicability in routine clinical practice. 
Robust interobserver agreement is one of the pivotal steps to establish the evidence basis necessary for the implementation of PSMA PET/ $\mathrm{CT}$ into clinical practice and therefore has been investigated by several study groups $[18,19]$. Despite these studies used different methods for PET interpretation, they show high observer agreement of PSMA PET/CT among the involved readers. Standardization of PSMA PET/CT evaluation is important to enhance the transmission and exchange of clinical information. Several studies specifically addressed interobserver variablity according the aforementioned EANM Consensus Criteria, PSMARADS and PROMISE criteria [12-14]. In the original PROMISE article, seven readers judged whether or not several predefined regions on PSMA PET/ $\mathrm{CT}$ were anomalous (binary scale) [12]. Interobserver agreement in this setting was moderate (Krippendorff's $(K)$ alpha $=0.47$ ). Interestingly, when the readers had to judge whether the anomalous findings represented pathologic, uncertain or non-pathologic images (3-point scale), interobserver agreement improved (K's alpha $=0.64$ ). Aforementioned findings demonstrate that a 3-point scale outperforms a binary scale, probably since the readers were left more space to translate their clinical view into a standardized score. A prospective study analyzed interobserver agreement for the application of the PSMA-RADS classification in 50 ${ }^{18} \mathrm{~F}-\mathrm{DCFPYL}$ PET/CT scans [20]. Four readers assigned a PSMA-RADS score $(1,2,3 A, 3 B, 3 C, 3 D, 4$ or 5$)$ both to a maximum of five target lesions and to the overall scan impression. Also, overall scan result and involvement of organ and lymph nodes were scored on a binary scale (positive/negative). Excellent interobserver agreement was demonstrated for the binary scored parameters, such as overall scan impression (intraclass correlation coefficient (ICC) 0.75) organ and lymph node involvement (ICC 0.80 and 0.78 , respectively). Logically, agreement among readers slightly decreased regarding their judgments on a 5-point scale: In 50\% of the 58 identical chosen target lesions among the four observers, all readers designated an identical PSMA-RADS score, resulting in an ICC of 0.60. Interobserver agreement regarding identical chosen target lesions by three and two observers was also good (ICC 0.60 and 0.62 , respectively). Considering these findings, scoring of PSMA PET/CT imaging according to both a binary scale and a 5-point scale resulted in robust interobserver agreement. Although a 5-point scale causes slightly more discordance among readers as a result 
of extended number of choices, Eiber et al. recommends the assessment of diagnostic certainty according to a 5-point scale [14]. The present study also supports 5-point based evaluation of PSMA PET/CT imaging, since it offers the possibility to apply the nuance necessary in clinical reports, with each score implying different appropriate clinical management directions.

A comparative study on interobserver variability according to the three aforementioned criteria [21], showed impaired agreement on PSMA-RADS 3 lesions. This was partly attributed to the broadly defined subcategories within this method. Instead, with its clearly determined categories, the newly proposed classification system represents an easy to memorize method that secures a fair balance between accuracy and time investment.

A limitation of the present study includes PET reporting in absence of clinical information, including previous imaging, medical history, recent PSA-level, PSA-kinetics and indication for imaging. This might have impaired the interobserver agreement observed in this study. Despite clinical parameters might be helpful to guide ${ }^{68} \mathrm{Ga}$-PSMA PET/ CT interpretation, the applicability of the proposed classification method was considered best tested according to this 'worst case scenario' reflecting daily clinical practice. Secondly, (histopathological) validation of the assigned scores was not performed. Future studies with a focus on prospective evaluation of the 5-point classification with histopathologic reference, as well as assessment of its impact on patient prognosis and management, are required.

\section{CONCLUSIONS}

Interobserver agreement using a straightforward 5-point classification provides substantial agreement with regard to the detection of PCa and regional lymph node metastases on ${ }^{68} \mathrm{Ga}-\mathrm{PSMA}$ PET/CT. Structured classification methods for ${ }^{68} \mathrm{Ga}-\mathrm{PSMA}$ PET/CT evaluation in daily practice is recommended. 


\section{REFERENCES}

6. Sweat SD, Pacelli A, Murphy GP, Bostwick DG, et al. Prostate-specific membrane antigen expression is greatest in prostate adenocarcinoma and lymph node metastases. Urology. 1998 Oct;52(4):637-40.

7. Perera M, Papa N, Christidis D, Wetherell D, Hofman MS, Murphy DG, et al. Sensitivity, Specificity, and Predictors of Positive ${ }^{68} \mathrm{Ga}$-Prostate-specific Membrane Antigen Positron Emission Tomography in Advanced Prostate Cancer: A Systematic Review and Meta-analysis. Eur Urol. 2016 Dec;70(6):926937.

8. Hofman MS, Lawrentschurk N, Francis RJ, Tang C, Vela I, Thomas P, et al. Prostate-specific membrane antigen PET-CT in patients with high-risk prostate cancer before curative-intent surgery or radiotherapy (proPSMA): a prospective, randomised, multi-centre study. Lancet. DOI: 10.1016/S01406736(20)30314-7

9. Lee B, Whitehead MT. Radiology Reports: What YOU Think You're Saying and What THEY Think You're Saying. Curr Probl Diagn Radiol. 2017 May Jun;46(3):186-195

10. How Sure Are You, Doctor? A Standardized Lexicon to Describe the Radiologist's Level of Certainty. David M. Panicek1,2 and Hedvig Hricak1,2 American Journal of Roentgenology. 2016;207: 2-3.

11. Werner RA, Bundschuh RA, Bundschuh L, et al. Novel Structured Reporting Systems for Theranostic Radiotracers. J Nucl Med. 2019;60(5):577-584.

12. Orel SG, Kay N, Reynolds C, et al. BI-RADS categorization as a predictor of malignancy. Radiology. 1999 Jun;211(3):845-50.

13. Weinreb JC, Barentsz JO, Choyke PL, et al. PI-RADS Prostate Imaging Reporting and Data System: 2015, Version 2. Eur Urol. 2016 Jan;69(1):16-40.

14. McKee BJ, Regis SM, McKee AB, et al. Performance of ACR Lung-RADS in a clinical CT lung screening program. J Am Coll Radiol. 2015 Mar;12(3):273-6.

15. Purysko AS, Remer EM, Coppa CP, et al.LI-RADS: a case-based review of the new categorization of liver findings in patients with end-stage liver disease. Radiographics. 2012 Nov-Dec;32(7):1977-95.

16. Tessler FN, Middleton WD, Grant EG, et al. ACR Thyroid Imaging, Reporting and Data System (TI-RADS): White Paper of the ACR TI-RADS Committee.J Am Coll Radiol. 2017 May;14(5):587-595.

17. Fanti S, Minozzi S, Morigi JJ, et al. Development of standardized image interpretation for 68Ga-PSMA PET/CT to detect prostate cancer recurrent lesions. Eur J Nucl Med Mol Imaging. 2017 Sep;44(10):1622-1635.

18. Rowe SP, Pienta KJ, Pomper MG, et al. Proposal for a Structured Reporting System for Prostate-Specific Membrane Antigen-Targeted PET Imaging: PSMA-RADS Version 1.0. J Nucl Med. 2018 Mar;59(3):479-485. 
19. Eiber M, Herrmann K, Calais J, et al. Prostate Cancer Molecular Imaging Standardized Evaluation (PROMISE): Proposed miTNM Classification for the Interpretation of PSMA-Ligand PET/CT. J Nucl Med. 2018 Mar;59(3):469-478.

20. Boellaard R, Delgado-Bolton R, Oyen WJG, et al. FDG PET/CT: EANM procedure guidelines for tumour imaging: version 2.0 Eur J Nucl Med Mol Imaging (2015) 42:328-354

21. Fendler WP, Eiber M, Beheshti M, et al. Ga-PSMA PET/CT: Joint EANM and SNMMI procedure guideline for prostate cancer imaging: version 1.0. Eur J Nucl Med Mol Imaging. 2017 Jun;44(6):1014-1024.

22. Buyyounouski MK, Choyke PL, McKenney JK, Sartor O, Sandler HM, Amin $\mathrm{MB}$, et al. Prostate cancer-major changes in the American Joint Committee on Cancer 8th edition cancer staging manual. CA Cancer J Clin. 2017 May 6;67(3):245-253

23. Sabour S. Agreement for the interpretation of 68Ga-prostate-specific membrane antigen-I\&T positron emission tomography/computed tomography imaging; methodological issues to avoid misinterpretation. Nucl Med Commun. 2020;41(3):294.)

24. Fendler WP, Calais J, Allen-Auerbach $\mathrm{M}$, et al. ${ }^{68} \mathrm{Ga}$ - PET/CT Interobserver Agreement for Prostate Cancer Assessments: An International Multicenter Prospective Study. J Nucl Med. 2017 Oct;58(10):1617-1623.

25. Werner RA, Bundschuh RA, Bundschuh L, et al. Interobserver Agreement for the Standardized Reporting System PSMA-RADS 1.0 on ${ }^{18} \mathrm{~F}-\mathrm{DCFPyL}$ PET/CT Imaging. J Nucl Med. 2018 Dec;59(12):1857-1864.

26. Toriihara A, Nobashi T, Baratto L, Duan H, Moradi F, Park S, Hatami N, Aparici C, Davidzon G, lagaru A. Comparison of three interpretation criteria of 68GaPSMA11 PET based on inter- and intra-reader agreement. J Nucl Med. 2019 Sep 27. 




\section{CHAPTER 4}

\section{Comparison of $\left[{ }^{68} \mathrm{Ga}\right] \mathrm{Ga}-\mathrm{PSMA}-11$ and $\left[{ }^{18} \mathrm{~F}\right] \mathrm{F}$-DCFPyL PET/CT in patients with prostate}

cancer and primary or secondary biochemical recurrence after radical prostatectomy

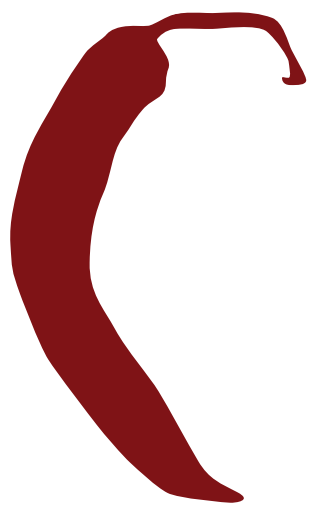

L.W.M. van Kalmthout, M. Wondergem,

B.H. Jansen, H.H.E. van Melick, D.E. Oprea-Lager, A. Vis,

J.M.H. de Klerk, F.M. van der Zant, M.G.E.H. Lam 


\section{ABSTRACT}

\section{Background}

${ }^{68} \mathrm{Gallium}\left({ }^{68} \mathrm{Ga}\right.$ )-labeled PET tracers, e.g. ${ }^{68} \mathrm{Ga}-\mathrm{PSMA}-11$, targeting prostatespecific membrane antigen (PSMA), are used to localize prostate cancer (PCa) in patients with a biochemical recurrence (BCR). Labeling of PSMA tracers with fluor-18 $\left({ }^{18} \mathrm{~F}\right)$, e.g. ${ }^{18} \mathrm{~F}-\mathrm{DCFPyL}$, may enhance detection of metastases. The present study compares detection rate of ${ }^{68} \mathrm{Ga}$-PSMA PET/ CT to ${ }^{18} \mathrm{~F}$-DCFPyL PET/CT in patients with a primary BCR (first BCR after radical prostatectomy) or secondary BCR (after prior salvage treatments).

\section{Methods}

From 2015 to 2018, all patients scanned for primary and secondary BCR (PSA level: $0.5-3.5 \mathrm{ng} / \mathrm{ml}$ ) after radical prostatectomy in four hospitals in the Netherlands, were analyzed. Imaging was performed according to standard acquisition protocols using ${ }^{68} \mathrm{Ga}-\mathrm{PSMA}-11$ (1.5-2.0 MBq/kg, PET $45 \mathrm{~min}$ post-injection) or ${ }^{18} \mathrm{~F}-\mathrm{DCFPyL}(3.0 \mathrm{MBq} / \mathrm{kg}$, PET $120 \mathrm{~min}$ postinjection). Both tracers were compared on basis of PSA stratified detection rates, site of tumor recurrence and number of detected lesions.

\section{Results}

A total of 156 consecutive patients ( ${ }^{68} \mathrm{Ga}-\mathrm{PSMA}-11: \mathrm{n}=80$ and ${ }^{18} \mathrm{~F}-\mathrm{DCFPyL}$ : $\mathrm{n}=76$ ) were retrospectively analyzed. Overall detection rate of ${ }^{68} \mathrm{Ga}$ PSMA PET/CT and ${ }^{18}$ F-DCFPyL PET/CT was $73.8 \%$ and $72.4 \%(p=0.85)$, respectively. For PSA levels of $0.5-2.0$ and $2.0-3.5 \mathrm{ng} / \mathrm{ml}$, detection rates were respectively $68.6 \%$ and $82.8 \%\left({ }^{68} \mathrm{Ga}-\mathrm{PSMA}-11\right)$ versus $69.0 \%$ and 83.3\% ( $\left.{ }^{18} \mathrm{~F}-\mathrm{DCFPyL}\right)$. Differences in detection rate were not found to be statistically significant. A comparable number of lesions was detected with ${ }^{68} \mathrm{Ga}$-PSMA-11 compared to ${ }^{18} \mathrm{~F}-\mathrm{DCFPyL}$.

\section{Conclusions}

Our data suggest that performance of ${ }^{68} \mathrm{Ga}-\mathrm{PSMA}-11$ and ${ }^{18} \mathrm{~F}-\mathrm{DCFPyL}$ to detect $P C a$ in patients with a primary or secondary BCR after radical prostatectomy is comparable. 


\section{INTRODUCTION}

Prostate cancer ( $\mathrm{PCa}$ ) is the most diagnosed malignancy in males in Western countries, with an annual incidence of 450,000 new cases in Europe and 174,650 in the USA [1,2]. After radical prostatectomy, levels of prostate-specific antigen (PSA) typically decrease below detection threshold. A consecutive increased prostate-specific antigen (PSA) level $\geq 0.2 \mathrm{ng} / \mathrm{ml}$ after surgery, commonly referred to as biochemical recurrence $(B C R)$, indicates a recurrence of PCa [3]. In patients with a 'primary' BCR after treatment with curative intent, image-guided tumor localization is of major importance to define the most suitable treatment strategy: e.g. salvage radiotherapy, metastasis-directed procedures or systemic therapy. In post-radical prostatectomy patients, onset of salvage radiation therapy at the earliest sign of recurrence provides a long-term PSA response in nearly 50\% of the patients [4]. Unfortunately, in some patients, elevated PSA levels reoccur or persist after salvage treatments. Also in this patient group, imaging modalities assist in the selection of the most suitable subsequent treatment regimen. In this study, these patients are considered to have a 'secondary' BCR. In daily clinical care, staging of both patients with a 'primary' (after treatment with curative intent) and 'secondary' (after prior salvage treatments) BCR remains challenging, especially when PSA levels are low. Over recent years, imaging with positron emission tomography/computed tomography (PET/CT) targeting the Prostate Specific Membrane Antigen receptor (PSMA), has gained prominence in the detection of PCa. PSMA is a type II trans-membrane glycoprotein that is significantly overexpressed by malignant PCa cells, and therefore represents an attractive target for imaging with radiotracers [5]. Previously published studies predominantly focused on the detection capacity of ${ }^{68} \mathrm{Ga}$-PSMA PET/CT. A recent metaanalysis concluded that ${ }^{68} \mathrm{Ga}$-labeled radiotracers performed well in localizing sites of PCa in patients with BCR. Detection rates of $63 \%$ and $94 \%$ were found in patients with PSA levels $<2.0$ and $>2.0 \mathrm{ng} / \mathrm{ml}$, respectively [6]. Recent data on the performance of ${ }^{18} \mathrm{~F}-D C F P y L$ showed promising results too [7-9]. The high potential of ${ }^{18} \mathrm{~F}-\mathrm{DCFP} \mathrm{L}$ was reflected by prospective data showing its high specificity (88.9\%) and sensitivity 
(71.4\%) for lymph node detection in primary staging of PCa [10]. More importantly, it was suggested that ${ }^{18} \mathrm{~F}-\mathrm{DCFPyL}$ outperforms ${ }^{68} \mathrm{Ga}$ PSMA in patients with low PSA levels (PSA: 0.5-3.5 ng/ml) and a BCR after radical prostatectomy [11]. This is an important finding, because early detection of recurrent disease at low PSA levels appears to have clinical implications with regard to treatment options and long-term outcomes $[7,12]$. The present study aims to validate earlier findings of the superior diagnostic performance of ${ }^{18} \mathrm{~F}$-labeled PSMA tracers by a comparative study assessing diagnostic performance of ${ }^{68} \mathrm{Ga}-\mathrm{PSMA}$ PET/CT versus ${ }^{18} \mathrm{~F}-\mathrm{DCFPYL}$ PET/CT in post-radical prostatectomy patients with a primary or secondary BCR.

\section{MATERIALS AND METHODS}

\section{Ethics}

For this retrospective study, the Institutional Review Board of the UMC Utrecht waived the need for informed consent (chairperson: prof. dr. Louis de Bont; IRB protocol number: 18-369/C; date: 28-5-2018). All procedures performed in this study involving human participants are in accordance with the ethical standards of the 1964 Helsinki declaration and its later amendments or comparable ethical standards.

\section{Patient population}

In this retrospective analysis, all consecutive patients with BCR after initial radical prostatectomy were included in four Dutch institutions from May 2015 up to December 2018: UMC Utrecht, Noordwest Ziekenhuisgroep in Alkmaar (NWZ), Amsterdam UMC (VU University), and the Meander Medical Center in Amersfoort (MMC). Patients were considered candidates for inclusion according to the following selection criteria: (1) an elevated PSA level $\geq 0.2 \mathrm{ng} / \mathrm{ml}$ after radical prostatectomy (curative intent) with or without having received prior salvage treatments (2) PSA level ranging from $0.5-3.5 \mathrm{ng} / \mathrm{ml}$ (for comparison with previously published data by Dietlein et al. [11]). Baseline characteristics of the included patients with regard to age, current PSA level, T-stage at time of diagnosis, 
histopathological Gleason score of the prostate specimen following radical prostatectomy, resection status following radical prostatectomy, histopathological $\mathrm{N}$-status after pelvic lymph node dissection, previous salvage therapies and usage of hormonal agents during PET-scanning were collected. Patients with insufficient data on recent PSA level were excluded from analysis. Detected number of lesions $(0,1,2,3,4,5,>5)$ and anatomical localization of detected lesions (local recurrence, local or distant lymph nodes, bone and visceral lesions) were assessed for all scans. Detection rates of both tracers were calculated for different PSA categories: 0.5-1.0, 1.0-1.5, 1.5-2.0, 2.0-2.5, 2.5-3.0 and 3.0-3.5 ng/ml. Using logistic regression analysis, administered radiotracer and recent PSA level were tested as predictors for a positive scan. A subgroup analysis, including all patients with a primary $B C R$, e.g. patients who did not receive any prior salvage treatments, was performed to evaluate detection rates of both tracers.

\section{Tracer synthesis}

${ }^{68} \mathrm{Ga}$-PSMA-11 (UMC Utrecht) was prepared using a Good Manufacturing Practice-grade ${ }^{68} \mathrm{Ge} /{ }^{68} \mathrm{Ga}$ generator and a semi-automated ModularLab eazy synthesis module (Eckert \& Ziegler, Berlin, Germany). Each synthesis was performed following the manufacturers' instructions using prefabricated materials including a cassette, an acetate buffer, a C18 purification cartridge and a $0.22 \mu \mathrm{m}$ pore size sterilization filter (Eckert \& Ziegler, Berlin, Germany). Forty $\mu \mathrm{g}$ (42 nmol) of PSMA-11 ligand (ABX, Radeberg, Germany) per preparation was used, leading to a mean administered amount of 14.5 (range 5.1 - 40.0) $\mu$ g ligand per patient depending on patient weight and ${ }^{68} \mathrm{Ge}$ generator decay, and labelling yield. ${ }^{18} \mathrm{~F}$-DCFPyL was synthesized under GMP conditions at the on-site cyclotron facilities of two hospitals [12], using the precursor of ABX (ABX $\mathrm{GmbH}^{\oplus}$, Germany).

PET/CT acquisition and image reconstruction ${ }^{68} \mathrm{Ga}$-PSMA PET/CT (UMC Utrecht): Images were acquired from skull vertex to the mid-thigh using a Biograph mCT40 scanner (Siemens, Erlangen, Germany). At 45 minutes post-injection of a mean dose of $158.3 \mathrm{Mbq}{ }^{68} \mathrm{Ga}$-PSMA-11, PET images 
were acquired. PET acquisitions were combined with a low-dose CT (40 $\mathrm{mAs}, 120 \mathrm{kV}$ ), performed approximately 60 minutes after radiotracer administration. All images were corrected for decay, scatter, and random coincidences; photon attenuation correction was performed using lowdose CT. All images were acquired according to the European Association of Nuclear Medicine (EANM)-criteria, EARL-reconstructions, with the following parameters: PET with time-of-flight and point spread function reconstruction, 4 iterations, 21 subsets, with a Gaussian filter of $7.5 \mathrm{~mm}$ full width at half maximum [14]. The reconstructed images had a maximum image matrix size of 200x200, voxel size $4 \times 4 \times 3 \mathrm{~mm}$.

${ }^{18} \mathrm{~F}-\mathrm{DCFP}$ L PET/CT (NWZ/Amsterdam UMC/MMC): Images were acquired from the mid-thigh to the base of the skull (5 minutes per bed position) using a Siemens Biograph-16 TruePoint PET/CT scanner (Siemens Healthcare, Knoxville, U.S.) or a Philips Ingenuity (Philips Healthcare, Best, The Netherlands). At 120 minutes post-injection of a mean dose of 281.8 $\mathrm{MBq}{ }^{18} \mathrm{~F}-\mathrm{DCFP} \mathrm{L}, \mathrm{PET}$ images were acquired. Ten $\mathrm{mg}$ furosemide was co-administered to all patients from NWZ and MMC. PET acquisitions were combined with a low-dose CT or contrast-enhanced CT scan (30$110 \mathrm{mAs}, 110-130 \mathrm{kV}$ ). All images were corrected for decay, scatter, and random coincidences; photon attenuation correction was performed using low-dose CT. Images were reconstructed with the vendor-provided BLOB-based Ordered-Subsets Expectations Maximization algorithm on the Philips system (3 iterations; 33 subsets) and the Ordered-Subsets Expectations Maximization algorithm on the Siemens system (4 iterations; 16 subsets, including a $5 \mathrm{~mm}$ Gaussian filter). The reconstructed images had a maximum image matrix size of $256 \times 256$, voxel size $2.67 \times 2.67 \times 4 \mathrm{~mm}$ (Siemens data) and matrix size $288 \times 288$, voxel size $2 \times 2 \times 2 \mathrm{~mm}$ (Philips data).

\section{Image analysis}

Experienced nuclear medicine physicians read all included PET/CT scans. PET-findings as described in regular clinical reports were used for this study. In case of missing parameters, the PET/CT scans were additionally reviewed by experienced nuclear medicine physician (JdK en ML). Scans 
were considered positive in case radiotracer uptake was present in the prostatic fossa, loco-regional lymph nodes, distant lymph nodes, bone or visceral organs (according to TNM for prostate cancer; $7^{\text {th }}$ edition).

\section{Statistical Analysis}

For this study, a sample size calculation indicated 80 patients being required in each group (alpha 0.05 , beta 0.85 ), based on a $20 \%$ difference in overall detection ratio between ${ }^{68} \mathrm{Ga}-\mathrm{PSMA}-11$ (66\%) and ${ }^{18} \mathrm{~F}-\mathrm{DCFPyL}$ (88\%) as observed in Dietlein et al. [10]. Continuous data at baseline were compared using the independent samples T-test. The Kruskal Wallis Test and the Mann Whitney $U$ test were used in case of not normally distributed data. To compare differences in number of detected lesions and detection rate between both tracers in different PSA categories, the Kruskal Wallis Test was used. Statistical significance was established for $p$-values $<0.05$. Statistical analyses were performed using IBM SPSS Statistics for Mac, Amsterdam, The Netherlands, version 24.

\section{RESULTS}

\section{Baseline}

A total of 156 patients with PSA $0.5-3.5 \mathrm{ng} / \mathrm{ml}$ after radical prostatectomy were included in four institutions. Eighty patients underwent ${ }^{68} \mathrm{Ga}$-PSMA PET/CT (UMC Utrecht). Seventy-six patients underwent ${ }^{18} \mathrm{~F}-\mathrm{DCFPyL}$ PET/ CT (29 Amsterdam UMC, 31 NWZ and 16 MMC). Characteristics of all included patients are shown in Table 1. Statistically significant differences in baseline characteristics regarding age, histopathological N-status and previous salvage therapies were observed between the ${ }^{68} \mathrm{Ga}-\mathrm{PSMA}$ group and the ${ }^{18} \mathrm{~F}$-DCFPyL group. A total number of 47 patients (58.8\%) in the ${ }^{68} \mathrm{Ga}$-PSMA group and 29 patients (38.2\%) in the ${ }^{18} \mathrm{~F}$-DCFPyL group underwent salvage radiation therapy following initial curative therapy. Six patients (7.5\%) in the ${ }^{68} \mathrm{Ga}$-PSMA group ( ${ }^{18} \mathrm{~F}$-DCFPyL group: 0 patients) underwent salvage lymph node dissection. Four patients (5.0\%) in the ${ }^{68} \mathrm{Ga}$ PSMA group underwent a combination of salvage radiation therapy and surgical procedures ( ${ }^{18} \mathrm{~F}-\mathrm{DCFPyL}$ group: 0 patients). Baseline characteristics 
Part I| Prostate cancer imaging

Table 1. Baseline Table

\begin{tabular}{|c|c|c|c|}
\hline & $\begin{array}{c}{ }^{68} \mathrm{Ga}-\mathrm{PSMA} \\
(\mathrm{n}=80)\end{array}$ & $\begin{array}{c}{ }^{18} \text { F-DCFPyL } \\
(n=76)\end{array}$ & p-value \\
\hline Mean age (y; range) & $67(49-83)$ & $71(61-80)$ & $0.04^{*}$ \\
\hline Mean PSA level (ng/ml), (range) & $1.6(0.5-3.0)$ & $1.4(0.5-3.3)$ & NS $(0.06)^{*}$ \\
\hline Histopathological T-stage (n, \%) & & & NS $(0.76)^{* *}$ \\
\hline $\mathrm{T} 2 \mathrm{a}$ & $6(7.5)$ & $3(3.9)$ & \\
\hline $\mathrm{T} 2 \mathrm{~b}$ & $6(7.5)$ & $1(1.3)$ & \\
\hline $\mathrm{T} 2 \mathrm{C}$ & $17(21.3)$ & $19(25.0)$ & \\
\hline Т3a & $27(33.8)$ & $9(11.8)$ & \\
\hline $\mathrm{T} 3 \mathrm{~b}$ & $16(20.0)$ & $14(18.4)$ & \\
\hline $\mathrm{T} 4$ & $1(1.3)$ & $2(2.6)$ & \\
\hline Missing & $7(8.8)$ & $28(36.8)$ & \\
\hline Histopathological ISUP Grade & & & NS $(0.40)^{* * *}$ \\
\hline \multicolumn{4}{|l|}{ Group (n, \%) } \\
\hline 1 & $11(13.8)$ & $2(2.6)$ & \\
\hline 2 & $19(23.8)$ & $18(23.7)$ & \\
\hline 3 & $15(18.8)$ & $11(14.5)$ & \\
\hline 4 & $9(11.3)$ & $3(3.9)$ & \\
\hline 5 & $15(18.8)$ & $14(18.4)$ & \\
\hline Missing & $11(13.8)$ & $28(36.8)$ & \\
\hline Resection status after RP & & & NS $(0.94)^{* *}$ \\
\hline RO & $28(35.0)$ & $20(26.3)$ & \\
\hline R1 & $36(45.0)$ & $25(32.9)$ & \\
\hline Missing & $16(20.0)$ & $31(40.8)$ & \\
\hline Histopathological $\mathrm{N}$-status & & & $0.04^{* *}$ \\
\hline $\mathrm{N}-$ & $26(32.5)$ & $21(27.6)$ & \\
\hline $\mathrm{N}+$ & $15(18.8)$ & $3(3.9)$ & \\
\hline No PLND performed & $34(42.5)$ & $31(40.8)$ & \\
\hline Missing & $5(6.3)$ & $21(27.6)$ & \\
\hline
\end{tabular}


Table 1. Continued

\begin{tabular}{lccc}
\hline & $\begin{array}{c}{ }^{68} \mathrm{Ga}-\mathrm{PSMA} \\
(\mathrm{n}=80)\end{array}$ & $\begin{array}{c}{ }^{18} \mathrm{~F}-\mathrm{DCFPyL} \\
(\mathrm{n}=76)\end{array}$ & p-value \\
\hline $\begin{array}{l}\text { Previous Salvage Therapies (n, \%) } \\
\text { None }\end{array}$ & $29(36.3)$ & $46(60.5)$ & $0.001^{* *}$ \\
Salvage radiation therapy & $37(46.3)$ & $26(34.2)$ & \\
$\quad$ Prostate region & $7(8.8)$ & $2(2.6)$ & \\
Lymph node/osseous lesions & $3(3.8)$ & $1(1.3)$ & \\
$\quad$ Combination & $6(7.5)$ & 0 & \\
Salvage PLND & $4(5.0)$ & 0 & \\
Combination of salvage strategies & $2(2.5)$ & $1(1.3)$ & \\
Missing & & & \\
ADT during scan (n, \%) & $76(95.0)$ & $73(96.1)$ & \\
No & $1(1.3)$ & $2(2.6)$ & \\
Yes & $3(3.8)$ & $1(1.3)$ & \\
Missing & & & \\
\hline
\end{tabular}

PLND = pelvic lymph node dissection; NS = not significant; *Independent samples t-test; ${ }^{* *}$ Kruskal Wallis Test; ***Mann Whitney U test

of a subgroup of 75 selected patients, who did not undergo any type of previous salvage therapy, are listed in Supplementary Table 1. Comparison of baseline features in this subcohort did not reveal any statistically significant differences.

\section{Diagnostic performance}

Overall detection rate of ${ }^{68} \mathrm{Ga}$-PSMA PET versus ${ }^{18} \mathrm{~F}$-DCFPyL was respectively $73.8 \%$ and $72.4 \%(p=0.85)$. Both tracers performed well at PSA levels $<2.0$ $\mathrm{ng} / \mathrm{ml}$; detection rates were $68.6 \%$ and $69.0 \%$ for respectively ${ }^{68} \mathrm{Ga}-\mathrm{PSMA}$ and ${ }^{18} \mathrm{~F}$-DCFPyL (Table 2, Figure1). Detection rate of both tracers for PSA $\geq 2.0$ $\mathrm{ng} / \mathrm{ml}$ were respectively $82.8 \%$ and $83.3 \%$ for ${ }^{68} \mathrm{Ga}$-PSMA and ${ }^{18} \mathrm{~F}$-DCFPyL. Stratified to PSA levels of 0.5-1.0, 1.0-1.5, 1.5-2.0, 2.0-2.5, 2.5-3.0 and 3.0$3.5 \mathrm{ng} / \mathrm{ml}$, detection rate of ${ }^{68} \mathrm{Ga}-P S M A$ was $63.3 \%, 75.0 \%, 83.3 \%, 84.6 \%$, 
Part I|Prostate cancer imaging

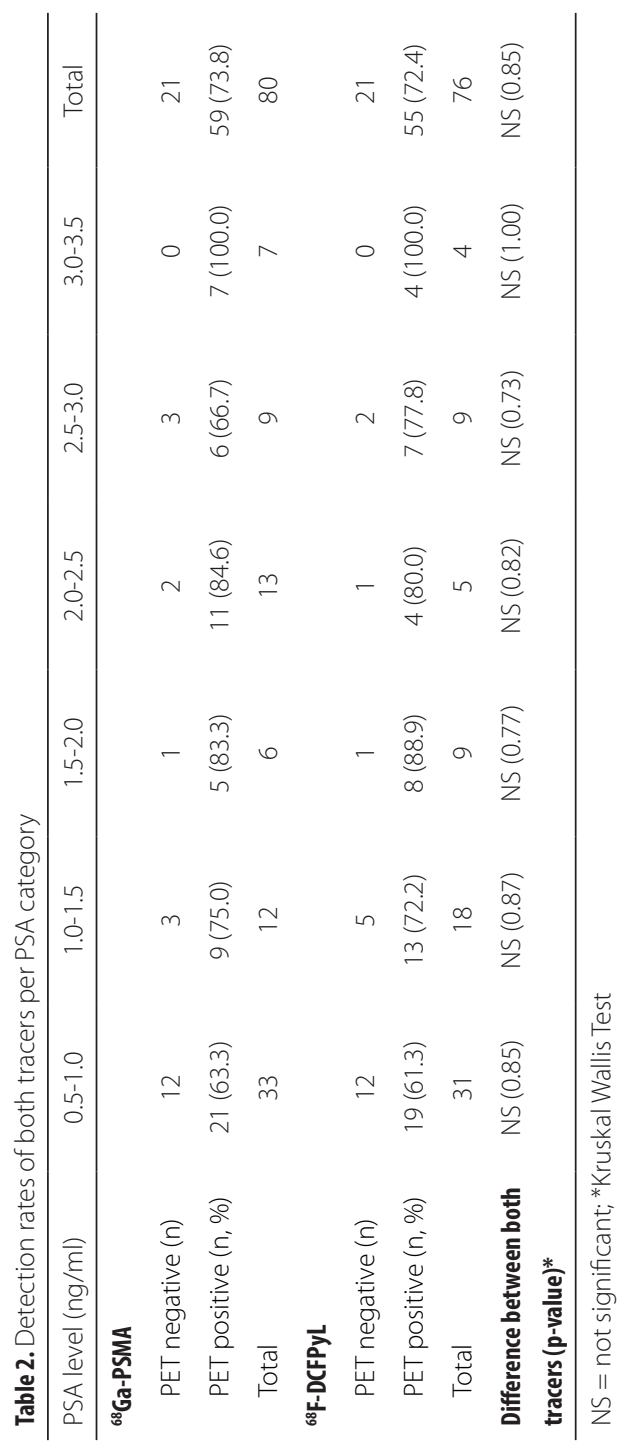


Figure 1. Detection rates of both tracers per PSA category

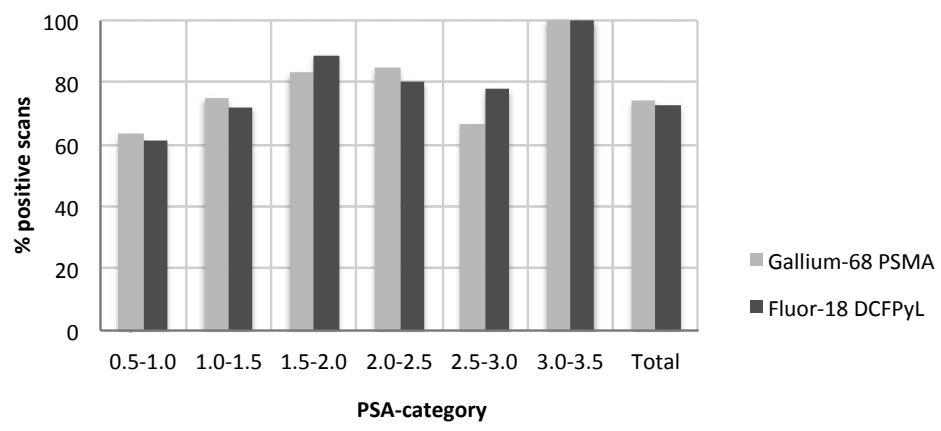

$66.7 \%$ and $100.0 \%$. Detection rate of ${ }^{18} \mathrm{~F}-\mathrm{DCFPyL}$ in these PSA categories was $61.3 \%, 72.2 \%, 88.9 \%, 80.0 \%, 77.8 \%, 100.0 \%$. Differences in detection rates between the two administered radiotracers were found to be not statistically significant. Recent PSA was identified as a predictor for a positive scan ( $p=0.01)$; administered radiotracer appeared not predictive $(p=0.97)$. With regard to the analyzed subgroup of 75 primary BCR patients, overall detection rate of ${ }^{68} \mathrm{Ga}$-PSMA and ${ }^{18} \mathrm{~F}$-DCFPyL was comparable (respectively $69.0 \%$ and 69.6\%; $p=0.96$; Supplementary Table 2 and Supplementary Figure 1). In this subgroup, comparable to the whole group analysis, recent PSA was identified as predictor for a positive scan $(p=0.006)$. Administered radiotracer was not found to have any predictive value for a positive scan $(p=0.75)$. Examples of tumor site detection of both tracers are shown in

\section{Figure 2 and Figure 3.}

\section{Detected lesions}

Table 3 shows the number of detected sites of recurrence in the studied patient population, differentiated by administered radiotracer ${ }^{68} \mathrm{Ga}$ PSMA-11 vs $\left.{ }^{18} \mathrm{~F}-\mathrm{DCFPyL}\right)$. Tumor recurrences in the prostate region were found equally frequent in both patient groups $(p=0.10)$. No difference was observed regarding the number of detected regional lymph nodes 
Part I|Prostate cancer imaging

0

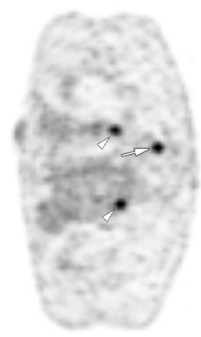

ш

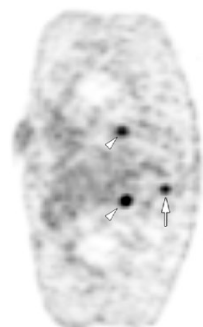

.

Ч

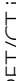

$\sum$

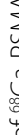


0

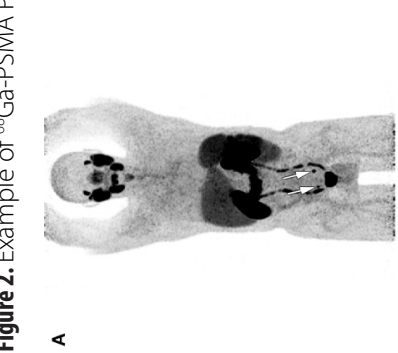

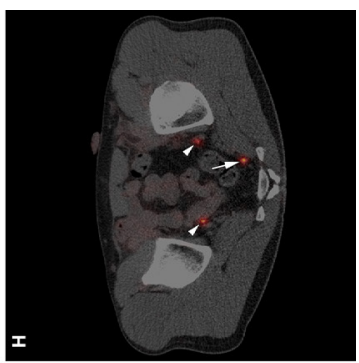

ㄷํㅇ ำ

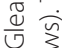

is

है

高

흑

워

$\bar{\xi}$

के $\frac{\overline{0}}{\mathrm{c}}$

$\wedge$.

i

40

$\overline{\frac{1}{2}} \cdot \frac{0}{8}$

过

近产

$\therefore 3$

$\stackrel{\oiiint}{\frac{1}{5}}$

38

满

華 है

$\frac{0}{0} \frac{1}{\frac{0}{0}}$

व.

\&

尔

o

43

ब.

ס

E 을

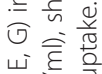

ن के गे

过

事

을 은

它

企苍

난. 증

0 : $\frac{0}{ \pm}$

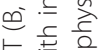

㟧考送

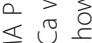

$\sum u \frac{c}{n}$

ज敒

0
0
0
0
0 
$\left[{ }^{68} \mathrm{Ga}\right] \mathrm{Ga}$-PSMA-11 vs $\left[{ }^{18} \mathrm{~F}\right] \mathrm{F}-\mathrm{DCFPYL}$ PET/CT in patients with a $B C R$ after radical prostatectomy

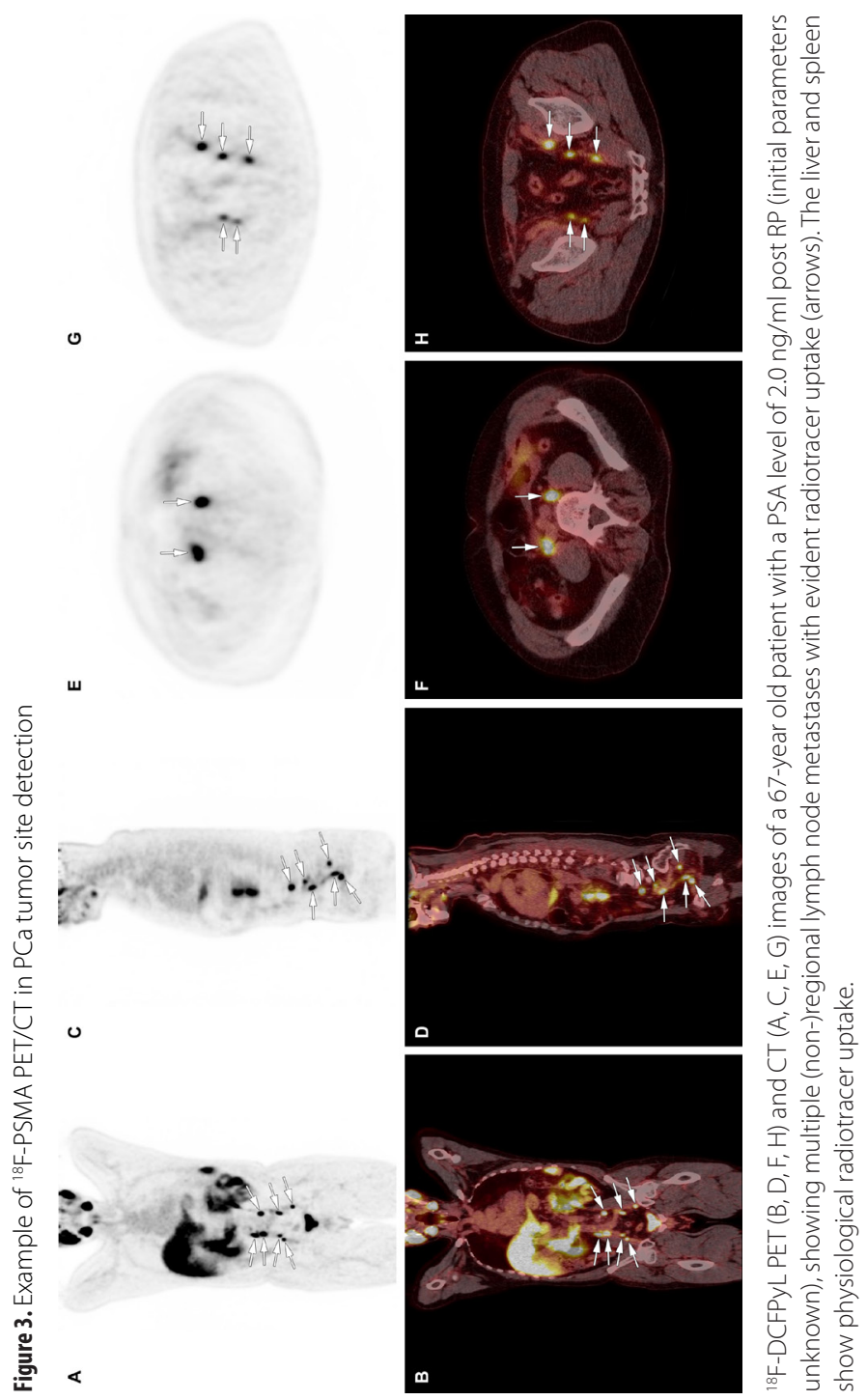


Part I|Prostate cancer imaging

Table 3. Detected sites of recurrence

\begin{tabular}{|c|c|c|c|}
\hline Presence of PCa (n, \%) & $\begin{array}{c}{ }^{68} \mathrm{Ga}-\mathrm{PS} M A \\
(\mathrm{n}=\mathbf{8 0})\end{array}$ & $\begin{array}{c}{ }^{18} \text { F-DCFPyL } \\
(n=76)\end{array}$ & Difference \\
\hline Local recurrence (T-stage) & & & NS $(0.10)^{*}$ \\
\hline No lesion(s) & $73(91.3)$ & $62(81.6)$ & \\
\hline Prostate region & $3(3.8)$ & $11(14.5)$ & \\
\hline Vesicles & $1(1.3)$ & $3(3.9)$ & \\
\hline Unclear & $3(3.8)$ & 0 & \\
\hline Regional lymph nodes (N-stage) & & & $\operatorname{NS}(0.17)^{*}$ \\
\hline No lesion(s) & $42(52.5)$ & $37(55.2)$ & \\
\hline 1 & $18(22.5)$ & $12(15.8)$ & \\
\hline 2 & $11(13.8)$ & $6(7.9)$ & \\
\hline 3 & $3(3.8)$ & $2(2.6)$ & \\
\hline 4 & $2(2.5)$ & $6(7.9)$ & \\
\hline 5 lesions & $2(2.5)$ & $3(3.9)$ & \\
\hline$>5$ lesions & $2(2.5)$ & $10(13.2)$ & \\
\hline Non-regional lymph nodes (M1a-stage) & & & $\operatorname{NS}(0.95)^{*}$ \\
\hline No lesion(s) & $64(80.0)$ & $61(80.3)$ & \\
\hline 1 & $7(8.8)$ & $6(7.9)$ & \\
\hline 2 & $2(2.5)$ & $3(3.9)$ & \\
\hline 3 & $2(2.5)$ & $2(2.6)$ & \\
\hline 4 & 0 & $1(1.3)$ & \\
\hline 5 lesions & 0 & 0 & \\
\hline$>5$ lesions & 5 & $3(3.9)$ & \\
\hline Bone lesions (M1b-stage) & & & NS $(0.09)^{*}$ \\
\hline No lesion(s) & $72(90.0)$ & $61(80.2)$ & \\
\hline 1 & $4(5.0)$ & $8(10.5)$ & \\
\hline 2 & $2(2.5)$ & $5(6.6)$ & \\
\hline 3 & 0 & 0 & \\
\hline 4 & 0 & 0 & \\
\hline 5 lesions & 0 & 0 & \\
\hline$>5$ lesions & $2(2.5)$ & $2(2.6)$ & \\
\hline Visceral lesions (M1c-stage) & & & $\operatorname{NS}(0.05)^{*}$ \\
\hline No lesion(s) & $76(95.0)$ & $76(100.0)$ & \\
\hline 1 & $2(2.5)$ & 0 & \\
\hline$>1$ lesion & $2(2.5)$ & 0 & \\
\hline
\end{tabular}

*Kruskal Wallis Test 
Table 4. Detected sites of recurrence in a selected subgroup (primary BCR patients) of the study population

\begin{tabular}{|c|c|c|c|}
\hline Presence of PCa (n, \%) & $\begin{array}{c}{ }^{68} \mathrm{Ga}-\mathrm{PS} M A \\
(\mathrm{n}=29)\end{array}$ & $\begin{array}{c}{ }^{18} \mathrm{~F}-\mathrm{DCFPyL} \\
(\mathrm{n}=46)\end{array}$ & Difference \\
\hline Local recurrence (T-stage) & & & NS $(0.67)^{*}$ \\
\hline No lesion(s) & $25(86.2)$ & $37(80.4)$ & \\
\hline Prostate region & $1(3.4)$ & $7(15.2)$ & \\
\hline Vesicles & 0 & $2(4.3)$ & \\
\hline Unclear & $3(10.3)$ & 0 & \\
\hline Regional lymph nodes (N-stage) & & & NS $(0.43)^{*}$ \\
\hline No lesion(s) & $18(62.1)$ & $25(54.3)$ & \\
\hline 1 & $4(13.8)$ & $7(15.2)$ & \\
\hline 2 & $1(3.4)$ & $4(8.7)$ & \\
\hline 3 & $2(6.9)$ & 0 & \\
\hline 4 & $2(6.9)$ & $2(4.3)$ & \\
\hline 5 lesions & $1(3.4)$ & $3(6.5)$ & \\
\hline$>5$ lesions & $1(3.4)$ & $5(10.9)$ & \\
\hline Non-regional lymph nodes (M1a-stage) & & & NS $(0.93)^{*}$ \\
\hline No lesion(s) & $26(89.7)$ & $41(89.1)$ & \\
\hline 1 & $2(6.9)$ & $3(6.5)$ & \\
\hline 2 & 0 & 0 & \\
\hline 3 & $1(3.4)$ & $1(2.2)$ & \\
\hline 4 & 0 & 0 & \\
\hline 5 lesions & 0 & 0 & \\
\hline$>5$ lesions & 0 & $1(2.2)$ & \\
\hline Bone lesions (M1b-stage) & & & NS $(0.48)^{*}$ \\
\hline No lesion(s) & $25(86.2)$ & $36(78.3)$ & \\
\hline 1 & $1(3.4)$ & $5(10.9)$ & \\
\hline 2 & $1(3.4)$ & $4(8.7)$ & \\
\hline 3 & 0 & 0 & \\
\hline 4 & 0 & 0 & \\
\hline 5 lesions & 0 & 0 & \\
\hline$>5$ lesions & $2(6.9)$ & $1(2.2)$ & \\
\hline Visceral lesions (M1c-stage) & & & $\operatorname{NS}(0.21)^{*}$ \\
\hline No lesion(s) & $28(96.6)$ & $46(100.0)$ & \\
\hline 1 & $1(3.4)$ & 0 & \\
\hline$>1$ lesions & 0 & 0 & \\
\hline
\end{tabular}

*Kruskal Wallis Test 
$(p=0.17)$ or bone lesions $(p=0.09)$ in both groups. In the ${ }^{68} \mathrm{Ga}-\mathrm{PSMA}-11$ group, visceral metastases were slightly more frequently detected ( $p=$ 0.05). For the sub-analysis of 75 primary BCR patients, in which patients who underwent any type of previous salvage treatments were excluded (three patients with unknown previous therapies were also excluded), the number and site of detected lesions was summarized in Table 4. Local recurrences, (non-)regional lymph nodes, bone lesions and visceral lesions were detected equally frequent in both patient groups.

\section{DISCUSSION}

This retrospective study compares diagnostic performance of ${ }^{68} \mathrm{Ga}$ PSMA PET/CT with ${ }^{18} \mathrm{~F}$-DCFPyL PET/CT in a large cohort of post-radical prostatectomy $\mathrm{PCa}$ patients with a primary and secondary BCR. Both overall and PSA stratified detection rates of ${ }^{68} \mathrm{Ga}$-PSMA PET versus ${ }^{18} \mathrm{~F}-\mathrm{DCFPYL}$ were similar. Both tracers performed well at low PSA levels.

Our findings approach the previously published results in a meta-analysis on ${ }^{68} \mathrm{Ga}$-PSMA PET/CT, in which a detection rate of $63 \%$ and $94 \%$ was described in patient groups with PSA levels of $<2.0$ and $>2.0$, respectively [6]. One study directly compared diagnostic performance of ${ }^{68} \mathrm{Ga}-\mathrm{PSMA}$ to ${ }^{18} \mathrm{~F}-\mathrm{DCFPyL}$ in the setting of BCR. This retrospective study by Dietlein et al. included 106 patients with BCR after radical prostatectomy [11]. Results were stratified for PSA levels. In the group with PSA levels ranging from 0.5-3.5 ng/ml, ${ }^{18} \mathrm{~F}-\mathrm{DCF} P y \mathrm{~L}$ showed significantly higher detection rate than ${ }^{68} \mathrm{Ga}$-PSMA (88\% versus 66\%, respectively; $p=0.042$ ). In patients with PSA levels $<0.5 \mathrm{ng} / \mathrm{ml}$ and $>3.5 \mathrm{ng} / \mathrm{ml}$, sensitivity of both radiotracers was found to be equal ( $<15 \%$ and $>85 \%$, respectively). These findings are in contrast with the results of another study, showing a detection rate of ${ }^{18} \mathrm{~F}-\mathrm{DCFP} y \mathrm{~L}$ of approximately $60 \%$ in patients with PSA levels $<0.5 \mathrm{ng} / \mathrm{ml}$ [7].

In the study by Dietlein et al., 25 patients received both ${ }^{68} \mathrm{Ga}-\mathrm{PSMA}$ and ${ }^{18} \mathrm{~F}-\mathrm{DCFPYL}$ PET/CT. In this subgroup, distribution patterns of both tracers were found to be similar, however ${ }^{18} \mathrm{~F}$-DCFPyL detected additional lesions in $36 \%$ of these patients. In the present study, the increased detection rate 
of ${ }^{18} \mathrm{~F}$-DCFPyL was not confirmed. Compared to the findings of Dietlein et al., who described $66 \%$ vs $88 \%$ positive scans in the ${ }^{68} \mathrm{Ga}-\mathrm{PSMA}$ and the ${ }^{18}$ F-DCFPyL group respectively, our study shows a similar detection rate for ${ }^{68} \mathrm{Ga}-\mathrm{PSMA}$ (73.8\% positive scans) and ${ }^{18} \mathrm{~F}-\mathrm{DCFPyL}$ (72.4\% positive scans).

The histopathological $\mathrm{N}$-status and the number of previous salvage therapies between the patients included in the ${ }^{68} \mathrm{Ga}$-PSMA versus the ${ }^{18}$ F-DCFPyL-group of our study was significantly different (Table $\mathbf{1}$ ), indicating a more intensively pre-treated patient group that was scanned with ${ }^{68} \mathrm{Ga}$-PSMA (i.e. derived from an academic, oncological referral center). Subsequently, a higher a-priori chance to detect metastases may be presumed, illustrated by the detection of visceral lesions in four patients in the ${ }^{68} \mathrm{Ga}$-PSMA cohort, while no visceral lesions were detected in the ${ }^{18} \mathrm{~F}-\mathrm{DCFPyL}$ group. However, a subgroup analysis in primary BCR patients who did not receive any salvage treatments showed no statistical differences in detection rate between both tracers either.

Early detection of local recurrence in primary BCR patients with an increasing PSA after radical prostatectomy is of paramount importance, since PSA level at onset of salvage radiation therapy was shown to be prognostic for the risk of systemic progression [12]. To detect sites of tumor recurrence, international guidelines recommend performing PSMA PET/CT imaging if PSA levels exceed $0.2 \mathrm{ng} / \mathrm{ml}$. Imaging results will influence subsequent treatment regimens. Whereas both ${ }^{18} \mathrm{~F}$ - and ${ }^{68} \mathrm{Ga}-$ labeled PSMA tracers appear safe, provide intense tumor uptake and high tumor-to-background ratio's [15], ${ }^{18} \mathrm{~F}$-labeled PSMA tracers have some technical advantages. The isotope ${ }^{18} \mathrm{~F}$ has an intrinsically shorter positron range and higher positron yield, offering higher PET image resolution, and resulting in potentially improved detection of small lesions, though not confirmed in the present study [16]. Furthermore, ${ }^{18} \mathrm{~F}$ is a cyclotronproduct, allowing for centralized production and commercial distribution of ${ }^{18} \mathrm{~F}$-labeled PSMA-tracers. This may contribute to better availability of the tracer. 
Some limitations of this retrospective study must be addressed. Firstly, due to the multicenter nature of the study, different scanners and scan protocols (with or without co-administration of furosemide) were used, potentially leading to differences in image quality and subsequent tumor detection. Furthermore, different readers in separate centers evaluated all PSMA PET/CT scans in conformance with clinical practice. On the one hand, blinded reading would favor the validity of the findings; on the other hand, the used approach translates well to current clinical practice. Validation of the PET-based suspected lesions was not performed since this should be investigated in future prospective studies. However, a high specificity of ${ }^{68} \mathrm{Ga}$-PSMA PET/CT and ${ }^{18} \mathrm{~F}$-DCFPyL PET/CT for detection of lymph node metastases was demonstrated in validation studies comparing PET results to histopathology in initial staging of PCa $[6,10]$. Furthermore, new insights indicate that ${ }^{18} \mathrm{~F}$-DCFPyL might outperform detection efficacy of ${ }^{68} \mathrm{Ga}$-PSMA PET/CT in patients with PSA levels below $0.5 \mathrm{ng} / \mathrm{ml}$ [7]. Unfortunately, this patient group was not included in this study.

\section{CONCLUSIONS}

Diagnostic performance of ${ }^{68} \mathrm{Ga}$-PSMA versus ${ }^{18} \mathrm{~F}-\mathrm{DCFPyL}$ appears comparable in restaging of patients with a primary or secondary BCR after radical prostatectomy. Our findings provide a rationale for implementation of both tracers in daily clinical practice, according to local availability. 


\section{REFERENCES}

1. Ferlay J, Colombet M, Soerjomataram I, Dyba T, Randi G, Bettio M, et al. Cancer incidence and mortality patterns in Europe: Estimates for 40 countries and 25 major cancers in 2018. Eur J Cancer. 2018 Aug 9.

2. American Cancer Society. Key statistics for Prostate Cancer [internet]. Atlanta, USA. American Cancer Society; 2019 [cited 2019 Aug 9]. Available from: https://www.cancer.org/cancer/prostate-cancer/about/key-statistics.html

3. Heidenreich A, Bastian PJ, Bellmunt J, Bolla M, Joniau S, van der Kwast T, et al. EAU Guidelines on Prostate Cancer. Part II: Treatment of Advanced, Relapsing, and Castration-Resistant Prostate Cancer. Eur Urol. 2014 Feb;65(2):467-79.

4. Stephenson AJ, Scardino PT, Kattan MW, et al. Predicting the outcome of salvage radiation therapy for recurrent prostate cancer after radical prostatectomy. J Clin Oncol. 2007 May 20;25(15):2035-41.

5. Mannweiler S, Amersdorfer P, Trajanoski S, Pisansky TM, Slawin KM, Klein EA, et al. Heterogeneity of prostate-specific membrane antigen (PSMA) expression in prostate carcinoma with distant metastasis. Pathol Oncol Res. 2009 Jun;15(2):167-72.

6. Hope TA, Goodman JZ, Allen IE, Calais J, Fendler WP, Carroll PR, et al. Metaanalysis of ${ }^{68} \mathrm{Ga}-\mathrm{PSMA}-11$ PET Accuracy for the Detection of Prostate Cancer Validated by Histopathology. J Nucl Med. 2018 Dec 7.

7. Wondergem M, Jansen BHE, van der Zant FM, van der Sluis TM, Knol RJJ, van Kalmthout LWM, et al. Early lesion detection with 18F-DCFPyL PET/CT in 248 patients with biochemically recurrent prostate cancer. Eur J Nucl Med Mol Imaging. 2019 Aug;46(9):1911-1918.

8. Giesel FL, Knorr K, Spohn F, Will L, Maurer T, Flechsig P, et al. Detection efficacy of [(18)F]PSMA-1007 PET/CT in 251 Patients with biochemical recurrence after radical prostatectomy. J Nucl Med. 2018.

9. Rahbar K, Afshar-Oromieh A, Seifert R, Wagner S, Schafers M, Bogemann $M$, et al. Diagnostic performance of (18)F-PSMA-1007 PET/CT in patients with biochemical recurrent prostate cancer. Eur J Nucl Med Mol Imaging. 2018;45(12):2055-61.

10. Gorin MA, Rowe SP, Patel HD, Vidal I, Mana-Ay M, Javadi MS, et al. Prostate Specific Membrane Antigen Targeted ${ }^{18}$ F-DCFPyL Positron Emission Tomography/Computerized Tomography for the Preoperative Staging of High Risk Prostate Cancer: Results of a Prospective, Phase II, Single Center Study. J Urol. 2018 Jan;199(1):126-132.

11. Dietlein F, Kobe C, Neubauer S, Schmidt M, Stockter S, Fischer T, et al. PSA-Stratified Performance of 18F- and 68Ga-PSMA PET in Patients with Biochemical Recurrence of Prostate Cancer. J Nucl Med. 2017 Jun;58(6):947952. 
Part I|Prostate cancer imaging

12. Fossati N, Karnes RJ, Colicchia M, Boorjian SA, Bossi A, Seisen T, et al. Impact of Early Salvage Radiation Therapy in Patients with Persistently Elevated or Rising Prostate-specific Antigen After Radical Prostatectomy. Eur Urol. 2017 Aug 2. pii: S0302-2838(17)30655-3.

13. Ravert HT, Holt DP, Chen Y, Mease RC, Fan H, Pomper MG, et al. An improved synthesis of the radiolabeled prostate-specific membrane antigen inhibitor, [(18) F]DCFPyL. J Labelled Comp Radiopharm. 2016;59(11):439-50.

14. Boellaard R, Delgado-Bolton R, Oyen WJG, Giammarile F, Tatsch K, Eschner W, et al. FDG PET/CT: EANM procedure guidelines for tumour imaging: version 2.0. Eur J Nucl Med Mol Imaging. 2015 42:328-354

15. Lütje S, Heskamp S, Cornelissen AS, PoeppelTD, van den Broek SA, RosenbaumKrumme S, et al. PSMA Ligands for Radionuclide Imaging and Therapy of Prostate Cancer: Clinical Status. Theranostics. 2015 Oct 18;5(12):1388-401.

16. Rowe SP, Gorin MA, Allaf ME, Pienta KJ, Tran PT, Pomper MG, et al. PET imaging of prostate-specific membrane antigen in prostate cancer: current state of the art and future challenges. Prostate Cancer Prostatic Dis. 2016 Sep;19(3):223-30. 


\section{SUPPLEMENTARY MATERIAL}

Supplementary Table 1. Baseline characteristics of a selected subgroup (primary BCR patients) of the study population

\begin{tabular}{|c|c|c|c|}
\hline & $\begin{array}{c}{ }^{68} \mathrm{Ga}-\mathrm{PSMA} \\
(\mathrm{n}=29)\end{array}$ & $\begin{array}{c}{ }^{18} \text { F-DCFPyL } \\
(n=46)\end{array}$ & p-value \\
\hline Mean age (y; range) & $66(49-83)$ & $71(61-80)$ & $0.01^{*}$ \\
\hline Mean PSA level (ng/ml), (range) & $1.5(0.5-3.4)$ & $1.4(0.5-3.3)$ & $0.48^{*}$ \\
\hline \multicolumn{3}{|l|}{ Initial pT-stage (n, \%) } & $0.65^{* *}$ \\
\hline $\mathrm{T} 2 \mathrm{a}$ & $3(10.3)$ & $1(2.2)$ & \\
\hline $\mathrm{T} 2 \mathrm{~b}$ & $2(6.9)$ & $1(2.2)$ & \\
\hline $\mathrm{T} 2 \mathrm{c}$ & $6(20.7)$ & $11(23.9)$ & \\
\hline T3a & $12(41.4)$ & $7(15.2)$ & \\
\hline $\mathrm{T} 3 \mathrm{~b}$ & $5(17.2)$ & $7(15.2)$ & \\
\hline T4 & 0 & $1(2.2)$ & \\
\hline Missing & $1(3.4)$ & $18(39.1)$ & \\
\hline \multicolumn{3}{|c|}{ Histopathological ISUP Grade Group (n, \%) } & $0.06^{* * *}$ \\
\hline 1 & $7(24.1)$ & 0 & \\
\hline 2 & $6(20.4)$ & $7(15.2)$ & \\
\hline 3 & $5(17.2)$ & $3(6.5)$ & \\
\hline 4 & $3(10.3)$ & $3(6.5)$ & \\
\hline 5 & $6(20.7)$ & $10(21.7)$ & \\
\hline Missing & $2(6.9)$ & $18(39.1)$ & \\
\hline \multicolumn{3}{|l|}{ Resection status after RP } & $0.89 * *$ \\
\hline RO & $13(44.8)$ & $14(30.4)$ & \\
\hline R1 & $13(44.8)$ & $13(28.3)$ & \\
\hline Missing & $3(10.3)$ & $19(41.3)$ & \\
\hline \multicolumn{3}{|l|}{ Histopathological N-status } & $0.18^{* *}$ \\
\hline $\mathrm{N}-$ & $9(31.0)$ & $13(29.3)$ & \\
\hline $\mathrm{N}+$ & $7(24.1)$ & $2(4.3)$ & \\
\hline No PLND performed & $12(41.4)$ & $17(37.0)$ & \\
\hline Missing & $1(3.4)$ & $14(30.4)$ & \\
\hline
\end{tabular}

*Independent samples t-test; ${ }^{* *}$ Kruskal Wallis Test; ${ }^{* * *}$ Mann Whitney U test 
Part I|Prostate cancer imaging

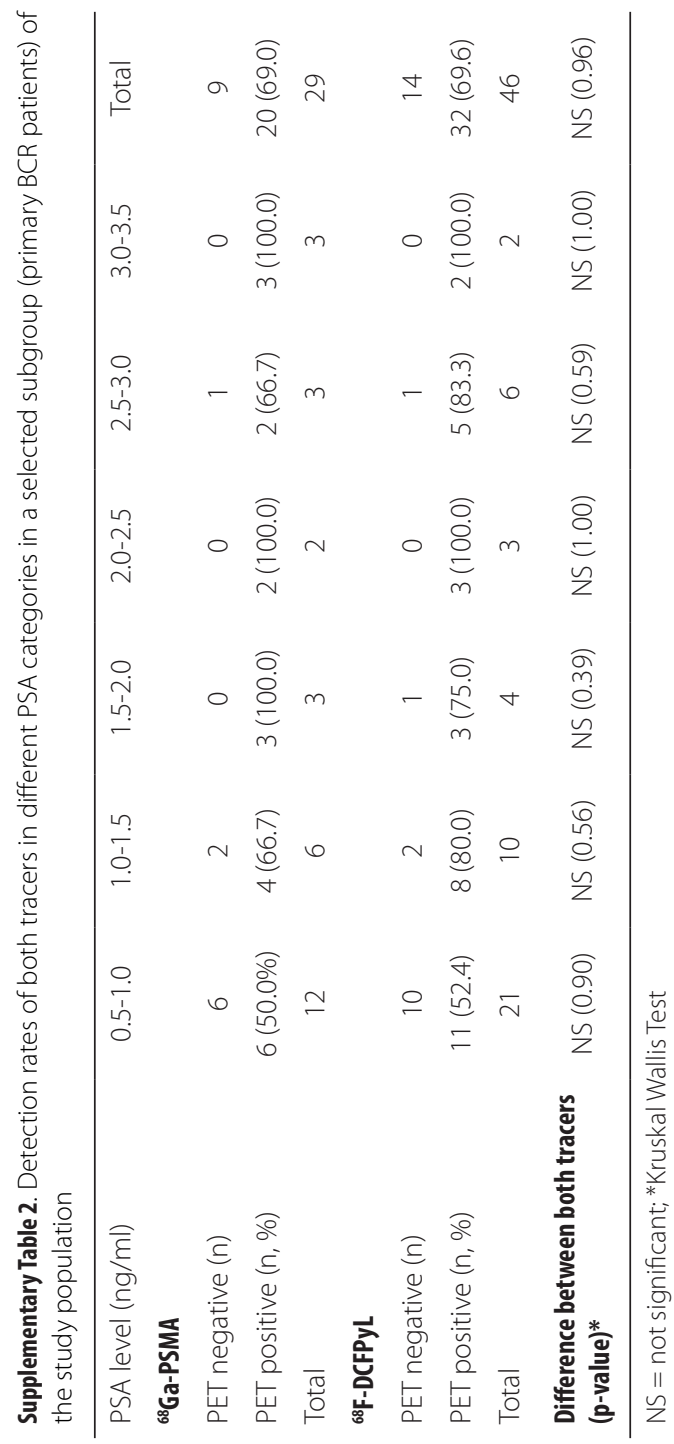




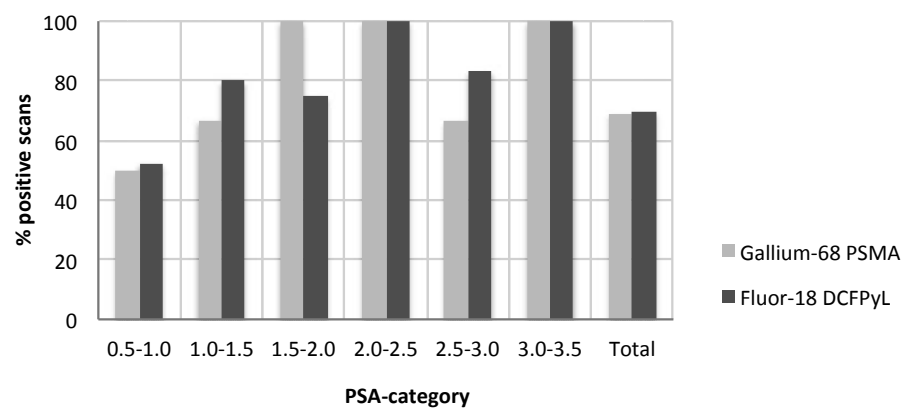

Supplementary Figure 1. Detection rates of both tracers per PSA category 



\section{PART II}

PROSTATE CANCER THERAPY

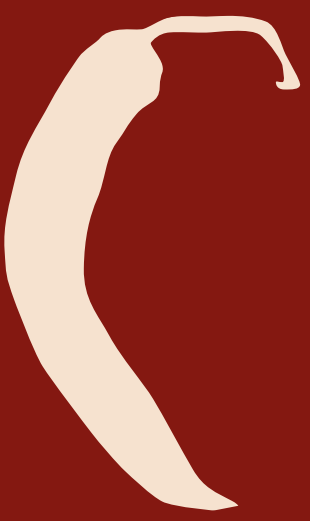





\section{CHAPTER 5}

Case report

Toepassing van [ ${ }^{177}$ Lu]Lu-PSMA bij een patiënt met gemetastaseerd castratieresistent prostaatcarcinoom

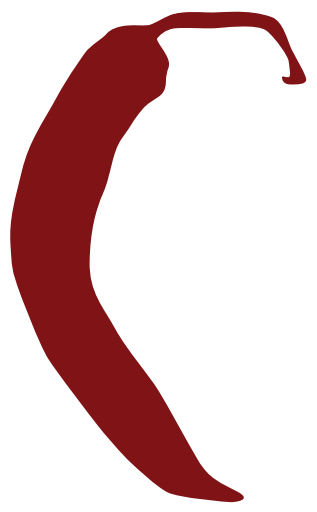

L.W.M. van Kalmthout, A.J.A.T. Braat, G.C. Krijger,

T.F. Ververs, R. de Roos, B. de Keizer, M.G.E.H. Lam

Tijdschrift voor Urologie, 8, pages 16-18 (2018) 


\section{ABSTRACT}

In December 2016, the first patient in the Netherlands was treated with lutetium-177 'prostate specific membrane antigen' ( ${ }^{177} \mathrm{Lu}$-PSMA) therapy; a promising application of radionuclide therapy in prostate carcinoma. This article discusses the working mechanism of ${ }^{177}$ Lu-PSMA therapy. Furthermore, an overview of the published literature on this specific subject is presented.

\section{NEDERLANDSE SAMENVATTING}

In December 2016 werd de eerste patiënt in Nederland behandeld met lutetium-177 'prostaat specifiek membraan antigeen' ( ${ }^{177} \mathrm{Lu}-\mathrm{PSMA}$ ) therapie; een veelbelovende toepassing van radionuclidentherapie bij prostaatcarcinoom. Aan de hand van deze casus beschrijft het artikel het werkingsmechanisme van behandeling middels ${ }^{177}$ Lu-PSMA en wordt een kort overzicht van het tot nu toe verkregen wetenschappelijk bewijs verschaft.

\section{INLEIDING}

Voor gemetastaseerde, castratie-resistente prostaatkanker patiënten is momenteel een aantal behandelingsopties voor handen, zoals niet-steroïdale testosteronreceptorblokkers (enzalutamide), CYP17A1blokkers (abiraterone), chemotherapeutica (docetaxel en cabazitaxel) en radionuclidentherapie bij botmetastasen (radium-223-dichloride). Ondanks de ontwikkeling van bovengenoemde middelen, bestaat er nog steeds grote behoefte aan nieuwe behandelopties met minder bijwerkingen en een gunstiger effect op overleving.

Het transmembraaneiwit glutamate carboxypeptidase II (GCPII), ook wel PSMA (Prostaat Specifiek Membraan Antigeen) genoemd, wordt in vergelijking met benigne prostaatcellen door prostaatkankercellen verhoogd tot expressie gebracht. PSMA vormt daarmee een bruikbaar doelwit voor diagnostiek en therapie van prostaatkanker middels radioactief gelabelde liganden. Wanneer PSMA-liganden worden gekoppeld aan bijvoorbeeld gallium-68 $\left({ }^{68} \mathrm{Ga}\right)$, kunnen zowel de primaire tumor als 
metastasen middels PET-imaging in beeld worden gebracht. Wanneer het PSMA-ligand gekoppeld wordt aan een bèta-straler, bijvoorbeeld lutetium-177 ( $\left.{ }^{177} \mathrm{Lu}\right)$, kunnen tumorcellen zeer lokaal worden bestraald. ${ }^{177}$ Lu-PSMA wordt intraveneus toegediend op de afdeling Nucleaire Geneeskunde. Patiënten krijgen tot 6 behandelcycli met een interval van 6 - 8 weken; afhankelijk van de individuele biochemische respons (PSA-daling), de respons op beeldvorming (stapeling van activiteit in metastasen en toename/afname van metastasen op post-injectie skeletscintigrafie) en tolerantie. Per cyclus wordt op dit moment een activiteit van $6 \mathrm{GBq}$ toegediend. ${ }^{177} \mathrm{Lu}$-PSMA wordt 'in-house' magistraal bereid onder GMP(-Z) condities.

\section{CASUS}

In december 2016 werd voor het eerst in Nederland een prostaatkankerpatiënt behandeld met ${ }^{177}$ Lu-PSMA. Bij deze 78-jarige man verergerden de pijnklachten en steeg het PSA door tot $890 \mathrm{ng} / \mathrm{ml}$ na initiële behandeling middels maximale androgeenblokkade, enzalutamide en radium-223-dichloride. Voorafgaand aan de behandeling werden de pijnklachten (Visual Analoge Scale 8) bestreden met oxycontin, NSAID's en paracetamol/coffeïne, waarbij patiënt last had van opiaat geïnduceerde obstipatie, waarvoor laxantia. Binnen 1 week na de eerste cyclus met 6 GBq ${ }^{177}$ Lu-PSMA in december 2016 was zowel pijnstilling (oxycontin en paracetamol/coffeïne) als laxantiagebruik niet meer noodzakelijk. Het PSA daalde naar 280 ng/ml. In februari 2017 kreeg patiënt de $2^{e}$ cyclus ${ }^{177} \mathrm{Lu}-$ PSMA toegediend, waarna het PSA verder daalde naar $84 \mathrm{ng} / \mathrm{ml}$. Er werd geen beenmergdepressie of andere toxiciteit gezien. De follow-up PSMA PET/CT na twee cycli toonde forse afname van de bekende metastasen (Afbeelding 1B) in vergelijking met de baseline PSMA PET/CT (Afbeelding 1A). De derde en vierde cyclus ${ }^{177}$ Lu-PSMA volgden in maart en mei 2017; hierbij daalde het PSA verder door naar 22 en $10 \mathrm{ng} / \mathrm{ml}$, respectievelijk (totale PSA-daling van 98.9\%). Beenmergdepressie en klinische toxiciteit bleef uit en ook de pijnklachten bleven weg. De PSMA-PET/CT 5 weken na de $4^{\mathrm{e}}$ cyclus toonde verdere tumorregressie (Afbeelding 1C). Op de PSMA PET/CT 3 maanden na de vierde en laatste cyclus werd een verdere afname van de ossale metastasen, maar toename van de primaire tumor 

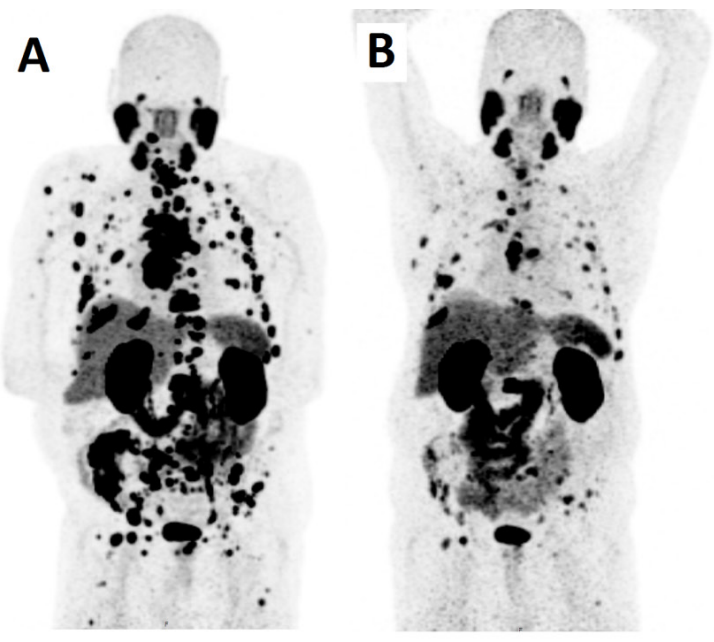

\section{C}
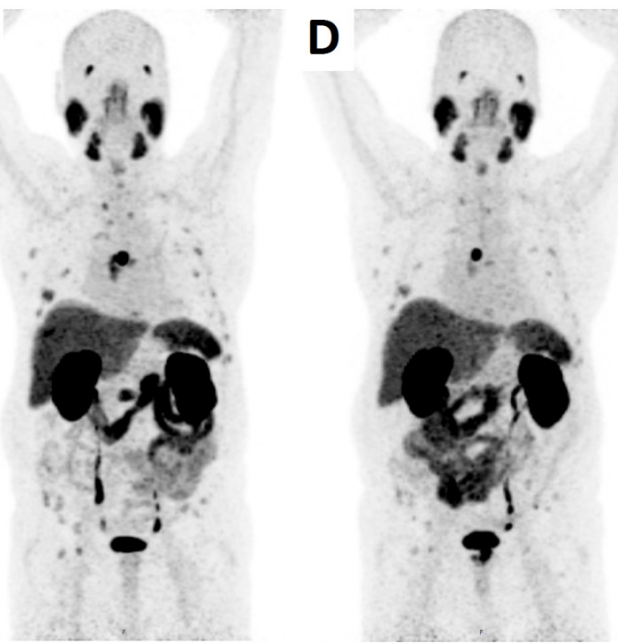

Afbeelding 1. Baseline (A) en follow-up (B na 2 cycli; $C$ na 4 cycli; D na 4 cycli + drie maanden follow-up) PSMA PET/CT van een patiënt met gemetastaseerd, castratieresistent prostaatcarcinoom, die vanaf december 2016 werd behandeld middels ${ }^{177}$ Lu-PSMA. 
gezien (Afbeelding 1D). Vanwege de goede klinische en biochemische respons werd in oktober besloten om voorlopig af te wachten. Patiënt zal poliklinisch worden vervolgd; afhankelijk van de beeldvorming zal in januari 2018 het vervolgbeleid worden bepaald.

\section{DISCUSSIE}

Kleinschalige onderzoeken in heterogene studiecohorten beschrijven de effectiviteit van behandeling middels ${ }^{177}$ Lu-PSMA aan de hand van uitkomstmaten als veiligheid, antitumor respons (PSA-daling en afname van tumorload op beeldvorming) en klinische uitkomsten (ECOG performance status en ernst van de pijn). Binnen deze studies, waarin totaal 162 patiënten worden beschreven, leidde behandeling met ${ }^{177} \mathrm{Lu}$-PSMA tot $>30 \%$ en $>50 \%$ PSA-daling in respectievelijk $60 \%$ (range $29-82 \%$ ) en 50\% (range $24-73 \%$ ) van de bestudeerde patiënten. ${ }^{2}$ Direct na behandeling werden in deze studies geen toxische effecten gerapporteerd. Toxische lange termijneffecten waren mild en omvatten anemie (5-43\%), leukopenie (7-20\%) en trombocytopenie (10-23\%). De belangrijkste niet-hematologische bijwerking was tijdelijke xerostomie (4-37\%).

Tot op heden is weinig bekend over het effect op overleving. In een kleine retrospectieve studie werden 28 patiënten behandeld met ${ }^{177}$ Lu-PSMA vergeleken met een historische controlegroep van 20 vergelijkbare patiënten met best supportive care, waarbij een significant langere overleving werd beschreven in de ${ }^{177} \mathrm{Lu}$-PSMA groep ( 29 weken versus 20 weken; $p=0.032 ; 95 \% \mathrm{Cl}$ 0.20-0.95). ${ }^{3}$ In een recent gepubliceerde multicenter retrospectieve studie ondergingen 145 gemetastaseerde castratieresistente patiënten 1-4 cycli met ${ }^{177} \mathrm{Lu}$ PSMA. ${ }^{4}$ De gemiddeld toegediende activiteit ${ }^{177} \mathrm{Lu}$-PSMA per cyclus was $5.9 \mathrm{GBq}$ (range 2-8 GBq). Bij 45\% van de patiënten werd een PSAdaling $>50 \%$ gezien na meerdere cycli toediening van ${ }^{177} \mathrm{Lu}-\mathrm{PSMA}$. Met betrekking tot lange termijneffecten werd bij 18/145 patiënten matigernstige hematotoxiciteit gerapporteerd: 10\%, 4\%, en 3\% respectievelijk een anemie, thrombocytopenie, en leukopenie (volgens de Common Terminology Criteria for Adverse Events = CTCAE-graad 3 of 4). Milde 
klachten van xerostomie werden gezien bij $8 \%$ van de patiënten. Meest voorkomende klinische toxiciteit was milde vermoeidheid in 13\% (CTCAE graad 1-2). Therapie-gerelateerd overlijden kwam niet voor.

Tot voor kort was behandeling middels ${ }^{177}$ Lu-PSMA uitsluitend in Duitse centra beschikbaar, maar met ingang van december 2016 wordt deze toepassing ook in het UMC Utrecht aangeboden; uitsluitend een salvage setting bij uitbehandelde patiënten binnen de wettelijke kaders die daarvoor gelden. Andere centra zoals het Radboud UMC, het Erasmus MC, Nederlands Kanker Instituut-AvL en het St. Antonius Ziekenhuis exploreren momenteel mogelijkheden voor het opstarten van deze toepassing. De behandelingen met ${ }^{177} \mathrm{Lu}$-PSMA worden door het UMC Utrecht zelf gefinancierd. Tot op heden zijn in deze setting 27 patiënten behandeld. De data die -vooralsnog buiten studieverband- op deze manier worden gegenereerd, zullen retrospectief worden geanalyseerd en zullen als externe validatie dienen van de tot nu toe gepubliceerde Duitse resultaten. Daarnaast wordt een wetenschappelijke basis gevormd voor de opzet en financiering van prospectieve studies, waarin o.a. dosimetrie, dosisescalatie en de effectiviteit ten opzichte van best supportive care kan worden onderzocht. Mogelijkheden voor de opzet van een landelijke prospectieve studie worden momenteel onderzocht door een Nederlands consortium. Het is uiteraard van groot belang dat de meerwaarde van deze behandeling prospectief en gecontroleerd uitgevoerd wordt.

\section{CONCLUSIE}

${ }^{177}$ Lu-PSMA is een veelbelovende behandeling voor gemetastaseerde castratieresistente prostaatkankerpatiënten, waarbij de hiervoor geregistreerde therapieën geen soelaas meer bieden of ongewenst dan wel gecontra-indiceerd zijn. Gerandomiseerd prospectief onderzoek zal moeten uitwijzen welke groepen patiënten zich voor deze therapie kwalificeren en in welk stadium van het ziekteproces de toepassing van ${ }^{177}$ Lu-PSMA het meest zinvol is. Ookzal meer opgehelderd moeten worden over de effectiviteit en lange termijneffecten wat betreft oncologische uitkomsten en overleving. 


\section{LITERATUURLIJST}

1. www.cijfersoverkanker.nl

2. Braat AJAT, Ahmadzadehfar. Lutetium-177 labelled PSMA ligands for the treatment of metastatic castrate-resistant prostate cancer. Tijdschr Nucl Geneesk. 2016;38:1627-34

3. Rahbar K, Bode A, Weckesser M et al. Radioligand Therapy With 177LuPSMA-617 as A Novel Therapeutic Option in Patients With Metastatic Castration Resistant Prostate Cancer. Clin Nucl Med. 2016;41:522-8

4. Rahbar K, Ahmadzadehfar H, Kratochwil C et al. German Multicenter Study Investigating ${ }^{177}$ Lu-PSMA-617 Radioligand Therapy in Advanced Prostate Cancer Patients. J Nucl Med. 2017;58:85-90 



\section{CHAPTER 6}

First experience with [ $\left.{ }^{177} \mathrm{Lu}\right] \mathrm{Lu}-\mathrm{PSMA}-617$ therapy for advanced prostate cancer in the Netherlands

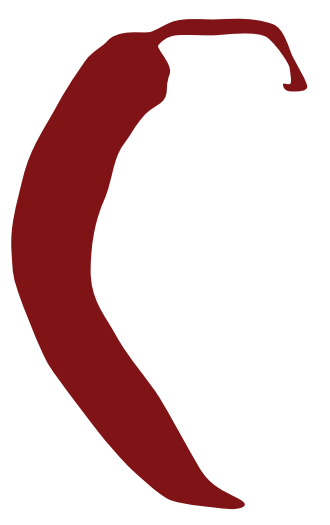

L.W.M. van Kalmthout, A.J.A.T. Braat, M.G.E.H. Lam,

R.S. van Leeuwaarde, G.C. Krijger, F.F.T. Ververs, N. Mehra, A. Bins, C.B. Hunting, B. de Keizer

Clinical Nuclear Medicine. 2019 Jun;44(6):446-451. 


\section{ABSTRACT}

\section{Purpose of the Report}

The present study summarizes the first experience with Lutetium177-PSMA-617 (177Lu-PSMA) treatment in metastatic Castrate Resistant Prostate Cancer (CRPC) in our institution.

\section{Materials and methods}

Analysis of the first 30 consecutive patients who underwent ${ }^{177}$ Lu-PSMA therapy. Biochemical response was defined as $\geq 50 \%$ PSA decrease. Clinical toxicity was based on standardized physician's report and biochemical and hematological toxicity was graded according to the common toxicity criteria for adverse events (CTCAE)-criteria. Clinical response was objectified in terms of severity of pain and usage of analgesics after separate treatment cycles.

\section{Results}

Thirty patients with advanced prostate cancer received therapy cycles with 6 GBq Lu-177-PSMA-617 (median 4; range 1 - 6). After the first cycle, usage of analgesics decreased in $45 \%$ of the patients. During treatment, maximum PSA decrease was $\geq 50 \%$ and $\geq 90 \%$ in $57 \%$ and $24 \%$ of the patients, respectively. Despite CTCAE-grade III and IV anemia occurring in two patients (7\%), all other newly originated biochemical toxicity was limited to maximum CTCAE grade I-II. Grade II xerostomia occurred in 17\% of the patients. During a median follow-up length of 13.7 (range: 9.8-32.3) months, median overall survival from start of the first therapy cycle was 11.3 (range 1.4-32.3) months.

\section{Conclusions}

These results confirm the favorable safety and efficacy profile of ${ }^{177} \mathrm{Lu}$ PSMA-617, even up to six treatment cycles. Therefore, ${ }^{177} \mathrm{Lu}$-PSMA seems a promising therapeutic strategy for metastatic CRPC patients. However, randomized-controlled trials are warranted to obtain robust data. 


\section{INTRODUCTION}

Prostate cancer (PCa) is the second most common primary tumor affecting men worldwide. Since its aggressiveness tends to increase over time, this disease ultimately causes death of over 250.000 men every year. ${ }^{1}$ Despite several innovations in the treatment of metastatic castration resistant prostate carcinoma (CRPC), with chemotherapy agents (Docetaxel, Cabazitaxel) and advanced hormonal therapies (Enzalutamide, Abiraterone), there is still a profound necessity for improved treatment regimens with significant antitumor effect and minimal toxicity. In the field of nuclear medicine, systemic administration of radium-223-dichloride ${ }^{223} \mathrm{Ra}$ ) proved to be beneficial in metastatic CRPC patients suffering from symptomatic osseous metastases, in terms of improved overall survival. ${ }^{2}$ However, about one third of these patients cannot be treated with ${ }^{223} \mathrm{Ra}$ due to significant lymph node or visceral metastases, a contra indication for this therapy. ${ }^{3}$

Prostate Specific Membrane Antigen (PSMA) is a type II transmembrane glycoprotein, that is expressed and highly upregulated in both primary and metastatic PCa tissue. PSMA is a promising target for delivery of $\beta$-emitting radionuclides, such as the peptide radioligand lutetium177-PSMA-617 (177Lu-PSMA). ${ }^{4}$ After ${ }^{177}$ Lu-PSMA binds to the cell surface of prostate cancer cells, the radioligand is internalized, resulting in intracellular radiation of PCa cells, complex and clustered DNA damage and sequentially leading to 'triggered apoptosis' of cancer cells. ${ }^{5}$

Over the last years, therapy with ${ }^{177}$ Lu-PSMA-617 has been introduced into clinical practice in several institutions in Germany and Australia. Since December 2016, the University Medical Center (UMC) Utrecht in the Netherlands provides in this treatment for advanced CRPC patients. Presumably, application of ${ }^{177} \mathrm{Lu}$-PSMA will further increase during the following decades on a national and international scale. The present study summarizes our first experience with ${ }^{177}$ Lu-PSMA treatment. 


\section{MATERIALS AND METHODS}

\section{Patient population}

Patients who underwent ${ }^{177}$ Lu-PSMA-617 treatment in the UMC Utrecht from December 2016 up to September 2018 were analyzed. This product is investigational, and is not approved for clinical use. Criteria for treatment in our institution included (1) confirmed histological diagnosis of PCa and metastatic malignancy with no alternative cytotoxic treatment options, (2) $\geq 1$ previous episode of chemotherapy, hormonal therapy and either Enzalutamide or Abiraterone in past medical history and/or inadequacy to undergo chemo-/hormonal therapy, (4) World Health Organisation (WHO) performance status $\leq 2$, (5) Sufficient bone marrow capacity, defined as haemoglobin level $>5 \mathrm{mmol} / \mathrm{L}$, leukocytes $>2.0 \times 10^{\%} / \mathrm{l}$, neutrophils $>1.5$, platelets $>75 \times 10^{9} / \mathrm{l}$, (6) sufficient renal function, defined as glomerular filtration rate $>45 \mathrm{ml} / \mathrm{min}$, (7) baseline ${ }^{68} \mathrm{Ga}$-PSMA PET/CT $\leq 2$ months prior to administration of the first therapy cycle, (8) and metastatic disease with dominant tumor sites showing relatively high PSMA-expression (visual assessment; tumor uptake >> normal liver parenchyma) on baseline ${ }^{68} \mathrm{Ga}$-PSMA PET/CT. Patients received up to six cycles of intravenous ${ }^{177}$ Lu-PSMA-617, at six weekly intervals. Prior to the follow-up visit at 5 weeks after every cycle, laboratory tests (full blood count, liver function tests and PSA) were done. To evaluate tumor response, repeated ${ }^{68} \mathrm{Ga}$-PSMA PET/CT scans were performed after 2, 4 and 6 cycles. Whether or not to continue therapy was discussed in a multidisciplinary tumor board meeting after every 2 cycles. The multidisciplinary tumor board made the final decision, only when unequivocal clinical progression was observed, and at least 12 weeks after start of treatment. In patients with exceptional response, further treatment cycles were temporarily postponed and restarted after evident biochemical progression. Patients were informed with regard to possible side effects and risks of this new therapeutic agent. The institutional review board of the UMC Utrecht approved this retrospective study. 


\section{Preparation of ${ }^{177}$ Lu-PSMA-617}

PSMA-617 (GMP-grade) was obtained from ABX GmbH, Radeberg, Germany. Quality control parameters were monitored as follows: radiochemical purity, radiochemical identity, $\mathrm{pH}$ value, endotoxin content, and proof of sterility. The radiopharmaceutical was finally released by a hospital pharmacist.

\section{Administration of ${ }^{177}$ Lu-PSMA-617}

Six GBq ${ }^{177}$ Lu-PSMA-617 per 40-250 micrograms peptide was administered intravenously, with a planned interval of 6 weeks. The first three treatments ${ }^{177} \mathrm{Lu}$ was labelled to 250 micrograms peptide, the rest of the treatments $6 \mathrm{GBq}{ }^{177}$ Lu was labelled to 40 micrograms PSMA-617. Patients were admitted to the hospital overnight. Patients were released from the nuclear medicine ward according to Dutch regulatory radiation guidelines ( $20 \mu \mathrm{Sv} / \mathrm{h}$ measured at a distance of $1 \mathrm{~m}$ ).

\section{Clinical, biochemical \& imaging response}

Clinical response (i.e. pain) was assessed in patients who experienced pain symptoms at baseline for which analgesics were used. Severity of newly originated pain and cessation/decreased usage of analgesics compared to baseline, after 1, 2 and 4 cycles, as well as after completion of all treatment cycles was assessed.

The prostate-specific antigen (PSA) level was determined at baseline and after each therapy cycle. Biochemical response was categorized according to the Prostate Cancer Working Group 3 criteria ${ }^{7}$ into: any decrease, $50-90 \%$ decrease and $>90 \%$ decrease. Biochemical response was defined as $\geq 50 \%$ PSA-decrease. Stable PSA was defined as $<25 \%$ PSAchange; progressive PSA was defined as $\geq 25 \%$ PSA increase. Experienced nuclear medicine physicians evaluated imaging response on ${ }^{68} \mathrm{Ga}-\mathrm{PSMA}$ PET/CT after 2, 4 and 6 treatment cycles according to the European Organization for Research and Treatment of Cancer (EORTC)-criteria, as used previously. ${ }^{8}$ Response was categorized into: 1) complete response; defined as a complete resolution of ${ }^{68} \mathrm{Ga}$-PSMA uptake within the tumor region defined on the baseline PET-scan, so that it was indistinguishable 
from surrounding normal tissue, 2) partial response; defined as a reduction of $>25 \%{ }^{68} \mathrm{Ga}$-PSMA uptake in the predefined tumor lesions, 3) stable disease; defined as an increase in ${ }^{68} \mathrm{Ga}$-PSMA uptake of $<25 \%$ or a decrease of $<15 \%$ and no visible increase in extent of ${ }^{68} \mathrm{Ga}$-PSMA uptake, 4 ) progressive disease; defined as an increase in ${ }^{68} \mathrm{Ga}$-PSMA uptake of $>25 \%$ within the predefined tumor lesions, visible increase in the extent of ${ }^{68} \mathrm{Ga}$ PSMA uptake or the appearance of new ${ }^{68} \mathrm{Ga}$-PSMA uptake in metastatic lesions and 5) mixed response; defined as a reduction of $>25 \%{ }^{68} \mathrm{Ga}-\mathrm{PSMA}$ uptake in a selection of the predefined tumor lesions in combination with increase in ${ }^{68} \mathrm{Ga}$-PSMA uptake of $>25 \%$ within other predefined tumor lesions and/or visible increase in the extent of ${ }^{68} \mathrm{Ga}$-PSMA uptake or the appearance of new ${ }^{68} \mathrm{Ga}$-PSMA uptake in metastatic lesions.

\section{Clinical, biochemical and hematological toxicity}

Laboratory results, including (differential) leukocyte, erythrocyte, haemoglobin and platelet counts, renal and liver function, were examined at baseline and 2-6 weeks after every therapy cycle. Biochemical toxicity was categorized using the Common Toxicity Criteria for Adverse Events (CTCAE version 4.03). Additionally, clinical toxicity and medical complications during and after ${ }^{177}$ Lu-PSMA-617 therapy were reported according to a standardized questionnaire including clinical symptoms (e.g. fatigue, xerostomia, nausea, vomiting, gastro-intestinal complaints, other complaints) and CTCAE-grade.

\section{Statistics}

Statistical analyses were performed using IBM SPSS Statistics for Mac, version 24. Data are presented as medians and ranges or as frequencies. Statistical significance was established for $p$-values of $<0.05$.

\section{RESULTS}

\section{Baseline characteristics}

Thirty consecutive patients treated with ${ }^{177}$ Lu-PSMA-617 were analyzed. No patients were excluded from analysis. Baseline characteristics are summarized in Table 1. Median age was 70 (range: 54-83) years. Patients 
Table 1. Baseline characteristics

Subjects (n)

\section{Age (years)}

Median

Range

\section{Previous treatment strategies (n, \%)}

Androgen deprivation therapy

Chemotherapy*

Abiraterone

Enzalutamide

Radionuclide therapy (Radium-223)

Salvage radiation therapy

\section{Number of administered cycles}

Median

Range

\section{PSA at baseline $(\mathrm{ng} / \mathrm{ml})$}

Median

*Includes both docetaxel and cabazitaxel

underwent 1-6 cycles with ${ }^{177}$ Lu-PSMA; median number of cycles was 4. Therapy of three patients was discontinued after 1 cycle: one of these patients died after 1 cycle; another patient suffered from evident progressive disease due to which he did not feel able to undergo further therapy cycles. In the last patient, therapy was stopped because of disappointing tumor targeting on the post therapeutic lutetium scan in combination with rapidly increasing PSA (from 760 to $1000 \mathrm{ng} / \mathrm{ml}$ ).

Mean administered radioactivity was 6 (range: 5.6-6.4) GBq per cycle. Median interval between therapy cycles was 6 weeks (range: 5.5-35 weeks). Median duration of follow-up from start of the first therapy cycle was 10 months (range: 1 week - 21 months). Ten patients died during follow-up: seven patients most likely due to progressive disease, one patient suffering from cancerous peritonitis due to sepsis and consequent 
renal insufficiency, one patient with pre-existent cardiomyopathy due to cardiac decompensation and a co-existent pneumonia, and one patient died following physician-assisted euthanasia. Amongst these 10 patients, three patients underwent four cycles, six patients underwent two cycles; one patient underwent one cycle. Clinical symptoms at baseline predominantly comprised pain in 67\% and fatigue in 37\% (supplementary Table 1a). Baseline biochemical abnormalities mainly included anemia (93\%) and renal impairment (17\%); all CTCAE-grade I-II (supplementary Table 1b).

\section{Clinical response}

After the first cycle, a decreased usage of analgesics was seen in 9/20 evaluable patients (45\%) who experienced pain at baseline. After two and four cycles, usage of analgesics decreased in 8/15 (52\%) and in 6/8 (75\%) evaluable patients, respectively. In all three patients (100\%) who suffered from pain at baseline and who were treated with six cycles, the pain symptoms were ameliorated during six therapeutic cycles. Results are summarized in supplementary Table 2.

\section{Biochemical response}

Median PSA level at baseline was 200 (range: 4.3-3800.0) ng/ml. During treatment, PSA level decreased $\geq 50 \%$ in $57 \%$ of the patients; $\geq 90 \%$ PSA decrease was observed in $24 \%$ of the patients. Best PSA response after treatment is displayed in a waterfall plot (Figure 1). After the first treatment cycle, $38 \%$ and $3 \%$ of the patients showed $\geq 50 \%$ and $\geq 90 \%$ PSA decrease, respectively. After two cycles, $38 \%$ and $17 \%$ of the patients showed $\geq 50 \%$ and $\geq 90 \%$ PSA decrease, respectively. After the $4^{\text {th }}$ cycle, the fraction of patients showing a $\geq 50 \%$ and $\geq 90 \%$ PSA decrease respectively, increased to 64\% (9/14 patients) and 29\% (4/14 patients). After six cycles, PSA level of $1 / 4$ patients $(25 \%)$ decreased with $\geq 90 \%$. Notably, all biochemically stable patients $(n=4)$ after the first cycle became biochemical responders after the second cycle. Of the 7 patients who were biochemically progressive after the first cycle, only one patient showed a secondary decrease and became stable after the second cycle. PSA-level of two other patients, however, increased after an initial PSA decrease of $>60 \%$. 


\section{Imaging response}

Baseline PSMA PET showed diverse tumor load throughout the whole patient sample. A (partial) imaging response during treatment was observed in 50\% of the patients. After the second, fourth and sixth cycle, respectively 52\%, 47\% and 75\% showed a partial response, and progressive disease was seen in respectively 17\%, 20\% and 0\%. Mixed response was noted in 9\%,13\% and $25 \%$ of patients after two, four and six cycles, respectively. In these patients, quantity and intensity of the initial metastases declined, but new metastatic sites originated as well.

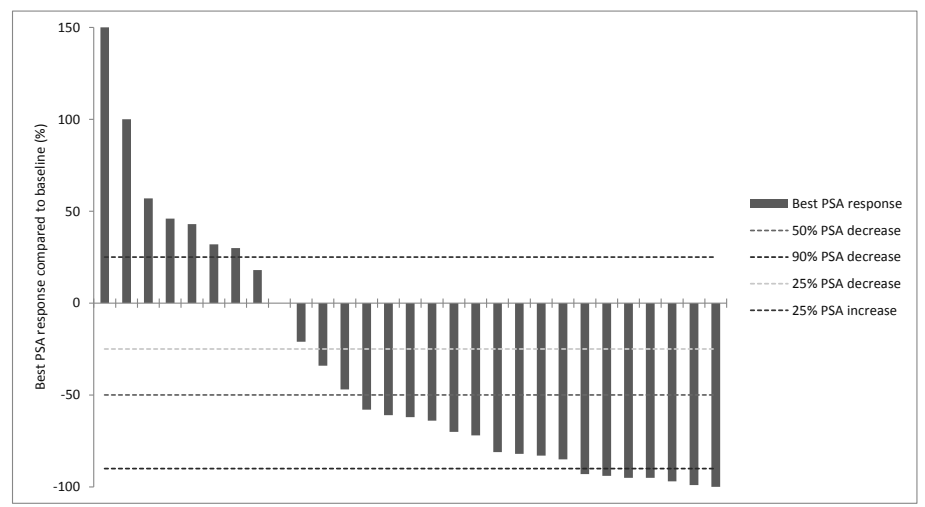

Figure 1. Best PSA response after treatment

\section{Clinical toxicity}

At baseline, 11 patients (37\%) reported fatigue; four patients (13\%) reported xerostomia. During all treatment cycles, newly originated fatigue was reported in $36 \%$ of the patients and remained limited to grade I-II. With regard to xerostomia, $47 \%$ of the patients reported new origin of grade I-II dry mouth. All clinical symptoms that occurred during the treatment cycles are summarized in Table $\mathbf{2 a}$. 
Table 2a. Newly originated Clinical Toxicity per CTCAE-grade, n (\%)

\begin{tabular}{lcccc}
\hline & Grade I & Grade II & Grade III & Grade IV \\
\hline Gastrointestinal disorders & & & & \\
Xerostomia & $9(30 \%)$ & $5(17 \%)$ & 0 & 0 \\
Anorexia & $2(7 \%)$ & $1(3 \%)$ & 0 & 0 \\
Nausea/vomiting & $3(10 \%)$ & $2(7 \%)$ & 0 & 0 \\
Obstipation & $1(3 \%)$ & 0 & 0 & 0 \\
Diarrhea & $3(10 \%)$ & $2(7 \%)$ & 0 & 0 \\
Ileus & 0 & 0 & 0 & $1(3 \%)$
\end{tabular}

\section{General disorders}

$\begin{array}{lcccc}\text { Fatigue } & 10(33 \%) & 1(3 \%) & 0 & 0 \\ \text { Stiffness } & 1(3 \%) & 0 & 0 & 0 \\ \text { Sepsis } & 0 & 0 & 0 & 1(3 \%)\end{array}$

\section{Urinary disorders}

$\begin{array}{lcccc}\text { Urinary tract infection } & 0 & 1(3 \%) & 0 & 0 \\ \text { Hematuria } & 1(3 \%) & 0 & 1(3 \%) & 0 \\ \text { Hydronephrosis } & 0 & 0 & 1(3 \%) & 0\end{array}$

\section{Cardiovascular disorders}

$\begin{array}{lcccc}\text { Atrial Fibrillation } & 0 & 1(3 \%) & 0 & 0 \\ \text { Edema } & 1(3 \%) & 0 & 0 & 0 \\ \text { Deep venous throm- } & 0 & 1(3 \%) & 0 & 0 \\ \text { bosis } & 0 & 0 & 0 & 1(3 \%) \\ \text { Ascites } & & & & \end{array}$

\section{Respiratory disorders}

$\begin{array}{lcccc}\text { Dyspnea } & 1(3 \%) & 0 & 0 & 0 \\ \text { Pneumonia } & 0 & 1(3 \%) & 0 & 0\end{array}$

\section{Neurologic disorders}

$\begin{array}{lllll}\text { TIA/stroke } & 0 & 0 & 0 & 1(3 \%) \\ \text { Papilledema } & 0 & 0 & 0 & 1(3 \%) \\ \text { Paraplegia } & 0 & 0 & 0 & 1(3 \%)\end{array}$

\section{Musculoskeletal disorders}

Bone fracture

$0 \quad 0$

0

0

Arthritis

$0 \quad 1(3 \%)$

0

0


Table $\mathbf{2 b}$. Medical complications during ${ }^{177}$ Lu-PSMA treatment

\begin{tabular}{|c|c|c|c|c|}
\hline & Complication & $\begin{array}{l}\text { CTCAE } \\
\text { grade }\end{array}$ & Underlying pathology & Treatment \\
\hline 1 & Hydronefrosis & III & $\begin{array}{l}\text { Ureteral obstruction due to } \\
\text { abdominal metastases of PCa }\end{array}$ & $\begin{array}{l}\text { Surgical placement } \\
\text { of JJ-catheter }\end{array}$ \\
\hline 2 & Papilledema & IV & $\begin{array}{l}\text { Unknown origin, possibly } \\
\text { following obstruction due to } \\
\text { leptomeningeal metastases of } \\
\text { PCa or toxic radiation effects } \\
\text { following }{ }^{177} \text { Lu-PSMA therapy }\end{array}$ & Liquor drainage \\
\hline 3 & lleus & IV & Adhesions of unknown origin & Surgical adhesiolysis \\
\hline 4 & $\begin{array}{l}\text { Sepsis (+ subse- } \\
\text { quent cardiac de- } \\
\text { compensation) }\end{array}$ & IV & $\begin{array}{l}\text { Pneumonia in combination } \\
\text { with pre-existent cardiomyo- } \\
\text { pathy }\end{array}$ & Antibiotic therapy i.v. \\
\hline 5 & Paraplegia & IV & $\begin{array}{l}\text { Myelocompression due to can- } \\
\text { cerous depositions of PCa }\end{array}$ & $\begin{array}{l}\text { - Laminectomy, fol- } \\
\text { lowed by radiation } \\
\text { therapy }\end{array}$ \\
\hline 6 & TIA/stroke & IV & Carotid stenosis & $\begin{array}{l}\text { Carotid endarterec- } \\
\text { tomy }\end{array}$ \\
\hline 7 & Ascites (+ sepsis) & IV & $\begin{array}{l}\text { Pre-existent portal hyperten- } \\
\text { sion due to liver cirrhosis + } \\
\text { peritonitis following peritoneal } \\
\text { depositions of } \mathrm{PCa}\end{array}$ & $\begin{array}{l}\text { Ascites drainage + } \\
\text { antimicrobial } \\
\text { I therapy i.v. }\end{array}$ \\
\hline 8 & $\begin{array}{l}\text { Hematuria with } \\
\text { blood clots, causing } \\
\text { obstruction of per- } \\
\text { cutaneous nephros- } \\
\text { tomy catheter }\end{array}$ & III & $\begin{array}{l}\text { Advanced PCa with cancerous } \\
\text { peritonitis in combination with } \\
\text { usage of oral anticoagulants } \\
\text { (indication: myocardial infarc- } \\
\text { tion in past medical history) }\end{array}$ & $\begin{array}{l}\text { Change of percuta- } \\
\text { neous nephrostomy } \\
\text { catheter }\end{array}$ \\
\hline
\end{tabular}


Generally, severity of baseline clinical symptoms did not deteriorate during the treatment cycles. A total number of eight events ( $\geq$ CTCAE grade III) were reported during the follow-up period, including 1) abdominal soft tissue swelling causing deep venous thrombosis and hydronephrosis, 2) papilledema causing visual deficit ${ }^{9}$, 3) ileus, 4) pneumonia causing sepsis and cardiac decompensation, 5) paraplegia, 6) stroke, 7) carcinomatous peritonitis causing ascites and sepsis, 8) hematuria (Table $\mathbf{2 b}$ ). For all medical complications, intervention and/or hospital admission was required. All clinical symptoms that occurred after separate cycles are summarized in supplementary Table 1a.

\section{Biochemical toxicity}

Laboratory results at baseline showed $67 \%$ of the patients having grade I anemia, while 10\% and 3\% had grade II and III anemia. Only one patient (3\%) had grade I leukocytopenia at baseline. Grade I and II thrombocytopenia was found in $7 \%$ and $3 \%$ of the patients, respectively. With regard to renal insufficiency, 17\% of the patients had grade I elevated creatinine levels. Results on biochemical and hematological toxicity according to CTCAE-classification at baseline and after separate therapy cycles are summarized in the supplementary Table 1b. During all treatment cycles, newly originated grade I anemia occurred in $17 \%$ of the patients; grade II, II and IV occurred in 7\%,3\% and 3\%, respectively. New leukocytopenia was limited to grade I and occurred in $20 \%$ of the patients. New grade I and II thrombocytopenia was found in respectively $14 \%$ and $3 \%$ of the patients, while new grade I and II renal insufficiency occurred in $10 \%$ and $3 \%$ of the patients. Results on biochemical and hematological toxicity according to CTCAE-classification during all treatment cycles are summarized in Table 2c.

\section{Follow-up}

During a median follow-up length of 13.7 (range: 9.8-32.3) months, median overall survival was 11.3 (range 1.4-32.3) months. 
Table 2c. Newly originated Haematological Toxicity per CTCAE-grade, $n$ (\%)

\begin{tabular}{lcccc}
\hline & Grade I & Grade II & Grade III & Grade IV \\
\hline Anemia & $5(17 \%)$ & $2(7 \%)$ & $1(3 \%)$ & $1(3 \%)$ \\
Leukocytopenia & $6(20 \%)$ & 0 & 0 & 0 \\
Thrombocytopenia & $4(14 \%)$ & $1(3 \%)$ & 0 & 0 \\
Renal insufficiency & $3(10 \%)$ & $1(3 \%)$ & 0 & 0 \\
\hline
\end{tabular}

\section{DISCUSSION}

This retrospective observational study summarizes the results of the first experience with ${ }^{177}$ Lu-PSMA-617 therapy in the UMC Utrecht, the Netherlands. In this patient cohort, comprising heavily pretreated metastatic CRPC patients, $\geq 50 \%$ and $\geq 90 \%$ PSA response was found in $57 \%$ and $24 \%$ respectively. Furthermore, in 52\% of the patients who experienced pain prior to commencement of ${ }^{177} \mathrm{Lu}-\mathrm{PSMA}-617$ therapy, a rapid onset of pain relief was achieved after two cycles. In general, ${ }^{177}$ Lu-PSMA-617 therapy was well-tolerated with a mild toxicity profile (predominantly CTCAE grade I-II) that was self-limiting and/ or easily treated. Imaging response rates were quite comparable to the earlier described findings and showed a partial response in 50\% of the patients during all treatment cycles. ${ }^{10}$ As such, our data support the value of ${ }^{177}$ Lu-PSMA-617 therapy for patients with metastatic CRPC.

Several retrospective studies investigated efficacy (decrease of tumor load on imaging, PSA-decline) and toxicity (ECOG performance scores and severity of pain) of ${ }^{177}$ Lu-PSMA-617 therapy in heterogenic cohorts of metastatic CRPC patients. ${ }^{11-17}$ An overall biochemical response after $\geq$ 1 cycles was reported in 68-82\%. ${ }^{177}$ Lu-PSMA therapy led to $>30 \%$ and $>50 \%$ PSA-decline in respectively 60\% (range 29-82\%) and 50\% (range 24$73 \%$ ) of the patients. Data on overall survival is sparse and currently only evaluated by Rahbar et al. in a small retrospective study..$^{16}$ Compared to a matched historical cohort, provided with best supportive care, patients 
treated with ${ }^{177}$ Lu-PSMA-617 showed a median survival of 29.4 weeks versus 19.7 weeks. Results on efficacy and toxicity of the present study are in line with the abovementioned retrospective data. However, our findings with regard to median overall survival do not correspond, with a longer median overall survival of 11.3 months in our cohort, most likely a result of differences in patient selection.

Recently, the first prospective studies were published. ${ }^{10,18}$ In the first phase II study, including 30 heavily pretreated CRPC patients, 1-4 cycles ${ }^{177} \mathrm{Lu}-$ PSMA-617 were administered. ${ }^{10}$ Mean administered radioactivity was 7.5 (range: 4.4-8.7) GBq per cycle; dependent of weight and tumor load. Over $50 \%$ PSA decrease was found in $57 \%$ of the patients. No treatment-related deaths were reported. The most frequently reported therapy-related clinical toxicities were CTCAE grade I xerostomia (87\%), CTCAE grade I-II transient nausea (50\%) and fatigue (50\%). Regarding biochemical toxicity, CTCAE grade III-IV thrombocytopenia and CTCAE grade III anemia and neutropenia occurred in 27\%, $13 \%$ and $7 \%$ of the patients, respectively. Objective imaging response was found in 14 out of 17 patients (82\%) with measurable disease. Furthermore, a clinically meaningful pain reduction after one cycle was found in $37 \%$ of the 27 patients who experienced pain at baseline. A ten-point improvement of quality of life was found in $37 \%$ of the patients after the second cycle. In $90 \%$ of the patients PSA levels further progressed during follow-up; PSA progression-free survival was 7.6 months (95\% Cl 6.3-9.0). Median overall survival was 13.5 months (95\% Cl 10.4-22.7). Twenty-two patients (73\%) died during the follow-up period; causes of death comprised pneumonia $(n=1)$ and PCa progression $(n=21)$. Importantly, it was found that biochemical responders (>50\% PSA decrease) had higher progression-free and overall survival rates than patients with a PSA response lower than 50\%. In the second study, in which imaging predictors of treatment response were studied, 14 men underwent therapy with ${ }^{177}$ Lu-PSMA-617.. ${ }^{18}$ Ten men (71\%) had a PSA response (mean reduction 59\%). A $\geq 30 \%$ and $\geq 50 \%$ PSA decline occurred in $64 \%$ and $36 \%$, respectively. Besides the standardized uptake value (SUV) on baseline PET being predictive of 
$\geq 30 \%$ PSA reduction, no imaging parameters were found to predict $\geq 50 \%$ PSA decrease. Volume, disease localization and FDG parameters did not predict PSA response.

The specific expression of the PSMA antigen allows targeted and prolonged radiation, inducing complex DNA damage during a long period of time. Unfortunately, tissue with physiological PSMA expression like the salivary glands, is susceptible to radiation damage resulting in the side effect xerostomia. ${ }^{19}$ It has been advised to apply bilateral icepacks covering the salivary glands to prevent xerostomia, however, preliminary prospective research in our institution did not confirm a clinically meaningful effect of this intervention. ${ }^{20}$ Hence, from December 2016 up to April 2017, bilateral icepacks were applied in only an early subset of patients. Despite this intervention, a substantial proportion new xerostomia was reported (36\% of the patient sample; mostly self-limiting grade I). Although in line with the results published by the only available prospective study (in which xerostomia was reported in $87 \%$ of the patients), occurrence of xerostomia in the present study was significantly higher than reported by others. One explanation might be that patients were more informed and more alert to the occurrence of xerostomia and patients were systematically questioned. Remarkably, grade III-IV xerostomia was not observed among the patients who were analyzed in our study. Their advanced disease status with high tumor load might lead to a decreased radiotracer uptake in the salivary glands. ${ }^{21}$ Nonetheless, given the clinical impact of xerostomia on quality of life, future research is needed to define strategies preventing this side effect. ${ }^{22}$

The occurrence of therapy-related biochemical toxicity in our patient sample was low. Only two patients presented with grade III and IV anemia; no grade IV biochemical or hematological toxicities were reported. However, a total number of eight medical complications $\geq$ CTCAE grade III was reported, as could be expected with regard to our heavily pretreated patients with extensive advanced disease. 
Our study has several limitations. As a result of its retrospective design, clinical symptoms were not systematically reported. Although a standard questionnaire was used, clinical (pain) response and usage of analgesics may have been under-reported. This may have lead to underestimation in our results. However, we consequently performed follow-up blood tests and PET-imaging every two cycles. Therapy continuation was evaluated based on clinical and biochemical parameters combined with imaging results, in a multidisciplinary setting after every two cycles. Patients suffering from progressive disease were excluded from further treatment cycles. As such, the reported responses after two and four treatment cycles were an overestimation of the overall therapeutic effect. Evaluation of tumor response on CT or skeletal scintigraphy according to the RECIST 1.1 criteria, was unfortunately not executed.

With the introduction of ${ }^{177}$ Lu-PSMA-617 into clinical practice of our institution, definite procedural protocols were lacking. Therefore, the applied candidacy criteria, treatment details and follow-up procedures evolved from the available consensus guidelines. ${ }^{23}$ Evolving insights with regard to eligibility (e.g. tumor load on baseline PET), treatment protocols and follow-up procedure resulted in some heterogeneity of the patient sample and consequently, a reduced generalizability of our results. At present, detailsonoptimalactivity, interval betweentheadministered cycles as well as which patients benefit most from the therapy, are not clearly defined. Moreover, although several methods are currently used to evaluate tumor response (RECIST, EORTC), to date, no standardized criteria that were specifically developed for PSMA-PET imaging are available. Future research could focus on optimization of imaging evaluation by standardization of PET evaluation methods.

Despite the aforementioned limitations, our results on clinical, biochemical and imaging response generally are in accordance with previously described findings and support the promising features of ${ }^{177}$ Lu-PSMA-617 therapy. Results from randomized, prospective studies are awaited to ultimately implement ${ }^{177}$ Lu-PSMA-617 therapy on an international scale..$^{24}$ 


\section{CONCLUSION}

Based on these preliminary results, ${ }^{177} \mathrm{Lu}$-PSMA-617 appears a promising treatment strategy for $\mathrm{MCRPC}$ patients, however, randomized-controlled trials are warranted to determine the definite role and place of ${ }^{177} \mathrm{Lu}$ PSMA-617 in the treatment of prostate cancer.

\section{ACKNOWLEDGEMENTS}

We thank A. Henderson for his advice on our manuscript. 


\section{REFERENCES}

1. Lozano R, Naghavi M, Foreman K, et al. Global and regional mortality from 235 causes of death for 20 age groups in 1990 and 2010: a systematic analysis for the Global Burden of Disease Study 2010. Lancet. 2012;380:2095-128.

2. Parker $C$, Nilsson S, Heinrich D, et al. Alpha emitter radium-223 and survival in metastatic prostate cancer. N Engl J Med. 2013;369:213-23.

3. Pond GR, Sonpavde G, de Wit R et al. The prognostic importance of metastatic site in men with metastatic castration-resistant prostate cancer. Eur Urol. 2014;65:3-6.

4. Haberkorn U, Eder M, Kopka K, et al. New Strategies in Prostate Cancer: Prostate-Specific Membrane Antigen (PSMA) Ligands for Diagnosis and Therapy. Clin Cancer Res. 2016;22:9-15.

5. Mavragani IV, Nikitaki Z, Souli MP, et al. Complex DNA Damage: A Route to Radiation-Induced Genomic Instability and Carcinogenesis. Cancers. 2017:18;9.

6. Delker A, Fendler WP, Kratochwil C, et al. Dosimetry for (177)Lu DKFZPSMA-617: a new Radiopharmaceutical for the treatment of metastatic prostate cancer. Eur J Nucl Med Mol Imaging. 2016;43:42-51.

7. Scher HI, Morris MJ, StadlerWM, et al. Trial Design and Objectives for Castration Resistant Prostate Cancer: Updated Recommendations From the Prostate Cancer Clinical Trials Working Group 3. J Clin Oncol. 2016;34:1402-1418.

8. Young $\mathrm{H}$, Baum $\mathrm{R}$, Cremerius $U$. Measurement of clinical and subclinical tumour response using $\left[{ }^{18} \mathrm{~F}\right]$ fluorodeoxyglucose and positron emission tomography: review and 1999 EORTC recommendations. European Organization for Research and Treatment of Cancer (EORTC) PET Study Group. Eur J Cancer. 1999;35:1773-1782.

9. van Kalmthout L, Stam A, Gans R, et al. Visual deficit possibly caused by lutetium-177 PSMA treatment. BMJ Case Rep. 2018:8;2018.

10. Hofman MS, Violet J, Hicks RJ et al. ["17/Lu]-PSMA-617 radionuclide treatment in patients with metastatic castration-resistant prostate cancer (LuPSMA trial): a single-centre, single-arm, phase 2 study. Lancet Oncol. 2018:;19:825-833.

11. Ahmadzadehfar $H$, Eppard E, Kürpig $S$, et al. Therapeutic response and side effects of repeated radioligand therapy with 177Lu-PSMA-DKFZ-617 of castrate-resistant metastatic prostate cancer. Oncotarget. 2016;7:12477-88.

12. Baum RP, Kulkarni HR, Schuchardt C, et al. Lutetium-177 PSMA Radioligand Therapy of Metastatic Castration Resistant Prostate Cancer: Safety and Efficacy. J Nucl Med. 2016;57:1006-13.

13. Ahmadzadehfar H, Rahbar K, Kürpig S, et al. Early side effects and first results of radioligand therapy with (177)Lu-DKFZ-617 PSMA of castrate-resistant metastatic prostate cancer: a two-centre study. EJNMMI Res. 2015;5:114. 
14. Heck MM, Retz M, D Alessandria C, et al. Systemic radioligand therapy with 177Lu-PSMA-I\&T in patients with metastatic castration-resistant prostate cancer. J Urol. 2016;"196:382-91.

15. Kratochwil C, Giesel FL, Stefanova M, et al. PSMA-targeted radionuclide therapy of metastatic castration resistant prostate cancer with Lu-177 labeled PSMA-617. J Nucl Med. 2016 Aug;57(8):1170-6.

16. RahbarK, Bode A, Weckesser M, et al. RadioligandTherapy With ${ }^{177}$ Lu-PSMA-617 as A Novel Therapeutic Option in Patients With Metastatic Castration Resistant Prostate Cancer. Clin Nucl Med. 2016;41:522-8.

17. Rahbar K, Ahmadzadehfar H, Kratochwil C, et al. German Multicenter Study Investigating 177Lu-PSMA-617 Radioligand Therapy in Advanced Prostate Cancer Patients. J Nucl Med. 2017;58:85-90.

18. Emmett L, Crumbaker M, Ho B, et al. Results of a Prospective Phase 2 Pilot Trial of ${ }_{177}$ Lu-PSMA-617 Therapy for Metastatic Castration-Resistant Prostate Cancer Including Imaging Predictors of Treatment Response and Patterns of Progression. Clin Genitourin Cancer. 2018:27.

19. Foletti JM, Bardiès M, Rocchi P, et al. PSMA-Targeted Radionuclide Therapy and salivary gland toxicity: why does it matter? J Nucl Med. 2018;59:747-748.

20. van Kalmthout LWM, Lam MGEH, de Keizer B, et al. Impact of external cooling with icepacks on ${ }^{68} \mathrm{Ga}$-PSMA uptake in salivary glands. EJNMMI Res. 2018;8:56.

21. Gaertner FC, Halabi K, Ahmadzadehfar $\mathrm{H}$, et al. Uptake of PSMA-ligands in normal tissues is dependent on tumor load in patients with prostate cancer. Oncotarget. 2017;8:55094-55103

22. Taïeb D, Foletti JM, Bardiès M,et al. PSMA-Targeted Radionuclide Therapy and salivary gland toxicity: why does it matter? J Nucl Med. 2018;59:747-748.

23. Fendler WP, Rahbar K, Herrman K, et al. 177Lu-PSMA Radioligand Therapy for Prostate Cancer. J Nucl Med. 2017;58:1196-1200.

24. http://investor.endocyte.com/news-releases/news-release-details/ endocyte-announces enrollment-first patient-phase-3-vision-trial 


\section{SUPPLEMENTARY TABLES AND FIGURES}

Supplementary Table 1a. Clinical toxicity according to CTCAE-classification, including serious adverse events

\begin{tabular}{lccccccc}
\hline Treatment cycle & Baseline & $\mathbf{1}$ & $\mathbf{2}$ & $\mathbf{3}$ & $\mathbf{4}$ & $\mathbf{5}$ & $\mathbf{6}$ \\
\hline Total evaluable $(\mathbf{n})$ & 30 & 29 & 24 & 17 & 14 & 6 & 4
\end{tabular}

\section{Gastrointestinal disorders (n, max grade)}

$\begin{array}{lccccccc}\text { Xerostomia } & 4(\mathrm{I}) & 11(\mathrm{I}-\mathrm{II}) & 9(\mathrm{I}) & 10(\mathrm{I}-\mathrm{II}) & 11(\mathrm{I}-\mathrm{II}) & 5(\mathrm{I}) & 3(\mathrm{I}) \\ \text { Anorexia } & 1(\mathrm{I}) & 2(\mathrm{I}) & 0 & 1(\mathrm{I}) & 0 & 0 & 0 \\ \text { Weight loss } & 1(\mathrm{I}) & 1(\mathrm{I}) & 0 & 0 & 0 & 0 & 0 \\ \text { Nausea/vomiting } & 2(\mathrm{I}-\mathrm{II}) & 8(\mathrm{I}-\mathrm{II}) & 1(\mathrm{I}) & 2(\mathrm{I}-\mathrm{III}) & 0 & 1(\mathrm{I}) & 0 \\ \text { Obstipation } & 1(\mathrm{I}) & 0 & 0 & 0 & 1(\mathrm{I}) & 0 & 0 \\ \text { Diarrhea } & 1(\mathrm{I}) & 3(\mathrm{I}) & 0 & 1(\mathrm{II}) & 0 & 0 & 0 \\ \text { Ileus } & 0 & \mathrm{I}(\mathrm{IV}) & 0 & 0 & 0 & 0 & 0\end{array}$

General disorders ( $\mathrm{n}$, max grade)

$\begin{array}{lccccccc}\text { Fatigue } & 11(I) & 17(I-I) & 8(I) & 6(I-I I) & 6(I-I I) & 3(I) & 1(I) \\ \text { Stiffness } & 0 & 1(I) & 0 & 0 & 0 & 0 & 0 \\ \text { Headache } & 0 & 0 & 0 & 0 & 0 & 0 & 0 \\ \text { Sepsis } & 0 & 0 & 1(I V) & 0 & 2(I I) & 0 & 0\end{array}$

\section{Urinary disorders (n, max grade)}

$\begin{array}{lccccccc}\text { Incontinence } & 2(I-I I) & 0 & 0 & 0 & 0 & 0 & 0 \\ \text { Urinary tract } & 0 & 1(I I) & 0 & 0 & 0 & 0 & 0 \\ \text { infection } & & & & & & & \\ \text { Hematuria } & 1(I I I) & 0 & 0 & 0 & 1(I) & 0 & 0 \\ \text { Hydronephrosis } & 0 & 0 & 1(I I I) & 0 & 0 & 0 & 0\end{array}$

\section{Cardiovascular disorders ( $\mathbf{n}$, max grade)}

\begin{tabular}{lccccccc} 
Atrial Fibrillation & 0 & 0 & 0 & 0 & 1 (II) & 0 & 0 \\
Edema & 0 & $1(\mathrm{I})$ & 0 & 0 & 0 & 0 & 0 \\
$\begin{array}{l}\text { Deep venous } \\
\text { thrombosis }\end{array}$ & 0 & 0 & 1 (II) & 0 & 0 & 0 & 0 \\
Ascites & 0 & 0 & $1(\mathrm{IV})$ & 0 & 0 & 0 & 0 \\
\hline
\end{tabular}


Supplementary Table 1a. Continued

\begin{tabular}{|c|c|c|c|c|c|c|c|}
\hline Treatment cycle & Baseline & 1 & 2 & 3 & 4 & 5 & 6 \\
\hline \multicolumn{8}{|c|}{ Respiratory disorders (n, max grade) } \\
\hline Dyspnea & 0 & $1(I)$ & 0 & 0 & 0 & 0 & 0 \\
\hline Pneumonia & 0 & 0 & 0 & 0 & 1 (II) & 0 & 0 \\
\hline
\end{tabular}

Neurologic disorders ( $\mathbf{n}$, max grade)

$\begin{array}{lccccccc}\text { Vertigo } & 0 & 0 & 0 & 0 & 0 & 0 & 0 \\ \begin{array}{l}\text { Peripheral } \\ \text { neuropathy }\end{array} & 1 \text { (II) } & 0 & 0 & 0 & 0 & 0 & 0 \\ \text { TIA/stroke } & 0 & 0 & 1(\mathrm{IV}) & 0 & 0 & 0 & 0 \\ \text { Visual deficit } & 0 & 0 & 1(\mathrm{IV}) & 0 & 0 & 0 & 0 \\ \text { Paraplegia } & 0 & 0 & 0 & 0 & 1 \text { (IV) } & 0 & 0\end{array}$

Musculoskeletal disorders ( $\mathrm{n}$, max grade)

$\begin{array}{llllclll}\text { Bone fracture } & 0 & 0 & 0 & 0 & 0 & 0 & 0 \\ \text { Arthritis } & 0 & 0 & 0 & 1 \text { (II) } & 0 & 0 & 0\end{array}$

0ther complaints* ( $n$, max grade)

\begin{tabular}{ccccccc}
$2(I)$ & $1(I)$ & 0 & 0 & 0 & 0 & $1(\mathrm{I})$ \\
\hline n = number
\end{tabular}

$\mathrm{n}=$ number of patients. *Includes: flatulence, sweating, flushes, limb numbness, muscle cramps, dry eyes and mild hearing loss 
Supplementary Table $\mathbf{1 b}$. Biochemical toxicity according to CTCAE-classification after separate therapy cycles

\begin{tabular}{lccccccc}
\hline Treatment cycle & Baseline & $\mathbf{1}$ & $\mathbf{2}$ & $\mathbf{3}$ & $\mathbf{4}$ & $\mathbf{5}$ & $\mathbf{6}$ \\
\hline Total evaluable (n) & 30 & 29 & 24 & 16 & 15 & 6 & 4 \\
Anemia, $\mathbf{n}(\%)$ & & & & & & & \\
Grade I & $20(67)$ & $22(76)$ & $19(79)$ & $10(63)$ & $9(60)$ & $4(67)$ & $3(75)$ \\
Grade II & $3(10)$ & $5(17)$ & $3(13)$ & $1(6)$ & $1(7)$ & 0 & 0 \\
Grade III & $1(3)$ & 0 & $1(4)$ & $1(6)$ & 0 & 0 & 0 \\
Grade IV & 0 & 0 & - & 0 & $1(7)$ & 0 & 0
\end{tabular}

Leukocytopenia, $\mathbf{n}(\%)$

$\begin{array}{lccccccc}\text { Grade I } & 1(3) & 2(7) & 2(8) & 0 & 1(7) & 1(17) & 1(25) \\ \text { Grade II } & 0 & 0 & 0 & 0 & 0 & 0 & 0 \\ \text { Grade III } & 0 & 0 & 0 & 0 & 0 & 0 & 0 \\ \text { Grade IV } & 0 & 0 & 0 & 0 & 0 & 0 & 0\end{array}$

Thrombocytopenia, $\mathbf{n}(\%)$

$\begin{array}{lccccccc}\text { Grade I } & 2(7) & 3(10) & 2(8) & 3(19) & 3(20) & 1(17) & 0 \\ \text { Grade II } & 1(3) & 0 & 0 & 0 & 1(7) & 0 & 0 \\ \text { Grade III } & 0 & 0 & 0 & 0 & 0 & 0 & 0 \\ \text { Grade IV } & 0 & 0 & 0 & 0 & 0 & 0 & 0\end{array}$

\section{Renal insufficiency, $\mathbf{n}(\%)$}

$\begin{array}{lccccccc}\text { Grade I } & 5(17) & 5(19) & 3(13) & 2(13) & 4(27) & 2(33) & 1(25) \\ \text { Grade II } & 0 & 0 & 1(4) & 1(7) & 0 & 0 & 0 \\ \text { Grade III } & 0 & 0 & 0 & 0 & 0 & 0 & 0 \\ \text { Grade IV } & 0 & 0 & 0 & 0 & 0 & 0 & 0\end{array}$

Deterioration, $\mathrm{n}(\boldsymbol{\Delta})$

$\begin{array}{lcccccc}\text { Anemia } & 6(I) & 3(I), 2(I I) & 0 & 2(I) & 0 & 0 \\ \text { Leukocytopenia } & 2(I) & 2(I) & 0 & 1(I) & 1(I) & 1(I) \\ \text { Thrombocytopenia } & 2(I) & 1(I) & 2(I) & 3(I), 1(I I) & 1(I) & 0 \\ \text { Renal insufficiency } & 1(I) & 2(I) & 2(I) & 2(I) & 1(I) & 0\end{array}$

Improvement, $\mathbf{n}(\boldsymbol{\Delta})$

\begin{tabular}{llccccc} 
Anemia & $2(I)$ & $1(I)$ & $1(I)$ & 0 & 0 & 0 \\
Leukocytopenia & $1(I)$ & 0 & 0 & 0 & 0 & 0 \\
Thrombocytopenia & $1(I)$ & 0 & 0 & $1(I)$ & 0 & 0 \\
Renal insufficiency & $1(I)$ & $2(I)$ & $2(I)$ & $2(I)$ & 0 & 0 \\
\hline
\end{tabular}

$\mathrm{n}=$ number of patients, $\Delta=$ change in CTCAE grade compared to baseline 
Supplementary Table 2. Clinical, biochemical \& imaging response on PSMA PET/CT after separate therapy cycles

\begin{tabular}{|c|c|c|c|c|}
\hline Treatment cycle & 1 & 2 & 4 & 6 \\
\hline Evaluable for PSA response, $n$ (\%) & 29 & 24 & 14 & 4 \\
\hline Increase $\geq 25 \%$ & $7(24)$ & $4(2)$ & $2(14)$ & 0 \\
\hline Stable PSA* & $8(28)$ & $6(25)$ & $1(7)$ & $1(25)$ \\
\hline$\geq 25-50 \%$ decrease & $3(10)$ & $5(36)$ & $2(14)$ & 0 \\
\hline$\geq 50-90 \%$ decrease & $10(34)$ & $5(21)$ & $5(36)$ & $2(50)$ \\
\hline$\geq 90 \%$ decrease & $1(3)$ & $4(17)$ & $4(29)$ & $1(25)$ \\
\hline Evaluable for imaging response, $n(\%)$ & & 23 & 15 & 4 \\
\hline Complete response & NA & 0 & 0 & 0 \\
\hline Partial response & NA & $12(52)$ & $7(47)$ & $3(75)$ \\
\hline Mixed response & NA & $2(9)$ & $2(13)$ & $1(25)$ \\
\hline Stable disease & NA & $5(22)$ & $3(20)$ & 0 \\
\hline Progressive disease & NA & $4(17)$ & $3(20)$ & 0 \\
\hline Evaluable for pain response, $n$ (\%) & 20 & 15 & 8 & 3 \\
\hline Increased use of analgesics & $4(20)$ & $2(13)$ & 0 & 0 \\
\hline Decreased use of analgesics & $9(45)$ & $8(52)$ & $6(75)$ & $3(100)$ \\
\hline Unchanged use of analgesics & $5(25)$ & $4(27)$ & $2(25)$ & 0 \\
\hline
\end{tabular}





\section{CHAPTER 7}

Visual deficit possibly caused by $\left[{ }^{177} \mathrm{Lu}\right]$ Lu-PSMA treatment

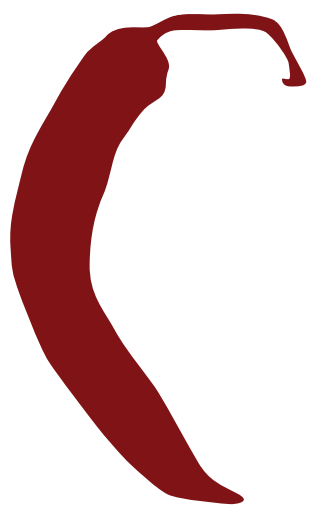

L.W.M. van Kalmthout, A.H. Stam, R. Gans, M.G.E.H. Lam BMJ Case Reports. 2018 Oct 8;2018:bcr2018225508. 


\section{INTRODUCTION}

Over the last years, Prostate Specific Membrane Antigen (PSMA)-targeting radiotracers in the setting of prostate carcinoma diagnosis (Gallium-68 $\left({ }^{68} \mathrm{Ga}\right)$ PSMA-11) and treatment (Lutetium-177 ( $\left.{ }^{177} \mathrm{Lu}\right)$ PSMA-617) are increasingly used. Expressed by the epithelial cells of the prostate, PSMA is a transmembrane glycoprotein that is upregulated in prostate carcinoma cells [1].

Since expression of the PSMA receptor on the cell surface of prostate cancer cells is associated with the tumor's aggressiveness, it represents an attractive target for diagnosis and treatment of prostate carcinoma using radiotracers: so-called Peptide Receptor Ligand Therapy (PRLT). After binding to the PSMA receptor, the radioligand is transported into the cell and induces local radiation of the primary tumor and (distant) metastases.

Since its introduction in German institutions several years ago, safety of ${ }^{177}$ Lu-PSMA-617 therapy has only been established in one prospective study in which ${ }^{177}$ Lu-PSMA-617 therapy was found to be well-tolerated with low toxic effects [2]. This report describes a case in which a potential therapy-related adverse event occurred. Describing this case, we aim to add to the discussion on ${ }^{177}$ Lu-PSMA safety, in which randomizedcontrolled research will ultimately offer definite answers.

\section{CASE REPORT}

A 54-year old patient with metastatic castration resistant prostate cancer (mCRPC), was referred to our hospital because of Prostate Specific Antigen (PSA)-progression while undergoing treatment with Abiraterone. He was diagnosed with high risk PCa (initial PSA 281; Gleason Score 9) in October 2015. Previous therapies included androgen deprivation therapy and chemotherapy (Docetaxel and Cabazitaxel). Besides fatigue and leg stiffness, the patient did not suffer from any relevant symptoms at baseline. Laboratory parameters showed no signs of hematological toxicity, alkaline phosphatase was increased (3114 U/I) and PSA-level was $3500 \mathrm{ng} / \mathrm{ml}$. PSA doubling time was 1 month. Baseline ${ }^{68} \mathrm{Ga}$-PSMA PET/ 
CT showed extensive diffuse bone-dominant metastatic disease, with multiple PSMA-positive lymph nodes (Figure 1A). Whereas involvement of the skull was found, no intracerebral lesions were detected. Considering the extensive PSMA uptake of the osseous lesions, the patient was indicated for ${ }^{177}$ Lu-PSMA therapy.
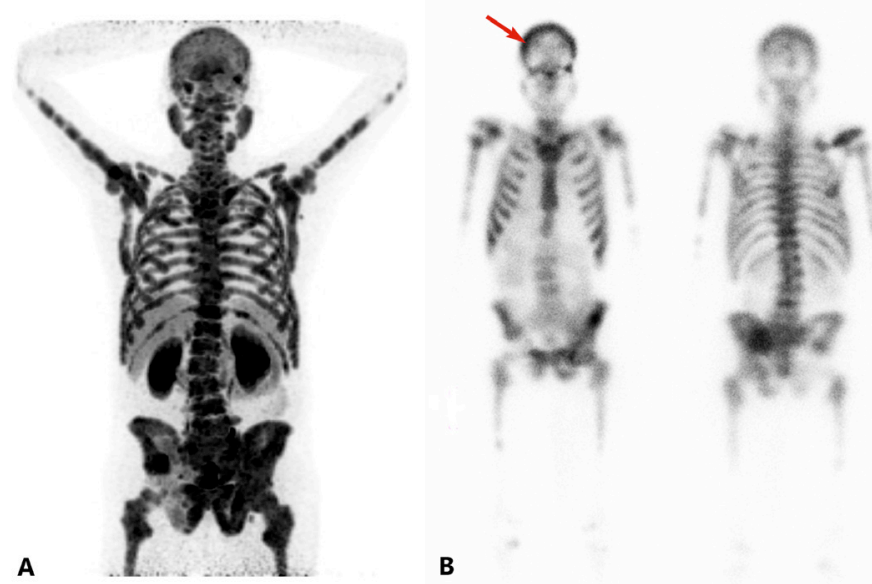

Figure 1. A (baseline ${ }^{68} \mathrm{Ga}-\mathrm{PSMA}-11 \mathrm{PET} / \mathrm{CT}$ September 2017) and B (post-treatment scintigraphy of the $2^{\text {nd }}$ treatment). Image $A$ shows extensive bone-dominant metastatic disease with involvement of the whole axial and appendicular skeleton, including the skull. Additionally, multiple PET-positive bilateral para-aortic, para-iliac and inguinal lymph nodes were detected. Image B shows intense PSMA uptake in the whole skeleton including the skull (red arrow). No new lesions were detected.

Administration of 6.0 GBq ${ }^{177} \mathrm{Lu}-\mathrm{PSMA}-617$ (40 $\mu \mathrm{g}$ PSMA-617) took place in October 2017. Post-therapy scintigraphy showed intense PSMA uptake in the known diffuse bone lesions. After the first cycle, (preexistent) symptoms of fatigue, muscle stiffness and (new) xerostomia were reported, all CTCAE (Common Terminology Criteria Adverse Events) grade I. Hematological toxicity was limited to a CTCAE grade I leukopenia. 
Considering the absence of serious side effects and the significant decrease of alkaline phosphatase to $1648 \mathrm{U} / \mathrm{L}$, it was decided to continue with the second therapy cycle, although PSA-level increased to $5900 \mathrm{ng} / \mathrm{ml}$.

The second cycle with ${ }^{177}$ Lu-PSMA- 617 was administered 6 weeks after. Disaccording with the sharply rising PSA, post-therapy scintigraphy showed stable disease with similar PSMA uptake in the known skeletal lesions (Figure 1B). During hospital admission, patient did not mention vision-related symptoms. One week later however, patient visited the oncology outpatient clinic with a slowly impairing, bilateral visual loss. In retrospect he had visual complaints since two months and also suffered from unilateral paresthesia in the tongue, suggestive of hypoglossal nerve involvement. He reported no headache. Patient was referred to the ophthalmologist, who found severe bilateral papilledema on fundoscopy (Figure 2). Magnetic resonance imaging (MRI) of the brain and orbita revealed diffuse dural thickening with gadolinium enhancement (Figure 3). No cranial nerve enhancement, retro-orbital pathology or hydrocephalus was seen.

Patient was admitted to the neurology department for further examinations. Lumbar puncture revealed an elevated opening pressure (47, $>50$ and $>50 \mathrm{~cm} \mathrm{H}_{2} \mathrm{O}$, respectively). Cerebrospinal fluid (CSF) white blood cell count was normal $\left(0 \times 10^{6} / \mathrm{L}\right)$, protein slightly elevated $(0.75 \mathrm{~g} / \mathrm{L})$ and glucose normal (3.7 mmol/L). Cytological examination, up to three times, did not reveal malignant cells within the CSF. Sinus thrombosis was excluded by CT cerebral venography. A thrombus was found in the left jugular vein, but without severe occlusion. Therefore the increased intracranial pressure (ICP) could not be explained. Spine MRI showed extensive diffuse metastatic bone disease with epidural and foraminal extension on several levels, but no linear or nodular enhancement along the spine or cauda equina suggestive of leptomeningeal metastasis.

Aiming to preserve residual vision, drainage of the liquor was performed, first via repeated lumbar punctures and later via an external lumbar drain. Unfortunately, the ICP remained high, the patient's vision further 


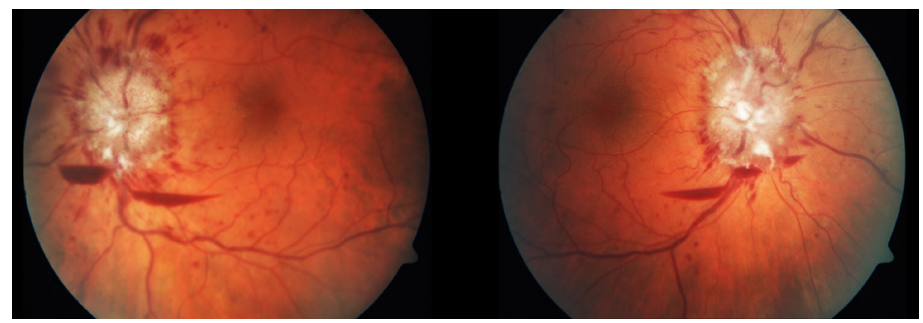

Figure2. Severe bilateral papilledema on fundoscopy. The severity of the papilledema suggests compressive or infiltrative optic neuropathy rather than toxic neuropathy.

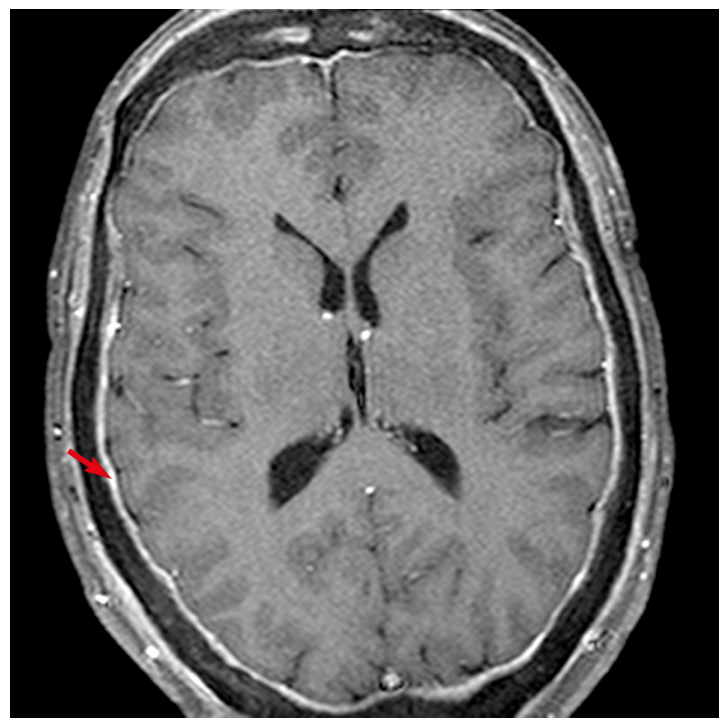

Figure 3. Gadolineum enhanced T1-weighted brain MRI showing diffuse dural thickening and enhancement suggestive of pachymeningitis or dural metastasis. No leptomeningeal or cranial nerve enhancement was seen. 
deteriorated and ultimately the patient became completely blind. Treatment with acetazolamide and dexamethasone was started to pragmatically reduce the ICP. Left-sided ptosis, bilateral hearing loss suggestive of cranial nerve palsy occurred. In absence of any other mCRPC treatment options, the patient received best supportive care. Considering the poor prognosis, patient was transported to a hospice after hospital admission for 11 days. The patient died in January 2018. Postmortem autopsy was refused, so a histopathological confirmation of either dural metastases or diffuse inflammation after ${ }^{177}$ Lu-PSMA-617 is lacking. All procedures performed in this analysis were in accordance with the ethical standards of the institutional and/or national research committee and with the 1964 Helsinki declaration and its later amendments or comparable ethical standards.

\section{DISCUSSION}

To our knowledge, this is the first case of a MCRPC patient who developed severe bilateral papilledema after initiation of ${ }^{177}$ Lu-PSMA-617 therapy. However, the aforementioned prospective study, describing ${ }^{177}$ Lu-PSMA treatment in 30 patients, reported on one case in which base of skull disease caused oculomotor nerve disorder [2]. ${ }^{177}$ Lu-PSMA-617 therapy in this patient was continued. Overall, clinical and biochemical toxic effects amongst the treated patients were infrequent and mild. Hence, the authors considered ${ }^{177}$ Lu-PSMA-617 to be associated with low toxicity profiles. A retrospective multicenter-study including 145 mCRPC patients, reported on safety profiles of ${ }^{177}$ Lu-PSMA therapy [3]. Included patients underwent 1-4 cycles with $5.9 \mathrm{GBq}$ (range 2-8 GBq) ${ }^{177} \mathrm{Lu}-\mathrm{PSMA}-617$. Median follow-up was 16 weeks (range 2-30 weeks). In 126 patients (87\%) the tumor involved osseous structures; lymph nodes were affected in 112 patients (77\%), the liver in 30 patients (20\%), lung tissue in 20 patients (14\%) and other sites in 3 patients (2\%). Unfortunately, the latter lesions were not further specified.

Data on physician-reported toxicity was available in 145 patients, of which neurologic disorders included mild vertigo in 1 patient (1\%) and stroke 
in 2 patients (1\%). Nineteen patients (13\%) died during the observation period; therapy-related death was not reported. It was concluded that ${ }^{177}$ Lu-PSMA-617 demonstrated favorable safety in MCRPC patients.

Besides developing lymphatic metastases, hematogenous spread of prostate cancer predominantly results in bone metastases. Involvement of visceral metastatic sites such as lung and liver are quite common, while pleural metastases, carcinomatous peritonitis and adrenal gland metastases have also been documented [4]. Conversely, brain metastases are seldom and occur in only $0.6-2.1 \%$ of the mCRPC patients [5][6]. Leptomeningeal metastases in particular have only sporadically been described in the setting of $\mathrm{MCRPC}$ [7][8]. Although the brain is believed to be relatively resistant to the development of metastases, epidural metastases can develop through contiguous spread from the calvaria to the meninges [6]. Clinically apparent brain metastases typically develop once mCRPC has spread to the brain parenchyma, leptomeninges or skull [9]. Prognosis of these patients appears limited. In a large study including 16.280 patients, overall median survival was only 1 month ( $95 \%$ Cl: 0.8 to 1.2 months) [6].

In our patient, the clinical presentation was most likely the result of the high ICP due to impediment of CSF circulation, possibly related to obstructive dural thickness, either caused by dural and/or leptomeningeal metastases of advanced mCRPC or by local radiation induced inflammation following ${ }^{177}$ Lu-PSMA therapy. Although considered rare, dural enhancement on MRI and the progressive cranial nerve involvement during hospital admission suggest the presence of dural and/or leptomeningeal metastases. Most likely, these metastases became symptomatic while our patient was progressing on his ${ }^{177}$ Lu-PSMA therapy cycles.

On the other hand, several findings do not support this hypothesis. Firstly, CSF cytology was negative up to three times. Secondly, there was no leptomeningeal enhancement on MRI, which would be expected in case the extreme high intracranial pressure was the result of leptomeningeal 
metastasis. Ultimately, the diffuse smooth aspect of dural enhancement without focal masses argues against dural metastasis. Thus, ${ }^{177}$ Lu-PSMA therapy may have led to toxic radiation effects, resulting in inflammation and dural thickening, occluding CSF flow and raised intracranial pressure. No such toxicity has been described before in patients treated with multiple cycles of either ${ }^{90} Y$ - or ${ }^{177}$ Lu-DOTATATE (even when combined with external beam radiotherapy) for malignant or inoperable meningiomas. Nonetheless, literature on radionuclide treatments in meningioma patients is sparse as well.

To our knowledge, this is the first case describing a possible neurological toxicity of ${ }^{177} \mathrm{Lu}-\mathrm{PSMA}$ treatment, although development of diffuse leptomeningeal metastases by progressive disease during ${ }^{177}$ Lu-PSMA therapy seems an alternative explanation. Additionally, the severity of the papilledema supports compressive or infiltrative optic neuropathy rather than direct toxic effects of ${ }^{177}$ Lu-PSMA therapy [10]. Unfortunately, lacking post-mortem autopsy results in our patient, any of the abovementioned scenarios can not be excluded, nor proven.

\section{CONCLUSION}

${ }^{177} \mathrm{Lu}-\mathrm{PSMA}$ therapy is promising in the setting of mCRPC. Although initial published results show favorable efficacy with minimal toxicity, more knowledge on safety profiles is needed. Randomized-controlled studies are warranted to investigate definite safety of ${ }^{177}$ Lu-PSMA therapy. 


\section{REFERENCES}

1. Wright GL, Jr., Haley C, Beckett ML, Schellhammer PF. Expression of prostatespecific membrane antigen in normal, benign, and malignant prostate tissues. Urol Oncol. 1995 Jan-Feb;1 (1):18-28.

2. Hofman MS, Violet J, Hicks RJ, et al.. [777Lu]-PSMA-617 radionuclide treatment in patients with metastatic castration-resistant prostate cancer (LuPSMA trial): a single-centre, single-arm, phase 2 study. Lancet Oncol. 2018 Jun;19(6):825833.

3. Rahbar K, Ahmadzadehfar H, Kratochwil C, et al. German Multicenter Study Investigating 177Lu-PSMA-617 Radioligand Therapy in Advanced Prostate Cancer Patients. J Nucl Med. 2017 Jan;58(1):85-90.4.

4. van Houte M, Meijer RP, Hobbelink MGG. Case report. Peritoneaal gemetastaseerd prostaatcarcinoom op de Gallium-68 PSMA PET/CT-scan. Case report. Peritoneaal gemetastaseerd prostaatcarcinoom op de Gallium-68 PSMA PET/CT-scan. Tijdschrift voor Urologie 2016:5.

5. Baumann MA, Holoye PY, Choi H. Adenocarcinoma of prostate presenting as brain metastasis. Cancer. 1984 Oct 15;54(8):1723-5.

6. Tremont-Lukats IW, Bobustuc G, Lagos GK, Lolas K, Kyritsis AP, Puduvalli VK. Brain metastasis from prostate carcinoma: the M.D. Anderson Cancer Center experience. Cancer. 2003;98:363-8.

7. Caffo O, Gernone A, Ortega C, et al. Central nervous system metastases from castration-resistant prostate cancer in the docetaxel era. J Neurooncol. 2012 Mar;107(1):191-6.

8. Cante D, Franco P, Sciacero P, et al. Leptomeningeal metastasis from prostate cancer. Tumori. 2013 Jan-Feb;99(1):6e-10e.

9. Baumann MA, Holoye PY, Choi H. Adenocarcinoma of prostate presenting as brain metastasis. Cancer. 1984;54:1723-5. Benjamin R. Neurologic complications of prostate cancer. Am Fam Physician. 2002;65:1834-40

10. Behbehani et al. clinical approach to optic neuropathies. Clin Ophthalmol. 2007 Sep;1 (3):233-46. 



\section{CHAPTER 8}

\section{Impact of external cooling on PSMA uptake in salivary glands}

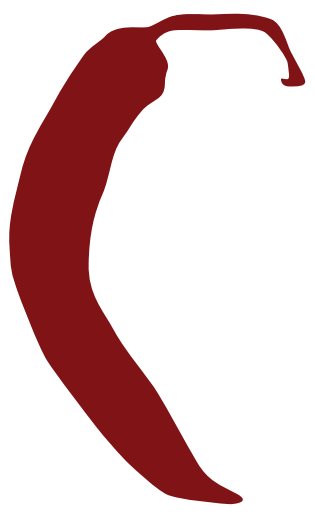

L.W.M. van Kalmthout, M.G.E.H. Lam, B. de Keizer, G.C. Krijger, F.F.T. Ververs, R. de Roos, A.J.A.T. Braat 


\section{ABSTRACT}

\section{Purpose}

External cooling of the salivary glands is advised to prevent xerostomia in lutetium-177-PSMA treatment for advanced prostate cancer. Since evidence addressing this subject is sparse, this study aims to determine impact of icepacks application on uptake in salivary glands.

\section{Methods}

Eighty-nine patients referred for gallium-68-PSMA PET/CT for (re)staging of prostate cancer were prospectively included. Twenty-four patients were scanned with unilateral (solely left-sided) icepacks; 20 with bilateral icepacks; 45 without icepacks. Icepacks were applied approximately 30 minutes prior to tracer injection. PET/CT acquisition started 1 hour post-injection. Radiotracer uptake was measured in the parotid- and submandibular glands.

\section{Results}

When comparing the intervention group with the control group, uptake in the left parotid gland significantly differed: SUVmax: $11.07 \pm 3.53$ versus $12.95 \pm 4.16 ; p=0.02$. SUVpeak: $9.91 \pm 3.14$ versus $11.45 \pm 3.61$; $p=0.04$. SUVmax and SUVpeak were reduced with $14.52 \%$ and $13.45 \%$. All other SUV values did not significantly differ. Patients with bilateral icepacks showed no significant differences in PSMA uptake compared to the control group (all: $p>0.05$ ). Intra-patient analysis revealed some significant differences in SUVmax and SUVpeak between the cooled and non-cooled parotid gland (SUVmax: $11.12 \pm 3.71$ versus $12.69 \pm 3.75 ; \mathrm{p}=$ 0.00. SUVpeak: $9.93 \pm 3.32$ versus $11.25 \pm 3.25 ; p=0.00$ ).

\section{Conclusions}

Impact of icepacks on PSMA uptake seems to be limited to the parotid glands. As clinical relevance of these findings is debatable, structural application of icepacks in the setting of lutetium-177 PSMA therapy needs careful consideration. 


\section{BACKGROUND}

Prostate Specific Membrane Antigen (PSMA)-targeting radiotracers have gained popularity over the last years in the setting of prostate carcinoma diagnosis (Gallium-68 ( $\left.{ }^{68} \mathrm{Ga}\right)$ PSMA) and treatment (Lutetium-177 $\left({ }^{177} \mathrm{Lu}\right)$ PSMA). PSMA is a transmembrane glycoprotein that is expressed by epithelial cells of the prostate. PSMA is 100-1000 times upregulated in prostate carcinoma cells, compared to benign prostate tissue. Its expression is directly correlated with the tumor's aggressiveness [1]. Therefore, it represents an attractive target for diagnosis and treatment of prostate carcinoma using radioligands: so-called Peptide Receptor Ligand Therapy (PRLT). ${ }^{177} \mathrm{Lu}-\mathrm{PSMA}$ is a low molecular weight ligand that binds to the cell surface of prostate cancer cells. It is subsequently transported into the cell by receptor mediated endocytosis, resulting in beta-emission and local radiation of prostate cancer cells to both the primary tumor and (distant) metastases.

Initially believed to be prostate-specific, the PSMA receptor is expressed by other, both benign and malignant, tissues including the kidneys (proximal tubules), the jejunum (brush border), astrocytes and Schwann cells in the central nervous system, ductal epithelium of breast tissue and skeletal muscle [2]. In addition, significant PSMA expression is evident in the salivary glands: mean SUV ${ }_{\max }$ in the parotid and submandibular glands 1 hour post-injection was found to be 13.8 (9.0-28.3) and 14.5 (7.227.5), respectively [3]. Preliminary research in our institution also found a physiological high tracer accumulation in the salivary glands in 30 consecutive patients who underwent ${ }^{68} \mathrm{Ga}$-PSMA PET/CT for (re)staging of prostate cancer. Mean SUV ${ }_{\max }$ in the parotid and submandibular glands 1 hour post-injection was 12.3 (range 5.2-22.9) and 11.7 (range 6.0-22.2), respectively [4].

The high accumulation of therapeutic radioligands in the salivary glands may result in the frequently observed, undesirable side effect xerostomia. External cooling of the salivary glands is hypothesized to cause vasoconstriction, reduce blood flow and decrease PSMA uptake in 
the salivary glands to ultimately prevent the salivary glands for radiation toxicity [5]. Therefore, external cooling of the salivary glands with icepacks, considered to be a harmless and well-tolerable procedure, is currently performed in clinical practice [6]. To date however, there has been no established evidence that cooling indeed decreases PSMA uptake in the salivary glands, without additional patient discomfort.

Since it is expected that ${ }^{177}$ Lu-PSMA therapy will be more widely applied over the next years, universal optimization of per-procedural scan protocols are needed. This study aims to clarify the impact of cooling with icepacks on PSMA uptake in salivary glands to guide ${ }^{177}$ Lu-PSMA treatment in the future.

\section{METHODS}

\section{Study population}

Patients referred for a ${ }^{68} \mathrm{Ga}$-PSMA-11 PET/CT for (re)staging of prostate cancer were consecutively included in this analysis from September 2016 up to March 2017, after obtaining informed consent. We first included the intervention group: 20 patients who were scanned with bilateral icepacks, followed by 24 patients who were scanned with unilateral (solely leftsided) icepacks. The control group included 45 patients who were retrospectively included. Patients who underwent previous radiation therapy on the head/neck-region were excluded from analysis.

\section{Ga-PSMA-11 preparation}

${ }^{68} \mathrm{Ga}-\mathrm{PSMA}-11$ was prepared using a GMP-grade ${ }^{68} \mathrm{Ge} /{ }^{68} \mathrm{Ga}$ generator and a semi-automated Modular-Lab eazy synthesis module (Eckert \& Ziegler, Berlin, Germany). Each synthesis was performed following the manufacturers' instructions using prefabricated materials including a cassette, an acetate buffer, a C18 purification cartridge and a $0.22 \mu \mathrm{m}$ pore size sterilization filter (Eckert \& Ziegler, Berlin, Germany). $40 \mu \mathrm{g}$ (42 nmol) of PSMA-11 ligand (ABX, Radeberg, Germany) per preparation was used, leading to the a mean administered amount of 14.5 (range $5.1-41.1) \mu \mathrm{g}$ ligand per patient depending on patient weight and ${ }^{68} \mathrm{Ge}$ decay. 


\section{PET/CT acquisition and image reconstruction}

Images were acquired from skull vertex to the thighs using a Biograph mCT40 scanner (Siemens, Erlangen, Germany). After intravenous injection of $2 \mathrm{MBq} / \mathrm{kg}{ }^{68} \mathrm{Ga}-\mathrm{PSMA}-11,500 \mathrm{ml}$ of saline was intravenously administered. Frozen icepacks were placed in an in-house made synthetic cover, allowing for full coverage of the targeted salivary glands and effective fixation to the patient's face. An example of this cooling device is shown in Figure 1. In the patient group scanned with unilateral icepacks, the icepack was exclusively placed on the left side of the cover. The icepacks were applied approximately 30 minutes prior to tracer injection up to termination of the scanning procedure (approximately 100 minutes). All icepacks were replaced for new ones 30 minutes prior to PET/CT acquisition to ensure continuous, effective cooling of the salivary glands. PET-images were acquired 45 minutes after radiotracer administration. A low dose CT was performed directly following PET-imaging, approximately 60 minutes after radiotracer administration. Images were acquired according to the European Association of Nuclear Medicine (EANM)criteria, a.k.a. EARL-reconstructions, with the following parameters: PET with time-of-flight and point spread function reconstruction, 4 iterations, 21 subsets, with a filter of $7.5 \mathrm{~mm}$ full width at half maximum [7].

\section{Image analysis}

Radiotracer uptake in the parotid glands and the submandibular glands was quantitatively assessed, using a commercial software package (Syngo.via; Siemens Healthcare). Mean, peak and maximum standardized uptake values (SUV max $_{\text {, }}$ SUV $V_{\text {peak }}$ and SUV mean $_{\text {) }}$ ) were measured by placing a 3D-volume of interest (VOI) within bilateral parotid and submandibular gland region on the PET/CT images. Salivary glands were delineated using a $10 \%$ threshold of the maximum pixel value within the VOI (isocontour). Measurements were corrected for Lean Body Mass, according to the formula as defined in the EANM guidelines [8]. Measurements were executed by one involved researcher and were randomly checked by an experienced nuclear medicine physician. Blinding of images, masking the applied icepacks, was not performed. 

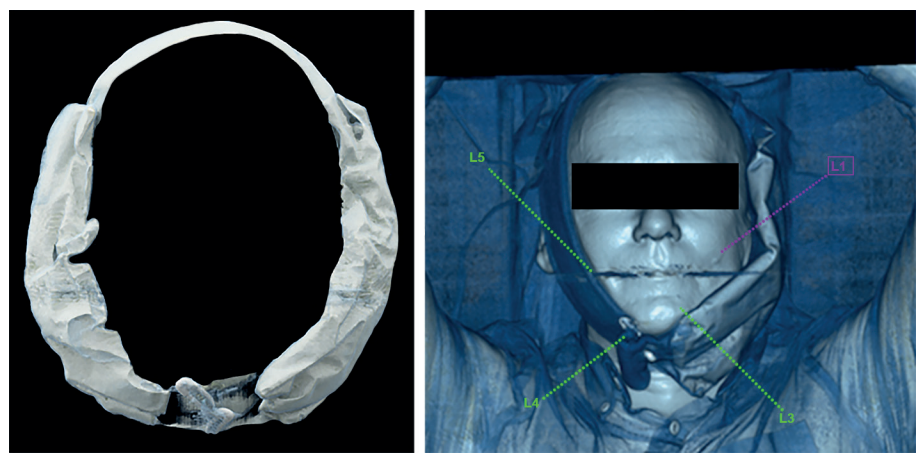

Figure 1. The cooling device as used in this study (left); a patient scanned with a unilateral left-sided icepack (right)

\section{Statistical Analysis}

Statistical analyses were performed using IBM SPSS Statistics for Mac, version 24. Aiming at a PSMA uptake reduction of $40 \%$ by the application of icepacks and assuming a type I error of 0.05, a power-analysis revealed the required number of patients for comparison to be 45 in the intervention group and 45 in the control group. Means of continuous data at baseline were compared using the oneway-anova test. Means of nominal data were analyzed using the chi-square test. To compare mean radiotracer uptake in the bilateral icepack group with the control group, an independent T-test was used. A paired T-test was used to compare inpatient radiotracer uptake differences in the unilateral icepack group. Statistical significance was established for $p$-values of $<0.05$.

\section{RESULTS}

A total number of 71 patients was approached for inclusion. Twenty-five patients did not agree with inclusion; 2 patients were excluded because of a previous history of radiation therapy to the head/neck-region. Twenty-four patients were scanned with a unilateral icepack on the left side, allowing intra-individual analysis, and 20 patients were scanned with 
bilateral icepacks, totaling 44 patients in the intervention group. A control group of 45 patients was scanned without icepacks, in line with regular clinical practice. Baseline characteristics of the included patient groups are presented in Table 1. Comparison of various baseline criteria did not reveal any statistical differences.

\section{Radiotracer activity in the intervention group versus control group}

When comparing SUV values in the intervention group (bilateral + unilateral icepacks-group) with the control (no-icepacks) group, significant differences were found with regard to radiotracer uptake in the left parotid gland. In the control group, SUV ${ }_{\max }$ in the left parotid gland was $12.95 \pm 4.16$, versus $11.07 \pm 3.53$ in the intervention group $(p=0.02)$. Absolute reduction was $14.52 \%$. SUV peak $_{\text {in }}$ in the control group was $11.45 \pm$ 3.6), compared to $9.91 \pm 3.14$ in the intervention group $(p=0.04)$. SUV $V_{\text {peak }}$ was reduced with $13.45 \%$. All other SUV values did not significantly differ, as shown in Table 2.

\section{Radiotracer activity in the bilateral icepack-group versus control group}

Patients with bilateral icepacks showed no significant differences in PSMA uptake, when compared to the control group (all $p>0.05$ ); right parotid

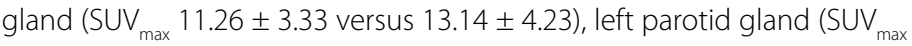
$11.01 \pm 3.40$ versus $12.96 \pm 4.16$ ), right submandibular gland (SUV ${ }_{\max } 12.36$ \pm 3.38 versus $12.54 \pm 3.36$ ) and left submandibular gland (SUV ${ }_{\max } 11.74$

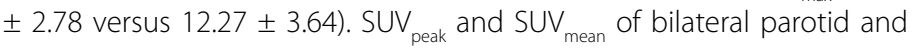
submandibular glands in both groups did not significantly differ either. Results are summarized in Table 3.

\section{Radiotracer activity in the unilateral icepack-group (intra-patient analysis)}

In the unilateral icepack-group (with cooled left side), some significant

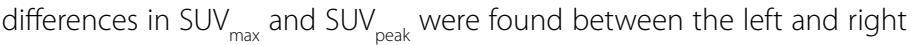
parotid gland (SUV max $_{\text {max }}$ cooled left side: $11.12 \pm 3.71$ versus SUV $_{\max }$ noncooled right side: $12.69 \pm 3.75 ; p=0.00$. SUV ${ }_{\text {peak }}$ cooled left side: $9.93 \pm 3.32$ versus SUV $_{\text {peak }}$ non-cooled right side: $11.25 \pm 3.25 ; \mathrm{p}=0.00$ ). Fractional 
Part II| Prostate cancer therapy

Table 1. Baseline characteristics

\begin{tabular}{|c|c|c|c|c|}
\hline \multirow[t]{2}{*}{ Subjects } & \multicolumn{2}{|c|}{$\begin{array}{l}\text { Intervention group } \\
\qquad(\mathrm{n}=44)\end{array}$} & \multicolumn{2}{|c|}{$\begin{array}{l}\text { Control group } \\
(n=45)\end{array}$} \\
\hline & $\begin{array}{l}\text { Left-sided } \\
\text { icepacks } \\
(n=24)\end{array}$ & $\begin{array}{l}\text { Bilateral } \\
\text { icepacks } \\
(n=20)\end{array}$ & $\begin{array}{c}\text { no icepacks } \\
(n=45)\end{array}$ & P-value* \\
\hline \multicolumn{5}{|l|}{ Age (years) } \\
\hline $\begin{array}{l}\text { Mean }( \pm S D) \\
\text { Range (years) }\end{array}$ & $\begin{array}{c}72.79 \\
( \pm 4.86) \\
64-81\end{array}$ & $\begin{array}{l}71.00 \\
( \pm 5.91) \\
62-82\end{array}$ & $\begin{array}{c}70.67 \\
( \pm 7.57) \\
49-91\end{array}$ & 0.46 \\
\hline Initial Gleason Score (n) & 24 (0 missing) & 18 (2 missing) & 41 (4 missing) & \\
\hline $\begin{array}{l}\text { Low risk }(<7) \\
\text { Intermediate risk }(7) \\
\text { High risk }(>7)\end{array}$ & $\begin{array}{l}9 \\
7 \\
8\end{array}$ & $\begin{array}{l}9 \\
5 \\
4\end{array}$ & $\begin{array}{c}8 \\
19 \\
14\end{array}$ & 0.17 \\
\hline \multicolumn{5}{|l|}{ PSA at scan (ng/ml) } \\
\hline $\begin{array}{l}\text { Mean }( \pm S D) \\
\text { Range }\end{array}$ & $\begin{array}{c}24.3( \pm 35.23) \\
1.10-164.7\end{array}$ & $\begin{array}{c}11.79( \pm 10.61) \\
0.12-35.0\end{array}$ & $\begin{array}{c}18.17( \pm 31.68) \\
0.20-120.0\end{array}$ & 0.38 \\
\hline Scan Indication (n) & 24 (0 missing) & 20 (0 missing) & 45 (0 missing) & \\
\hline $\begin{array}{l}\text { Primary staging } \\
\text { Re-staging } \\
\text { Other indications }\end{array}$ & $\begin{array}{c}5 \\
19 \\
0\end{array}$ & $\begin{array}{c}2 \\
17 \\
1\end{array}$ & $\begin{array}{c}4 \\
35 \\
6\end{array}$ & \\
\hline
\end{tabular}

Previous therapy regimens (n) 24 (0 missing) 19 (1 missing) 45 (0 missing)

$\begin{array}{lccc}\text { No treatment } & 5 & 0 & 4 \\ \text { Radical prostatectomy } & 3 & 6 & 17 \\ \text { Radiation therapy } & 10 & 11 & 12 \\ \begin{array}{l}\text { Radiation therapy + } \\ \text { hormonal therapy (Bolla }\end{array} & & & \\ \begin{array}{l}[22]) \\ \text { Other treatment }\end{array} & 4 & 1 & 7 \\ \text { regimens } & & 1 & 5\end{array}$

Adjuvant/salvage (radiation/ 24 (0 missing) 17 (3 missing) 44 (1 missing) 0.34 hormonal) therapy regimens (n)

\begin{tabular}{cccc} 
Yes & 9 & 3 & 11 \\
No & 15 & 14 & 33 \\
\hline
\end{tabular}

$P<0.05$ is considered significant 
Impact of external cooling on PSMA uptake in salivary glands

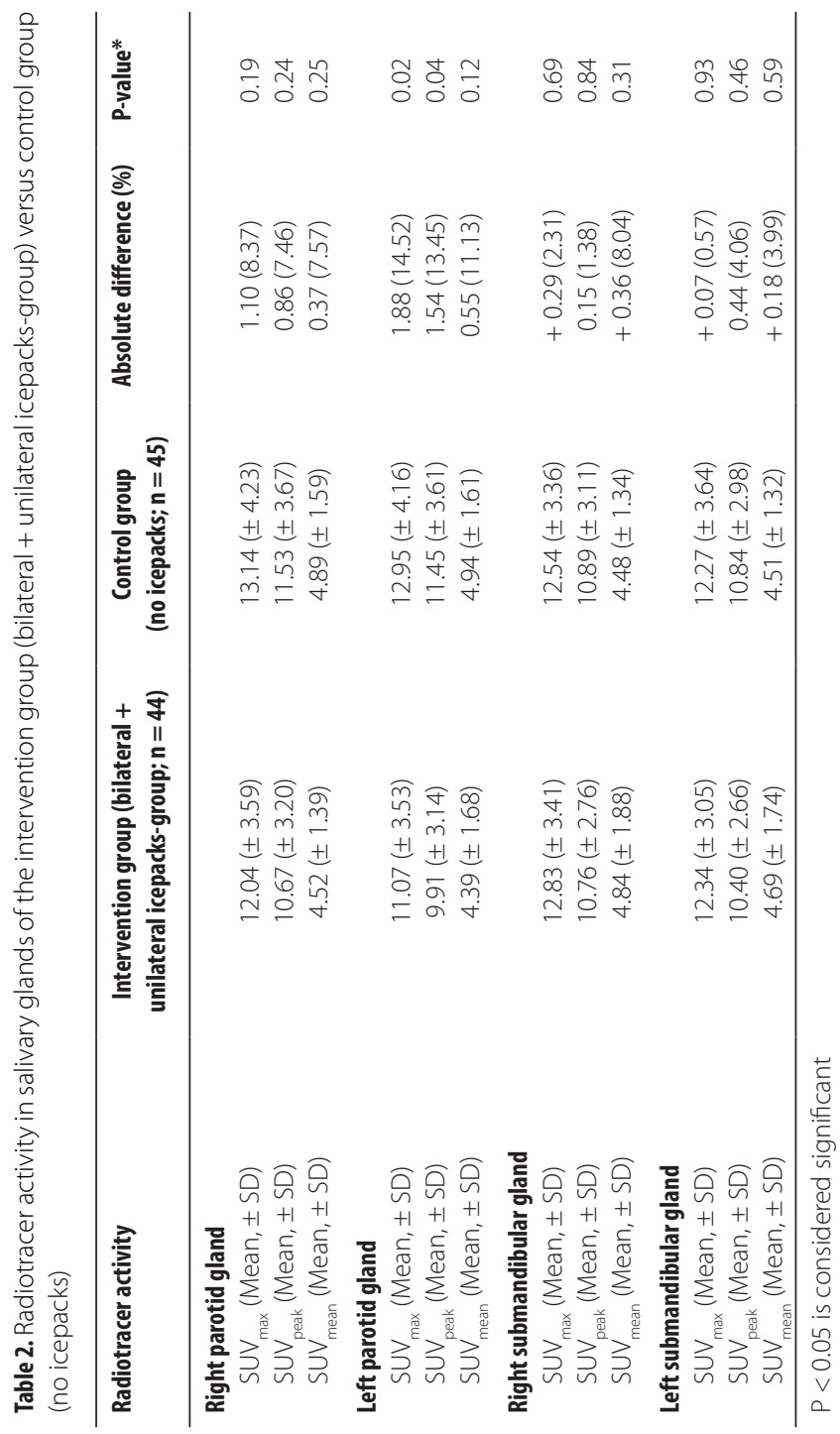


Part II| Prostate cancer therapy

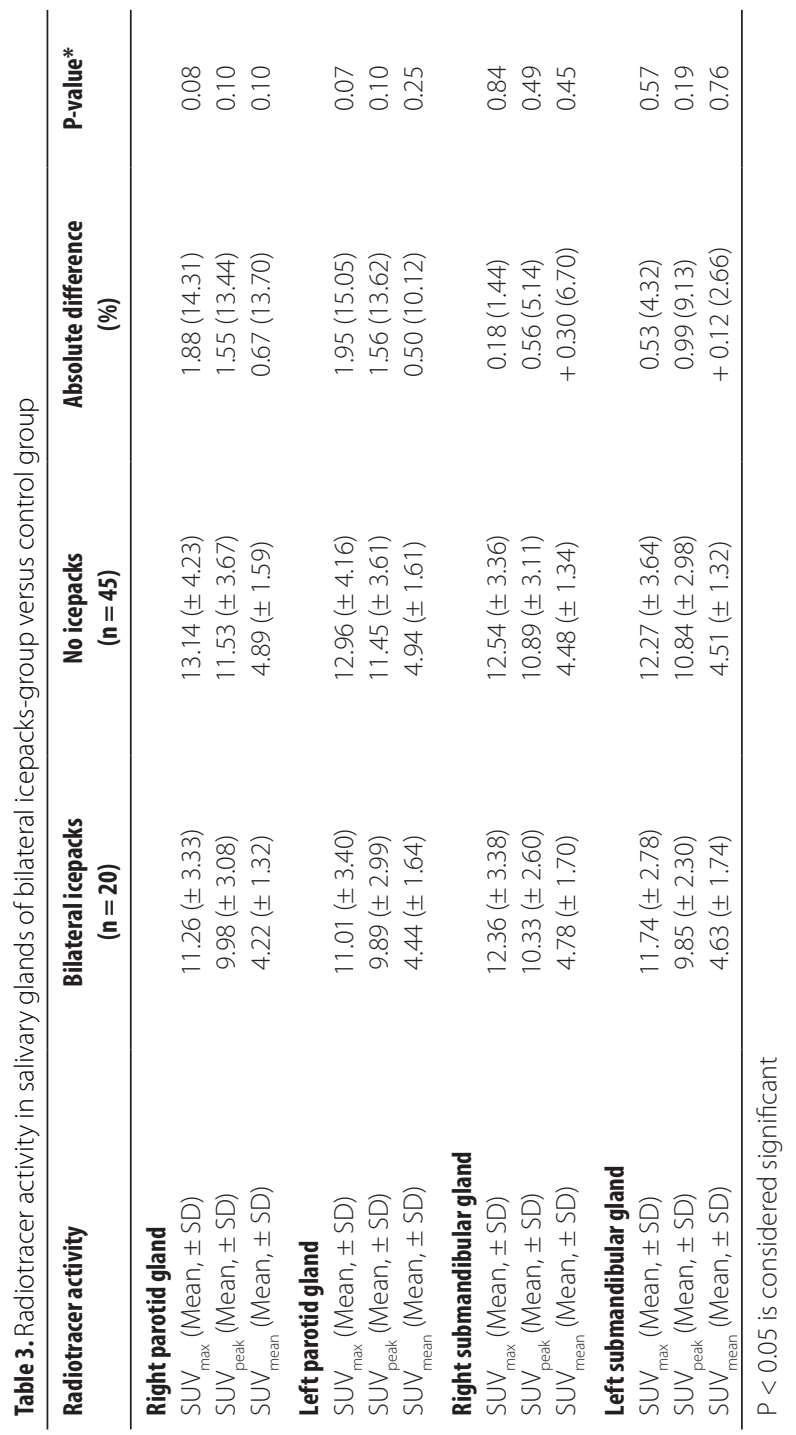




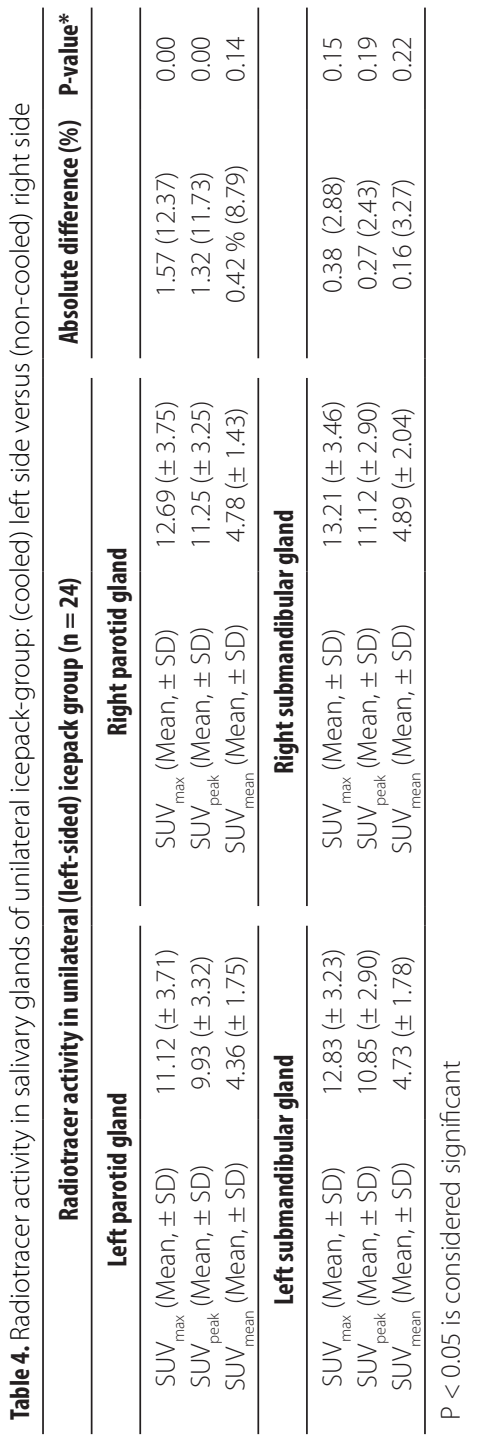



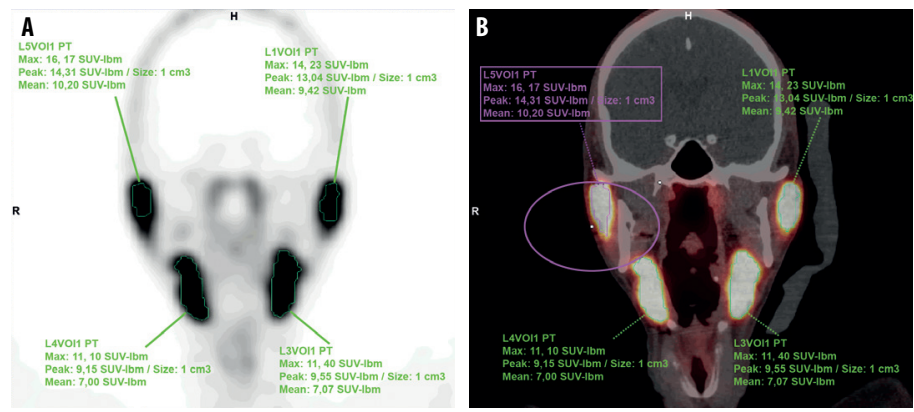

Figure 2. Measurements on PSMA uptake in both parotid glands in a patient who was scanned with a left-sided Icepack; Differences in PSMA uptake were observed, when comparing the cooled side (A) to the non-cooled side (B).

differences were $12.37 \%\left(\right.$ SUV $\left._{\text {max }}\right)$ and $11.73 \%\left(S_{\text {peak }}\right)$. Mean SUV mean $_{\text {men }}$ between the bilateral parotid glands and all parameters on PSMA uptake in the right versus the left submandibular glands did not significantly differ. SUV ${ }_{\text {mean }}$ in the parotid glands decreased with 8.79\%. Fractional difference of SUV values in the submandibular gland ranged from 2.43 to $3.27 \%$. Results are shown in Table 4.

\section{DISCUSSION}

The present study shows no significant differences in PSMA uptake comparing the patient group that was scanned with bilateral icepacks to the patient group that was scanned without icepacks. When comparing radiotracer uptake in the intervention group with the control group, however, significant differences were found with regard to radiotracer uptake in the left parotid gland. These findings were confirmed by the intra-patient analysis. Based on these results, external cooling of the salivary glands seems to have some impact. Clinical relevance of these findings, however, remains debatable. 
The rationale of skin cooling in the attempt to induce vasoconstriction of the peripheral blood vessels was earlier described in the literature on chemotherapy-induced alopecia [9]. Cooling is assumed to reduce skin perfusion, decrease concentration of chemotherapy in the scalp and consequently diminish cellular uptake by the hair follicles (due to a decreased metabolic activity of the cells). In a recently published review of 10 studies comprising 654 patients, it was concluded that scalp hypothermia indeed represents an effective preventative measure [10]. The same underlying mechanism is assumed to prevent the salivary glands for toxicity in patients undergoing ${ }^{177}$ Lu-PSMA therapy, hopefully reducing both specific as unspecific binding [11]. To our knowledge however, the effect of external cooling on PSMA uptake in the salivary glands was not investigated.

This is the first study that aims to systematically determine impact of external cooling on PSMA uptake in salivary glands in patients referred for ${ }^{68} \mathrm{Ga}$-PSMA PET/CT imaging in the setting of prostate cancer (re)-staging. However, several conference abstracts did address this issue earlier $[12,13]$. Gaertner et al. measured PSMA uptake (SUV mean $_{\text {and }}$ SUV $\left.{ }_{\max }\right)$ in the bilateral parotid and submandibular glands of an intervention group of 25 patients [12]. In this group, bilateral salivary glands were cooled with icepacks. PSMA uptake in the salivary glands was compared to SUV values of a control group that consisted of 33 patients. As a result of external

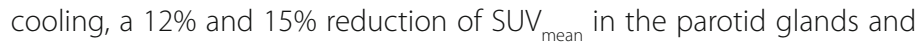
submandibular glands was found, respectively (all: $p<0.01$ ). Mean SUV $_{\max }$ decreased significantly in both parotid glands and submandibular glands as well (all: $p<0.01$ ). Bohn et al. included 50 patients undergoing diagnostic ${ }^{68} \mathrm{Ga}$-PSMA PET/CT for prostate cancer. PSMA uptake in an intervention group of 25 patients, of whom the left parotid gland was cooled with icepacks was compared with a control group of 25 patients who were scanned without icepacks [13]. Intra-patient analysis revealed the cooled left parotid gland showing 12\% less radiotracer uptake compared to the non-cooled side (range: $0-42 \% ; p=0.01$ ); a statistical significant difference that was, as expected, not found under 'normal' (non-cooled) circumstances. 
Several German studies assessed efficacy and toxicity of ${ }^{177}$ Lu-PSMA therapy in metastatic castration-resistant prostate cancer patients [1420]. The included patients in the studies by Ahmadzadehfar et al., Heck et al. and Rahbar et al. all underwent external cooling of the salivary glands $[14,15,17,19]$. These patients received bilateral icepacks covering the cheeks from 30 minutes prior to treatment, up to 4 hours postadministration of ${ }^{177}$ Lu-PSMA. Xerostomia was reported in $4-37 \%$ of the patients, probably caused by the high uptake of PSMA ligands in the salivary glands.

In the aforementioned study by Ahmadzadehfar et al., patients received icepacks covering the parotid and submandibular glands from 30 minutes prior to and up to 4 hours after administration of a single cycle ${ }^{177} \mathrm{Lu}$ PSMA [14]. All patients in this study underwent dynamic salivary gland scintigraphy with Technetium-99m ( $\left.{ }^{99 m} \mathrm{Tc}\right)$-pertechnetate combined with salivary gland stimulation by lemon juice 20 min post injection on the treatment day and 8 weeks after ${ }^{177}$ Lu-PSMA therapy to investigate salivary gland function. Comparison of baseline with follow-up salivary gland scintigraphy did not show therapy-induced functional impairment

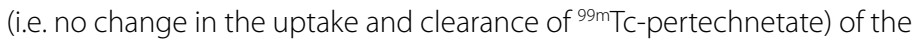
salivary glands. It was concluded that it is unclear whether cooling of the salivary glands is effective to prevent the salivary glands from therapyrelated damage. Furthermore, the need for a study addressing the change in uptake of ${ }^{68} \mathrm{Ga}$-PSMA with and without icepacks, was underlined.

The other study groups that did not apply icepacks reported on xerostomia in $4-7 \%$ of the patients $[16,18]$. Rahbar et al. investigated 56 metastatic castration-resistant prostate cancer patients that underwent ${ }^{177}$ Lu-PSMA-617 therapy. Whereas mean PSMA uptake in the salivary glands was found to be greater than the dose that was absorbed by the kidneys, only 2 patients (4\%) experienced mild, transient, xerostomia after 3 and 4 cycles. In the study by Kratochwil et al., 30 patients underwent 1-3 cycles ${ }^{177}$ Lu-PSMA-617 therapy. 2/30 patients developed xerostomia after the third cycle, in which prescription of artificial saliva was required. Less than $10 \%$ of the patients experienced temporal xerostomia after the 
first and second cycle, not affecting quality of life. It must be noted that the absolute number of patients experiencing transient xerostomia after treatment was not reported.

Evaluating the results of the abovementioned studies, remarkably less xerostomia was found in the patient groups that underwent therapy without cooling of the salivary glands, when compared to the patients that were supplied with icepacks during ${ }^{177} \mathrm{Lu}$-PSMA administration by other study groups. In this respect, it is important to note that the PSMA uptake in the salivary glands in the abovementioned studies was not objectified. Differences may have been caused by bias as a result of the subjective experience of therapy-related toxicity: patients undergoing ${ }^{177}$ Lu-PSMA therapy that were supplied with icepacks may have been more focused on xerostomia than patients that were not supplied with icepacks. Furthermore, since it concerned a retrospective study, results may have been reported less accurately.

The results of the present study are in line with those found in the abovementioned conference abstracts. Intra-patient analysis with regard to PSMA uptake in the parotid gland indeed revealed some significant findings. Comparison of radiotracer activity in the salivary glands of the entire intervention group versus the control group confirmed these findings: a significant reduction of SUV ${ }_{\text {max }}(p=0.02)$ and SUV $V_{\text {peak }}(p=0.04)$ was found in the left parotid gland. The absolute reduction was $14.52 \%$ and $13.45 \%$, respectively. A direct (inter-patient) comparison of the bilateral icepack-group with the control group did not reveal significant differences concerning radiotracer uptake in the salivary glands. Having a closer look to these specific results, however, marginal non-significant differences in radiotracer uptake were found regarding the SUV ${ }_{\max }$ in the bilateral parotid glands (right side $p=0.08$; left side: $p=0.07$ ). Absolute SUV $_{\max }$ reduction in the right parotid gland was $14.3 \%$ and $15.1 \%$ on the left side. These findings suggest that our results would be significantly different in a larger patient sample. On the other hand, when determining the required sample size for this study, a $40 \%$ reduction of radiotracer uptake was considered clinically relevant. 
The general, but not significant observed lower mean SUV values in the submandibular glands may be explained by the argument that cutaneous cooling is not equally affective for both the parotid and submandibular glands. The first explanation for this observation might be that the parotid glands are more susceptible to external cooling than submandibular glands, due to their more superficial anatomical localization. Secondly, the parotid glands may have been cooled more effectively than the submandibular glands, causing a greater difference between the cooled and the non-cooled side. Another, although less likely, potential factor may be that the parotid and submandibular glands respond differently to cooling: causing differences in vasoconstriction, blood flow, cellular metabolism, and radiotracer uptake. A vast analysis of the assumed relation between skin temperature, perfusion of the salivary glands and radiotracer uptake in patients undergoing PRLT may offer some clarification to the assumed underlying mechanism.

The general value of external cooling of the salivary glands to prevent of xerostomia in patients undergoing ${ }^{177} \mathrm{Lu}$-PSMA therapy remains debatable. Firstly, it is suggested that external cutaneous cooling of the skin induces reactive vasodilatation, undoing the intended vasoconstrictive effect that is assumed to prevent radiotracer uptake in the salivary glands [21]. Furthermore, the presented ${ }^{68} \mathrm{Ga}$-PSMA accumulation data are meant to predict the behavior of ${ }^{177}$ Lu-PSMA. However, compartment modeling of radiotracer kinetics showed the presence of a relatively rapid blood clearance and a relatively slow early elimination phase of ${ }^{68} \mathrm{Ga}-\mathrm{PSMA}$, while the effect of external cooling on these rates are not well determined [22]. In the case of a relatively slow uptake of ${ }^{177}$ Lu-PSMA from interstitial or intracellular space into the salivary glands, in combination with the long half-life time of ${ }^{177} \mathrm{Lu}$, the reduction of PSMA uptake in salivary glands by cooling during a relatively short period of time can be anticipated to be even less effective.

Limitations comprise the measurements executed by one unblinded investigator, potentially affecting their accuracy. However, an experienced nuclear medicine physician randomly checked measurements. 
Secondly, baseline temperature of the icepacks was not standardized or systematically measured prior to application, making inter-patient differences possible, leading to potential differences in the effect of cooling and subsequent radiotracer uptake. However, the icepacks were cooled in the same fridge, in which the standard temperature of the freezer unit was approximately -18 degrees Celsius. Strong points of the present study include the prospective design allowing for both interpatient and intrapatient analysis.

Diagnostics and therapy using PSMA directing radioligands are gaining popularity. The first experiences with ${ }^{177}$ Lu-PSMA therapy show little side effects and with favorable toxicity profiles. However, xerostomia represents an undesirable side effect that needs to be reduced. Since the clinical relevance of our results is debatable, we suggest that long-term application of icepacks during the therapeutic procedure could be considered, but most likely does not contribute to reduction of xerostomia. Extension of knowledge on the mechanisms of non-specific uptake of PSMA ligands in the salivary glands may lead to new preventive strategies while improved treatments of salivary gland dysfunction, if these can be identified, are also important. We await the results of ongoing gene therapy trials with interest. Promising strategies encompassing intraglandular injection of several compounds (e.g. botulinum toxine), but also gene- and stem cell therapy, have been suggested to prevent xerostomia and might offer a solution to in the future [11]. Prospective studies, investigating efficacy and toxicity including oncological outcomes regarding overall survival, are warranted to direct future ${ }^{177}$ Lu-PSMA therapy.

\section{CONCLUSION}

External cooling of salivary glands using icepacks seems to reduce ${ }^{68} \mathrm{Ga}$ PSMA uptake in the parotid glands only. However, as clinical relevance of these findings is debatable, structural application of icepacks in patients undergoing ${ }^{177} \mathrm{Lu}$-PSMA therapy in advanced prostate cancer should remain optional, but most likely does not contribute to reduction of xerostomia. 


\section{REFERENCES}

1. Wright GL, Jr., Haley C, Beckett ML, Schellhammer PF. Expression of prostatespecific membrane antigen in normal, benign, and malignant prostate tissues. Urol Oncol. 1995 Jan-Feb;1(1):18-28.

2. Ristau BT, O'Keefe DS, Bacich DJ. The prostate-specific membrane antigen: lessons and current clinical implications from 20 years of research. Urol Oncol. 2014 Apr;32(3):272-9.

3. Afshar-Oromieh A, Hetzheim H, Kratochwil C, et al. The Theranostic PSMA Ligand PSMA-617 in the Diagnosis of Prostate Cancer by PET/CT: Biodistribution in Humans, Radiation Dosimetry, and First Evaluation of Tumor Lesions. J Nucl Med. 2015 Nov;56(11):1697-705.

4. Klein Nulent TJW, Valstar MH, de Keizer B, et al. Physiologic distribution of PSMA-ligand in salivary glands and seromucous glands of the head and neck on PET/CT. Oral Surg Oral Med Oral Pathol Oral Radiol. 2018 Jan 31.

5. Braat A, Ahmadzadehfar H. Lutetium-177 labelled PSMA ligands for the treatment of metastatic castrate-resistant prostate cancer. Tijdschr Nucl Geneesk. 2017; 38. 1627-1634.

6. Fendler WP, Rahbar K, Herrmann K, Kratochwil C, Eiber M. 177Lu-PSMA Radioligand Therapy for Prostate Cancer. J Nucl Med. 2017 Aug;58(8):11961200.

7. Boellaard R, Delgado-Bolton R, Oyen WJG et al. FDG PET/CT: EANM procedure guidelines for tumour imaging: version 2.0 Eur J Nucl Med Mol Imaging (2015) 42:328-354

8. Fendler WP, Eiber M, Beheshti $M$, et al. Ga-PSMA PET/CT: Joint EANM and SNMMI procedure guideline for prostate cancer imaging: version 1.0. Eur J Nucl Med Mol Imaging. 2017 Jun;44(6):1014-1024

9. Janssen FP, Rajan V, Steenbergen W, van Leeuwen GM, van Steenhoven AA. The relationship between local scalp skin temperature and cutaneous perfusion during scalp cooling. Physiol Meas. 2007 Aug;28(8):829-39.

10. Rugo HS, Voigt J. Scalp Hypothermia for Preventing Alopecia During Chemotherapy. A Systematic Review and Meta-Analysis of Randomized Controlled Trials. Clin Breast Cancer. 2017 Aug 10. pii: S1526-8209(16)30543-2.

11. Taïeb D, Foletti JM, Bardiès M, Rocchi P, Hicks R, Haberkorn U. PSMA-Targeted Radionuclide Therapy and salivary gland toxicity: why does it matter? J Nucl Med. 2018 Feb 9.

12. Gaertner FC, Ahmadzadehfar H, Bundschuh RA, Kürpig S, Eppard E, Essler M. Does cooling of the salivary glands reduce uptake of radiolabeled PSMAligands? In: EAMN 2015; 2015

13. Bohn KP, Kletting $P$, Solbach $C$, Beer AJ, Krohn T. Effekt der Kühlung von Speicheldrüsen bei der Therapie mit PSMA-Radioliganden. Nuklearmedizin. 56, A2-A91, 2017 
14. Ahmadzadehfar $\mathrm{H}$, Rahbar K, Kurpig S, et al. Early side effects and first results of radioligand therapy with 177Lu-DKFZ-617 PSMA of castrate-resistant metastatic prostate cancer: a two-centre study. EJNMMI Res. 2015;5:114.

15. Ahmadzadehfar H, Eppard E, Kurpig S, et al. Therapeutic response and side effects of repeated radioligand therapy with 177Lu-PSMA-DKFZ-617 of castrate resistant metastatic prostate cancer. Oncotarget. 2016;7:1247712488.

16. Baum RP, Kulkarni HR, Schuchardt C, et al. 177Lu-Labeled Prostate-Specific Membrane Antigen Radioligand Therapy of Metastatic Castration-Resistant Prostate Cancer: Safety and Efficacy. J Nucl Med. 2016 Jul;57(7):1006-13.

17. Heck MM, Retz M, D'Alessandria C, et al. Systemic Radioligand Therapy with (177)Lu Labeled Prostate Specific Membrane Antigen Ligand for Imaging and Therapy in Patients with Metastatic Castration Resistant Prostate Cancer. J Urol. 2016 Aug;196(2):382-91.

18. Kratochwil C, Giesel FL, Stefanova M, et al. PSMA-targeted radionuclide therapy of metastatic castration-resistant prostate cancer with Lu-177 labeled PSMA-617. J Nucl Med. 2016;57:1170-1176.

19. Rahbar K, Bode A, Weckesser M, et al. Radioligand Therapy With 177LuPSMA-617 as A Novel Therapeutic Option in Patients With Metastatic Castration Resistant Prostate Cancer. Clin Nucl Med. 2016 Jul;41 (7):522-8.

20. Rahbar K, Ahmadzadehfar H, Kratochwil C, et al. German Multicenter Study Investigating 177Lu-PSMA-617 Radioligand Therapy in Advanced Prostate Cancer Patients. J Nucl Med. 2017 Jan;58(1):85-90.

21. Pérgola PE, Johnson JM, Kellogg DL, Jr, Kosiba WA. Control of skin blood flow by whole body and local skin cooling in exercising humans. Am J Physiol Heart Circ Physiol 270: H208-H215, 1996

22. Abuqbeitah M, Demir M, Uslu-Beşli L, Yeyin N, Sönmezoğlu K. Blood clearance and occupational exposure for 177Lu-DOTATATE compared to 177Lu-PSMA radionuclide therapy. Radiat Environ Biophys. 2018 Mar;57(1):55-61.

23. Bolla M, de Reijke TM, Van Tienhoven G, et al.; EORTC Radiation Oncology Group and Genito-Urinary Tract Cancer Group. Duration of androgen suppression in the treatment of prostate cancer. N Engl J Med. 2009 Jun 11;360(24):2516-27. 



\section{CHAPTER 9}

\section{Comparison between $6.0 \mathrm{GBq}$ and 7.4 GBq [ $\left.{ }^{177} \mathrm{Lu}\right] \mathrm{Lu}-\mathrm{PSMA}-617$ in prostate cancer}

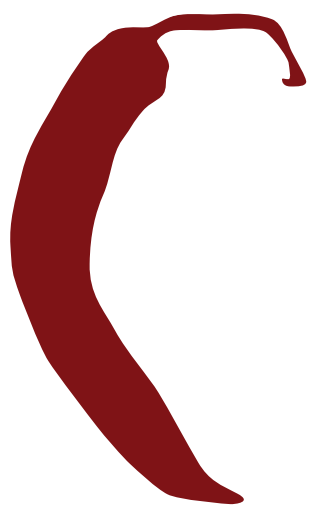

L.W.M. van Kalmthout, A. Rulof, A.J.A.T. Braat, G.C. Krijger, F.F.T. Ververs, R. de Roos, B. de Keizer, M.G.E.H. Lam 


\section{ABSTRACT}

\section{Purpose}

Lutetium-177 [ ${ }^{177} \mathrm{Lu}$ Lu-PSMA-617 therapy is currently administered in a fixed dose of 6.0 or $7.4 \mathrm{GBq}$ per cycle. Since a comparison between both activities is lacking, this study compares toxicity rates of 6.0 versus 7.4 $\mathrm{GBq}\left[{ }^{177} \mathrm{Lu}\right] \mathrm{Lu}-\mathrm{PSMA}-617$ treatment in patients with metastatic castrationresistant prostate cancer.

\section{Methods}

All patients referred for [ $\left.{ }^{177} \mathrm{Lu}\right] \mathrm{Lu}-\mathrm{PSMA}-617$ treatment in our institution were included in this retrospective study. Clinical and biochemical toxicity was graded according to the Common Terminology Criteria for Adverse Events (CTCAE). Treatment-related response was evaluated with PSA measurements and tumor load changes on PSMA-PET/CT.

\section{Results}

Thirty consecutive patients with advanced prostate cancer were analyzed after two cycles with $6.0 \mathrm{GBq}(\mathrm{n}=15)$ or $7.4 \mathrm{GBq}(\mathrm{n}=15)\left[{ }^{177} \mathrm{Lu}\right] \mathrm{Lu}$ PSMA-617. In the 6.0 GBq and 7.4 GBq group, CTCAE-grade 1-2 xerostomia occurred in respectively $13 \%$ and $20 \%$ and grade 3 anemia occurred in respectively $20 \%$ and $27 \%$ of the patients. One patient in the $7.4 \mathrm{GBq}$ group (7\%) had grade 3 thrombocytopenia. All other newly originated toxicities were limited to maximum grade 2 . During treatment, maximum PSA decline of $>50 \%$ was observed in $60 \%$ and in $33 \%$ of the patients in respectively the $6.0 \mathrm{GBq}$ group and the $7.4 \mathrm{GBq}$ group. No significant differences were found.

\section{Conclusion}

Toxicity following the administration of 6.0 and $7.4 \mathrm{GBq}\left[{ }^{177} \mathrm{Lu}\right] \mathrm{Lu}-$ PSMA-617 in two cycles appears limited. Therefore, the administration of both activities seems defendable in advanced prostate cancer patients. To obtain robust data, however, prospective dosimetry studies in larger patient groups are needed. 


\section{INTRODUCTION}

Prostate cancer (PCa) is the most frequent cause of cancer-related death in men in economically developed countries [1]. When diagnosed, approximately $10-20 \%$ of patients have advanced disease and $>40 \%$ will eventually progress to metastatic castration-resistant prostate cancer [2]. In metastasized PCa, 5-year survival rate significantly drops to approximately 30\% [3]. Standard treatments in advanced PCa patients include chemotherapy (i.e. docetaxel and cabazitaxel) and new hormonal agents (i.e. enzalutamide and abiraterone).

Over recent years, radioligand therapy has emerged as a promising treatment option for PCa. Previously performed research predominantly focused on the beta-radiation emitting radioligand [ $\left.{ }^{177} \mathrm{Lu}\right] \mathrm{Lu}-\mathrm{PSMA}-617$, a small molecule inhibitor targeting Prostate Specific Membrane Antigen (PSMA). PSMA is a type II transmembrane glycoprotein that is mainly expressed on prostate tissue but also in lesser abundance on cells of the salivary glands and small intestine [4]. PSMA is significantly overexpressed by most prostate cancers [5], as well as other solid tumors [6], and thus serves as a suitable target for both diagnostics and treatment.

To date, despite the growing number of (awaited) publications in this field (e.g. clinicalTrials.gov identifier NCT03511664 and Clinical Trial Protocol ANZUP 1603), a proper phase 1 study has not been performed. In previous studies, various dosages ranging from $1.3 \mathrm{GBq}$ [7] to $9.3 \mathrm{GBq}$ [8] were administered, however, only one dose-escalation study was performed so far [8]. Consequently, several important parameters regarding $\left[{ }^{177} \mathrm{Lu}\right]$ Lu-PSMA-617 treatment, including the optimal administered activity per cycle (in a fixed dose or based on individual dosimetry) the optimal number of cycles and the optimal interval between cycles, remain unclear. At present, $\left[{ }^{177} \mathrm{Lu}\right] \mathrm{Lu}-\mathrm{PSMA}-617$ therapy is generally administered in a fixed dose of 6.0 or $7.4 \mathrm{GBq}$ per cycle usually for four cycles with an interval of 6-9 weeks, similar to the protocols followed in peptide receptor radionuclide therapy (PRRT) [9]. Interestingly, studies comparing toxicity rates between the two administered activities are lacking. Therefore, this 
study aims to compare toxicity rates in two patient groups, treated in our institution with either $6.0 \mathrm{GBq}$ or $7.4 \mathrm{GBq}$ [ $\left.{ }^{177} \mathrm{Lu}\right] \mathrm{Lu}-\mathrm{PSMA}-617$. Secondary, therapeutic efficacy in both patient groups was evaluated.

\section{MATERIALS AND METHODS}

\section{Patient population}

Patients treated with either $6.0 \mathrm{GBq}$ or $7.4 \mathrm{GBq}\left[{ }^{177} \mathrm{Lu}\right] \mathrm{Lu}-\mathrm{PSMA}-617$ in the UMC Utrecht between December 2017 and February 2019, were analysed. Because of the lack of phase I study data and the available literature at the time of treatment introduction, at first, a dosage of $6 \mathrm{GBq}$ was used and was later escalated to $7.4 \mathrm{GBq}$ after shown tolerability and publications on higher dosages in literature. Patients were selected retrochronologically from February 2019 and were excluded if insufficient data on baseline imaging or laboratory characteristics were present. Current treatment criteria in our institution are based on those described previously [10] and include (1) confirmed histological diagnosis of PCa and metastatic malignancy with no alternative cytotoxic treatment options; (2) $\geq 1$ previous episode of chemotherapy, hormonal therapy and either enzalutamide or abiraterone in past medical history, and/or inadequacy to undergo chemo-/hormonal therapy; (3) World Health Organisation (WHO) performance status $\leq 2$; (4) Sufficient bone marrow capacity, defined as haemoglobin level $>5 \mathrm{mmol} / \mathrm{L}$, leukocytes $>2.0$ $\times 10^{9} /$, neutrophils $>1.5 \times 10^{\%}$, platelets $>75 \times 10^{9} /$; (5) sufficient renal function, defined as glomerular filtration rate $>45 \mathrm{ml} / \mathrm{min}$.; and (6) metastatic disease with dominant tumor sites showing relatively high PSMA-expression (visual assessment; tumor uptake $>$ normal liver parenchyma) on baseline PSMA PET/CT, being either performed with $\left[{ }^{68} \mathrm{Ga}\right] \mathrm{Ga}$-PSMA or $\left[{ }^{18} \mathrm{~F}\right] \mathrm{F}-\mathrm{DCFP} y \mathrm{~L}$.

\section{Preparation of [ ${ }^{177} \mathrm{Lu}$ ]Lu-PSMA-617}

PSMA-617 (GMP-grade) was obtained from ABX GmbH, Radeberg, Germany and radiolabelled using $\left.{ }^{177} \mathrm{Lu}\right] \mathrm{Lu}$-chloride (Endolucin beta, ITG, München, Germany. Per patient 50 mg PSMA-617 per cycle was used. 
Radiochemical yield and purity was determined by ITLC-SG and HPLC. Also other quality parameters of the final product were confirmed by the assessment of $\mathrm{pH}$, sterility and the absence of bacterial endotoxins, as described before [10].

\section{Treatment protocol}

All patients underwent two cycles of intravenous [177Lu]Lu-PSMA-617, with a mean interval of seven weeks (range: 40-79 days), after obtaining informed consent. Due to Dutch regulatory radiation guidelines, patients were admitted to the hospital overnight and were released from the nuclear medicine ward only when measured radiation exposure rate at 1 $\mathrm{m}$ fell below $20 \mu \mathrm{Sv} / \mathrm{h}$. The institutional review board of the UMC Utrecht approved this retrospective study.

\section{Clinical and biochemical toxicity}

Clinical toxicity and medical complications during and after $\left.{ }^{177} \mathrm{Lu}\right]$ Lu-PSMA-617 administration were routinely reported according to a standardized questionnaire including clinical symptoms (e.g. fatigue, xerostomia, nausea, vomiting, gastro-intestinal complaints, other complaints) and scored according to the CTCAE-grading system version 4.03. To assess biochemical and haematological toxicity, laboratory results including (differential) leukocyte, erythrocyte, haemoglobin and platelet counts and renal and liver function, were examined at baseline and at a median of 36.5 days (range: 22-135 days) after every treatment cycle. Occurring biochemical and haematological toxicities were categorized according to the Common Terminology Criteria for Adverse Events (CTCAE version 4.03). Occurrence and grade of toxicities were compared between the two dosage groups. Patients who received blood transfusions during the follow-up period were counted as grade 3 anaemia.

\section{Clinical \& biochemical response}

Clinical response was evaluated for patients suffering from pain that required analgesics prior to study inclusion. Severity of newly originated pain and discontinuation/reduction of analgesic usage after one and two cycles of $\left[{ }^{177} \mathrm{Lu}\right] \mathrm{Lu}-\mathrm{PSMA}-617$ was assessed and compared to baseline. 
To determine biochemical response, baseline PSA level was compared to PSA level after each treatment cycle. Biochemical response was categorized according to the Prostate-Specific Antigen Working Group 3 criteria [11] into any decrease, 50-90\% decrease and $>90 \%$ decrease. Biochemical response was defined as $\geq 50 \%$ PSA-decrease. Differences regarding the proportion of biochemical responders between the two patient groups were analysed.

\section{Imaging response}

To evaluate tumor response, PSMA PET/CT scans were performed at baseline and after two cycles. Tumor load on the post-therapy scan was compared to baseline. Tumor load was assessed semi-automatically using SYNGO.VIA (Siemens Healthineers, Erlangen, Germany) with the multi-foci segmentation function, based on previously described PERCIST methods [12], and lesions $<0.3 \mathrm{ml}$ were automatically discarded. SYNGO. VIA was set to select all foci exceeding a threshold based on blood pool activity. Healthy tissues (lacrimal glands, salivary glands, bladder, kidneys and small intestine) were manually excluded from the final calculation. Furthermore, SUV $V_{\text {peak }}$ of the hottest lesion, total lesion PSMA uptake (TLPSMA, derived from total lesion glycolysis (TLG) and metabolic tumor volume (MTV) at baseline were calculated, as a resemblance of total PSMA uptake per patient. Subjects with scans impossible to segment due to the extent of PCa lesions were excluded from these calculations.

\section{Statistics}

Baseline characteristics were compared using a Student's t-test and Mann-Whitney $U$ test. PSA changes after two cycles compared to baseline between the two patient groups were assessed by a Mann-Whitney $U$ test. To assess PSA changes within treatment groups, paired t-tests were performed. Tumor load change between groups was assessed by a Mann-Whitney $U$ test. Tumor load change within the patient groups was assessed with a Wilcoxon signed ranks test. Statistical analyses were performed using IBM SPSS Statistics, version 25.0.02. Statistical significance was established for $\mathrm{p}$-values $<0.05$. 


\section{RESULTS}

Fifty patients were screened for this study, of whom twenty patients were excluded as a result of variable administered dosages [177Lu]Lu-PSMA-617 between the first and second cycle $(n=9)$, or in case patients completed less than two treatment cycles $(n=11)$. Thirty patients were included in this study. Baseline characteristics of the included patients are shown in Table 1. Baseline characteristics of both patient groups (6.0 GBq versus $7.4 \mathrm{GBq}$ ) did not significantly differ. Previous treatment strategies are summarized in Table 1.

With regard to the baseline laboratory results, only one patient in the $6.0 \mathrm{GBq}$ group reported $\geq$ grade 3 anaemia. No other $\geq$ grade 3 toxicities were found at baseline (Table 2). Fifteen patients were treated with a mean activity of 6107 (range: 5744-6466) MBq [177Lu]Lu-PSMA-617; fifteen patients were treated with a mean activity of 7448 (range: 7356-7550) MBq [ $\left.{ }^{177} \mathrm{Lu}\right] \mathrm{Lu}-\mathrm{PSMA}-617$. Median interval between the two cycles was 49 days (range: 40-79 days) in the $6.0 \mathrm{GBq}$ group and 44 days (range: 42-65 days) in the $7.4 \mathrm{GBq}$ group. Median duration of follow-up from start of the first treatment cycle in the $6.0 \mathrm{GBq}$ group was 11.6 months (range: 2.8 23.1 months); mean duration of follow-up in the $7.4 \mathrm{GBq}$ was 3.23 months (range: 2.5 - 12.0 months). Eight patients died during follow-up ( $n=4$ in the $6.0 \mathrm{GBq}$ group; $\mathrm{n}=4$ in the $7.4 \mathrm{GBq}$ group).

\section{Newly originated biochemical toxicity}

In the $6.0 \mathrm{GBq}$ group, three patients received blood transfusions (grade 3 anaemia); one patient suffered from newly originated grade 2 leukocytopenia. Other newly originated biochemical toxicities were mild. In the $7.4 \mathrm{GBq}$ group, four patients received blood transfusions (grade 3 anaemia); one patient suffered from newly originated grade 2 anaemia; one patient from grade 3 thrombocytopenia. Other biochemical toxicities were mild (Table 3). 
Part II| Prostate cancer therapy

Table 1. Baseline characteristics of the analysed patients

\begin{tabular}{|c|c|c|c|c|}
\hline & $\begin{array}{l}6.0 \mathrm{GBq} \\
(\mathrm{n}=15)\end{array}$ & $\begin{array}{l}7.4 \mathrm{GBq} \\
(\mathrm{n}=15)\end{array}$ & $\begin{array}{c}\text { Total } \\
(\mathrm{n}=30)\end{array}$ & $\begin{array}{r}\text { Difference } \\
\text { (p-value) }\end{array}$ \\
\hline $\begin{array}{l}\text { Age (y); } \\
\text { mean (range) }\end{array}$ & $\begin{array}{c}68 \\
(61-81)\end{array}$ & $\begin{array}{c}66 \\
(51-84)\end{array}$ & $\begin{array}{c}68 \\
(51-84)\end{array}$ & 0.50 \\
\hline $\begin{array}{l}\text { PSA level at baseline ( } \mu \mathrm{g} / \mathrm{L}) \text {; } \\
\text { mean (range) }\end{array}$ & $\begin{array}{c}240 \\
(23-2900)\end{array}$ & $\begin{array}{c}270 \\
(39-9200)\end{array}$ & $\begin{array}{c}250 \\
(23-9200)\end{array}$ & 0.42 \\
\hline \multicolumn{5}{|l|}{ T-stage at primary diagnosis; $\mathbf{n}(\%)$} \\
\hline $\begin{array}{l}\text { T1 } \\
\text { T2 } \\
\text { T3 } \\
\text { T4 } \\
\text { Missing }\end{array}$ & $\begin{array}{c}1(7 \%) \\
0 \\
6(40 \%) \\
4(27 \%) \\
4(27 \%)\end{array}$ & $\begin{array}{c}0 \\
1(7 \%) \\
6(40 \%) \\
2(13 \%) \\
6(40 \%)\end{array}$ & $\begin{array}{c}1(3 \%) \\
1(3 \%) \\
12(40 \%) \\
6(20 \%) \\
10(33 \%)\end{array}$ & 0.57 \\
\hline \multicolumn{5}{|l|}{ Gleason score at primary diagnosis; $\mathbf{n}(\%)$} \\
\hline $\begin{array}{l}\leq 6 \\
7 \\
\geq 8 \\
\text { Missing }\end{array}$ & $\begin{array}{c}1(7 \%) \\
4(27 \%) \\
7(47 \%) \\
3(20 \%)\end{array}$ & $\begin{array}{c}0 \\
1(7 \%) \\
9(60 \%) \\
5(33 \%)\end{array}$ & $\begin{array}{c}1(3 \%) \\
5(17 \%) \\
16(53 \%) \\
8(27 \%)\end{array}$ & 0.10 \\
\hline \multicolumn{5}{|c|}{ Previous treatment strategies; $\mathbf{n}(\%)$} \\
\hline $\begin{array}{l}\text { Androgen deprivation therapy } \\
\text { Chemotherapy } \\
\text { Abiraterone } \\
\text { Enzalutamide } \\
\left.\left[{ }^{223} \mathrm{Ra}\right] \mathrm{Ra} \text { or }{ }^{89} \mathrm{Sr}\right] \mathrm{Sr} \\
\text { Salvage radiation therapy }\end{array}$ & $\begin{array}{l}15(100 \%) \\
14(93 \%) \\
7(47 \%) \\
13(87 \%) \\
5(33 \%) \\
5(33 \%)\end{array}$ & $\begin{array}{l}15(100 \%) \\
15(100 \%) \\
5(33 \%) \\
12(80 \%) \\
5(33 \%) \\
7(47 \%)\end{array}$ & $\begin{array}{l}30(100 \%) \\
29(97 \%) \\
12(40 \%) \\
25(83 \%) \\
10(33 \%) \\
12(40 \%)\end{array}$ & $\begin{array}{l}1.00 \\
0.32 \\
0.46 \\
0.63 \\
1.00 \\
0.54\end{array}$ \\
\hline \multicolumn{5}{|l|}{ Tumor sites at baseline; $\mathbf{n}(\%)$} \\
\hline $\begin{array}{l}\text { Lymph nodes } \\
\text { Bone lesions } \\
\text { Visceral lesions }\end{array}$ & $\begin{array}{l}10(67 \%) \\
13(87 \%) \\
2(13 \%)\end{array}$ & $\begin{array}{l}12(80 \%) \\
14(93 \%) \\
7(47 \%)\end{array}$ & $\begin{array}{c}22(73 \%) \\
27(90 \%) \\
9(30 \%)\end{array}$ & $\begin{array}{l}0.42 \\
0.55 \\
0.05\end{array}$ \\
\hline
\end{tabular}

PSA: Prostate Specific Antigen; eGFR: estimated Glomerular Filtration Rate; AF: Alkaline Phosphatase; Gamma-GT: Gamma-glutamyltransferase; ASAT: Aspartate transaminase; ALAT: Alanine transaminase; LD: Lactate dehydrogenase. 
Table 2. Laboratory results of the analysed patients at baseline

\begin{tabular}{|c|c|c|c|c|}
\hline & $\begin{array}{l}6.0 \mathrm{GBq} \\
(\mathrm{n}=15)\end{array}$ & $\begin{array}{l}7.4 \mathrm{GBq} \\
(\mathrm{n}=15)\end{array}$ & $\begin{array}{c}\text { Total } \\
(n=30)\end{array}$ & $\begin{array}{c}\text { Difference } \\
\text { (p-value) }\end{array}$ \\
\hline \multicolumn{5}{|c|}{ Hematologic function } \\
\hline $\begin{array}{l}\text { Haemoglobin in } \\
\text { mmol/L; Mean (range) } \\
\text { Missing (n) }\end{array}$ & $\begin{array}{c}7.4 \\
(4.7-9.1) \\
2\end{array}$ & $\begin{array}{c}6.8 \\
(4.6-8.8) \\
1\end{array}$ & $\begin{array}{c}7.1 \\
(4.6-9.1) \\
3\end{array}$ & 0.20 \\
\hline $\begin{array}{l}\text { Erythrocytes } \times 10^{12} / \mathrm{L} ; \\
\text { Mean (range) } \\
\text { Missing }(\mathrm{n})\end{array}$ & $\begin{array}{c}4.0 \\
(2.51-5.18) \\
2\end{array}$ & $\begin{array}{c}3.7 \\
(2.44-4.96) \\
1\end{array}$ & $\begin{array}{c}3.9 \\
(2.44-5.18) \\
3\end{array}$ & 0.25 \\
\hline $\begin{array}{l}\text { Thrombocytes } \times 10^{9} / \mathrm{L} ; \\
\text { Mean (range) } \\
\text { Missing }(\mathrm{n})\end{array}$ & $\begin{array}{c}253 \\
(126-468) \\
2\end{array}$ & $\begin{array}{c}319 \\
(159-660) \\
1\end{array}$ & $\begin{array}{c}288 \\
(126-660) \\
3\end{array}$ & 0.15 \\
\hline $\begin{array}{l}\text { Leukocytes } \times 10^{9} / \mathrm{L} ; \\
\text { Mean (range) }\end{array}$ & $\begin{array}{c}8.0 \\
(3.4-16.1)\end{array}$ & $\begin{array}{c}8.15 \\
(4.6-15.9)\end{array}$ & $\begin{array}{c}8.1 \\
(3.4-16.1)\end{array}$ & 0.90 \\
\hline Missing $(n)$ & 2 & 1 & 3 & \\
\hline \multicolumn{5}{|c|}{ Liver function } \\
\hline $\begin{array}{l}\text { AF in } U / L ; \\
\text { mean (range) } \\
\text { Missing }(n)\end{array}$ & $\begin{array}{c}186 \\
(55-742) \\
4\end{array}$ & $\begin{array}{c}229 \\
(44-1222) \\
1\end{array}$ & $\begin{array}{c}210 \\
(44-1222) \\
5\end{array}$ & 0.70 \\
\hline $\begin{array}{l}\text { Y-GT in } \mathrm{U} / \mathrm{L} ; \\
\text { mean (range) } \\
\text { Missing }(\mathrm{n})\end{array}$ & $\begin{array}{c}127 \\
(13-700) \\
6\end{array}$ & $\begin{array}{c}63 \\
(16-198) \\
1\end{array}$ & $\begin{array}{c}88 \\
(13-700) \\
7\end{array}$ & 0.40 \\
\hline $\begin{array}{l}\text { ASAT in } U / L ; \\
\text { mean (range) } \\
\text { Missing (n) }\end{array}$ & $\begin{array}{c}42 \\
(19-152) \\
6\end{array}$ & $\begin{array}{c}42 \\
(21-94) \\
1\end{array}$ & $\begin{array}{c}42 \\
(19-152) \\
7\end{array}$ & 0.99 \\
\hline $\begin{array}{l}\text { ALAT in } U / L ; \\
\text { mean (range) } \\
\text { Missing }(n)\end{array}$ & $\begin{array}{c}25 \\
(13-62) \\
6\end{array}$ & $\begin{array}{c}16.4 \\
(6-28) \\
1\end{array}$ & $\begin{array}{c}20 \\
(6-62) \\
7\end{array}$ & 0.07 \\
\hline $\begin{array}{l}\mathrm{LD} \text { in } \mathrm{U} / \mathrm{L} ; \\
\text { mean (range) } \\
\text { Missing }(\mathrm{n})\end{array}$ & $\begin{array}{c}521 \\
(130-2715) \\
6 \\
\end{array}$ & $\begin{array}{c}494 \\
(164-1437) \\
0\end{array}$ & $\begin{array}{c}504 \\
(130-2715) \\
6\end{array}$ & 0.91 \\
\hline \multicolumn{5}{|c|}{ Renal Function } \\
\hline eGFR >90 (n) & 6 & 7 & 13 & 0.98 \\
\hline eGFR <90 (n) & 7 & 8 & 15 & \\
\hline Missing (n) & 2 & 0 & 2 & \\
\hline $\begin{array}{l}\text { eGFR in } \mathrm{ml} / \mathrm{min} / 1,73 \\
\mathrm{~m}^{2} ; \text { mean (range) }\end{array}$ & $\begin{array}{c}75 \\
(54-85)\end{array}$ & $\begin{array}{c}78 \\
(56-90)\end{array}$ & $\begin{array}{c}77 \\
(54-90)\end{array}$ & \\
\hline
\end{tabular}




\section{Newly originated clinical toxicity}

During treatment, two and three patients reported mild (grade 1-2) xerostomia in respectively the 6.0 and 7.4 group. One $\geq$ CTCAE grade 3 event in the $6.0 \mathrm{GBq}$ group was reported in a patient who had a cerebral infarction. In the 7.4 GBq group, no $\geq$ CTCAE grade 3 toxicities occurred. Other newly originated CTCAE grade 1-2 toxicities are listed in Table 3.

Table 3. Newly originated toxicity per CTCAE grade during treatment

\begin{tabular}{|c|c|c|c|c|c|c|c|}
\hline & \multirow{2}{*}{$\begin{array}{l}\text { Treatment activity } \\
\text { CTCAE grade }\end{array}$} & \multicolumn{3}{|c|}{$6.0 \mathrm{GBq}$} & \multicolumn{3}{|c|}{$7.4 \mathrm{GBq}$} \\
\hline & & 1 & 2 & 3 & 1 & 2 & 3 \\
\hline \multirow[t]{5}{*}{$\begin{array}{l}\text { Clinical toxicity; } \\
\text { n (\%) }\end{array}$} & Fatigue & $\begin{array}{c}4 \\
(27 \%)\end{array}$ & $\begin{array}{c}1 \\
(7 \%)\end{array}$ & 0 & $\begin{array}{c}3 \\
(20 \%)\end{array}$ & 0 & 0 \\
\hline & Xerostomia & $\begin{array}{c}2 \\
(13 \%)\end{array}$ & 0 & 0 & $\begin{array}{c}2 \\
(13 \%)\end{array}$ & $1(7 \%)$ & 0 \\
\hline & Nausea & $\begin{array}{c}5 \\
(33 \%)\end{array}$ & 0 & 0 & $\begin{array}{c}4 \\
(27 \%)\end{array}$ & 0 & 0 \\
\hline & Diarrhea & $\begin{array}{c}2 \\
(13 \%)\end{array}$ & 0 & 0 & 0 & 0 & 0 \\
\hline & Haematuria & 0 & 0 & 0 & $\begin{array}{c}2 \\
(13 \%)\end{array}$ & 0 & 0 \\
\hline \multirow[t]{3}{*}{$\begin{array}{l}\text { Biochemical toxicity; } \\
\text { n (\%) }\end{array}$} & Anaemia & 0 & 0 & $\begin{array}{c}3 \\
(20 \%\end{array}$ & $\begin{array}{c}1 \\
(10 \%)\end{array}$ & $\begin{array}{c}1 \\
(10 \%)\end{array}$ & $\begin{array}{c}4 \\
(27 \%)\end{array}$ \\
\hline & Leukocytopenia & 0 & $\begin{array}{c}1 \\
(7 \%)\end{array}$ & 0 & $\begin{array}{c}2 \\
(13 \%)\end{array}$ & 0 & 0 \\
\hline & Thrombocytopenia & $\begin{array}{c}1 \\
(7 \%)\end{array}$ & 0 & 0 & $\begin{array}{c}3 \\
(20 \%)\end{array}$ & 01 & $1(7 \%)$ \\
\hline
\end{tabular}

\section{Clinical response}

Six of the fifteen patients treated with 6.0 GBq used analgesics at baseline. During follow-up, usage of analgesics decreased in five of these patients (83\%). Eight of the fifteen patients in the $7.4 \mathrm{GBq}$ group used analgesics at baseline. Of these patients, four patients (50\%) reduced their analgesic usage during follow-up. 


\section{Biochemical response}

After treatment with $6.0 \mathrm{GBq}\left[{ }^{177} \mathrm{Lu}\right] \mathrm{Lu}-\mathrm{PSMA}-617$, any decrease of PSA level was observed in 11 patients (73\%), of which $<50 \%$ PSA decrease was found in 2 patients (13\%), 50-90\% decrease in 8 patients (53\%) and $>90 \%$ decrease in one patient (7\%). Stable PSA and PSA progression was found in respectively two patients (13\%) and two patients (13\%). With regard to the $7.4 \mathrm{GBq}$ group, any PSA decrease was found in 10 patients (67\%), of which $<50 \%$ PSA decrease was found in 5 patients (33\%), 50$90 \%$ decrease in 4 patients (27\%) and $>90 \%$ decrease in one patient (7\%). Stable PSA and PSA progression was found in respectively two patients (13\%) and three patients (20\%). PSA change from baseline compared to after two cycles was not significantly different between the treatment groups. A waterfall plot of PSA change from baseline in both groups is shown in Figure 1.

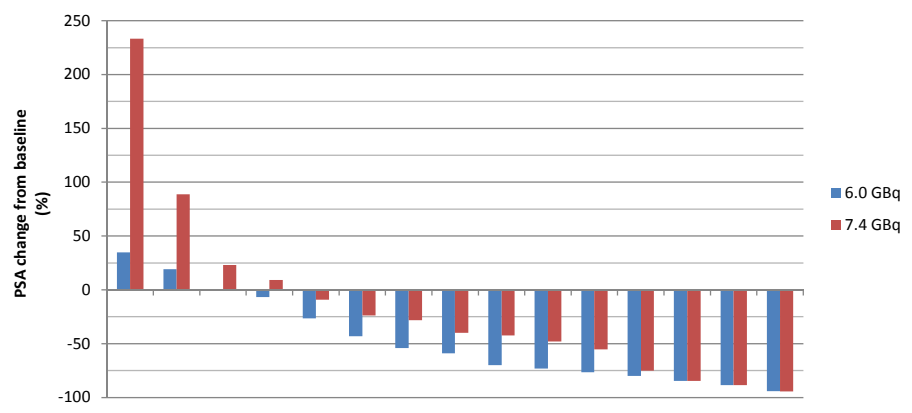

Figure 1. PSA change after 2 cycles of $6.0 \mathrm{GBq}$ (blue) and 7.4 GBq (red) $\left[{ }^{177} \mathrm{Lu}\right] \mathrm{Lu}-$ PSMA-617 compared to baseline

\section{Imaging response}

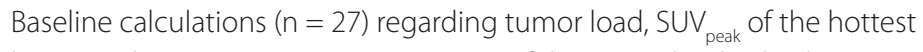
lesion and mean SUV max $_{\text {m }}$ (TL-PSMA/MTV) of the tumor load in both groups are displayed in Table 4. No statistically significant differences were found between the two patient groups. Three baseline scans were excluded from this analysis: two patients were scanned with [18F]F-PSMA-1007; 
Table 4. Tumor load measurements at baseline and after 2 cycles of $6.0 \mathrm{GBq}$ and $7.4 \mathrm{GBq}\left[{ }^{177} \mathrm{Lu}\right] \mathrm{Lu}-\mathrm{PSMA}-617$

\begin{tabular}{|c|c|c|c|}
\hline & $\begin{array}{l}6.0 \text { GBq group } \\
(n=15)\end{array}$ & $\begin{array}{l}7.4 \mathrm{GBq} \text { group } \\
(\mathrm{n}=12)\end{array}$ & $\begin{array}{l}\text { Difference } \\
\text { (p-value) }\end{array}$ \\
\hline $\begin{array}{l}\text { Tumor load at baseline (SUV- } \\
\text { lbm× } \mathrm{cm}^{3} \text { ); median (range) }\end{array}$ & $\begin{array}{c}3228.01 \\
(193.36-23942.41)\end{array}$ & $\begin{array}{c}1769.70 \\
(109.33-12628.23)\end{array}$ & 1.00 \\
\hline $\begin{array}{l}\text { SUV } \\
\text { peak of the hottest lesion } \\
\text { at baseline; median (range) }\end{array}$ & $\begin{array}{c}27.12 \\
(15.62-66.99)\end{array}$ & $\begin{array}{c}21.39 \\
(12.90-51.31)\end{array}$ & 0.22 \\
\hline $\begin{array}{l}\text { Mean SUV } \text { max }_{\text {of the tumor }} \\
\text { load at baseline (TL-PSMA/ } \\
\text { MTV); median (range) }\end{array}$ & $\begin{array}{c}9.31 \\
(5.19-17.72)\end{array}$ & $\begin{array}{c}8.50 \\
(5.22-24.18)\end{array}$ & 0.49 \\
\hline $\begin{array}{l}\text { Tumor load after } 2 \text { cycles } \\
\left(\text { SUV-lbm } \times \mathrm{cm}^{3}\right) \text {; median } \\
\text { (range) }\end{array}$ & $\begin{array}{c}1507.85 \\
(0-8333.46)\end{array}$ & $\begin{array}{c}660.84 \\
(135.76-14345.10)\end{array}$ & 0.43 \\
\hline
\end{tabular}

SUV: Standardized Uptake Value; TL-PSMA: Total Lesion PSMA; MTV: Metabolic Tumor Load

raw data of one patient were not available. Two more patients, in whom tumor response was not segmentable, were excluded from response analysis ( $n=1$ in the $6.0 \mathrm{GBq}$ group; $n=1$ in the $7.4 \mathrm{GBq}$ group). In the 6.0 GBq group, median tumor load was reduced from $3228 \mathrm{SUV}-\mathrm{Ibm} \times \mathrm{cm}^{3}$ at baseline to 1508 SUV-lbm× $\mathrm{cm}^{3}$ after two cycles (52\% reduction). More than $50 \%$ tumor load reduction occurred in four patients $(27 \%)$. In the $7.4 \mathrm{GBq}$ group, median tumor load decreased from 1770 SUV-lbm $\times \mathrm{cm}^{3}$ at baseline to 661 SUV-lbm× $\mathrm{cm}^{3}$ after two cycles (63\% reduction). More than 50\% tumor load reduction occurred in three patients (20\%).

\section{DISCUSSION}

The present study demonstrated no differences between $6.0 \mathrm{GBq}$ and 7.4 GBq $\left[{ }^{177} \mathrm{Lu}\right] \mathrm{Lu}-\mathrm{PSMA}-617$ with regard to incidence and gravity of newly originated biochemical and clinical toxicity during treatment. In both groups, toxicity appeared limited. Furthermore, treatment with $6.0 \mathrm{GBq}$ and $7.4 \mathrm{GBq}\left[{ }^{177} \mathrm{Lu}\right]$ Lu-PSMA-617 per cycle resulted in any PSA decrease in respectively $80 \%$ and $73 \%$ of the patients. Biochemical response 
(>50\% PSA decrease) during treatment was found in $60 \%$ and $33 \%$ of the patients, respectively.

The main objective of treatment with ${ }^{177}$ Lu]Lu-PSMA-617 in advanced PCa patients is to achieve tumor control. Toxicity is acceptable as long as it does not affect the treated patients' quality of life. Feared side effects of $\left.{ }^{177} \mathrm{Lu}\right] \mathrm{Lu}-\mathrm{PSMA}-617$ include myelosuppression, salivary and renal toxicity. The first ones are caused by binding of [ ${ }^{177} \mathrm{Lu}$ ]Lu-PSMA-617 to the PSMA receptor (pathologically expressed by PCa and its metastases; physiologically expressed by the salivary glands), internalisation of the radioligand into the cell, subsequent focal irradiation and cell death [4]. Renal toxicity is caused by the urinary excretion of the radioligand. In the present study, $\left.{ }^{177} \mathrm{Lu}\right] \mathrm{Lu}-\mathrm{PSMA}-617$ was well tolerated in both treatment groups. Haematological adverse events > grade 3 occurred in eight patients, of which three in the $6.0 \mathrm{GBq}$ group and five in the 7.4 $\mathrm{GBq}$ group. Deterioration of renal function was not observed. Only five patients developed mild xerostomia during therapy; two patients in the 6.0 GBq group and three patients in the $7.4 \mathrm{GBq}$ group. One patient in our study developed a cerebral infarction. This patient had a history of stroke and a causal relation of this event with the [ $\left.{ }^{177} \mathrm{Lu}\right]$ Lu-PSMA-617 treatment was not likely.

A recently published review summarized toxicity rates reported by 17 initial studies on [ ${ }^{177}$ Lu]Lu-PSMA-617 ( $n=14$ studies), [ ${ }^{177}$ Lu]Lu-PSMA-I\&T ( $n=2$ studies) or both compounds ( $n=1$ study) [13]. Eleven case series administered a [177Lu]Lu-PSMA-617 activity of approximately $6 \mathrm{GBq}$ per cycle. One study increased the administered [177Lu]Lu-PSMA-617 activity from 3 to $6 \mathrm{GBq}$ [14], one study administered 4.0 GBq to $9.3 \mathrm{GBq}$ [8] and another 3.7 to $6.0 \mathrm{GBq}$ [15]. In one study, $7.5 \mathrm{GBq}\left[{ }^{177} \mathrm{Lu}\right] \mathrm{Lu}-\mathrm{PSMA}-617$ per cycle was administered [16]. Of all analyzed patients in this review, anemia occurred most commonly in 23\% (interquartile range (IQR) 7-35\%) of the patients. Leukocytopenia and thrombocytopenia occurred in respectively 14.2\% (IQR 8-25\%) and 15\% (IQR 6-24\%) of the cases. Nephrotoxicity and salivary gland toxicity was observed in respectively 9.5\% (IQR 0-20\%) and $14.5 \%$ (IQR 5.5-33.5\%) of the patients. In the only prospective study by 
Hofman et al., the majority of the 30 included patients received at least three therapy cycles with a mean activity of 7.5 (range: $4.4-8.7$ ) GBq [177Lu]Lu-PSMA-617. Observed toxicity rates were quite similar to those reported in the abovementioned review. Grade 3 anemia was reported in 13\%; neutropenia occurred in 7\%, and grade 3-4 thrombocytopenia occurred in $27 \%$ of the patients. No renal toxicities occurred. A remarkably high proportion of patients suffered from grade 1 xerostomia (87\%), being attributed to the specific questioning in this prospective study. Apart from the incidence of xerostomia being much lower in our study, both biochemical and clinical toxicity rates are congruent with those found in the abovementioned publications.

Only few previously published studies report on patients treated with different administered activities of $\left[{ }^{177} \mathrm{Lu}\right] \mathrm{Lu}-\mathrm{PSMA}-617[8,14,15]$. Unfortunately, toxicity in the different dosage groups was sparsely described separately. Fendler et al. found a similar incidence of adverse events for the administration of either $3.7 \mathrm{GBq}(n=5)$ or $6.0 \mathrm{GBq}(n=10)$ in two cycles [15]. The administered dose of $6.0 \mathrm{GBq}$ was recommended as an appropriate treatment activity based on previous dosimetry calculations, in which the kidney was identified as a dose-limiting organ [17]. Hematologic toxicity rates in both patients groups were low and occurred almost equally often. In the $6.0 \mathrm{GBq}$ group, two patients had grade 3 anaemia and leukocytopenia. Mild xerostomia was observed in seven patients. No grade $\geq 4$ toxicities or other serious events were observed. Nine patients (60\%) had a best PSA response of $>50 \%$. Seven of them were treated with $6.0 \mathrm{GBq}\left[{ }^{177} \mathrm{Lu}\right] \mathrm{Lu}-\mathrm{PSMA}-617$, suggesting increased efficacy in the higher treatment regimen. The administered activity of $6.0 \mathrm{GBq}\left[{ }^{177} \mathrm{Lu}\right] \mathrm{Lu}-\mathrm{PSMA}-617$ was concluded to be safe and resulted in promising response rates. Based on the dosimetry calculations performed, the authors concluded that more than three cycles of $6.0 \mathrm{GBq}$ $\left[{ }^{177} \mathrm{Lu}\right] \mathrm{Lu}-\mathrm{PSMA}-617$ can be safely administered. In a dose escalation study performed by Rathke et al., 40 patients underwent 1-3 cycles with 4.0 $\mathrm{GBq}, 6.0 \mathrm{GBq}, 7.4 \mathrm{GBq}$ or $9.3 \mathrm{GBq}\left[{ }^{177} \mathrm{Lu}\right] \mathrm{Lu}-\mathrm{PSMA}-617$, with an interval of two months [8]. In the $4.0 \mathrm{GBq}$ group, one patient suffered from grade 3 thrombocytopenia. In the patient group treated with $6.0 \mathrm{GBq}$, no $\geq$ grade 
3 toxicities were reported. In the $7.4 \mathrm{GBq}$ group, grade 3 leukocytopenia was reported only once. In the $9.3 \mathrm{GBq}$ group, grade 4 thrombocytopenia was reported only in one patient. Serious non-haematological adverse events or the occurrence of xerostomia were not reported. Biochemical responders after the first cycle were found in 40\%, 30\%, 50\% and 30\% of patients for 4.0 GBq, 6.0 GBq, 7.4 GBq and 9.3 GBq respectively, showing no major differences between the treatment groups. Nineteen of the 40 patients did not complete the three intended cycles as a result of disease progression or incomplete recovery of decreased blood cell counts. Most of these patients were treated with $9.3 \mathrm{GBq}$, implying that the maximum tolerated activity was reached. However, the patients treated with 9.3 $\mathrm{GBq}$ also appeared to be most heavily pre-treated with chemotherapy and had the highest alkaline phosphatase and PSA levels. Thus, the doselimiting effects, regarded as being caused by the activity of $9.3 \mathrm{GBq}$, may have been a coincidental observation as a result of patient selection, and even higher activities may be administrated to well-selected patients.

To individualize $\left[{ }^{177} \mathrm{Lu}\right] \mathrm{Lu}-\mathrm{PSMA}-617$ therapy, we may learn from the research performed in the field of $\left[{ }^{177} \mathrm{Lu}\right]$ Lu-DOTATATE, also known as PRRT. PRRT is currently approved for patients with somatostatin receptorpositive gastroenteropancreatic neuroendocrine tumors for four treatment cycles with a fixed activity of 7.4 GBq/cycle for every 8-12 weeks [18]. To guide PRRT individualized treatment, the use of renal dosimetry has been investigated, resulting in a considerable variability in the number of cycles each patient may tolerate [19]. Unfortunately, initial studies using this patient tailored approach do not seem to show a significantly increased efficacy (yet) [20]. Based on the available dosimetry data on $\left[{ }^{177} \mathrm{Lu}\right] \mathrm{Lu}-$ PSMA-617, red bone marrow, kidneys and salivary glands are identified as dose-limiting organs. Radiotherapy-derived maximum cumulative doses of 23 Gy for the kidneys, 26-50 Gy for the salivary glands and 30 Gy for red bone marrow have been reported [14, 17, 21-26]. Function of these critical organs, as well as various tumor-related and non-tumor related factors have been proposed to guide the selection of the appropriate dosage of administered [ $\left.{ }^{177} \mathrm{Lu}\right] \mathrm{Lu}-\mathrm{PSMA}-617$ [27]. 
Although not representing the primary outcome of the present study, the proportion of biochemical responders in both patient groups was quite similar, suggesting comparable efficacy of both administered activities. These promising results match those found in previously published literature on $\left.{ }^{[177} \mathrm{Lu}\right] \mathrm{Lu}-\mathrm{PSMA}-617$ treatment. However, the most accurate activity, cycle interval and number of treatment cycles still has to be determined for (individual) PCa patients.

Whereas the present study was performed according to standardized procedures (treatment protocol and CTCAE grading system), its retrospective design includes limitations. Additionally, the small sample size did not allow for reasonable statistical calculations and subsequent conclusions on which radioactivity level provides the optimal therapeutic range. In particular, the low incidence of reported toxicities complicated comparison between both treatment groups. However, since the results of the present study demonstrate mild toxicity profiles for treatment with both $6.0 \mathrm{GBq}$ and $7.4 \mathrm{GBq}\left[{ }^{177} \mathrm{Lu}\right] \mathrm{Lu}-\mathrm{PSMA}-617$, the administration of higher activities may be safe and feasible. A prospective randomised study should be undertaken to prove this. Thirdly, evaluation was performed after only two cycles of [ $\left.{ }^{177} \mathrm{Lu}\right] \mathrm{Lu}-\mathrm{PSMA}-617$ and follow-up was limited. Ultimately, the globally performed prospective randomized phase 3 VISION study, aims to evaluate treatment with 7.4 GBq [ $\left.{ }^{177} \mathrm{Lu}\right] \mathrm{Lu}-\mathrm{PSMA}-617$ per cycle for up to 6 cycles on a large scale $(n=750)$. The VISION study will provide solid evidence on efficacy, toxicity and safety; however, additional prospective randomised dose escalation studies are needed to further define the optimal administered treatment activity of [ $\left.{ }^{177} \mathrm{Lu}\right] \mathrm{Lu}-\mathrm{PSMA}-617$.

\section{CONCLUSION}

In this study, [ ${ }^{177}$ Lu]Lu-PSMA-617 therapy was well tolerated with a mild toxicity profile in patients treated with either $6.0 \mathrm{GBq}$ or $7.4 \mathrm{GBq}$ per cycle and no significant differences between these two groups. This indicates that both treatment activities are safe and may be considered in patients with metastatic castration-resistant PCa. 


\section{REFERENCES}

1. Jemal A, Bray F, Center MM et al. Global cancer statistics. CA Cancer J Clin. 2011; 61(2): 69-90

2. Yap TA, Zivi A, Omlin A et al. The changing therapeutic landscape of castrationresistant prostate cancer. Nat Rev Clin Oncol 2011; 8(10): 597-610.

3. Survival Rates for Prostate Cancer. In: American Cancer Society. 2017. https:// www.cancer.org/cancer/prostate-cancer/detection-diagnosis-staging/ survival-rates.html. Accessed 16 Feb 2019.

4. Troyer JK, Beckett ML, Wright GL Jr. Detection and characterization of the prostate-specific membrane antigen (PSMA) in tissue extracts and body fluids. Int J Cancer. 1995; 62(5):552-8

5. Catalona WJ, Smith DS, Ratliff TL et al. Measurement of Prostate-Specific Antigen in Serum as a Screening Test for Prostate Cancer. N Engl J Med. 1991; 324(17):1156-61

6. Conway RE, Petrovic N, Li Z et al. Prostate-specific membrane antigen regulates angiogenesis by modulating integrin signal transduction. Mol Cell Biol. 2006; 26(14):5310-24

7. Wang J, Zang J, Wang $H$ et al. Pretherapeutic 68Ga-PSMA-617 PET May Indicate the Dosimetry of 177Lu-PSMA-617 and 177-Lu-EB-PSMA-617 in Main Organs and Tumor Lesions. Clin Nucl Med. 2019; 44(6): 431-438

8. Rathke H, Giesel FL, Flechsig P et al. Repeated ${ }^{177}$ Lu-Labeled PSMA-617 Radioligand Therapy Using Treatment Activities of Up to $9.3 \mathrm{GBq}$. J Nucl Med. 2018; 59(3): 459-465

9. Strosberg J, El-Haddad G, Wolin E, et al. Phase 3 Trial of ${ }^{177}$ Lu-Dotatate for Midgut Neuroendocrine Tumors. N Engl J Med. 2017 Jan 12;376(2):125-135.

10. van Kalmthout L, Braat A, Lam M, et al. First Experience With 177Lu-PSMA-617 Therapy for Advanced Prostate Cancer in the Netherlands. Clin Nucl Med. 2019 Jun;44(6):446-451.

11. Scher HI, Morris MJ, StadlerWM, et al. Trial Design and Objectives for Castration Resistant Prostate Cancer: Updated Recommendations From the Prostate Cancer Clinical Trials Working Group 3. J Clin Oncol. 2016;34:1402-1418.

12. Wahl RL, Jacene H, Kasamon Y, Lodge MA. From RECIST to PERCIST: Evolving Considerations for PET response criteria in solid tumors. J Nucl Med. 2009 May;50 Suppl 1:122S-50S.

13. Yadav MP, Ballal S, Sahoo RK, Dwivedi SN, Bal C'. Radioligand Therapy With ${ }^{177}$ Lu-PSMA for Metastatic Castration-Resistant Prostate Cancer: A Systematic Review and Meta-Analysis. AJR Am J Roentgenol. 2019 Aug;213(2):275-285.

14. Kratochwill C, Giesel FL, Stefanova M et al. PSMA-Targeted Radionuclide Therapy of Metastatic Castration-Resistant Prostate Cancer with 177LuLabeled PSMA-617. J Nucl Med. 2016; 57(8): 1170-6 
15. Fendler WP, Reinhardt S, Ilhan H et al. Preliminary experience with dosimetry, response and patient reported outcome after 177Lu-PSMA-617 therapy for metastatic castration-resistant prostate cancer. Oncotarget. 2017; 8(2): 35813590

16. Hofman MS, Violet J, Hicks RJ, et al. [ $\left.{ }^{177} \mathrm{Lu}\right]-P S M A-617$ radionuclide treatment in patients with metastatic castration-resistant prostate cancer (LuPSMA trial): a single-centre, single-arm, phase 2 study. Lancet Oncol. 2018 Jun;19(6):825-833.

17. Delker A, Fendler WP, Kratochwil C, et al. Dosimetry for (177)Lu-DKFZPSMA-617: a new radiopharmaceutical for the treatment of metastatic prostate cancer. Eur J Nucl Med Mol Imaging. 2016; 43:42-51.

18. Strosberg J, El-Haddad G, Wolin E, et al. Phase 3 Trial of ${ }^{177}$ Lu-Dotatate for Midgut Neuroendocrine Tumors. N Engl J Med. 2017 Jan 12;376(2):125-135.

19. Sundlöv A, Sjögreen-Gleisner K, Svensson J, et al. Individualised ${ }^{177} \mathrm{Lu}-$ DOTATATE treatment of neuroendocrine tumours based on kidney dosimetry. Eur J Nucl Med Mol Imaging. 2017 Aug;44(9):1480-1489.

20. Del Prete M, Buteau FA, Arsenault F, et al. Personalized ${ }^{177}$ Lu-octreotate peptide receptor radionuclide therapy of neuroendocrine tumours: initial results from the P-PRRT trial. Eur J Nucl Med Mol Imaging. 2019 Mar;46(3):728-742

21. Kabasakal L, AbuQbeitah M, Aygu"n A, et al. Pre-therapeutic dosimetry of normal organs and tissues of 177Lu-PSMA-617 prostate-specific membrane antigen (PSMA) inhibitor in patients with castration-resistant prostate cancer. Eur J Nucl Med Mol Imaging. 2015 Dec;42(13):1976-83.

22. Yadav MP, Ballal S, Tripathi M, et al. Post-therapeutic dosimetry of 177Lu- DKFZPSMA-617 in the treatment of patients with metastatic castration-resistant prostate cancer. Nucl Med Commun. 2017;38:91-98.

23. Kabasakal L, Toklu T, Yeyin N, et al. Lu-177-PSMA-617 prostate-specific membrane antigen inhibitor therapy in patients with castration-resistant prostate cancer: stability, bio-distribution and dosimetry. Mol Imaging Radionucl Ther. 2017;26:62-68.

24. Emami B, Lyman J, Brown A, et al. Tolerance of normal tissue to therapeutic irradiation. Int J Radiat Oncol Biol Phys. 1991; 21:109-122.

25. Gensheimer MF, Liao JJ, Garden AS, Laramore GE, Parvathaneni U. Submandibular gland-sparing radiation therapy for locally advanced oropharyngeal squamous cell carcinoma: patterns of failure and xerostomia outcomes. Radiat Oncol. 2014; 9:255.

26. Hey J, Setz J, Gerlach R, et al. Parotid glandrecovery after radiotherapy in the head and neck region-36 months follow-up of a prospective clinical study. Radiat Oncol. 2011; 6:125.

27. Kulkarni HR, Singh A, Schuchardt C, et al. PSMA-Based Radioligand Therapy for Metastatic Castration-Resistant Prostate Cancer: The Bad Berka Experience Since 2013. J Nucl Med. 2016 Oct;57(Suppl 3):97S-104S. 




\section{PART III}

SUMMARY AND DISCUSSION

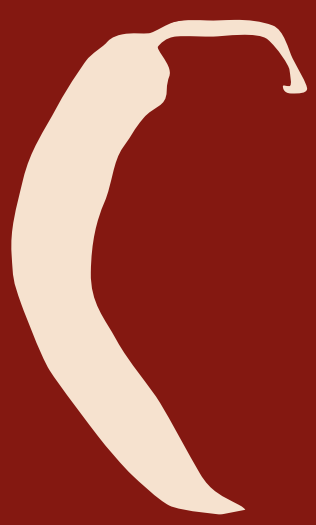





\section{CHAPTER 10}

Summary

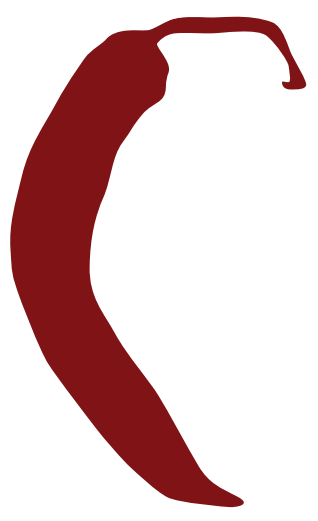


Chapter 1 (general introduction) provides an overview the development of radioactive labelled ligands being suitable for imaging and therapy of prostate cancer.

Prostate cancer is the most commonly diagnosed malignancy in the western world and represents the second-ranked cause of cancer mortality among men in the Netherlands.

Lymph node metastases in prostate cancer patients are considered as an adverse prognostic factor and are associated with systemic metastases. Therefore, adequate staging is essential. To detect pelvic lymph node metastases, an extended pelvic lymph node dissection currently is considered the gold standard. Since an extended pelvic lymph node dissection is an invasive procedure, reliable imaging alternatives are desirable.

Over the last decade, hybrid imaging with prostate specific membrane antigen (PSMA) PET/CT emerged as a sensitive new imaging technique for the detection of prostate cancer. PSMA is a transmembrane glycoprotein and is significantly overexpressed in the majority of the prostate cancer cells. Labelled PSMA tracers bind with a high affinity to the PSMA receptor, allowing for targeted imaging (e.g. with gallium-68 ([ $\left.{ }^{68 \mathrm{Ga}}\right] \mathrm{Ga}$ )-labelled or fluorine-18 ([18 F]F)-labelled PSMA tracers) and radioligand therapy, e.g. with lutetium-177 ([177Lu]Lu)-PSMA.

The present thesis consists of four parts. Part I concentrates on PSMAtargeting imaging with positron-emission tomography (PET). Part II focusses on PSMA-targeting therapy with lutetium-177, a promising treatment strategy for advanced prostate cancer patients, followed by the summary and general discussion (part III) and the appendices (part IV).

\section{PART I: PROSTATE CANCER IMAGING}

Chapter 2 presents the results of the PEPPER-study: a prospective validation study aiming to define diagnostic value of $\left[{ }^{68} \mathrm{Ga}\right] \mathrm{Ga}$-PSMA PET/CT in newly diagnosed prostate cancer patients. In candidates for 
extended pelvic lymph node dissection, $\left[{ }^{68} \mathrm{Ga}\right] \mathrm{Ga}$-PSMA PET/CT was performed prior to surgery. Sensitivity, specificity, and positive and negative predictive value for the detection of lymph node metastases were calculated using histopathology as a reference. In newly diagnosed intermediate-high risk prostate cancer patients with $>10 \%$ MSKCC risk of lymph node involvement and negative skeletal scintigraphy, $\left[{ }^{68} \mathrm{Ga}\right]$ Ga-PSMA PET/CT detected lymph node metastases with high specificity (90.9\%) and moderate sensitivity (41.5\%). Implementation of $\left[{ }^{68} \mathrm{Ga}\right] \mathrm{Ga}$ PSMA PET/CT into the diagnostic work-up of these patients led to change of management in $12.6 \%$. Although a negative $\left[{ }^{68} \mathrm{Ga}\right] \mathrm{Ga}-\mathrm{PSMA}$ PET/CT cannot rule out the presence of lymph node metastases, it was concluded that $\left[{ }^{68} \mathrm{Ga}\right] \mathrm{Ga}$-PSMA PET/CT, considering its significant impact on patient management, may guide future patient selection.

In chapter 3, interobserver agreement in $\left.{ }^{68} \mathrm{Ga}\right] \mathrm{Ga}-\mathrm{PSMA}$ PET/CT reporting is determined using a standardized, straightforward, 5-point scale, characterizing level of suspicion of lesions. Two experienced nuclear medicine physicians retrospectively evaluated $118\left[{ }^{68} \mathrm{Ga}\right] \mathrm{Ga}$-PSMA PET/ CT scans. It was found that structured classification with this 5-point scale provides substantial interobserver agreement in localizing tumor sites in the prostate region $(k=0.67)$, regional lymph nodes $(k=0.62)$ and osseous structures on $\left[{ }^{68} \mathrm{Ga}\right] \mathrm{Ga}$-PSMA PET/CT $(k=0.62)$. It was therefore concluded that structured reporting according to this method may be used to optimize $\left[{ }^{68} \mathrm{Ga}\right] \mathrm{Ga}-\mathrm{PSMA}$ PET/CT interpretation.

In chapter 4, a retrospective study is presented, assessing diagnostic performance of $\left[{ }^{18} \mathrm{~F}\right] \mathrm{F}-\mathrm{DCFP}$ L PET/CT compared to $\left[{ }^{68} \mathrm{Ga}\right] \mathrm{Ga}$-PSMA PET/ CT.PSA-stratified detections rate of both tracers was calculated in 156 postradical prostatectomy patients with a primary biochemical recurrence (first biochemical recurrence after treatment with curative intent) or secondary biochemical recurrence (after prior salvage treatments). All patients had PSA-levels ranging from $0.5-3.5 \mathrm{ng} / \mathrm{ml}$. Overall detection rate of $\left[{ }^{68} \mathrm{Ga}\right] \mathrm{Ga}$-PSMA PET/CT and $\left[{ }^{18} \mathrm{~F}\right] \mathrm{F}-\mathrm{DCFP} y L \mathrm{PET} / \mathrm{CT}$ was respectively $73.8 \%$ and $72.4 \%(p=0.85)$. These results are in contrast with the earlier published results by Dietlein et al. (2017), suggesting that [ $\left.{ }^{18} \mathrm{~F}\right] \mathrm{F}-\mathrm{DCFPyL}$ 
outperforms $\left[{ }^{68} \mathrm{Ga}\right] \mathrm{Ga}$-PSMA in patients with low PSA levels (PSA: 0.5-3.5 $\mathrm{ng} / \mathrm{ml}$ ). Therefore, our data suggest that the diagnostic performance of both $\left[{ }^{68} \mathrm{Ga}\right] \mathrm{Ga}-P S M A-11$ and $\left[{ }^{18} \mathrm{~F}\right] \mathrm{F}-\mathrm{DCFPyL}$ in the setting of biochemical recurrence of prostate cancer post-prostatectomy is comparable and both tracers can be used interchangeably in clinical practice.

\section{PART II: PROSTATE CANCER THERAPY}

Chapter 5 describes the first patient with advanced prostate cancer, who underwent $\left[{ }^{177} \mathrm{Lu}\right] \mathrm{Lu}$-PSMA-617 therapy in the UMC Utrecht. Related to this case, in which an exceptional clinical and biochemical response was observed, the working mechanism of $\left[{ }^{177} \mathrm{Lu}\right] \mathrm{Lu}$-PSMA therapy is discussed. Furthermore, a brief overview of the published literature on this specific subject is presented.

Chapter 6 summarizes the first experience with [177Lu]Lu-PSMA therapy to treat prostate cancer in the Netherlands. In this study, 30 patients with advanced prostate cancer received 1-6 therapy cycles with $6 \mathrm{GBq}\left[{ }^{177} \mathrm{Lu}\right]$ Lu-PSMA-617. It was found that, after the first cycle, usage of analgesics decreased in $45 \%$ of the patients. During treatment, maximum PSA decrease was $\geq 50 \%$ in $57 \%$ of the patients. Despite CTCAE-grade III and IV anemia occurring in two patients (7\%), all other newly originated biochemical toxicity was mild and limited to maximum CTCAE grade I-II. Grade II xerostomia occurred in $17 \%$ of the patients. The results of this study confirmed the favorable safety and efficacy profile of $\left[{ }^{177} \mathrm{Lu}\right] \mathrm{Lu}-\mathrm{PSMA}-617$, that was earlier observed in small, German studies.

In chapter 7, the case of a 54-year old patient with metastatic castration resistant prostate cancer was described, in which $\left[{ }^{177} \mathrm{Lu}\right] \mathrm{Lu}$-PSMA therapy possibly led to severe bilateral papilledema causing visual deficit. The anticipated causes for this presentation, including either neurological toxicity following $\left[{ }^{177} \mathrm{Lu}\right] \mathrm{Lu}$-PSMA treatment, or the development of diffuse leptomeningeal metastases by progressive disease during [ $\left.{ }^{177} \mathrm{Lu}\right] \mathrm{Lu}-\mathrm{PSMA}$ therapy, are discussed. Unfortunately, lacking post-mortem autopsy results in this patient, any of the abovementioned scenarios could not be 
excluded, nor proven. Thus, despite the initially published results showing a favorable toxicity profile of [ ${ }^{177} \mathrm{Lu}$ ]Lu-PSMA therapy, more knowledge on this aspect is needed.

High accumulation of therapeutic radioligands in the salivary glands may result in the undesirable side effect xerostomia. In chapter $\mathbf{8}$, the impact of external cooling with icepacks on PSMA uptake in salivary glands was prospectively studied in 89 prostate cancer patients. Twenty-four patients were scanned with unilateral (solely left-sided) icepacks; 20 with bilateral icepacks; 45 without icepacks. No significant differences were found in PSMA uptake comparing the patient group that was scanned with bilateral icepacks to the patient group that was scanned without icepacks. When comparing radiotracer uptake in the intervention group (bilateral + unilateral icepacks-group) with the control group, however, significant differences were found with regard to radiotracer uptake in the left parotid gland (SUV max $_{11} 11.07$ versus 12.95; $p=0.02 ;$ SUV $_{\text {peak }}: 9.91$ versus $11.45 ; p=0.04$ ). These findings were confirmed by intra-patient analysis, revealing significant differences in SUV max $_{\text {max }}$ and SUV $V_{\text {peak }}$ between

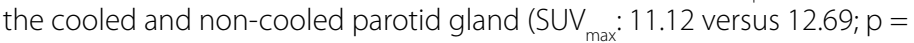
$0.00 ;$ SUV $_{\text {peak }}: 9.93$ versus $11.25 ; p=0.00$ ). The results of this study indicate that impact of icepacks on PSMA uptake seems to be limited to the parotid glands. As clinical relevance of these findings is debatable, it was concluded that structural application of icepacks in the setting of $\left[{ }^{177} \mathrm{Lu}\right]$ Lu-PSMA therapy needs careful consideration.

In chapter 9, a retrospective study is presented, in which toxicity profiles of 6.0 and $7.4 \mathrm{GBq}\left[{ }^{177} \mathrm{Lu}\right] \mathrm{Lu}-\mathrm{PSMA}$ therapy per cycle were compared. In the $6.0 \mathrm{GBq}$ and $7.4 \mathrm{GBq}$ group, CTCAE-grade 1-2 xerostomia occurred in respectively $13 \%$ and $20 \%$ and grade 3 anemia occurred in respectively $20 \%$ and $27 \%$ of the patients. One patient in the $7.4 \mathrm{GBq}$ group (7\%) had grade 3 thrombocytopenia. All other newly originated toxicities were limited to maximum grade 2 . During treatment, maximum PSA decline of $>50 \%$ was observed in $60 \%$ and in $33 \%$ of the patients in respectively the $6.0 \mathrm{GBq}$ group and the $7.4 \mathrm{GBq}$ group. No significant differences were found, indicating that both activities are well-tolerated and may be considered in patients with advanced prostate cancer. 



\section{CHAPTER 11}

General discussion

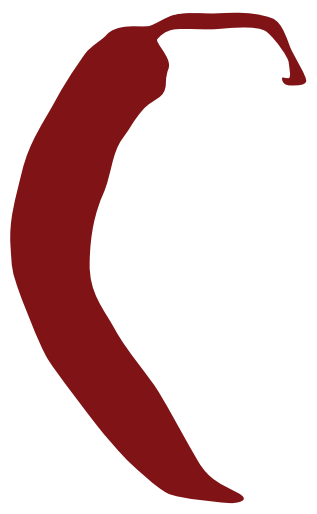


This thesis highlights prostate-specific membrane antigen (PSMA) imaging (part I) and treatment (part II) of prostate cancer (PCa) patients.

\section{PART I: PROSTATE CANCER IMAGING}

\section{Guidelines}

At the start of my PhD trajectory in 2016, imaging with PSMA PET/ CT had caused an atmosphere of excitement among both nuclear medicine physicians and urologists, who welcomed this novelty with open arms for its highly superior detection capacity over conventional imaging techniques. Since then, PSMA targeting imaging strategies gained prominence and were introduced into clinical practice for both initial staging and restaging of $\mathrm{PC}$, although robust data on its diagnostic were not yet available. At present, the benefit of gallium-68 ( $\left.\left[{ }^{68} \mathrm{Ga}\right] \mathrm{Ga}\right)-P S M A$ PET/CT in primary staging is confirmed by various initial studies. ${ }^{1-8}$ A recently published meta-analysis on this topic reported high sensitivity (74\%) and specificity (96\%) in detection of lymph node metastases. ${ }^{9}$ Additionally, $\left.{ }^{[68} \mathrm{Ga}\right] \mathrm{Ga}$-PSMA PET/CT has a high impact on clinical management in PCa patients. ${ }^{10}$ As PSMAPET/CT appeared to be more sensitive than conventional imaging techniques in lymph node staging, current national guidelines recommend to perform PSMA PET/CT in newly diagnosed PCa patients who have an indication for screening of metastatic disease. ${ }^{11}$ However, according to the European Association of Urology guidelines, screening of metastases in newly diagnosed high-risk localized or locally advanced PCa patients should still be performed with 'abdominopelvic imaging' and skeletal scintigraphy. ${ }^{12}$ PSMA PET/CT imaging is not advocated in these guidelines. Besides decisive factors such as limited availability and increased costs, these guidelines are presumably formulated with caution, since the clinical value of earlier detection of metastases has not been clarified yet, and, equally important, optimal management of patients diagnosed with metastasized PCa by PSMA PET/CT is currently unknown. 
The results of the successfully completed PEPPER-study (chapter 2 of this thesis) significantly adds to the already existing evidence on validation of $\left[{ }^{68} \mathrm{Ga}\right] \mathrm{Ga}$-PSMA PET/CT as a diagnostic modality for primary staging of PCa patients, being mostly derived from small, retrospective patient cohorts. ${ }^{1-8}$ Further large prospective studies need to be systematically analyzed in future reviews and meta-analyses to provide a significant contribution to the evidence that needs to be created to incorporate PSMA PET/CT into clinical guidelines.

\section{PSMA-targeting radiotracers}

Various PSMA-targeting radiotracers are currently used in daily clinical practice. Amongst them, the first available and the most intensively studied is $\left[{ }^{68} \mathrm{Ga}\right] \mathrm{Ga}-\mathrm{PSMA}$. Also, alternative $\left[{ }^{18} \mathrm{~F}\right] \mathrm{F}$-labelled PSMA ligands have been developed over the last years, most notably $\left[{ }^{18} \mathrm{~F}\right] \mathrm{F}-\mathrm{DCFP} y \mathrm{~L}$ and, more recently, $\left[{ }^{18} \mathrm{~F}\right] \mathrm{F}-\mathrm{PSMA}-1007 . \quad\left[{ }^{18} \mathrm{~F}\right] \mathrm{F}-\mathrm{PSMA}$ is a cyclotron-product with a relatively long half-life (109 minutes) compared to $\left.{ }^{68} \mathrm{Ga}\right] \mathrm{Ga}$-PSMA (68 minutes), which allows transport to nearby institutions. Additionally, $\left[{ }^{18} \mathrm{~F}\right] \mathrm{F}$-labelled PSMA tracers offer higher PET image resolution than $\left[{ }^{68} \mathrm{Ga}\right] \mathrm{Ga}$-labelled PSMA tracers as a result of their intrinsically shorter positron range and higher positron yield. This potentially leads to advantages in detection of small lesions. ${ }^{13-15}$ Furthermore, $\left[{ }^{18} \mathrm{~F}\right] \mathrm{F}-\mathrm{PSMA}-1007$ has a reduced urinary clearance and may improve the assessment of the prostate region. ${ }^{16}$ However, with regard to $\left[{ }^{18} \mathrm{~F}\right] \mathrm{F}$-labelled PSMA tracers, more non-specific accumulation in the skeleton and subsequent higher false-positive rates were also reported. ${ }^{17}$ Since the development of PSMA-targeting tracers is overall regarded as a major step forward, all aforementioned tracers are interchangeably used in current clinical practice. Whether or not the pharmacological differences of the PSMA-targeting radiotracers will translate into substantially deviant detection rates, must be determined by large prospective studies currently being conducted at the Amsterdam UMC, location VUmc (the SALT-study; NL6754), and the Canisius Wilhelmina Ziekenhuis in Nijmegen (the MINT-study; NL7428). 
A perhaps more crucial factor that determines detection rate of PSMA PET/CT includes the capacity of the used PET camera. Recently, digital PET cameras were introduced into clinical practice. These cameras facilitate scanning with $2 \mathrm{~mm}$ slices - a major improvement compared to the $4 \mathrm{~mm}$ slices of the 'time-of-flight' cameras that were formerly used. However, the arrival of digital PET cameras also introduced interinstitutional differences regarding image quality and reproducibility. In order to minimize these differences, it is of utmost importance to standardize the PET-imaging procedures, as was the initial goal of the EARL criteria. ${ }^{18}$ In the light of the abovementioned developments, these criteria are currently under revision.

\section{Lymph node staging}

In contrast with the reported findings of the abovementioned metaanalysis (sensitivity and specificity rates of respectively $74 \%$ and $96 \%$ ), we demonstrated that ${ }^{68} \mathrm{Ga}$ ] Ga-PSMA PET/CT has moderate patientbased sensitivity (41.5\%), yet high specificity (90.9\%) in detection of lymph node metastases in newly diagnosed PCa patients (chapter 2 of this thesis). ${ }^{19}$ Additionally, $\left[{ }^{68} \mathrm{Ga}\right.$ ]Ga-PSMA PET/CT provides improved detection of distant metastases in comparison with conventional bone scintigraphy. ${ }^{20}$ For lymph node metastases with a diameter of the metastatic deposit of $\geq 4.5 \mathrm{~mm}$ and $\geq 2.3 \mathrm{~mm}$, sensitivity rates of respectively $90 \%$ and $50 \%$ were reported. ${ }^{21}$

For $\left[{ }^{18} \mathrm{~F}\right] \mathrm{F}-\mathrm{DCFPyL}$ PET/CT, sensitivity and specificity rates of $71.4 \%$ and $88.9 \%$ were found in a smaller study with similar design ${ }^{22}$, however, larger-scale results from the SALT-study are eagerly awaited. These results suggest that PSMA PET/CT imaging may represent an adequate alternative option for lymph node staging instead of extended pelvic lymph node dissection (ePLND) in well-selected newly diagnosed PCa patients, since this surgical (diagnostic) intervention is associated with potential morbidity and its therapeutic effect remains controversial. ${ }^{23}$ Owing to the high specificity of PSMA PET/CT, unnecessary ePLNDs may be reasonably avoided in certain patient groups, such as (1) PCa patients with $>4$ PET positive lymph nodes within and/or beyond 
the surgical template of ePLND, and (2) PCa patients with distant metastatic disease on PSMA PET/CT. In both patient groups, the current standard of care, palliative androgen deprivation therapy (ADT), can be started earlier with or without local radiotherapy of the prostate, depending on the burden of metastatic disease. More importantly, costs and surgical toxicities (e.g. lymphoceles, lymph edema and thromboembolic events) associated with an unnecessary ePLND may be avoided. In conclusion, staging with PSMA PET/CT could be highly cost-efficient in these patients and will be addressed in future research at our institution.

Despite the limited evidence for the threshold within this therapeutic strategy, patients staged by ePLND as $\mathrm{N}+$ with limited ( $\leq 4)$ nodal disease, currently receive curative intent external beam radiotherapy (EBRT) to the prostate and pelvic nodes, combined with up to 3 years ADT. ${ }^{24}$ Given the moderate sensitivity of PSMA PET/CT, small lesions are likely to be missed. Consequently, patients may be understaged by PSMA PET/CT. It therefore seems a bridge too far to replace ePLND by PSMA PET/CT in newly diagnosed patients with no or limited nodal involvement on PSMA PET/CT. Further research may focus on the extent of understaging by PSMA PET/CT. Perhaps, a ratio exists between the number of lymph nodes detected by PSMA PET/ $\mathrm{CT}$ and those found during histopathological examination. Such a ratio may provide input for the development of novel pre-operative multiparametric nomograms, in which the number of PET-detected lymph nodes, in addition to predictive clinical parameters and tumor characteristics are incorporated to identify patients suitable for ePLND.

At present however, lymph node staging by ePLND still represents the standard of care. To guide the selection of patients suitable for this invasive procedure, various preoperative predictive nomograms to estimate risk of lymph node involvement are used in daily practice (e.g. MSKCC, Briganti, Roach Formula and others) ${ }^{25-29}$, in which clinical parameters (i.e. age, PSA level, Gleason score, clinical T-stage and number of positive and negative biopsy cores) are taken into 
consideration. The decision to perform an ePLND based on these nomograms relies on the locally chosen cut-off for suspected lymph node involvement. To prevent patients from missing malignant lymph nodes, ePLND is recommended in all high-risk PCa patients. For intermediate-risk PCa patients, thresholds of 5\% and 2\% are advised by respectively the European Association of Urology guideline and the National Comprehensive Cancer Network guideline. ${ }^{12,30}$ In clinical practice, these low thresholds result in $75-85 \%$ unnecessary ePLNDs $s^{31-33}$.

The combination of imaging (PSMA PET/CT) and clinical and tumor parameters may potentially be helpful to select suitable patients for ePLND, reflected by the results of a study including 60 intermediate to high-risk PCa patients who underwent both PSMA PET imaging (combined with MRI) and ePLND. ${ }^{34}$ Risk prediction based on visual lymph node status, total PSMA uptake of the primary tumor, PSA level and Gleason score was found to be superior (area under the curve $(A \cup C)$ of 0.90 ) to mostly applied nomograms alone (AUC ranging from 0.63-0.83). These results underline the predictive potential of qualitative and quantitative PET parameters.

\section{Detection of bone metastases}

The superior sensitivity and specificity of PSMA PET/CT over conventional modalities (i.e. skeletal scintigraphy and $\mathrm{CT}$ ) with regard to the detection of bone metastases was demonstrated ${ }^{20,35-37}$ and likely relies on the ability to detect early-stage bone marrow lesions. These bone marrow lesions originate earlier in the metastatic process than sclerotic lesions, on which detection by conventional skeletal scintigraphy is based. A study among 112 PCa patients demonstrated that $\left[{ }^{68} \mathrm{Ga}\right] \mathrm{Ga}-\mathrm{PSMA}-11$ PET/CT detects metastatic bone lesions in $10 \%$ of patients without metastases on skeletal scintigraphy. ${ }^{38}$ These results are congruent with the data presented in chapter 2 of this thesis, in which nine patients with negative skeletal scintigraphy had PET positive bone lesions. Despite the fact that the conservative EAU guidelines still recommend preoperative staging with CT and skeletal 
scintigraphy in high-risk PCa patients, skeletal scintigraphy has been replaced by PSMA PET/CT in some hospitals in the Netherlands. Based on the abovementioned studies, this seems an evidencebased approach. However, skeletal scintigraphy can be still used in patients with very high-risk, in whom bone lesions are expected, because of lower costs and accessibility. In this context, it must be noted that particularly solitary (rib) lesions on PSMA PET/CT should be interpreted with caution ${ }^{39}$, as was also our experience with one of the biopsied patients (PET positive, PA negative) in the PEPPER-study (chapter $\mathbf{2}$ of this thesis). Well-designed prospective validation studies, preferably with histopathological proof as reference standard, must ultimately define diagnostic value of PSMA PET/CT in initial staging of distant metastases in the near future.

\section{PSMA PET interpretation}

PSMA PET/CT imaging has evolved as a widely used diagnostic tool for PCa due to its superior performance over earlier molecular imaging modalities. ${ }^{40}$ This performance, however, can be negatively affected by both inadequate interpretation of imaging (by nuclear medicine physicians) and imaging reports (by referring physicians). ${ }^{41}$ To minimize bilateral interpretation ambiguities, the usage of homogenous terminology, according to a standardized lexicon, has been advocated. ${ }^{42}$ To differentiate benign from malignant lesions on $\left[{ }^{68} \mathrm{Ga}\right] \mathrm{Ga}$-PSMA PET/CT, standardized interpretation criteria have been developed. ${ }^{43-45}$ Nonetheless, a recently published study comparing these three common standardized PSMA PET reporting methods (i.e. the EANM criteria, the PROMISE criteria and the PSMA-RADS criteria), found only moderate agreement on interpretation of distant lesions according to the PSMA-RADS criteria. ${ }^{46}$ The differing concordance rate was attributed to the differences between the proposed criteria with regard to interpretation of PSMA negative lesions and underlines the need for translation of all proposals into one easy-applicable, yet accurate classification method, as we attempted in chapter $\mathbf{3}$ of this thesis. In addition, further studies are required to assess diagnostic accuracy of this (newly designed) method. 


\section{Interpretation of pelvic lesions}

Uniform interpretation of PSMA PET/CT requires experience and is subject to a learning curve, supported by the decreased interobserver variability in more experienced readers. ${ }^{47,48}$ One of the main challenges is represented by the interpretation of pelvic lesions near the urinary system (i.e. ureters, prostate gland, bladder neck and para-aortic lymph nodes)..$^{49}$ Due to physiological renal excretion of [ $\left.{ }^{68} \mathrm{Ga}\right] \mathrm{Ga}-\mathrm{PSMA}$, accumulation of radiotracer in the urinary tract may compromise examination of PSMA PET/CT by masking suspected lesions in surrounding structures. To overcome this problem, furosemide may be administered in order to reduce urine radiotracer activity. This concept is based on preliminary research on urinary excretion of other radiotracers (e.g. Fluor-18 ([18F]F)-FDG), elucidating that forced diuresis combined with oral/parenteral hydration increases urinary flow and consequently decreases radiotracer activity in the lower urinary tract. ${ }^{50,51}$

Two studies addressed the impact of furosemide co-administration on image quality of PSMA PET/CT.52,53 Firstly, in the study by Derlin et al., furosemide co-administration resulted in a significantly decreased urine activity in the urinary bladder and ureters compared to the control group.52 However, subjective image quality of the prostate bed as a result of furosemide co-administration was not significantly enhanced. Secondly, Fennessy et al. investigated the impact of furosemide on excreted activity artifacts and diagnostic certainty of $\left.{ }^{68} \mathrm{Ga}\right] \mathrm{Ga}$-PSMA PET/CT interpretation. ${ }^{53}$ They also found decreased radiotracer activity in the bladder and ureters. Additionally, a significantly enhanced image quality in the intervention group was shown. However highly subjective, confidence level of the reporters significantly improved as a result of the reduced radiotracer activity in the urinary tract. Therefore, the authors advocated co-administration of furosemide in $\left.{ }^{68} \mathrm{Ga}\right] \mathrm{Ga}$-PSMA PET/CT imaging, particularly in the setting of re-staging. Following the experience in our institution, in which the additional value of furosemide was not clearly demonstrated, I would like to emphasize the importance of a carefully 
considered balance between the advantages and disadvantages (frequent voiding) of diuretics for individual patients.

\section{Future perspectives}

Whereas PSMA is currently considered one of the most successful targets used for imaging of $\mathrm{PC}$, it is not clear whether earlier diagnosis leads to improved oncological outcomes in terms of disease-free and overall survival. After all, in this PSMA era, patients who were formerly not considered metastasized, are now diagnosed with metastatic $\mathrm{PCa}$ - a phenomenon also known as stage migration. As a result of improved detection of (lymph node) metastases we assume that suitable treatment regimens may be started earlier and ePLND may be omitted in well-selected patients. As such, the number of complications associated with this surgical intervention will decrease and the opportunity to maintain a high quality of life for patients will be provided. However, these assumptions may not be correct. Further clinical studies will be needed to evaluate whether earlier diagnosis with PSMA PET/CT indeed translates into oncological benefit, as the limited follow-up period in most imaging studies does not provide these data. Furthermore, the current basis for treatment decisions in newly metastasized patients is derived from studies that divide patients according to their disease burden (low versus high volume disease) based on conventional imaging. ${ }^{54-58}$ Since it is not feasible to translate these 'old' data to the PSMA era, new landmark studies are urgently needed to define how to tailor treatment based on PSMA PET/CT.

\section{PART II: PROSTATE CANCER THERAPY}

Soon after the successful introduction of PSMA as an imaging ligand, it also proved to be effective for therapy when labelled with the alfa emitter Actinium-225 ([225Ac]) or the beta emitter lutetium-177 ([177Lu]). In this thesis, $\left[{ }^{177} \mathrm{Lu}\right] \mathrm{Lu}-\mathrm{PSMA}$ radioligand therapy (RLT) was acknowledged as a promising treatment strategy for advanced PCa patients, as it appeared safe, effective and induced minimal side 
effects (chapter 6). A recent meta-analysis, summarizing all published results in the field of [ $\left.{ }^{177} \mathrm{Lu}\right] \mathrm{Lu}$-PSMA treatment so far, confirmed these favorable outcomes. ${ }^{59}$

The optimal activity and administration schedule for [ $\left.{ }^{177} \mathrm{Lu}\right] \mathrm{Lu}-\mathrm{PSMA}$ has not been clearly defined and the choice for currently applied treatment protocols is a pragmatic one. At present, [ $\left.{ }^{177} \mathrm{Lu}\right] \mathrm{Lu}-\mathrm{PSMA}$ is generally administered at 6-8 weekly intervals with a fixed activity of 6.0 - $7.4 \mathrm{GBq}$ for each cycle - a regimen derived from $\left[{ }^{177} \mathrm{Lu}\right] \mathrm{Lu}$ DOTATATE therapy (also termed peptide receptor radionuclide therapy (PRRT)) in patients with neuroendocrine tumors. These typical intervals and activities are in accordance with recommendations by the German Society of Nuclear Medicine. ${ }^{60}$ Awaited data generated by two underway phase III trials (the Endocyte VISION trial, NCT03511664 and the ANUP TheraP trial, NCT03392428) will provide further details on safety, efficacy and toxicity profile of [ ${ }^{177}$ Lu]Lu-PSMA RLT. However, some important aspects of [ $\left.{ }^{177} \mathrm{Lu}\right] \mathrm{Lu}-\mathrm{PSMA}$ therapy will not be clarified by these studies, such as the optimal amount of activity, number of cycles, cycle interval and selection criteria. In the general discussion of this thesis, I would like to elaborate on these topics.

\section{Patient selection}

Positive PSMA uptake on pre-therapeutic PSMA PET/CT has often have been regarded as an appropriate selection criterion for $\left[{ }^{177} \mathrm{Lu}\right]$ Lu-PSMA therapy, supported by the fact that patients with low PSMA expression responded less to therapy with $\left[{ }^{177} \mathrm{Lu}\right] \mathrm{Lu}-J 591$ (a PSMA antibody). ${ }^{61}$ Exclusion of patients with Iow PSMA uptake is also endorsed by the positive correlation observed between mean

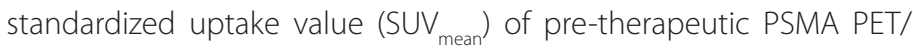
CT and the absorbed activity at tumor sites, as well as the positive correlation between the activity delivered to the whole body and biochemical response. ${ }^{62}$ The threshold below which PSMA uptake must be considered 'too low', however, has not been clearly defined yet. In the only prospective study on [ $\left.{ }^{177} \mathrm{Lu}\right]$ Lu-PSMA performed by Hofman et al. in 2018, sufficient PSMA uptake at tumor sites was 
defined as a maximum standardized uptake value (SUV ${ }_{\max }$ ) for tumor involvement exceeding 1.5 times SUV $_{\max }$ of the liver parenchyma. ${ }^{63}$ This approach was not evidence based, yet empiric and in line with the NETTER-1 trial on [ ${ }^{177}$ Lu]Lu-DOTATATE therapy. ${ }^{64}$ Additionally, in the study performed by Hofman et al., patients were excluded from participation if tumor heterogeneity attributed to dedifferentiated PCa was observed (i.e. patients with $\left[{ }^{18} \mathrm{~F}\right] \mathrm{F}-\mathrm{FDG}$ positive and PSMA negative metastatic sites). Again, this rationale was based on experience with PRRT, in which the combination of high $\left[{ }^{18} \mathrm{~F}\right] \mathrm{F}-\mathrm{FDG}$ uptake and low somatostatin receptor expression in tumor sites often represents sites of aggressive disease that are not considered to be effectively treated with targeted therapy. And indeed, 21 patients with low or discordant PSMA expression, who were considered not eligible for inclusion in the prospective trial by Hofman et al., appeared to have a poor prognosis (median OS 2.1 months, versus 13.5 months in their prospectively studied counterparts)..$^{65}$ Given the fact that $\geq 50 \%$ PSA decline was achieved in 57\% of the patients being selected according to the applied imaging criteria, these selection criteria might have been well chosen.

Interestingly, patients considered eligible for [ $\left.{ }^{177} \mathrm{Lu}\right] \mathrm{Lu}-\mathrm{PSMA}$ therapy within the abovementioned VISION trial (NCT03511664) were selected after central PSMA PET/CT reading, with the exact imaging criteria applied remaining unclear. One of the other selection criteria applied in this phase III trial required patients to have adequate organ function, defined as hemoglobin $\geq 5.59 \mathrm{mmol} / \mathrm{L}$ (or $\geq 90 \mathrm{~g} / \mathrm{L}$ ), white blood cell count $\geq 2.5 \times 10^{9} / \mathrm{L}$, platelet count $\geq 100 \times 10^{9} / \mathrm{L}$, serum creatinine $\leq 1.5 \times$ upper limit of normal (ULN) or clearance $\geq 50 \mathrm{~mL}$ / min, total bilirubin $\leq 1.5 \times \cup L N$, albumin $>30 \mathrm{~g} / \mathrm{L}$ and liver enzymes $\leq 3$ $\times$ ULN. Compared to the quantification of adequate organ function used in other studies, e.g. in our study ${ }^{66}$ (chapter $\mathbf{6}$ ) and by Hofman et al. ${ }^{63}$, including hemoglobin $\geq 90 \mathrm{~g} / \mathrm{L}$, platelets $\geq 75 \times 10^{9} / \mathrm{L}$, neutrophils $\geq 1.5 \times 10^{9} / \mathrm{L}$, glomerular filtration rate $\geq 40 \mathrm{~mL} / \mathrm{min}$ and albumin $>25$ $\mathrm{g} / \mathrm{L}$, some inconsistencies with regard to blood values regarded as 
'adequate' must be noted. These are presumably caused by the lack of solid evidence on relevant selection and exclusion criteria for $\left[{ }^{177} \mathrm{Lu}\right]$ Lu-PSMA therapy. In combination with the fact that several patients with hemoglobin levels $<5.5 \mathrm{mmol} / \mathrm{L}$ were treated without adverse effects, one may wonder what criteria are truly critical ones. Similarly, prior radioligand therapies (e.g. strontium-89, samarium-153-EDTMP, rhenium-186-HEDP and radium-223) or hemi-body irradiation $<6$ weeks prior to study inclusion were regarded as exclusion criteria by the VISION trial. Again, it remains unclear whether such criteria contribute to better patient selection, especially when considering the highly specific uptake of PSMA in tumor tissue resulting in relatively low radiotracer accumulation in bone marrow.

\section{Personalized medicine}

With regard to $\left[{ }^{177} \mathrm{Lu}\right] \mathrm{Lu}-\mathrm{PSMA}$ RLT, the kidneys, bone marrow and the salivary glands are regarded as critical organs with external beam radiotherapy-derived accepted tolerance dosages of respectively 23 Gy, 30 Gy and 26-50 Gy. ${ }^{67-74}$ Although important fundamental differences between external beam radiotherapy and RLT exist (e.g. regarding dose rate: fractioned versus continuous irradiation), these safety thresholds are currently the best available. Various radiation dosimetry studies with [ ${ }^{177} \mathrm{Lu}$ Lu-PSMA demonstrated absorbed dosages of $0.60-0.88 \mathrm{~Gy} / \mathrm{GBq}$ in the kidneys, 0.012-0.03 Gy/GBq in the red marrow and 1.17-1.40 Gy/GBq in the parotid glands. ${ }^{67-69}$ Hence, the critical mean absorbed dose in the kidneys, red bone marrow and the parotid glands will be reached by a cumulative activity of respectively 26-43 GBq, 1000-2500 GBq and 19-43 GBq [ $\left.{ }^{177} \mathrm{Lu}\right] \mathrm{Lu}-\mathrm{PSMA} .{ }^{75}$ These numbers roughly correspond with the variety of currently debated administration schedules for [ ${ }^{177}$ Lu] Lu-PSMA therapy.

The mild toxicity profile of $\left[{ }^{177} \mathrm{Lu}\right] \mathrm{Lu}-\mathrm{PSMA}$ RLT observed so far suggests that patients are being underdosed with the currently administered treatment activity. Thus, in well-selected patients, there may be space to increase the administered dose and/or the number 
of cycles, potentially resulting in even higher uptake at tumor sites and improved efficacy of ${ }^{177}$ Lu] Lu-PSMA treatment. In addition to the demonstrated individual variety of absorbed radiotracer uptake in critical organs ${ }^{69}$, it is interesting to discuss [ $\left.{ }^{177} \mathrm{Lu}\right] \mathrm{Lu}-P S M A$ RLT in the light of the phenomenon termed personalized medicine. In this setting, tumor load and individual dosimetry have been suggested as parameters to guide the administered activity of $\left[{ }^{177} \mathrm{Lu}\right] \mathrm{Lu}-\mathrm{PSMA} .{ }^{76}$ It is hypothesized that large-scale uptake of [ $\left.{ }^{177} \mathrm{Lu}\right] \mathrm{Lu}-\mathrm{PSMA}$ at tumor sites results in less radioligand being available for uptake in organs at risk, reducing treatment-related toxicity. This 'tumor steal effect' implies that patients with extensive disease may tolerate higher administered radioactivity dosages since the maximum tolerated dose in the critical organs will not be reached. Gaertner et al. studied this rationale and indeed found a mean reduction of PSMA uptake in reference organs of approximately $50 \%$ in the patient group categorized as having high tumor load. .5 On the contrary, another study only reported minimal impact of tumor volume on radiotracer uptake in the lacrimal glands, salivary glands, spleen and liver. ${ }^{77}$ The same study group concluded that the variability of absorbed dose in normal organs, including the lacrimal glands, salivary glands and spleen, is predominantly dependent on inter-patient factors, whereas radiotracer uptake in the liver and kidneys appeared mainly subject to intra-patient variability. ${ }^{78}$ These results are in contradiction with those reported by del Prete et al. in PRRT, showing the incorporation of a patient's individual radiotracer uptake in the kidney on pre-therapeutic SPECT/CT to be a solid basis for individual therapy planning. ${ }^{79}$

The results from aforementioned studies are too controversial to distill guidelines for therapy planning to further optimize the efficacy of PSMA-targeted radionuclide therapy. In this respect, results from large, prospective studies are needed, as these may demonstrate an increased number of treatment cycles and/or increased activity per cycle in selected patients with low radiotracer uptake in kidneys, bone marrow and salivary glands. 
In pursuit of personalized medicine, the administration of the alfa emitter Actinium-225 [225Ac]Ac-PSMA may be considered in selected patients. In $40 \mathrm{mCRPC}$ patients who were not eligible for $\left[{ }^{177} \mathrm{Lu}\right] \mathrm{Lu}$ PSMA therapy due to diffuse bone marrow metastases instead of a 'hot-spot pattern of tumor spread', treatment with 3 cycles of 100 $\mathrm{kBq} / \mathrm{kg}\left[{ }^{225} \mathrm{Ac}\right] \mathrm{Ac}-\mathrm{PSMA}-617$ appeared to have remarkable antitumor effect. ${ }^{80}$ Attributed to the short range in tissue, ${ }^{225}$ Ac-PSMA was found to cause lower hematological toxicity in comparison with $\left[{ }^{177} \mathrm{Lu}\right] \mathrm{Lu}-$ PSMA, however, higher rates of moderate to severe xerostomia were reported. Despite the promising but preliminary evidence on efficacy and toxicity of [225Ac]Ac-PSMA therapy, one may consider this treatment option in patients for whom [ $\left.{ }^{177} \mathrm{Lu}\right] \mathrm{Lu}-\mathrm{PSMA}$ is contraindicated or patients who relapsed after $\left[{ }^{177} \mathrm{Lu}\right] \mathrm{Lu}$-PSMA. Unfortunately, $\left[{ }^{225} \mathrm{Ac}\right]$ is not routinely available due to a difficult production process. This has seriously hampered the wider introduction of $\left[{ }^{225} \mathrm{Ac}\right] \mathrm{Ac}-\mathrm{PSMA}$ so far.

Whether advanced MCRPC patients with heterogenetic, yet adequate PSMA expression may still benefit from [ $\left.{ }^{177} \mathrm{Lu}\right] \mathrm{Lu}-\mathrm{PSMA}$ therapy, is subject to discussion. In the prospective study by Violet et al., initial responders predominantly progressed with new bone or liver metastases..$^{81}$ The observed PSMA expression in the hepatic metastases was low, whereas metabolic activity on [ $\left.{ }^{18} \mathrm{~F}\right] \mathrm{F}-\mathrm{FDG}$ PET/CT was high. Given the observed low PSMA expression in liver metastases in $\mathrm{mCRPC}$ in another study ${ }^{82}$, it was postulated that patients suffering from liver metastases may not benefit from [ $\left.{ }^{177} \mathrm{Lu}\right]$ Lu-PSMA therapy. Future studies are required to investigate whether liver metastases are more resistant to $\left.{ }^{177} \mathrm{Lu}\right] \mathrm{Lu}$-PSMA therapy. If indeed so, these patients may potentially benefit from the (sequential) combination of $\left[{ }^{177} \mathrm{Lu}\right]$ Lu-PSMA therapy with other (systemic) antitumor therapies, affecting tumor sites without PSMA expression. To date, one publication reported on the effect of $\left[{ }^{177} \mathrm{Lu}\right] \mathrm{Lu}-\mathrm{PSMA}-617 \mathrm{RLT}$ in combination with external beam radiotherapy in two patients with cerebral metastases of PCa, leading to a significant regression of tumor load. ${ }^{83}$ Ongoing trials (NCT03874884, NCT03658447) will further determine safety and efficacy of $\left[{ }^{177} \mathrm{Lu}\right] \mathrm{Lu}-\mathrm{PSMA}$ combined with other salvage therapies. 


\section{Treatment schedule}

Dose fractionation, a concept derived form radiotherapy, entails the administration of radioactive compounds in multiple cycles. Fractionation is assumed to deliver higher cumulative radiation activity to tumor sites with less or similar treatment-related toxicity in comparison with single-dose administration. Although the optimal fractionation schedule for [ $\left.{ }^{177} \mathrm{Lu}\right]$ Lu-PSMA has not been defined, 6-8 weekly intervals between the 1-6 treatment cycles are currently recommended ${ }^{84}$, following the schedule of approved radionuclide therapies with survival benefit being administered in multiple cycles, including lutetium-177 DOTATATE (4 cycles), radium-223 (6 cycles), and rhenium-188-HEDP (2 cycles). ${ }^{64,85,86}$

After administration of [ ${ }^{177}$ Lu]Lu-PSMA (physical half-life of 6.65 days), continuous irradiation of tumor cells occurs - with a peak immediately after injection, decreasing over days due to excretion and physical decay. Research on brachytherapy of PCa lesions has shown increased double-strand DNA breaks up to four weeks post-implantation of iodine-125 seeds. Thus, the result of DNA damage may take longer than 6-8 weeks before showing its optimal effect. Congruent with this, response to $\left[{ }^{177} \mathrm{Lu}\right] \mathrm{Lu}-\mathrm{PSMA}$ therapy has been seen after the second administered cycle (in absence of an initial response) ${ }^{87}$ In conclusion, the optimal interval between treatment cycles, and associated parameters (tumor biology?) should be addressed in future research. Interestingly, the ongoing study NCT03042468 is currently evaluating dose escalation of $\left.{ }^{177} \mathrm{Lu}\right]$ Lu-PSMA activity up to $22.2 \mathrm{GBq}$ given at 2-weekly intervals.

In line with the discussion on the optimal treatment schedule, the effect of re-treatment with [ $\left.{ }^{177} \mathrm{Lu}\right] \mathrm{Lu}-\mathrm{PSMA}$ was studied by Violet et al. ${ }^{81}$, reporting on long term outcomes of re-treatment of the previously studied (yet expanded) cohort by Hofman et al. in 2018. ${ }^{63}$ The total number of 50 analyzed patients was treated with a mean activity of 7.5 GBq (range 4-8.9 GBq) [177Lu]Lu-PSMA in four planned cycles with an interval of six weeks. Biochemical response ( $\geq 50 \%$ PSA decrease) was 
observed in $64 \%$ and $\geq 80 \%$ decrease in $44 \%$ of the patients. Objective response according to RECIST 1.1 was reported in 15 of the 27 patients (56\%) with measurable soft tissue disease at baseline. Conform the first analysis by Hofman et al., the most commonly observed toxicities were grade 1-2 xerostomia (66\%), grade 1-2 nausea (48\%), grade 3-4 thrombocytopenia (10\%) and grade 3 anemia (10\%). During a median follow-up period of 31.4 months (interquartile range 25.1 - 36.3 months), median OS was 13.3 months (95\% Cl 10.5-18.7).

In this study, a total of 15 patients (30\%) who initially responded to $\left[{ }^{177} \mathrm{Lu}\right] \mathrm{Lu}-\mathrm{PSMA}$ treatment (defined as a PSA decline $\geq 50 \%$ with imaging response), but relapsed following completion of study therapy after a median number of 359 days, underwent re-treatment with a median number of two cycles (range 1-5) [ $\left.{ }^{177} \mathrm{Lu}\right]$ Lu-PSMA, again resulting in a PSA decline $\geq 50 \%$ in 11 patients (73\%). Interestingly, only 4 of 21 patients (19\%) receiving other systemic therapies following disease progression (i.e. cabazitaxel, docetaxel, mitoxantrone, olaparib, pembrolizumab, enzalutamide and carboplatin) instead of $\left[{ }^{177} \mathrm{Lu}\right] \mathrm{Lu}-$ PSMA experienced a biochemical response. This study showed that re-treatment with $\left[{ }^{177} \mathrm{Lu}\right] \mathrm{Lu}-\mathrm{PSMA}$ is feasible in initially responding patients. As one of the patients was treated with nine cycles, this study also provides information on safety with regard to the administration of more than four cycles. Despite these favorable results however, duration of response following re-treatment with [ $\left.{ }^{177} \mathrm{Lu}\right] \mathrm{Lu}$-PSMA was significantly shorter than following initial treatment. This supports efforts to increase the depth and durability of response, which may require synergistic combinations of two or more agents to enhance control of micrometastatic disease, increase radiosensitivity of tumor sites or activate an adaptive immune response.

\section{Future perspectives}

As was the case with early studies investigating efficacy of abiraterone and enzalutamide, [ $\left.{ }^{177} \mathrm{Lu}\right] \mathrm{Lu}-\mathrm{PSMA}-617$ RLT has been mainly administered to patients with end-stage mCRPC who exhausted all established systemic treatments. As such, long-term toxicity is still unknown and the currently published data exclusively apply to advanced mCRPC patients. However, the initially demonstrated 
efficiency and limited toxicity in combination with dosimetry findings imply that there should be space for $\left[{ }^{177} \mathrm{Lu}\right]$ Lu-PSMA to be offered as an earlier line-of-therapy. More upfront administration of $\left[{ }^{177} \mathrm{Lu}\right] \mathrm{Lu}$ PSMA may induce longer tumor free periods with fewer side effects compared to traditional treatments. If the VISION and TheraP trials will reveal positive results, ${ }^{177}$ Lu]Lu-PSMA therapy will likely be integrated earlier in the disease continuum, for example aiming to postpone ADT in patients with recurrent disease due to a local recurrence or patients with oligometastatic PCa - a disease entity that was recently defined as 'limited metastatic spread at diagnosis, in the hormonesensitive setting' ${ }^{\prime 8}$

In our institution, we are currently working on an experimental approach to improve the absorbed activity at PCa sites. This study includes the administration of [ $\left.{ }^{177} \mathrm{Lu}\right] \mathrm{Lu}-\mathrm{PSMA}$ via the prostatic arteries. Intra-arterial administration may optimize the first-pass binding to PSMA expressing cells, possibly achieving a much higher dose in tumor cells after intra-arterial administration as compared with intravenous administration. This approach may be beneficial for patients who have locally advanced PCa (e.g. bladder neck involvement or in close proximity to the urethra) and who are therefore not eligible for regular radiation therapy, which would be associated with high toxicity rates (e.g. strictures, radiation cystitis). To investigate the safety and efficacy of intra-arterial administration of $\left[{ }^{177} \mathrm{Lu}\right]$ Lu-PSMA, dose-escalation phase I studies have to be performed.

\section{Theranostics in the Netherlands}

The concept theranostics involves the combination of diagnosis and therapy with the same radioactive compound. This has become a popular concept, and the usage of therapeutic radioligands will rapidly incline in the near future. The impact on the Nuclear Medicine community is expected to be major, since the focus within the nuclear medicine profession may shift from diagnostics to treatment. Consequently, closer collaboration between the nuclear medicine, urology, radiotherapy and oncology departments seems 
logical, aiming to join efforts to treat cancer in a multidisciplinary way. Secondly, the demand for more treatment facilities, in-patient nursing wards as well as outpatient clinics, will increase. More health care professionals, including nuclear medicine physicians, residents, biochemists, hospital pharmacists, analysts and nurses, must be (re-) trained to offer safe and high quality care for patients treated with radioactive compounds.

\section{REFERENCES}

1. Budaus L, Leyh-Bannurah SR, Salomon G, et al. Initial experience of 68GaPSMA PET/CT imaging in high-risk prostate cancer patients prior to radical 
prostatectomy. Eur Urol 2016;69:393-6.

2. Demirkol MO, Acar O, Ucar B, Ramazanotlu SR, Satlican Y, Esen T. Prostatespecific membrane antigen-based imaging in prostate cancer: impact on clinical decision making process. Prostate 2015;75:748-57.

3. Herlemann A, Wenter $V$, Kretschmer A, et al. 68Ga-PSMA positron emission tomography/computed tomography provides accurate staging of lymph node regions prior to lymph node dissection in patients with prostate cancer. Eur Urol 2016;70:553-7.

4. Kabasakal L, Demirci E, Ocak M, et al. Evaluation of PSMA PET/CT imaging using a Ga-68-HBED-CC ligand in patients with prostate cancer and the value of early pelvic imaging. Nucl Med Commun 2015;36:582-7.

5. Maurer T, Gschwend JE, Rauscher I, et al. Diagnostic efficacy of 68galliumPSMA positron emission tomography compared to conventional imaging in lymph node staging of 130 consecutive patients with intermediate to high risk prostate cancer. J Urol 2016;195:1436-43.

6. Sahlmann CO, Meller B, Bouter C, et al. Biphasic 68Ga-PSMA-HBEDCC-PET/CT in patients with recurrent and high-risk prostate carcinoma. Eur J Nucl Med Mol Imaging 2016;43:898-905.

7. Sterzing F, Kratochwil C, Fiedler $H$, et al. Ga-68-PSMA-11 PET/CT: a new technique with high potential for the radiotherapeutic management of prostate cancer patients. Eur J Nucl Med Mol Imaging 2016;43:34-41.

8. van Leeuwen PJ, Emmett L, Ho B, et al. Prospective evaluation of 68Galliumprostate-specific membrane antigen positron emission tomography/ computed tomography for preoperative lymph node staging in prostate cancer. BJU Int. 2017 Feb;119(2):209-215

9. Hope TA, Goodman JZ, Allen IE, Calais J, Fendler WP, Carroll PR. Metaanalysis of 68Ga-PSMA-11 PET Accuracy for the Detection of Prostate Cancer Validated by Histopathology. J Nucl Med. 2019 Jun;60(6):786-793.

10. Sonni I, Eiber M, Fendler WP, et al. Impact of 68Ga-PSMA-11 PET/CT on Staging and Management of Prostate Cancer Patients in Various Clinical Settings: A Prospective Single Center Study. J Nucl Med. 2020 Jan 10.

11. Federatie Medisch Specialisten. PSMAPET/CT bij prostaatcarcinoom - Richtlijn - Richtlijnendatabase. [Internet]. Available from: https://richtlijnendatabase. nl/richtlijn/prostaatcarcinoom/diagnostiek/beeldvormend_onderzoek/ psma_pet_ct_bij_prostaatcarcinoom.html. [Accessed 19 May 2020].

12. European Association of Urology. EAU Guidelines: Prostate Cancer | Uroweb. [Internet]. Available from: https://uroweb.org/guideline/prostate-cancer/\#5. [Accessed 19 May 2020].

13. Rowe SP, Gorin MA, Allaf ME, et al. PET imaging of prostate-specific membrane antigen in prostate cancer: current state of the art and future challenges. Prostate Cancer Prostatic Dis, 2016. 19(3): p. 223-30. 
PART III |Summary and discussion

14. Rahbar K, Weckesser M, Ahmadzadehfar H, Schäfers M, Stegger L, Bögemann M. Advantage of 18F-PSMA-1007 over 68Ga-PSMA-11 PET imaging for differentiation of local recurrence vs. urinary tracer excretion. Eur J Nucl Med Mol Imaging. 2018 Feb 14.

15. Dietlein F, Kobe C, Neubauer S, et al. PSA-Stratified Performance of 18F- and 68Ga-PSMA PET in Patients with Biochemical Recurrence of Prostate Cancer. J Nucl Med. 2017 Jun;58(6):947-952.

16. Giesel F, Hadaschik B, Cardinale J, et al. F-18 labelled PSMA-1007: biodistribution, radiation dosimetry and histopathological validation of tumor lesions in prostate cancer patients. Eur J Nucl Med Mol Imaging. 2017; 44(4): 678-688.

17. Rauscher I, Krönke M, König M, et al. Matched-Pair Comparison of 68GaPSMA-11 PET/CT and 18F-PSMA-1007 PET/CT: Frequency of Pitfalls and Detection Efficacy in Biochemical Recurrence After Radical Prostatectomy. J Nucl Med. 2020 Jan;61(1):51-57.

18. Boellaard R, Delgado-Bolton R, Oyen WJG et al. FDG PET/CT: EANM procedure guidelines for tumour imaging: version 2.0 Eur J Nucl Med Mol Imaging (2015) 42:328-354

19. van Kalmthout LWM, van Melick HHE, Lavalaye J, et al. Prospective Validation of Gallium-68 Prostate Specific Membrane Antigen-Positron Emission Tomography/Computerized Tomography for Primary Staging of Prostate Cancer. J Urol. 2020 Mar;203(3):537-545.

20. Hofman MS, Lawrentschuk N, Francis RJ, et al. Prostate-specific membrane antigen PET-CT in patients with high-risk prostate cancer before curativeintent surgery or radiotherapy (proPSMA): a prospective, randomised, multicentre study. Lancet. 2020 Apr 11;395(10231):1208-1216.

21. Jilg CA, Drendel V, Rischke HC, et al. Diagnostic Accuracy of Ga-68-HBED-CCPSMA-Ligand-PET/CT before Salvage Lymph Node Dissection for Recurrent Prostate Cancer. Theranostics. 2017 Apr 10;7(6):1770-1780.

22. Gorin MA, Rowe SP, Patel HD, et al. Prostate Specific Membrane Antigen Targeted (18)F-DCFPyL Positron Emission Tomography/Computerized Tomography for the Preoperative Staging of High Risk Prostate Cancer: Results of a Prospective, Phase II, Single Center Study. J Urol. 2018;199(1):126-32.

23. Fossati N, Willemse PM, Van den Broeck T, et al. The Benefits and Harms of Different Extents of Lymph Node Dissection During Radical Prostatectomy for Prostate Cancer: A Systematic Review. Eur Urol. 2017 Jul;72(1):84-109.

24. European Association of Urology. EAU Guidelines: Prostate Cancer | Uroweb. [Internet]. Available from: https://uroweb.org/guideline/prostate-cancer/\#6. [Accessed 19 May 2020]. 
25. Cagiannos I, Karakiewicz P, Eastham JA, et al. A preoperative nomogram identifying decreased risk of positive pelvic lymph nodes in patients with prostate cancer. J Urol. 2003;170:1798-803.

26. Yu JB, Makarov DV, Gross C. A new formula for prostate cancer lymph node risk. Int J Radiat Oncol Biol Phys. 2011;80:69-75.

27. Roach M 3rd, Marquez C, Yuo HS, et al. Predicting the risk of lymph node involvement using the pre-treatment prostate specific antigen and Gleason score in men with clinically localized prostate cancer. Int J Radiat Oncol Biol Phys. 1994;28:33-7.

28. Winter A, Kneib T, Rohde M, Henke RP, Wawroschek F. First nomogram predicting the probability of lymph node involvement in prostate cancer patients undergoing radioisotope guided sentinel lymph node dissection. Urol Int. 2015;95:422-8.

29. Tosoian JJ, Chappidi M, Feng Z, et al. Prediction of pathological stage based on clinical stage, serum prostate-specific antigen, and biopsy Gleason score: Partin Tables in the contemporary era. BJU Int. 2017;119:676-83.

30. National Comprehensive Cancer Network. Clinical Practice Guidelines in Oncology. [Internet]. Available from: https://www.nccn.org/professionals/ physician_gls/default.aspx\#site. [Accessed 19 May 2020].

31. Briganti A, Larcher A, Abdollah F, et al. Updated nomogram predicting lymph node invasion in patients with prostate cancer undergoing extended pelvic lymph node dissection: the essential importance of percentage of positive cores. Eur Urol. 2012;61:480-7.

32. Banapour P, Schumacher A, Lin JC, Finley DS. Radical prostatectomy and pelvic lymph node dissection in Kaiser Permanente Southern California: 15year experience. Perm J. 2019;23.

33. Roscigno $M$, Nicolai $M$, La Croce $G$, et al. Difference in frequency and distribution of nodal metastases between intermediate and high risk prostate cancer patients: results of a superextended pelvic lymph node dissection. Front Surg. 2018;5:52.

34. Ferraro DA, Muehlematter UJ, Garcia Schüler HI et al. 68Ga-PSMA-11 PET has the potential to improve patient selection for extended pelvic lymph node dissection in intermediate to high-risk prostate cancer. Eur J Nucl Med Mol Imaging. 2020 Jan;47(1):147-159.

35. Pyka T, Okamoto S, Dahlbender M, et al. Comparison of bone scintigraphy and 68Ga-PSMA PET for skeletal staging in prostate cancer. Eur J Nucl Med Mol Imaging. 2016 Nov;43(12):2114-2121.

36. Uslu-Beşli L, Sağer S, Akgün E, et al. Comparison of Ga-68 PSMA positron emission tomography/computerized tomography with Tc-99m MDP bone scan in prostate cancer patients. Turk J Med Sci. 2019 Feb 11:49(1):301-310. 
PART III |Summary and discussion

37. Lengana T, Lawal IO, Boshomane TG, et al. 68Ga-PSMA PET/CT Replacing Bone Scan in the Initial Staging of Skeletal Metastasis in Prostate Cancer: A Fait Accompli? Clin Genitourin Cancer. 2018 Oct;16(5):392-401.

38. Zacho HD, Ravn S, Afshar-Oromieh A, et al. Added value of 68Ga-PSMA PET/ CT for the detection of bone metastases in patients with newly diagnosed prostate cancer and a previous 99mTc bone scintigraphy. EJNMMI Res. 2020 Apr 8;10(1):31.

39. Chiu LW, Lawhn-Heath C, Behr S, et al. Factors predicting metastatic disease in 68Ga-PSMA-11 PET positive osseous lesions in prostate cancer. J Nucl Med. 2020 Apr 17.

40. Perera M, Papa N, Christidis D, et al. Sensitivity, Specificity, and Predictors of Positive 68Ga-Prostate-specific Membrane Antigen Positron Emission Tomography in Advanced Prostate Cancer: A Systematic Review and Metaanalysis. Eur Urol. 2016 Dec;70(6):926-937.

41. Lee B, Whitehead MT. Radiology Reports: What YOU Think You're Saying and What THEY Think You're Saying. Curr Probl Diagn Radiol. 2017 May Jun;46(3):186-195

42. Panicek DM, Hricak H. How Sure Are You, Doctor? A Standardized Lexicon to Describe the Radiologist's Level of Certainty. American Journal of Roentgenology. 2016;207: 2-3.

43. Fendler WP, Calais J, Allen-Auerbach M, et al. 68Ga-PSMA-11 PET/CT Interobserver Agreement for Prostate Cancer Assessments: An International Multicenter Prospective Study. J Nucl Med. 2017 Oct;58(10):1617-1623.

44. Eiber M, Herrmann K, Calais J, et al. Prostate Cancer Molecular Imaging Standardized Evaluation (PROMISE): Proposed miTNM Classification for the Interpretation of PSMA-Ligand PET/CT. J Nucl Med. 2018 Mar;59(3):469-478.

45. Rowe SP, Pienta KJ, Pomper MG, et al. Proposal for a Structured Reporting System for Prostate-Specific Membrane Antigen-Targeted PET Imaging: PSMA-RADS Version 1.0. J Nucl Med. 2018 Mar;59(3):479-485.

46. Toriihara A, Nobashi T, Baratto L, et al. Comparison of 3 Interpretation Criteria for 68Ga-PSMA11 PET Based on Inter- and Intrareader Agreement. J Nucl Med. 2020 Apr;61(4):533-539.

47. Piron S, De Man K, Schelfhout V, et al. Optimization of PET protocol and interrater reliability of 18F-PSMA-11 imaging of prostate cancer. EJNMMI Res. 2020 Feb 24;10(1):14.

48. Fendler WP, Calais J, Allen-Auerbach $M$, et al. 68Ga-PSMA-11 PET/CT Interobserver Agreement for Prostate Cancer Assessments: An International Multicenter Prospective Study. J Nucl Med. 2017 Oct;58(10):1617-1623.

49. Subhas N, Patel PV, Pannu HK, Jacene HA, Fishman EK, Wahl RL. Imaging of pelvic malignancies with in-line FDG PET-CT: case examples and common pitfalls of FDG PET. Radiographics. 2005 Jul-Aug;25(4):1031-43. 
50. Kamel EM, Jichlinski P, Delaloye JF, et al. Forced diuresis improves the diagnostic accuracy of 18F-FDG PET in abdominopelvic malignancies. J Nucl Med. 2006 Nov;47(11):1803-7.

51. Anjos DA, Etchebehere EC, Ramos CD, Santos AO, Albertotti C, Camargo EE. 18F-FDG PET/CT delayed images after diuretic for restaging invasive bladder cancer. J Nucl Med. 2007 May;48(5):764-70.

52. Derlin T, Weiberg D, von Klot C, et al. 68Ga-PSMA I\&T PET/CT for assessment of prostate cancer: evaluation of image quality after forced diuresis and delayed imaging. Eur Radiol. 2016 Dec;26(12):4345-4353.

53. Fennessy N, Lee J, Shin J, et al. Frusemide aids diagnostic interpretation of 68 Ga-PSMA positron emission tomography/CT in men with prostate cancer. J Med Imaging Radiat Oncol. 2017 Jun 17.

54. James ND, Sydes MR, Clarke NW, et al. Addition of docetaxel, zoledronic acid, or both to first-line long-term hormone therapy in prostate cancer (STAMPEDE): survival results from an adaptive, multiarm, multistage, platform randomised controlled trial. Lancet. 2016 Mar 19;387(10024):1163-77.

55. James ND, de Bono JS, Spears MR, et al. Abiraterone for Prostate Cancer Not Previously Treated with Hormone Therapy. N Engl J Med. 2017 Jul 27:377(4):338-351.

56. Gravis G, Boher JM, Joly F, et al. Androgen Deprivation Therapy (ADT) Plus Docetaxel Versus ADT Alone in Metastatic Non castrate Prostate Cancer: Impact of Metastatic Burden and Long-term Survival Analysis of the Randomized Phase 3 GETUG-AFU15 Trial. Eur Urol. 2016 Aug;70(2):256-62.

57. Gravis G, Boher JM, Chen YH, et al. Burden of Metastatic Castrate Naive Prostate Cancer Patients, to Identify Men More Likely to Benefit from Early Docetaxel: Further Analyses of CHAARTED and GETUG-AFU15 Studies. Eur Urol. 2018 Jun;73(6):847-855

58. Sweeney CJ, Chen YH, Carducci M, et al. Chemohormonal Therapy in Metastatic Hormone-Sensitive Prostate Cancer. N Engl J Med. 2015 Aug 20;373(8):737-46.

59. Yadav MP, Ballal S, Sahoo RK, Dwivedi SN, Bal C. Radioligand Therapy With 177Lu-PSMA for Metastatic Castration-Resistant Prostate Cancer: A Systematic Review and Meta-Analysis. AJR Am J Roentgenol. 2019 Aug;213(2):275-285.

60. Fendler WP, Kratochwil C, Ahmadzadehfar H, et al. 177Lu-PSMA-617 therapy, dosimetry and follow-up in patients with metastatic castration-resistant prostate cancer. Nuklearmedizin. 2016;55:123-8.

61. Tagawa ST, Milowsky MI, Morris M, et al. Phase II study of Lutetium-177labeled anti-prostate-specific membrane antigen monoclonal antibody J591 for metastatic castration-resistant prostate cancer. Clin Cancer Res, 19 (2013), pp. 5182-5191 
PART III |Summary and discussion

62. Violet JA, Jackson P, Ferdinandus J, et al. Dosimetry of Lu-177 PSMA- 617 in metastatic castration-resistant prostate cancer: correlations between pretherapeutic imaging and "whole body" tumor dosimetry with treatment outcomes. J Nucl Med. 2019 Apr;60(4):517-523.

63. Hofman MS, Violet J, Hicks RJ, et al. [177Lu]-PSMA-617 radionuclide treatment in patients with metastatic castration-resistant prostate cancer (LuPSMA trial): a single-centre, single-arm, phase 2 study. Lancet Oncol. 2018 Jun;19(6):825833.

64. Strosberg J, El-Haddad G, Wolin E, et al. Phase 3 trial of 177Lu-Dotatate for midgut neuroendocrine tumors. N Engl J Med. 2017;376:125-135.

65. Thang SP, Violet J, Sandhu S, et al. Poor Outcomes for Patients with Metastatic Castration-resistant Prostate Cancer with Low Prostate-specific Membrane Antigen (PSMA) Expression Deemed Ineligible for 177Lu-labelled PSMA Radioligand Therapy. Eur Urol Oncol. 2019 Nov;2(6):670-676.

66. van Kalmthout L, Braat A, Lam M, et al. First Experience With 177Lu-PSMA-617 Therapy for Advanced Prostate Cancer in the Netherlands. Clin Nucl Med. 2019 Jun;44(6):446-451.

67. Kratochwill C, Giesel FL, Stefanova M et al. PSMA-Targeted Radionuclide Therapy of Metastatic Castration-Resistant Prostate Cancer with 177LuLabeled PSMA-617. J Nucl Med. 2016; 57(8): 1170-6

68. Delker A, Fendler WP, Kratochwil C, et al. Dosimetry for (177)Lu-DKFZPSMA-617: a new radiopharmaceutical for the treatment of metastatic prostate cancer. Eur J Nucl Med Mol Imaging. 2016; 43:42-51.

69. Kabasakal L, AbuQbeitah M, Aygün A, et al. Pre-therapeutic dosimetry of normal organs and tissues of 177Lu-PSMA-617 prostate-specific membrane antigen (PSMA) inhibitor in patients with castration-resistant prostate cancer. Eur J Nucl Med Mol Imaging. 2015 Dec;42(13):1976-83.

70. Yadav MP, Ballal S, Tripathi M, et al. Post-therapeutic dosimetry of 177Lu- DKFZPSMA-617 in the treatment of patients with metastatic castration-resistant prostate cancer. Nucl Med Commun. 2017;38:91-98.

71. Kabasakal L, Toklu T, Yeyin N, et al. Lu-177-PSMA-617 prostate-specific membrane antigen inhibitor therapy in patients with castration-resistant prostate cancer: stability, bio-distribution and dosimetry. Mol Imaging Radionucl Ther. 2017;26:62-68.

72. Emami B, Lyman J, Brown A, et al. Tolerance of normal tissue to therapeutic irradiation. Int J Radiat Oncol Biol Phys. 1991; 21:109-122.

73. Gensheimer MF, Liao JJ, Garden AS, Laramore GE, Parvathaneni U. Submandibular gland-sparing radiation therapy for locally advanced oropharyngeal squamous cell carcinoma: patterns of failure and xerostomia outcomes. Radiat Oncol. 2014; 9:255. 
74. Hey J, Setz J, Gerlach R, et al. Parotid gland recovery after radiotherapy in the head and neck region-36 months follow-up of a prospective clinical study. Radiat Oncol. 2011; 6:125.

75. Gaertner FC, Halabi K, Ahmadzadehfar H, et al. Uptake of PSMA-ligands in normal tissues is dependent on tumor load in patients with prostate cancer. Oncotarget. 2017 Aug 15; 8(33): 55094-55103.

76. Eberlein U, Cremonesi $M$, Lassmann $M$. Individualized Dosimetry for Theranostics: Necessary, Nice to Have, or Counterproductive? J Nucl Med. 2017 Sep;58(Suppl 2):97S-103S.

77. Werner RA, Bundschuh RA, Bundschuh $L$, et al. Semiquantitative Parameters in PSMA-Targeted PET Imaging with [18F]DCFPyL: Impact of Tumor Burden on Normal Organ Uptake. Mol Imaging Biol. 2020 Feb;22(1):190-197.

78. Sahakyan K, Li X, Lodge MA, et al. Semiquantitative Parameters in PSMATargeted PET Imaging with [18F]DCFPyL: Intrapatient and Interpatient Variability of Normal Organ Uptake. Mol Imaging Biol. 2020 Feb;22(1):181-189.

79. Del Prete M, Buteau FA, Arsenault F, et al. Personalized 177Lu-octreotate peptide receptor radionuclide therapy of neuroendocrine tumours: initial results from the P-PRRT trial. Eur J Nucl Med Mol Imaging. 2019 Mar;46(3):728742

80. Kratochwil C. Bruchertseifer F, Rathke H. et al. Targeted a-Therapy of Metastatic Castration-Resistant Prostate Cancer With 225 Ac-PSMA-617: Swimmer-Plot Analysis Suggests Efficacy Regarding Duration of Tumor Control. J Nucl Med. 2018 May;59(5):795-802.

81. Violet J, Sandhu S, Iravani A, et al. Long term follow-up and outcomes of re-treatment in an expanded 50 patient single-center phase II prospective trial of Lutetium-177 (177Lu) PSMA-617 theranostics in metastatic castrateresistant prostate cancer. J Nucl Med. 2020;61(6):857-865

82. Paschalis A, Sheehan B, Riisnaes R, et al. Prostate-specific Membrane Antigen Heterogeneity and DNA Repair Defects in Prostate Cancer. Eur Urol. 2019;76(4):469-478

83. Wei X, Schlenkhoff C, Schwarz B, Essler M, Ahmadzadehfar H. Combination of 177Lu-PSMA-617 and external radiotherapy for the treatment of cerebral metastases in patients with castrationresistant metastatic prostate cancer. Clin NuclMed. 2017;42:704-6.

84. Kratochwil C, FendlerWP, Eiber M. EANM procedure guidelines for radionuclide therapy with 177Lu-labelled PSMA-ligands (177Lu-PSMA-RLT). Eur J Nucl Med Mol Imaging. 2019 Nov;46(12):2536-2544.

85. Parker C, Nilsson S, Heinrich D, et al. Alpha emitter radium-223 and survival in metastatic prostate cancer. N Engl J Med. 2013 Jul 18;369(3):213-23. 
PART III|Summary and discussion

86. Palmedo $H$, Manka-Waluch A, Albers $P$, et al. Repeated bone-targeted therapy for hormone-refractory prostate carcinoma: randomized phase II trial with the new, high-energy radiopharmaceutical rhenium-188 hydroxyethylidenediphosphonate. J Clin Oncol. 2003 Aug 1;21(15):2869-75.

87. Rahbar K, Bögeman M, Anna Yordanova A, et al. Delayed Response After Repeated 177 Lu-PSMA-617 Radioligand Therapy in Patients With Metastatic Castration Resistant Prostate Cancer. Eur J Nucl Med Mol Imaging. 2018 Feb;45(2):243-246.

88. Aluwini SS, Mehra N, Lolkema MP, et al. Oligometastatic Prostate Cancer: Results of a Dutch Multidisciplinary Consensus Meeting. Eur Urol Oncol. 2020;3(2):231-238. 



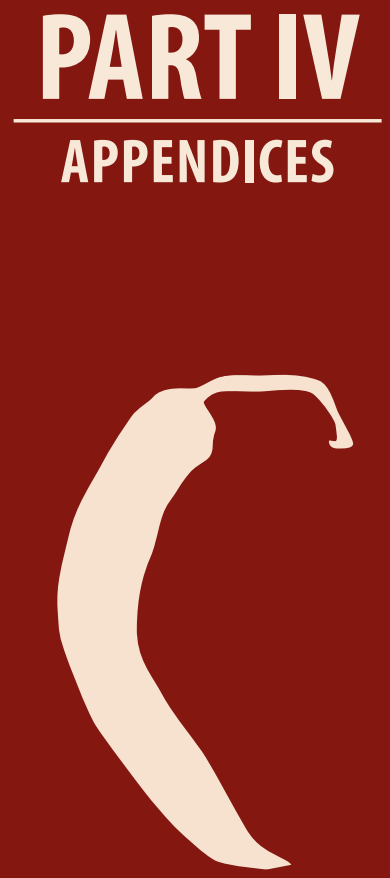



\section{APPENDIX}

Nederlandse samenvatting

List of Publications

Dankwoord

Biography

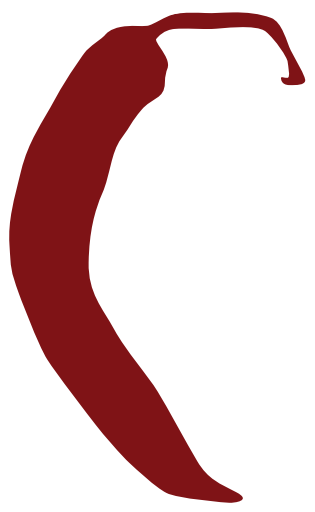


Dit proefschrift richt zich op prostaat-specifiek membraan antigeen (PSMA) als relatief nieuw en veelbelovend doelwit voor beeldvorming en behandeling van prostaatkanker middels radioactief gelabelde stoffen ('theranostics'). Het proefschrift bestaat uit twee delen, waarbij PSMAgerichte beeldvorming van prostaatkanker in deel I, en PSMA-gerichte therapie van prostaatkanker in deel II aan bod komt.

\section{DEEL I: PSMA-GERICHTE BEELDVORMING VAN PROSTAATKANKER}

Hoofdstuk $\mathbf{2}$ presenteert de resultaten van een prospectieve validatiestudie, waarin de diagnostische waarde (sensitiviteit, specificiteit, en positief en negatief voorspellende waarde) van gallium-68 $\left({ }^{68} \mathrm{Ga}\right)$-PSMA PET/CT voor het detecteren van lymfkliermetastasen bij nieuwe prostaatkanker patiënten wordt gedefinieerd. Bij kandidaten voor een pelviene lymfeklierdissectie werd voorafgaande aan deze operatie een $\left[{ }^{68} \mathrm{Ga}\right]$ Ga-PSMA PET/CT verricht. De scanresultaten werden vergeleken met de histopathologie van de uitgenomen klieren. Uit deze vergelijking bleek dat $\left[{ }^{68} \mathrm{Ga}\right] \mathrm{Ga}$-PSMA PET/CT lymfekliermetastasen met een hoge specificiteit (90.0\%) en een matige sensitiviteit (41.5\%) detecteert in deze groep patiënten met intermediate-high risk prostaatkanker en een negatief skeletscintigram. De positief en negatief voorspellende waarde waren respectievelijk $77.3 \%$ en $67.6 \%$. Verder leidden de bevindingen op de $\left[{ }^{68} \mathrm{Ga}\right] \mathrm{Ga}$-PSMA PET/CT in 13 patiënten (12.6\%) tot veranderingen in het vervolgbeleid, waaronder de annulering van de geplande lymfeklierdissectie bij 6 patiënten. De toevoeging van $\left[{ }^{68} \mathrm{Ga}\right]$ Ga-PSMA PET/CT aan de diagnostische work-up voor prostaatkanker leidt dus mogelijk tot de identificatie van patiënten, waarbij kan worden afgezien van een pelviene lymfeklierdissectie wegens de aanwezigheid van afstandsmetastasen. Gezien de matige sensitiviteit van $\left[{ }^{68} \mathrm{Ga}\right] \mathrm{Ga}$ PSMA PET/CT zal dit diagnosticum de klierdissectie echter niet kunnen vervangen.

Omdat beeldvorming middels PSMA PET/CT voor prostaatkanker steeds gangbaarder wordt, zijn internationaal diverse beoordelingscriteria ontwikkeld om de interpretatie en verslaglegging van PSMA PET/CT te 
structureren. Deze criteria lijken in de dagelijkse praktijk echter weinig te worden gebruikt, mogelijk vanwege hun uitgebreidheid en daardoor beperkte gebruiksvriendelijkheid. Hoofdstuk 3 presenteert een studie, waarin $118\left[{ }^{68} \mathrm{Ga}\right] \mathrm{Ga}$-PSMA PET/CT scans werden beoordeeld door twee ervaren nucleair geneeskundigen. Deze beoordeling vond plaats aan de hand van een vijfpunts (Likert)-schaal. Er werd een substantiële overeenstemming gevonden tussen de twee beoordelaars met betrekking tot de evaluatie van (gerecidiveerde) tumor in de prostaatregio $(\mathrm{K}=0.67)$, regionale lymfklieren $(\mathrm{K}=0.62)$ en botstructuren $(\mathrm{K}=0.62)$ op $\left[{ }^{68} \mathrm{Ga}\right] \mathrm{Ga}$-PSMA PET/CT. Deze resultaten onderstrepen de bruikbaarheid van de vijfpunts-schaal bij de beoordeling van PSMA PET scans, alsmede de robuustheid van diagnostiek middels $\left[{ }^{68} \mathrm{Ga}\right] \mathrm{Ga}$-PSMA PET/CT bij patiënten met prostaatkanker.

In hoofdstuk 4 wordt de detectieratio van [ $\left.{ }^{18} \mathrm{~F}\right] \mathrm{F}-\mathrm{DCFPyL}$ PET/CT vergeleken met $\left[{ }^{68} \mathrm{Ga}\right] \mathrm{Ga}$-PSMA PET/CT in 156 post-prostatectomie patiënten met een primair (eerste biochemisch recidief na in opzet curatieve therapie) of secundair biochemisch recidief (na eerdere salvage therapie). De PSA waarden van deze patiënten varieerden van 0.5 tot $3.5 \mathrm{ng} / \mathrm{ml}$. De detectieratio van $\left[{ }^{68} \mathrm{Ga}\right] \mathrm{Ga}-\mathrm{PSMA}$ PET/CT en $\left[{ }^{18} \mathrm{~F}\right] \mathrm{F}-\mathrm{DCFPyL}$ PET/CT was respectievelijk $73.8 \%$ en $72.4 \%$. Het verschil tussen beide tracers bleek niet statistisch significant ( $p=0.85$ ); ook niet wanneer de detectieratio werd gestratificeerd naar verschillende PSA strata. Hoewel de baseline karakteristieken van de twee met elkaar vergeleken patiëntengroepen van elkaar verschilden met betrekking tot de histopathologische lymfeklierstatus en eerder ondergane salvage behandelingen, suggereren de resultaten dat de diagnostische waarde van $\left[{ }^{18} \mathrm{~F}\right] \mathrm{F}-\mathrm{DCFPyL}$ PET/CT en $\left[{ }^{68} \mathrm{Ga}\right] \mathrm{Ga}$-PSMA PET/CT vergelijkbaar is bij patiënten met een biochemisch recidief van prostaatkanker na prostatectomie.

\section{DEEL II: PSMA-GERICHTE THERAPIE VAN PROSTAATKANKER}

In hoofdstuk 5 wordt een man met vergevorderde prostaatkanker beschreven, die als eerste patiënt in het UMC Utrecht succesvol werd behandeld met $\left.{ }^{177} \mathrm{Lu}\right]$ Lu-PSMA therapie, een veelbelovende -maar 
nog niet geregistreerde- toepassing van radionuclidentherapie bij prostaatcarcinoom. Aan de hand van deze casus, waarin een exceptionele klinische (afname van analgeticagebruik en opiaat-geïnduceerde obstipatie), biochemische (PSA daling van 98.9\%) en radiologische respons op therapie werden geobserveerd, wordt het werkingsmechanisme van behandeling middels $\left[{ }^{177} \mathrm{Lu}\right] \mathrm{Lu}$-PSMA uiteen gezet en wordt een kort overzicht van het tot dan toe verkregen wetenschappelijk bewijs voor deze therapie verschaft.

Hoofdstuk 6 vat de eerste ervaring met $\left[{ }^{177} L u\right] L u-P S M A$ therapie voor vergevorderde prostaatkanker samen. In deze retrospectieve studie ondergingen 30 patiënten 1-6 therapeutische cycli met $6 \mathrm{GBq}\left[{ }^{177} \mathrm{Lu}\right] \mathrm{Lu}$ PSMA-617. Na de eerste cyclus was het gebruik van pijnstilling afgenomen bij ongeveer de helft van de patiënten. Bij 57\% van de patiënten werd een maximale PSA daling van $\geq 50 \%$ gezien gedurende de behandeling. Ondanks dat bij twee patiënten (7\%) Common Terminology for Adverse Events (CTCAE)-graad III en IV anemie ontstond, bleef alle andere nieuw ontstane biochemische toxiciteit beperkt tot CTCAE graad I-II. Graad II xerostomie (droge mond) ontstond bij 17\% van de patiënten. De resultaten van deze studie onderschrijven de veiligheid en effectiviteit van $\left[{ }^{177} \mathrm{Lu}\right] \mathrm{Lu}-\mathrm{PSMA}-617$ bij patiënten met uitbehandelde prostaatkanker, zelfs tot en met zes therapeutische cycli. Robuuster bewijs zal echter geleverd moeten worden door prospectief, gerandomiseerd onderzoek.

In hoofdstuk 7 wordt de casus van een 54 jaar oude patiënt met gemetastaseerd castratie-resistente prostaatkanker beschreven, die werd behandeld met $\left.{ }^{177} \mathrm{Lu}\right] \mathrm{Lu}$-PSMA therapie. Tijdens zijn behandeling kreeg deze man klachten van gezichtsverlies met beide ogen. De symptomen van deze patiënt kunnen ofwel worden verklaard door neurologische toxiciteit van $\left[{ }^{177} \mathrm{Lu}\right] \mathrm{Lu}$-PSMA therapie, ofwel aan de progressie van diffuse leptomeningeale metastasen tijdens $\left.{ }^{177} \mathrm{Lu}\right] \mathrm{Lu}-\mathrm{PSMA}$ therapie. Bij een gebrek aan toestemming voor autopsie, kan helaas geen van bovenstaande scenario's worden geëxcludeerd noch bewezen. Daarom luidt de conclusie dat er meer kennis nodig is over het veiligheidsprofiel van $\left[{ }^{177} \mathrm{Lu}\right] \mathrm{Lu}-$ PSMA therapie, ondanks het gegeven dat de eerste resultaten gunstig en veelbelovend zijn. 
De hoge stapeling van therapeutische radioliganden in de speekselklieren kan resulteren in xerostomie als ongewenste bijwerking van $\left[{ }^{177} \mathrm{Lu}\right]$ Lu-PSMA therapie. Er wordt verondersteld dat externe koeling van de speekselklieren vasoconstrictie veroorzaakt, hetgeen bloedtoevoer en PSMA opname in de speekselklieren zou verminderen. Hiermee zouden de speekselklieren kunnen worden behoed voor de toxische effecten van straling. In hoofdstuk 8 wordt de invloed van koeling met icepacks op PSMA opname in de speekselklieren (de glandula parotis en glandula submandibularis) onderzocht in een prospectieve studie onder 89 patiënten, die een $\left[{ }^{68} \mathrm{Ga}\right] \mathrm{Ga}-\mathrm{PSMA}$ PET/CT ondergingen ter stadiering van prostaatkanker. Vierentwintig patiënten werden gescand met een unilaterale (linkszijdige) icepack (interventiegroep), 20 patiënten met bilaterale icepacks (interventiegroep), en 45 patiënten zonder icepacks (controlegroep). De opname van PSMA in de glandula parotis in de interventiegroep was significant lager dan in de controlegroep (SUV ${ }_{\max }$ : 11.07 versus $12.95 ; p=0.02$; SUV $_{\text {peak }}: 9.91$ versus $\left.11.45 ; p=0.04\right)$. De invloed van icepacks op PSMA opname bleek echter uitsluitend te gelden voor de glandula parotis. Daarbij lijkt de klinische relevantie van de gevonden absolute PSMA reductie discutabel. Gezien de resultaten van deze studie, in combinatie met het gegeven dat het dragen van icepacks tijdens de behandeling met [ $\left.{ }^{177} \mathrm{Lu}\right]$ Lu-PSMA therapie als belastend kan worden ervaren, wordt geconcludeerd dat het structureel aanbrengen van icepacks in de setting van $\left[{ }^{177}\right.$ Lu]Lu-PSMA therapie, zorgvuldig moet worden overwogen.

In hoofdstuk 9 wordt een retrospectieve studie gepresenteerd die het optreden van toxiciteit (secundaire uitkomstmaat: effectiviteit) van 6.0 GBq versus 7.4 GBq [177Lu]Lu-PSMA therapie met elkaar vergelijkt. Tussen de twee groepen, waarin ieder 15 patiënten werden behandeld, werden geen duidelijke verschillen gezien: CTCAE graad I-II xerostomie kwam voor bij respectievelijk 13\% en 20\% van de patiënten; graad III anemie kwam voor bij respectievelijk $20 \%$ en $27 \%$ van de patiënten. Bij een patiënt in de $7.4 \mathrm{GBq}$ groep werd graad III trombocytopenie geconstateerd. Alle andere nieuw ontstane toxiciteit was gelimiteerd tot maximaal CTCAE graad II. Dit impliceert dat beide toegediende activiteiten goed worden 


\section{PART IV|Appendices}

getolereerd en kunnen worden overwogen bij de behandeling van vergevorderde prostaatkanker. Om meer te weten te komen over hoe verschillende doseringen zich verhouden tot oncologische effectiviteit, echter, zijn prospectieve dosimetriestudies in grotere groepen patiënten noodzakelijk. 




\section{APPENDIX}

Nederlandse samenvatting

List of Publications

Dankwoord

Biography

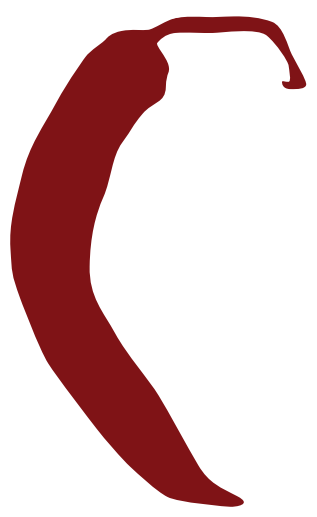


van Kalmthout LWM, Lam MGEH. Voorwoord bij het themanummer nucleaire geneeskunde: Theranostics voor diagnostiek en behandeling van prostaatkanker.

Tijdschr Urol 10, 99-100 (2020).

van Kalmthout LWM, van der Sar ECA, Braat AJAT B. de Keizer, M.G.E.H. Lam. Lutetium-177-PSMA therapy for prostate cancer patients - a brief overview of the literature.

Tijdschr Urol 10, 141-146 (2020).

van der Sar ECA, van Kalmthout LWM, Lam MGEH. PSMA PET/CT in primary prostate cancer diagnostics: an overview of the literature.

Tijdschr Urol 10, 101-108 (2020).

van Kalmthout LWM, van Melick HHE, Lavalaye J, Meijer RP, Kooistra A, de Klerk JMH, Braat AJAT, Kaldeway HP, de Bruin PC, de Keizer B, Lam MGEH. Reply by Authors. J Urol. 2020 Mar;203(3):545.

van Kalmthout LWM, van Melick HHE, Lavalaye J, Kooistra A, de Klerk JMH, Braat AJAT, Kaldeway HP, de Keizer B, e Bruin PC, Lam MGEH.

Prospective validation of Gallium-68 PSMA-PET/CT in primary staging of prostate cancer patients.

J Urol. 2020 Mar;203(3):537-545.

Wondergem M, Jansen BHE, van der Zant FM, van der Sluis TM, Knol RJJ, van Kalmthout LWM, Hoekstra OS, van Moorselaar RJA, Oprea-Lager DE, Vis AN. Early lesion detection with ${ }^{18} \mathrm{~F}-\mathrm{DCFPyL}$ PET/CT in 248 patients with biochemically recurrent prostate cancer.

Eur J Nucl Med Mol Imaging. 2019 Aug;46(9):1911-1918.

van Kalmthout LWM, Braat AJAT, Lam MGEH, van Leeuwaarde RS, Krijger GC, Ververs FFT, Mehra N, Bins A, Hunting CB, de Keizer B.

First experience with lutetium-177-PSMA-618 therapy for advanced prostate cancer in The Netherlands.

Clin Nucl Med. 2019 Jun;44(6):446-451. 
van Kalmthout L, Stam A, Gans R, Lam M.

Visual deficit possibly caused by lutetium-177 PSMA treatment.

BMJ Case Rep. 2018 Oct 8;2018.

van Kalmthout L, Lam M, de Keizer B, Braat $A$.

Impact of external cooling on PSMA uptake in salivary glands.

EJNMMI Res. 2018 Jul 3;8(1):56.

de Kleijn JL, van Kalmthout L, WM, van der Vossen MJB, Vonck BMD, Topsakal $\checkmark$, Bruijnzeel $\mathrm{H}$.

Identification of Pure Tone Audiologic Thresholds for Pediatric Cochlear Implant Candidacy: A Systematic Review.

JAMA Otolaryngol Head Neck Surg. 2018 Jul 1;144(7):630-638.

van Kalmthout LWM, Braat AJAT, Krijger GC, Ververs FFT, de Roos R, de Keizer B, Lam MGEH. Case report.

Toepassing van ${ }^{177} \mathrm{Lu}-\mathrm{PSMA}$ bij een patiënt met gemetastaseerd castratieresistent prostaatcarcinoom.

Tijdschr Urol. 8, pages 16-18(2018) 



\section{APPENDIX}

Nederlandse samenvatting

List of Publications

Dankwoord

Biography

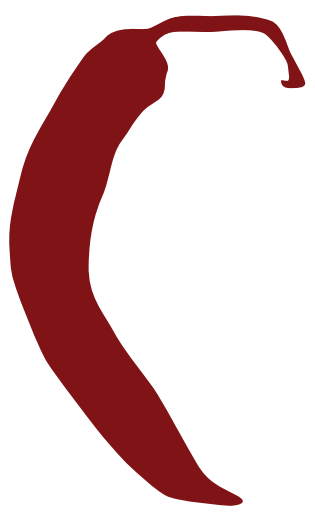


De afgelopen vier jaar heb ik met veel plezier aan dit proefschrift gewerkt. Tijdens deze periode heb ik veel mensen leren kennen die mij met hun ideeën en ervaring hebben geïnspireerd. Hoewel het bijna onmogelijk is om al deze mensen te bedanken, wil ik toch graag bij enkelen van hen in het bijzonder stilstaan.

Prof. dr. M.G.E.H. Lam, beste Marnix, ik kan me nog goed herinneren dat je bij de start van mijn wetenschapsstage als kersverse professor op de kruk naast me plaatsnam om samen na te denken over de details van mijn onderzoeksproject. Benaderbaarheid vind ik dan ook kenmerkend voor jouw rol als promotor. Veel dank dat ik onder jouw leiding heb mogen promoveren.

Dr. H.H.E. van Melick, beste Harm, door jouw enthousiasme voor het doen van onderzoek, werd mijn interesse voor de wetenschap al tijdens mij studententijd gewekt. Graag wil ik je danken voor je betrokkenheid bij mijn promotietraject en je inzet voor mijn klinische en wetenschappelijke carrière.

Dr. J. Lavalaye, beste Jules, onvermoeibaar enthousiasme en humor tekenen jouw copromotorschap. Wat heb ik gelachen om het PEPPERaureool om de hoofden van Harm, jou en mij op onze St. Antonius teamfoto. Veel dank voor de vrijmibo's in Nieuwegein, de etentjes tijdens congressen en bovenal: je vriendschap.

Leden van de beoordelingscommissie, prof. dr. H.M. Verkooijen, prof. dr. I. J. de Jong, prof. dr. F.A. Verburg, prof. dr. ir. H.W.A.M. de Jong en prof. dr. C.H.J. Terhaard, hartelijk dank voor het beoordelen van mijn proefschrift en het plaatsnemen in de oppositie.

Dr. A.J.A.T. Braat, beste Arthur, bij al mijn onderzoeksprojecten ben $\mathrm{jij}$, meestal vanaf de vroegste fase, betrokken geweest. Het was heel fijn om laagdrempelig met je van gedachten te kunnen wisselen. Het enthousiasme waarmee je kliniek, wetenschap en je sociale leven combineert, is absoluut aanstekelijk. 
Dr. B. de Keizer, beste Bart, veel dank voor de begeleiding bij jouw onderzoeksprojecten en de klinische zorg van de VISION-studie patiënten

Drs. M. Hobbelink en dr. N. Tolboom, beste Monique en Nelleke, dankzij jullie begon ik mijn werkdagen graag met de overdracht bij de afdeling Nucleaire Geneeskunde, waar ik -vanwege de nadruk op onderwijs en de mogelijkheid tot laagdrempelige klinische discussies- veel heb geleerd.

Gerard,Tessa en Remmert, tijdens mijn promotie heb ik me beziggehouden met een aantal klinisch-chemische en farmaceutische onderwerpen. Dit had nooit tot zinvolle passages in mijn manuscripten kunnen leiden zonder jullie hulp. Dank voor jullie scherpte, steun en betrokkenheid bij mijn promotietraject.

Drs. H.P. Kaldeway, beste Peter, de 'Lord of the Rings'-interpretatie van de PiP-RADS resultaten was werkelijk onvergetelijk. Dank voor de prettige samenwerking tijdens een groot aantal onderzoeksprojecten.

Dr. J.M.H de Klerk en dr. A. Kooistra, beste John en Anko, dank voor de gastvrijheid op de afdeling Nucleaire Geneeskunde en Urologie van het Meander Medisch Centrum. Ik voelde me altijd welkom om te overleggen, data te verzamelen voor het PEPPER-project, of gewoon zomaar - om te kletsen.

Graag wil ik alle patiënten danken voor hun deelname aan mijn onderzoeksprojecten. Zonder jullie had dit proefschrift nooit bestaan.

Collega's en kamergenoten voor langere en kortere tijd: wat hebben wij veel lief en leed gedeeld! Dank voor jullie luisterend oor, de lattemacchiato's met vleugje kaneel, de (aangebrande) tosti's en de troost.

Sabine en Nienke, vriendinnen, indirecte collega's in het UMC Utrecht en 'Tour-de-Venlo'-maatjes, dank voor jullie onstilbare honger naar verdieping, waardoor mijn ogen geopend bleven voor inspiratie van buitenaf: summerschools, culturele verrassingen, en fietstochten naar de uithoeken van het land. 
Mijn vriendinnen Vera, Hilde, Kirsten, Kristine, Maartje, Anneline, Bianca, Marloes, Denise, Tyche en Benthe: veel dank voor de gesprekken die vaak, maar gelukkig ook vaak niet, over werk gingen. Veel dank voor alles wat we de afgelopen jaren hebben ondernomen -borrelen op de Paramaribostraat, skutjesîlen in Lemmer, paardrijden in Reykjavik, selfies maken op de trap van Musée d'Orsay, boulderen in Fontainebleau, proosten bij Paters Vaetje en kamperen aan zee.

Gerda, Fred, Thea, Francisca, Ellis en lana, ik bof met jullie als schoonfamilie. Veel dank voor de gezellige avonden en fijne weekendjes weg, die meestal gepaard gaan met uitgebreide culinaire avonturen en creatieve uitspattingen.

Papa, veel dank voor je interesse in mijn promotietraject en de steun die ik de afgelopen jaren van je heb mogen ontvangen.

Lieve mama, veel dank voor je onvoorwaardelijke geloof en vertrouwen in mij. De tekeningen voor mijn boekje, die je met zo veel toewijding hebt gemaakt, zijn prachtig.

Lieve Don, tijdens de jaren van mijn promotie raakte je steeds meer betrokken bij mijn bezigheden. Uren van jouw vrije tijd zijn opgeslokt door het luisteren naar mijn promotieperikelen, het bijschaven van mijn computervaardigheden, en het bewerken van (het artwork van) mijn artikelen. Veel dank dat ik af en toe op jouw stabiliteit mag steunen. Ik hoop dat ik nog eindeloos lang van onze avonturen mag genieten. 




\section{APPENDIX}

Nederlandse samenvatting

List of Publications

Dankwoord

Biography

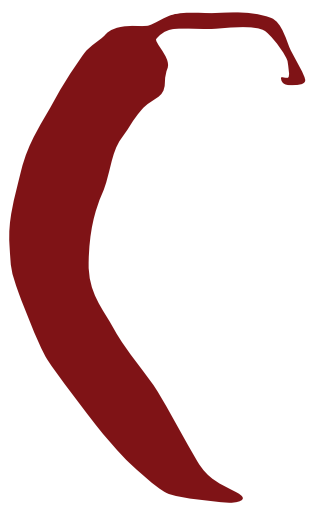




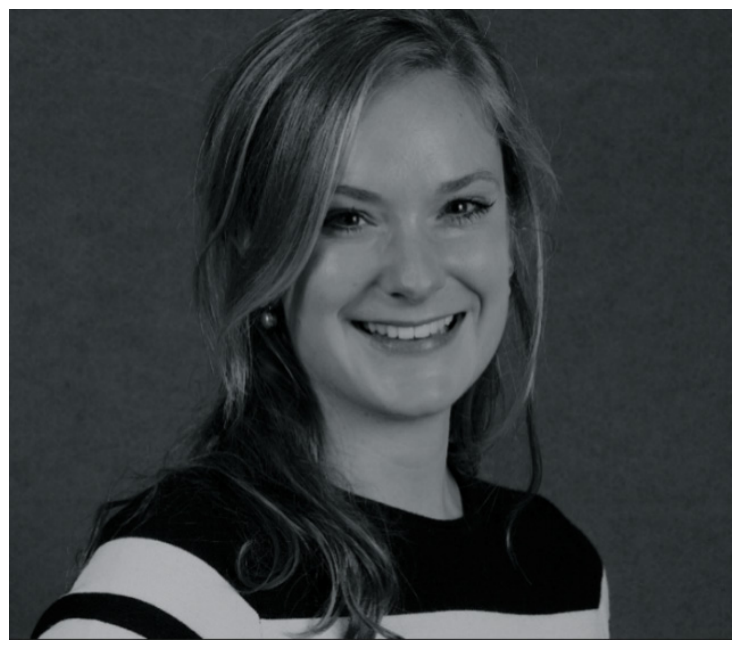

Ludovica Wilhelmina Maria (Ludwike) van Kalmthout was born in Nijmegen, the Netherlands on the $17^{\text {th }}$ of October 1987. After completing high school at Gymnasium Beekvliet in St. Michielsgestel in 2005, she commenced her Bachelors of Music Education (BEd) in Utrecht. In 2007, she achieved her propaedeutic diploma in Art History at the University of Utrecht and in 2010, Ludwike graduated from the Conservatory of Utrecht.

That same year, Ludwike started her studies in Medicine at the University of Utrecht. During the masters of this study, she developed a special interest in Urology, and therefore, her senior internship took place at the Urology department of the University Medical Center Utrecht (UMCU). The scientific research project in her final year was a collaboration between the Urology and the Nuclear Medicine Departments of the St. Antonius Hospital and the UMCU, and was focused on the PSMA PET/CT: a novel modality in prostate cancer imaging. 
After graduating from medical school in October 2016, she started as a PhD student at the Nuclear Medicine Department of the UMCU under supervision of prof. M.G.E.H. Lam, dr. H.H.E. van Melick and dr. J. Lavalaye. In her main research project, the PEPPER-study, she aimed to determine the diagnostic value of PSMA PET/CT in the detection of lymph node metastases in newly diagnosed prostate cancer patients. These results of this study are presented in this thesis. Ludwike combined her first year as a PhD student with a part-time position as urological resident not in training (ANIOS) at the St. Antonius Hospital in Nieuwegein. Being intrigued by oncological patient care, she has been working full-time as a radiation oncology resident in training (AIOS) at the UMC Utrecht since December 2019. Here, she is dedicated to add as much creativity to her clinical and scientific career as possible.

Ludwike currently lives in Utrecht and loves to spend her free time singing, playing the piano, mountainbiking, indoor and outdoor climbing, cooking and travelling. 
<smiles>[13CH2][13CH3]</smiles> 